\title{
Organ donation education
}

Citation for published version (APA):

Steenaart, E. (2020). Organ donation education: Vital for promoting active registrations. [Doctoral Thesis, Maastricht University]. ProefschriftMaken. https://doi.org/10.26481/dis.20201007es

Document status and date:

Published: 01/01/2020

DOI:

10.26481/dis.20201007es

Document Version:

Publisher's PDF, also known as Version of record

\section{Please check the document version of this publication:}

- A submitted manuscript is the version of the article upon submission and before peer-review. There can be important differences between the submitted version and the official published version of record.

People interested in the research are advised to contact the author for the final version of the publication, or visit the DOI to the publisher's website.

- The final author version and the galley proof are versions of the publication after peer review.

- The final published version features the final layout of the paper including the volume, issue and page numbers.

Link to publication

\footnotetext{
General rights rights.

- You may freely distribute the URL identifying the publication in the public portal. please follow below link for the End User Agreement:

www.umlib.nl/taverne-license

Take down policy

If you believe that this document breaches copyright please contact us at:

repository@maastrichtuniversity.nl

providing details and we will investigate your claim.
}

Copyright and moral rights for the publications made accessible in the public portal are retained by the authors and/or other copyright owners and it is a condition of accessing publications that users recognise and abide by the legal requirements associated with these

- Users may download and print one copy of any publication from the public portal for the purpose of private study or research.

- You may not further distribute the material or use it for any profit-making activity or commercial gain

If the publication is distributed under the terms of Article $25 \mathrm{fa}$ of the Dutch Copyright Act, indicated by the "Taverne" license above, 


\section{organ donation education vital for promoting active registrations}

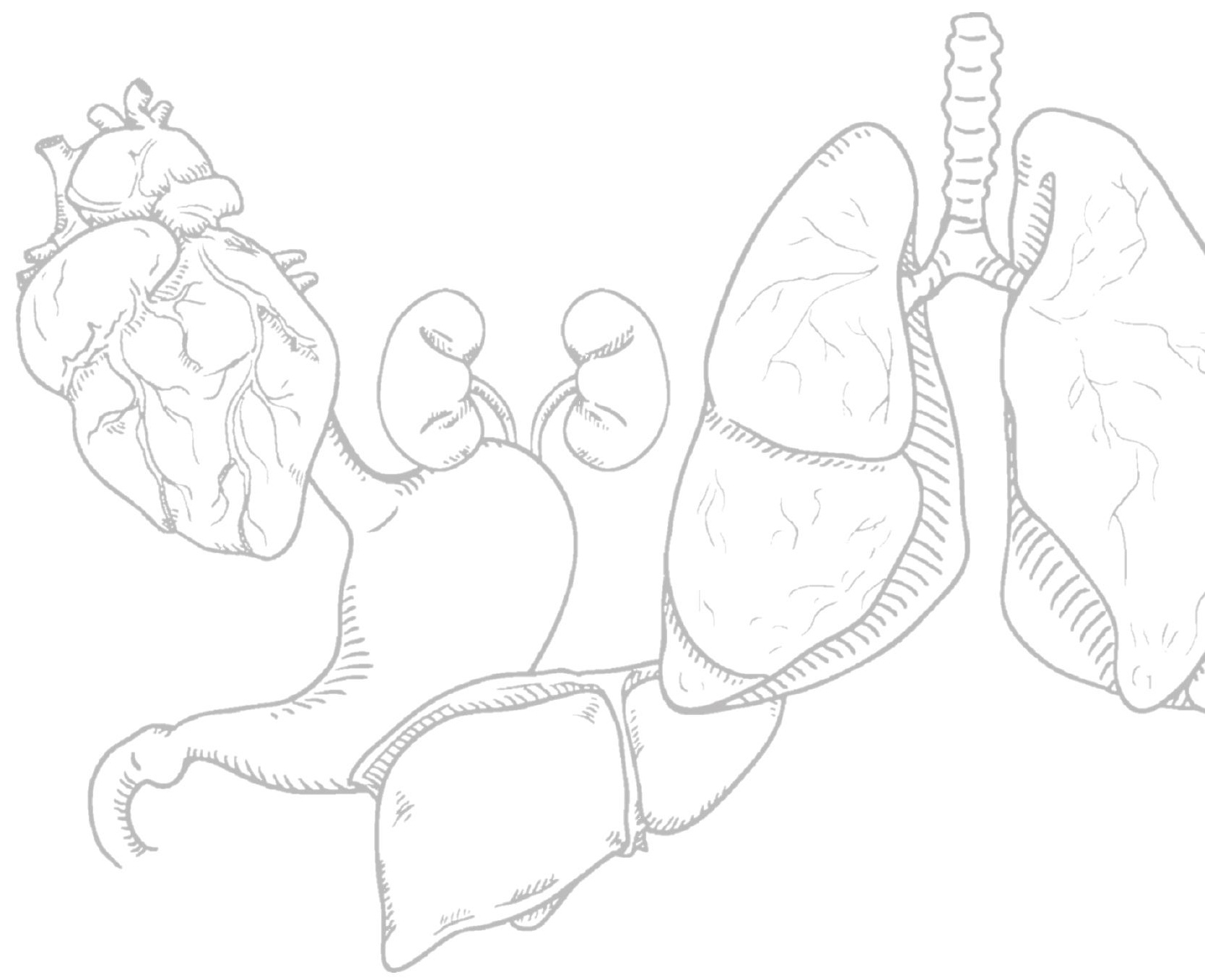




$\begin{array}{ll}\text { Cover } & \text { Sandy Broos } \\ \text { Layout } & \text { Sandy Broos } \\ \text { Printing } & \text { ProefschriftMaken } \\ \text { ISBN } & 978-94-6380-914-6\end{array}$

\section{(c) 2020 Esther Steenaart}

The research presented in this thesis was conducted at CAPHRI Care and Public Health Research Institute, Department of Health Promotion, of Maastricht University. CAPHRI participates in the Netherlands School of Public Health and Care Research CaRe.

Special thanks go to the SIDVO foundation for the collaboration and support during this project.

All rights reserved. No part of this publication may be reproduced, stored in a retrieval system or transmitted in any form or by any means, electronic, mechanical, photocopying, recording or otherwise, without prior permission of the author, or the copyright-owning journals for previous published chapters. 


\section{organ donation education \\ vital for promoting active registrations}

\section{PROEFSCHRIFT}

ter verkrijging van de graad van doctor aan de Universiteit Maastricht, op gezag van de Rector Magnificus, Prof. dr. Rianne M. Letschert, volgens het besluit van het College van Decanen, in het openbaar te verdedigen op woensdag 7 oktober 2020 om 14.00 uur door

\section{esther steenaart}

geboren op 13 mei 1994 te Alkmaar 


\section{Promotors}

Prof. dr. R. Crutzen

Prof. dr. N.K. de Vries

\section{Assessment committee}

Prof. dr. S.P.J. Kremers (voorzitter)

Prof. dr. H.W. van den Borne

Prof. dr. L.B. Hilbrands (Radboudumc)

Dr. H.J.M.M. Mertens

Prof. dr. R. E. O'Carroll (University of Stirling) 


\section{Table of contents}

Chapter 1 General introduction

\section{Part 1 Organ donation education}

Chapter 2 Complexity of organ donation registration: determinants of registration behaviour among lower-educated adolescents

Chapter 3 A web-based education program to encourage organ donation registration among lower-educated adolescents in the Netherlands: study protocol for a cluster randomized controlled trial

Chapter 4 The effectiveness of an interactive organ donation education intervention for Dutch lower-educated students: a cluster randomized controlled trial

Chapter 5 Implementation of an interactive organ donation education program for Dutch lower-educated students: a process evaluation

\section{Part 2 Organ donation registration systems}

Chapter 6 No objection against the new donor law, but even more responsibilities

Chapter 7 Beyond the ticked box: organ donation decision-making under 153 different registration systems

Chapter 8 General discussion

Valorisation addendum 219

References

Summary

Samenvatting 253

Curriculum Vitae 263

Publication list 267

Dankwoord 273 



$$
\text { chapter } 1
$$

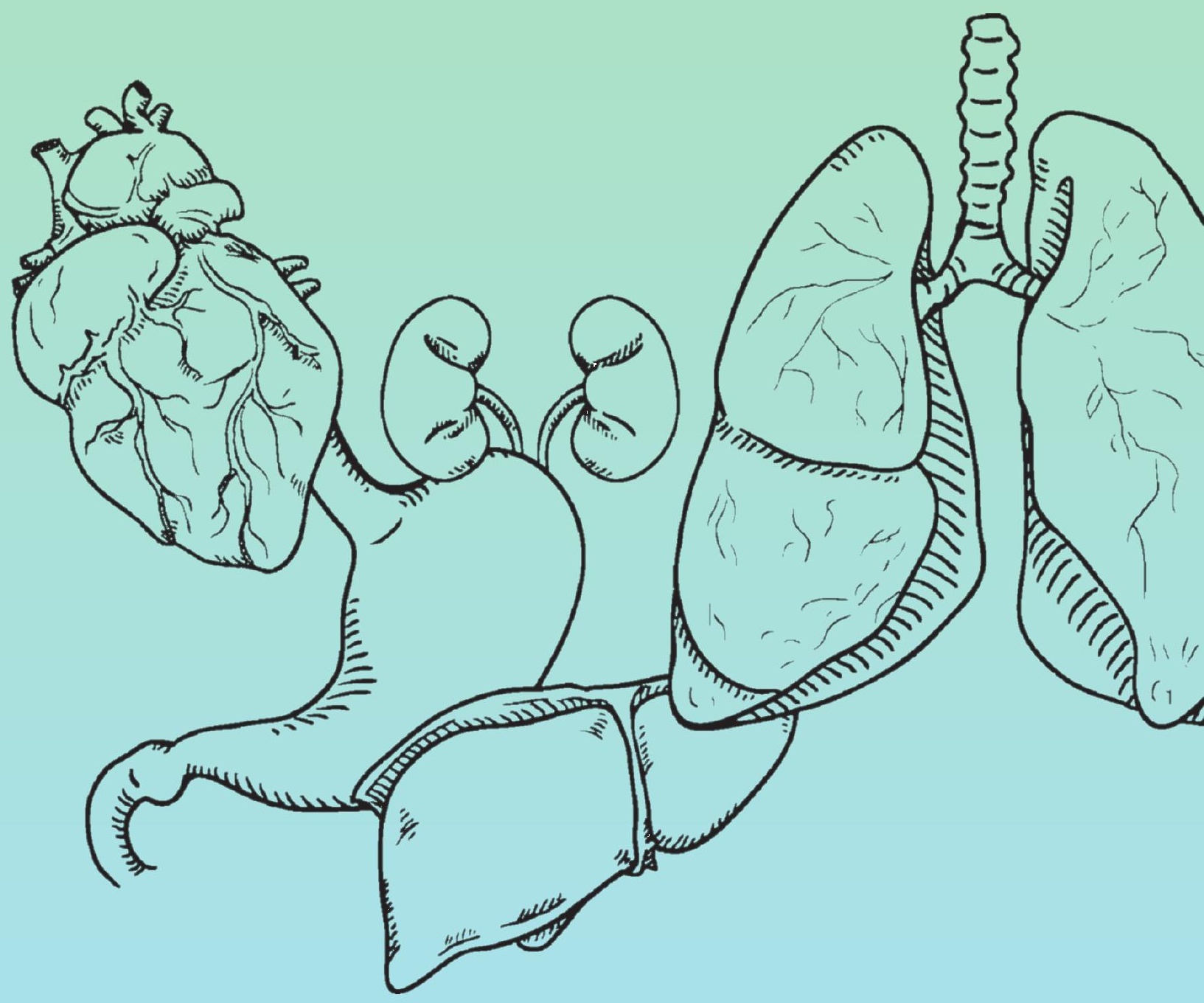


8 | organ donation education 
This thesis aims to contribute to a solution for the low organ donation rates in the Netherlands. It describes the adaptation, implementation and evaluation of an interactive educational program aimed at supporting lower-educated adolescents in the Netherlands to make a decision about organ donation. This is the first and main part of this thesis. The research in this thesis was performed in the turbulent time of an organ donation law change, which was accompanied by political discussions and media attention. This put the program in an interesting context, but also raised new questions about what this means for people's decision-making and registration behaviour in general. This is explored in the second part of this thesis.

This chapter describes the background of organ donation (education), elaborates on the political and societal context of the performed studies and ends with an outline of the thesis.

\section{History of organ donation procedures}

Nowadays, organ transplantation is known as the best and sometimes only form of treatment for patients with end-stage organ failure. However, it has only been available for a few decades, with the first successful kidney transplantation in 1954(1). During the first 30 years, survival rates were low, so the number of transplantations performed was also low. Since the early 80 s, mechanisms behind the rejection of organs by the body were discovered and new medical and diagnostic techniques and medications were found to prevent this from happening. Other advances helped to keep the vital functions of potential donors stable for a longer amount of time and to screen organs in a more effective and efficient way(2). All these developments led to higher survival rates, and more transplantations each year. Therefore, more people were eligible for receiving an organ and waiting lists increased.

There has always been a negative discrepancy between the supply and demand of organs for transplantation. Organ donation rates vary dramatically from country to country for different reasons(3), including registration systems, mortality from road traffic accidents, the extent and efficiency of transplant coordination, wealth, health expenditure, social demographics, religion, general legislative systems and internet 
access (access to information)(4). Even though there are countries that serve as a good example in terms of reaching relatively high donation rates, such as Spain or Croatia, the universal shortage of organs remains. This has to do with complicated logistics and organization around organ donation, but also just the simple fact that organs for transplantation are scarce. Out of a 150.000 people that die in the Netherlands every year, only 800 to 1000 people are eligible to donate their organs (of which organs are transplanted in only 250 cases, since no consent was obtained for the others)(5).

The waiting list - and thus the demand for organs - is expected to grow even faster in the upcoming years, due to the high prevalence of chronic diseases with end-stage organ dysfunction (including diabetes, cardiac failure and hepatitis C)(6, 7). Moreover, the supply of organs is expected to decrease due to population aging (fewer suitable organs because of a higher age at death), a further decrease in the number of traffic related deaths and better survival chances after having a stroke(7). These developments thus widen the gap between the supply and demand of organs.

\section{Organ donation in the Netherlands}

In the Netherlands, transplantation activities started relatively late (Wezel, van Sloof, van Goor, as cited in Meloen)(8). During the first years, the number of donors remained low, also after introducing the opportunity to voluntarily wear a donor codicil on you. In 1998, the Dutch organ donation law was introduced, initially with the aim to address organ donation procedures in a more systematic way and to give legal protection to all parties involved in organ donation. Moreover, there was hope that this law would help to increase the number of donors and thus transplantations. This law also resulted in the introduction of a national donor register, which gave people several registration options. These registration options are currently still used:

1. Yes, I give permission to transplant my organs and tissues (with the possibility to exclude certain organs or tissues)

2. No, I do not give permission to transplant my organs and tissues

3. My partner or family decides

4. I am authorizing a specific person to decide 
Finally, because of the voluntary nature of this law, people also have the option not to choose. Unfortunately, the majority of the population make use of this option(9). So, the lack of registrations remains a critical public health challenge.

Even though registration rates have been steadily, but slowly, increasing over the last years(9), the large proportion of people who are not (yet) registered is problematic. Both medical professionals and family members are burdened by the lack of registrations $(2,10,11)$. When an unregistered individual dies, medical professionals are expected to talk to family members to ask for consent for organ donation. This is a difficult situation for all parties involved. Medical professionals expressed having difficulties talking about organ donation with families. Families are in turn often overwhelmed by the donation question, causing 2 out of 3 families to object to organ donation when no donor record is available. Knowing a patient's preferences increases the likelihood of donating and the family's satisfaction with decisions about donation(12).

Moreover, of all people that are registered, only about half of them is registered as an organ donor (option 1), while 30\% decided to register as a non-donor and another $11 \%$ decided to leave the decision to family members. While the number of transplantations remains quite stable(13), waiting lists for organ transplantation keep increasing(14). Every year, 150 patients die while waiting for an organ and 100 patients are removed from the waiting list because their condition deteriorated(15).

Increasing registration rates and donation rates in the Netherlands is an important health promotion target, as patients, medical professionals and families of deceased potential donors benefit from this. Over $60 \%$ of the Dutch people say they are willing to donate their organs after death(16) (as opposed to only $24 \%$ that are registered as a donor). Only $10 \%$ of the population of sure they are opposed to donating their organs, which also means a large group is still undecided(16). While the actual behaviour (ticking a box on a form) seems very simple, this suggests that organ donation decision-making and registration is far more complex than just ticking that box. Health promotion interventions can help in the decision-making process and in closing the 
gap between willingness and actual registration. The next section will elaborate on different interventions that have been implemented over the years, varying in success.

\section{Promoting organ donation registrations}

Once transplantation procedures improved, and more patients were added to the waiting list, efforts have been taken to encourage registration. These started with the introduction of the organ donation law in 1998 (and the national donor register that came with this) and continued with other initiatives by the government and other parties. An important part of this were public campaigns, including an annual organ donation week, television commercials and billboards. These campaigns were often designed around slogans like "Are you already a donor?" and "The Netherlands say yes".

In 2007, the entire Dutch population was shocked by a reality television program called The Great Donor Show, in which a supposedly terminal patient would choose one out of three kidney patients to receive a kidney(17). Viewers of the show could send her an advice on whom to choose. The show was very controversial but appeared to be a big hoax. The terminal patient was in fact an actress, but the patients were real kidney patients, who agreed to participate in the stunt. It led to over 7000 people to register a decision in the first month after the show. It was of course not a solution to the donor shortage, as 10,000 new registrations are needed to have one extra donor each year(5). However, the show did get international media attention, both positive and negative, and the public and political debate about organ donation reached a new high.

In the aftermath of this show, a large project called the Masterplan Organ Donation was initiated to tackle the organ donation shortage in the Netherlands (7). This plan consisted of an integral approach with actions at the level of organization in hospitals (e.g. improving the quality of transplantations), education to the public (e.g. a positive and empathic message with a strong preference for choosing to say yes), registration systems and other stimuli/incentives (e.g. changing the current opt-in system to an opt-out system) and living donation (e.g. covering follow-up or non-medical costs by insurance). The goal of this plan was to increase the number of transplantations with 
a minimum of $25 \%$ in 5 years' time, preferably even $50 \%$. All recommended actions, except from a change in the registration system, were implemented. A budget of 20 million euros was allocated to this project(18), of which a large proportion was used to increase the registration rates. Despite this large budget, the goals of this Masterplan were never achieved. Especially in the area of the registration rates, as they barely changed.

In the end, all these efforts showed very limited effects. During the first year after the organ donation law in 1998, 37\% of the population registered their decision(19). Twenty years later, in 2018 , only $42 \%$ was in the donor register. Most initiatives focused on showing people the severity of the problem and sending them forms, but this did not automatically lead to registration behaviour. Decision-making about organ donation and behaviour change in general - is more complex. There have been many studies trying to tackle what predictors of organ donation registration are (e.g.(20)). Others suggest that organ donation registration is not a rational behaviour. O'Carroll and colleagues described this as the "ick factor"; a basic disgust response to the idea of organ procurement or transplantation(21). Also, it is important not to forget that in order to make organ transplantation possible, people need to die, which makes organ donation by definition a very emotionally charged subject.

Another possible reason for the low effectiveness of registration initiatives so far, is that even when people know what they want to do in terms of donating their organs or not, the actual registration behaviour can be difficult. People need to know where to find a registration form, how they should fill it out, where to find the details that are asked for and where to send it to. An important and successful initiative to tackle some of the abovementioned problems, is an annual mailing to 18-year-olds, asking them to register a decision about organ donation. Every year about 1 in 3 youngsters respond (including the people who already registered before receiving that letter). However, this also means that 2 in 3 do not. A survey among 1000 youngsters showed that they often do not register (yet) because they simply did not get to it yet (38\%), because they never even saw a registration form before (38\%) or because they did not yet know 
what choice to register (32\%)(22). Supporting youngsters in making and registering a decision could help to increase the response to this mailing and increase organ donation registration rates in this group.

\section{Classroom education on organ donation}

Providing education about organ donation in a classroom setting can be effective in increasing students' knowledge, changing their attitudes, prompting family discussions and increasing the willingness/intention to register(23). This makes schools a promising setting to reach youngsters around the time they receive the mailing. An educational program was developed for and implemented in a Dutch school setting by Reubsaet and colleagues(24). This program was, in contrast with many other initiatives, aimed at informed decision-making about organ donation, rather than encouraging people to become a donor. However, by increasing general registration rates, there will inevitably also be more registrations as a donor, even when the percentage of people choosing to register as a donor would be lower than in the rest of the population.

The program was systematically developed using constructs of the Social Cognitive Theory (extended with factors from other theoretical perspectives and literature). Three draft intervention components were developed and pilot tested before combining them in one cohesive intervention $(25,26)$. This intervention was delivered to students aged 15-18 years old, in a Dutch high school setting (i.e., the higher levels of high school; HAVO/VWO). It was found to be successful in increasing students' intentions to register a decision about organ donation, knowledge and self-efficacy regarding organ donation registration. Moreover, students had more positive social outcome expectations and less negative outcome expectations related to organ donation registration. After the initial effectiveness study, the program was implemented on a larger scale.

Organ donation education in a Dutch school setting thus has the potential to prepare adolescents for making a decision about their organs when they turn 18 , as $80 \%$ of all 18-year-olds still attend full-time education(27). However, only 1 in 6 students in the Netherlands actually receive organ donation education at school(28). This is partly 
because programs are usually developed for and implemented in either a primary school setting or a high school setting. This means that adolescents attending lowereducational levels are often neglected. They might have been reached with educational programs in primary schools, but not around the age when they actually are expected to make a decision about their donor status. This is striking, as lower-educated people generally have less positive attitudes about organ donation(20, 29, 30), collect less information about organ donation on the Internet, are less aware of news coverage on this topic, talk less about it with others(29), and are in the end less often registered compared to higher-educated people(31).

So, reaching the lower-educated adolescent group with organ donation registration initiatives seems very important. As Dutch adolescents have obligatory education until the age of 18 , the lower-educated school setting is suited to reach a large number of adolescents. Moreover, as school-based organ donation education has already been proven to be effective in many other settings, this also shows potential for a translation to a lower-educated school setting.

\section{Intermediate Vocational Education}

In the Netherlands, this lower-educated school setting entails Intermediate Vocational Education (IVE). By implementing organ donation education in IVE a large group of adolescents can be reached, as every year about half a million students attend IVE. Adolescents usually start this type of education around the age of 16(32). These students generally leave high school after four years (as opposed to 5 or 6 years for the higher educational levels) and attend IVE at one of the four available levels. IVE level 1 is considered as the entry level (for students who did not graduate from high school), while level 2, 3 and 4 are gradually more intellectually challenging. After finishing education at one level, students can proceed to a higher level or move to the labour market. All levels of IVE are considered as lower educational levels compared to college or university levels, but the majority of the Dutch population followed this type of education at some point in their lives. About 40\% of the entire Dutch working population has an IVE degree(33). 
Providing this group with information that fits their cognitive abilities and supporting them in decision-making and registration, is important to get this large proportion of society involved in organ donation as well. This is not necessarily easy, as IVE students' societal engagement is generally not that high(34). In a survey among IVE students, over $60 \%$ said they were not interested in the world's problems. This does not mean that they are not engaged with others, but they tend to be more action-oriented when it comes to people in their close environment.

\section{Implementation of classroom education on organ donation}

To reach lower-educated students with organ donation education, the original high school program of Reubsaet and colleagues(24) is adapted to an IVE school setting. The program is embedded in an existing course on Citizenship that all IVE students attend. Citizenship prepares students for participation in society and to function well in their future jobs. It consists of four different so-called "dimensions", namely: politicallegal, economic, societal-social and vital citizenship. Education on organ donation registration could be delivered in different possible dimensions. However, as Citizenship does not have clear requirements on what students should know at the end of their studies, organ donation is often not (yet) on the agenda of teachers and not included in the study books.

Even though an IVE setting would be suitable for implementing an organ donation education program, it is not possible to simply take a program from one setting and implement it in a new one. The effectiveness of a health education intervention relies on both the intervention itself, as well as the context for which they are developed(35). When transferring the high school program of Reubsaet and colleagues to an IVE setting, the question is whether the effectiveness of the program can still be achieved.

The transferability of a program, and thus the effectiveness of the program in this new setting, can depend on different factors. One factor is the implementation of the program, as lower quality implementation leads to poorer program effectiveness(36). However, even when implemented correctly, the results can still be different(37). 
Cambon and colleagues identified four categories of factors that can influence the transferability of a program; environment, implementation, support for transfer and population(38).

In order to transfer the program successfully to the IVE setting, adaptations can be made on those different levels. In terms of the environment and implementation, adaptations will be limited as the intervention is transferred from one school setting to another and the providers of the program (teachers) are similar. In terms of support for transfer, adaptations will be made to the program, based on the findings from the implementation of the original program. Moreover, the implementation of the program will be planned in detail by writing a protocol paper about the evaluation of the program. Finally, the largest adaptations are possibly related to the new population. There has been extensive research on determinants of organ donation registration (e.g.(20)), but little is known about the beliefs of this specific target group.

\section{Student characteristics}

IVE students have other very specific characteristics that come with new challenges, which might also be different according to their educational level within IVE. Students attending the lower educational levels of IVE (levels 1 and 2) were enrolled in those lower levels for several reasons, including lower cognitive abilities, a complex home environment or a lack of motivation to study in general(39). At the higher levels (3 and 4), the main challenge lies in the diversity of students and their goals. Another challenge within IVE in general is related to literacy levels. Large proportions of IVE students can be described as low literate(40), which makes reading and comprehending information more difficult for them. This means that the general public information campaigns might not reach them(28), they might not understand the information that does reach them and the process of registration is even more difficult to them. Next to those low reading levels, IVE students say they rather try something out than reading an instruction (e.g., 63.7\% agreed to this statement in a survey(34)). This could be another reason why adolescents do not return the registration form. It is a long form, with a lot of text and instructions. They might begin filling it out, get stuck somewhere and then leave it. 
A first step in the transfer of the organ donation education program to an IVE setting was therefore to find out whether the content of the program still fits the new users by means of a determinant study. The program was also adapted to the new target group in terms of length and language. Subsequently, a detailed protocol was written to plan the evaluation of the program. The evaluation of the program concerns both the effectiveness of the program in this new setting as well as the implementation.

\section{Contextual factors}

With this educational program, the focus lies on the individual behaviour. This has been the case with many registration related initiatives. However, individuals are embedded in and interact with their environments. Therefore, contextual factors that influence organ donation and registration behaviour should not be ignored. If we expect people to make a decision and register this decision, their environment should support them, but this is often not the case. Examples of impeding environmental factors are difficult registration forms or an opt-in registration system without any obligation. Next to supporting people in the decision-making process on an individual level, it is recommended to create an environment in which a behaviour, in this instance registration, becomes more convenient, attractive and economical(41). An example of an environmental change that could facilitate registration behaviour is a change in the registration system, i.e. moving from an opt-in to an opt-out system. Recent developments in the registration system in the Netherlands provided an important context for the future of organ donation education. Background on organ donation legislation, the developments in the Dutch organ donation laws and implications of this will be explored in the next part of this introduction.

\section{Organ donation legislation}

Most countries organize their organ donation registration in some form of an optin or opt-out system. In an opt-in system, the potential donor needs to give explicit consent for organ donation. In practice, when a person did not register this decision, family members will decide. When an individual wants to be sure their organs are not donated, the person will have to explicitly register a no. In an opt-out system (or presumed 
consent system), when someone did not object during their lifetime, organs can be used for transplantation as it is assumed that the potential donor has no problem donating their organs. Many countries make use the latter, including Spain, Belgium and Italy. More recently, Finland and Wales changed to an opt-out system as well and the United Kingdom follows in 2020. Countries vary in how the legislation works in practice. This can be referred to as hard or soft versions of the opt-out system(42). In hard versions of the opt-out system (e.g. Austria), transplantation will proceed when no registration is known and no consent from family members is actively sought. In a soft version (e.g. Spain), family members are intensively involved in the process and always asked for consent when no registration is available.

\section{Law change in the Netherlands}

As long as organ transplantations have been possible in the Netherlands, there have also been discussions about the registration system. In 1969, the option of having an opt-out system was discussed for the first time, and every few years this topic is raised again in public or political debates. In 2008, when the Masterplan Organ Donation was announced, this also included a change in the registration system(7). The coordination group that initiated this project was convinced that donor rates could only be increased if an integral approach would be used. This meant that there would be an integral responsibility for solving the problem by every actor (including the government, citizens, hospitals, medical professionals and patients) and that they should feel supported by knowledge, finance and a legal framework (i.e. an opt-out system). At the time, all advices from the Masterplan Organ Donation were implemented, except from the change in the registration system. This changed 10 years later, when in 2018 the parliament voted in favour of an opt-out system, to be implemented in the summer of 2020 . The first part of this thesis (adaptation, implementation and evaluation of the educational program) were thus already performed and written before this law was introduced.

The opt-out system that will be implemented in the Netherlands can be regarded as a soft version. During the first year of the implementation, every citizen who is not in the national register yet, will receive a registration form over the mail, asking them to make 
a decision(43). After they fail to respond to that mailing and a reminder 6 weeks later, they will be registered as "having no objection against organ donation". This is a new (passive) registration possibility next to the options of yes (with or without restrictions), no, leaving the decision to next of kin or leaving the decision to a specific person. When someone dies, who did not actively register him/herself in the register, family members will be told that this person "had no objection against organ donation", but in practice they will still be consulted and still have the opportunity to oppose.

\section{Implications of the new law}

The big question is whether a new registration system will finally lead to higher registration and donation rates. This is questionable as current evidence is inconclusive about which registration systems are most successful. When just looking at the numbers, opt-out systems seem to be most effective in reaching high registration and donation rates(44). However, there is no clear evidence that the system in place is the sole factor determining this(4). When looking at Spain, for instance, the president of the Spanish National Transplant Organization even explicitly said that the presumed consent law is not likely to be the reason why their donation rates are that high(45). One important reason in Spain seems the low family refusal rate (only $9 \%$ as opposed to $66 \%$ in the Netherlands).

Experiences from other countries show that changes in legislation are not always successful. While it has the potential to increase registration rates, it is also a challenging process. Costs of law changes are very high and there is a risk of losing medical and nursing professions' support as well as backlash from the public(46). This could in the end have a negative impact on the donation rates. Examples of countries where this happened are Brazil and France(45). The introduction of an opt-out system in those countries had a (temporary) negative effect on donation, partly because the law change led to increased mistrust towards medical professionals. In Brazil, the law was repealed a year later. Sweden is another example of a country in which the law change was not necessarily successful. The effects were not as detrimental as in Brazil or France, but donor rates are still low(46). 
So, when implementing an opt-out law, it is important to pair this with flanking policies, such as improved criteria for identifying and selecting donors, improved transplantation procedures and an increase in transplantation capacity (availability of surgeons and transplant centres)(47). Other factors influencing the success of an opt-out system in a country include the availability of potential donors, the infrastructure for transplantation, wealth and investment in healthcare and public attitudes(4). Most flanking policies were already introduced during the Masterplan Organ Donation and the project team believed the law change would be the missing piece.

In recent years, there have been several publications in which the reaction of the Dutch public on some form of an opt-out system were explored, but how this will play out in real life is yet to be discovered(48). The first reactions of the public in the months after acceptance of the law gives us an indication. The organ donation law passed the House of Representatives and Senate with the narrowest margins (75 against 74 and 38 against 36 respectively)(49, 50), already illustrating the controversy within the political context. One day after the law officially passed the Senate, over 30.000 people registered themselves with a no, including people who were registered as a donor before(51). Many people protested against the law and a large group of people even tried to enforce a referendum. These protests are quite ominous as the public attitude towards an opt-out system is important in determining the success of the system in increasing registration and donation rates in the end(4). This would be a waste of all efforts and money spent on the law change, as the actual differences between the optin system and soft opt-out system are rather small. Family members will keep having a key role in the decision in the end.

Whether the citizens realize what the new law entails and what the consequences are is not clear yet. The law is quite complicated and has been redesigned and adapted over the years to satisfy all parties involved, but the current version is not necessarily evidence-based. Even though giving consent might become easier (even this is questionable), this does not mean everyone will now register their decision. If people do not understand what the new law entails, this could have several implications. First, if people 
do not understand what the "no-objection" means, and how this is different from an active "yes", there is a risk that people will not actively register their choice anymore. Second, we know that being aware of the consent legislation in place, increases peoples' willingness to consent to organ donation(52). Preparing people for the law change is therefore essential for the success of the law in terms of active and informed decisions regarding organ donation registration.

Reaching the public with information and support is more important than ever, with changes in the legislation coming up. When evaluating the introduction of an opt-out system in Greece, this also became apparent(53). Only 3.8\% of the citizens considered the public to be adequately informed. A hasty implementation of a new donor registration system could conflict with peoples' spontaneous intention for solidarity. The authors of this study in Greece advised a long-term dialogue, closely followed by a nationally coordinated and culturally sensitive campaign.

To prevent a backlash from happening in the Netherlands, it is thus essential to reach everyone with information and support. From the year of 2020 onwards, citizens have to make a decision about organ donation and cannot postpone this any longer. An elaborate communication plan was developed by the Dutch government with which they aim to make $97 \%$ of the population aware of the new donor register and the consequences of not registering(54). The campaigns are currently implemented and evaluated, but the question remains whether their goals will be achieved and whether actual registration behaviour will change in the end. In the second part of this thesis, insight will be gained in how this new law might influence Dutch citizen's decisionmaking behaviour and to learn more about where this no-objection law stands compared to traditional opt-in or opt-out systems. 
This thesis aims to contribute to a solution for the low organ donation registration rates in the Netherlands. The first part of this thesis describes an educational program for lower-educated adolescents, aimed at supporting them in making a decision about organ donation and registering that decision. The second part of this thesis elaborates on the possible implications of the new donor law in the Netherlands on decision-making and registration rates. This thesis finishes with a reflection on all studies that were performed and a view to the future.

Chapter 2 describes a determinant study that was used to learn more about specific beliefs that lower-educated adolescents have regarding organ donation and registration. The results of this study were used to adapt the content of the educational program to this group. The studies in Chapter 3, 4 and $\mathbf{5}$ describe the evaluation study of the adapted program in a vocational school setting. A detailed study protocol was written in Chapter 3, elaborating on the different components of the educational program and study design of the cluster randomized controlled trial that was used to assess the effectiveness of the program and the (quality of) implementation. The results of the effect evaluation are found in Chapter 4. In this chapter, the effects on the program are presented to reveal whether the program was successful in increasing students' registration intentions and changing beliefs about organ donation (registration). Chapter 5 describes the results of the process evaluation that was done and elaborates on the implementation of the program. It also includes recommendations for the future of the program.

New research questions regarding the new donor law were explored in the second part of this thesis. Several concerns about the new donor law are discussed in Chapter 6. It describes what the new donor law could mean for responsibilities around the donation decision and the possible consequences of this. Whether the new donor law changes the way in which people make their donation decision, was explored in Chapter 7. It answers the question where this new donor law stands compared to a traditional optin and opt-out system. Chapter $\mathbf{8}$ discusses the studies in this dissertation and places 
them in a larger public and scientific context. It includes a reflection on current practices and elaborates on ideas for the future. Finally, a case is made for a comprehensive approach to increase active registration rates. 



\section{part $\underbrace{}_{\text {organ donation education }}$}

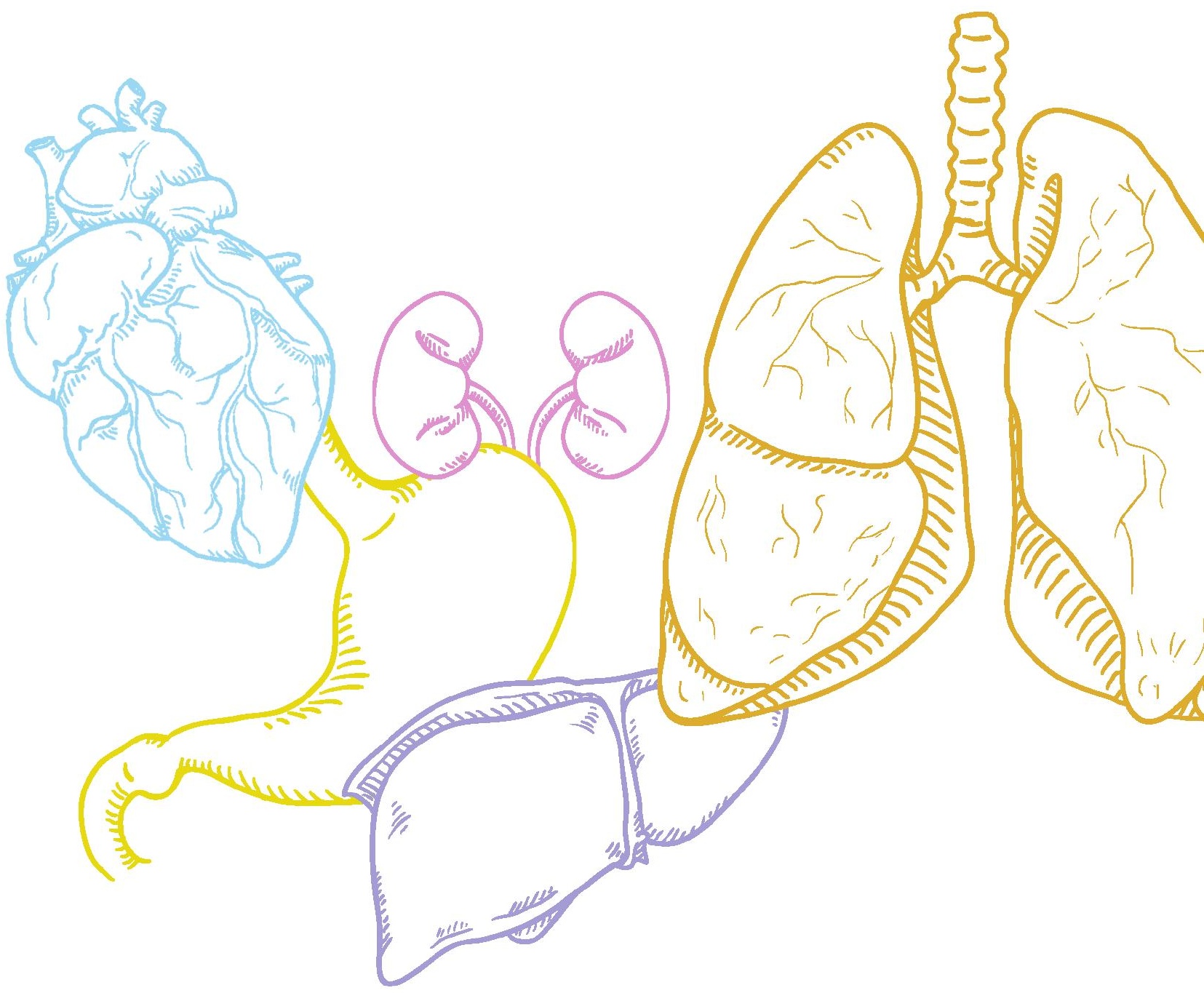





\section{chapter $\mathbf{2}$}

complexity of organ donation registration: determinants of registration behaviour among lower-educated adolescents



This chapter has been published as:

Steenaart, E., Crutzen, R., \& de Vries, N. K. Complexity of organ donation registration: determinants of registration behavior among lower-educated adolescents. Transplantation Proceedings. 2018;50(10):2911. 


\section{ABSTRACT}

\section{Background}

Registration rates are low for organ donation among lower-educated adolescents in The Netherlands. This could be improved by preparing them for making a decision regarding donation when they become 18 years old. To do so, more insight is needed into their beliefs about organ donation and registration.

\section{Methods}

A cross-sectional quantitative study was conducted among students in Intermediate Vocational Education schools. Data were gathered my means of self-administrated questionnaires. The outcome measurements included current registration status, being an organ donor, intention to register and intention to become a donor. Correlation coefficients were used to assess the strength of associations between beliefs and each of the 4 outcome measurements.

\section{Results}

A total of 405 participants (mean age, 18.86 years) were included, of whom $26.6 \%$ had already registered a decision. Most beliefs showed a significant correlation with one or more of the outcomes. In general, the correlations were of small to medium size and participants scored around the middle of the scales on the beliefs.

\section{Conclusion}

Means and correlations need to be combined to gain insight into the importance of certain beliefs for future interventions. However, it is plausible that in addition to these explicit beliefs, implicit factors play a role in registration behaviour. This could be explored in future research. Results could support intervention development for increasing registration rates. 
The gap between supply and demand of organ donors leads to long waiting lists. In the European Union, 70,000 people are on a waiting list for an organ transplant and 12 people die daily while waiting(55). This discrepancy between supply and demand is also found in The Netherlands. Although the number of donors is slowly increasing(56), the high demand still cannot be met. Potential donors are lost as consent for organ donation is often missing(57). Currently, the Dutch consent system is based on a voluntary process. In this opt-in system, individuals must give their explicit permission for donation. Five registration options are given: registering as a posthumous organ and tissue donor; registering as posthumous donor for specific organs and tissues; registering as non-donor; leaving the decision to the next of kin; and leaving the decision to a specific person. Currently, nearly $40 \%$ of the Dutch population over 12 years of age has registered their choice, of whom over $60 \%$ gave permission to use their organs and/or tissues after death (with or without restrictions)(58). Among adolescents 18-20 years old, the registration rate is much lower, namely under $17 \%$, of whom nearly $80 \%$ gave permission to use their organs and/or tissues after death (with or without restrictions).

Increasing the number of donors is of great importance. Moreover, the lack of registration in general, regardless of donor or non-donor, leads to several problems. When unregistered individuals die, the next of kin must make a decision about organ donation. This places a huge burden on both medical professionals and family members. Medical professionals experience difficulties when asking the family questions on this subject(2). Up to $10 \%$ of the families are not even approached to ask for consent(10). If families are asked for consent they are often overwhelmed(11). In the end, many potential donors are lost. When no consent or objection is known, the refusal rate by families is $66 \%(10)$.

Therefore, several efforts have been made to stimulate people to register. A national strategy was introduced in 1998 (and is ongoing) aimed at increasing and maintaining positive attitudes toward organ donation(59). This strategy has included, among others, public information campaigns, a charity TV show and mail shots. These efforts are successful, 
but the impact decreases over time. Another initiative was aimed at changing the registration system from an opt-in to an opt-out system. However, this may not be the solution as several studies have shown that opt-out systems do not necessarily lead to higher donation rates(60). Moreover, public support for this measure seems limited.

A more promising effort is a yearly initiative aimed at stimulating adolescents to register their choice by sending them a registration form by the age of 18 . This led to a response rate of $32.2 \%$ in 2016, with $73.5 \%$ registering as organ donors (with or without restrictions)(61). The response rate could be improved by preparing adolescents for this decision. To do so, more insight is needed regarding their beliefs about registration and organ donation. Previous studies, mainly using qualitative methods, revealed a wide variety of themes, such as social support and mistrust in the medical profession, playing a role in decision-making (e.g. 62, 63-65). However, little effort has been made in combining these findings into a quantitative study to get insight into the importance of beliefs underlying organ donation registration.

These beliefs are expected to differ between higher and lower-educated adolescents. Higher-educated individuals have a more positive attitude toward organ donation than lower-educated individuals(20, 29, 30), spend more time looking for information on the internet, talk more about organ donation with others, and are more aware of the news coverage on organ donation(29). In The Netherlands, higher-educated individuals have registered their choice more often than lower-educated individuals (57.5\% vs 19.6\%) and registered as an organ donor (with or without restrictions) more often (42.4\% vs $11.0 \%)$ (31).

Moreover, the degree to which certain beliefs are important may be different due to characteristics of this group when compared with the general population. For instance, religion has been found to be more important in organ donation decision-making among young people when compared with older people(65). The present study data could help us to understand the low response rate in this group. Moreover, the findings could lend support to further intervention strategies aimed at stimulating organ donation registration. 


\section{METHODS}

This cross-sectional study was conducted using self-administered questionnaires.

\section{Participants}

Participants were adolescents in the age range of 16 to early 20 s attending Intermediate Vocational Education (IVE). Within IVE, there is a distinction between 4 levels, all regarded as a lower level of education (as opposed to college or university education).

Data were collected by distributing questionnaires at 3 IVE schools in The Netherlands. Students from levels 2-4 from various disciplines (i.e., health care, engineering, economics, ICT, and social services) were included. Data for students who returned incomplete questionnaires were discarded $(n=5)$.

\section{Ethics approval}

The study was approved by the ethics committee of the Faculty of Health, Medicine and Life Sciences on February 14, 2017 (reference number: FHMLREC/2017/01).

\section{Procedure}

Paper-based questionnaires were distributed during class. A short explanation was given, after which participants completed the questionnaire in 5-10 minutes. The questionnaire started with an introduction, emphasizing the anonymity of the data and the option to stop at any given time. It was also stressed that there were no "right" or "wrong" answers, as the focus was on participants' opinion. After assessing demographics, a small section with information on organ donation was included, as prior knowledge was expected to be low.

One person entered the data into the SPSS statistical software program. A data entry check was performed by two other persons on $10 \%$ of the questionnaires, showing an accuracy of $99.9 \%$. 


\section{Questionnaire}

The questionnaire assessed the aspects described in what follows. The full questionnaire is available at https://osf.io/frbvq/. During a pilot test, participants $(\mathrm{N}=6)$ were asked to consider topics that were not included in the questionnaire and to reflect on readability and understandability. Five questions were removed as they were not interpreted well. One question was substituted by another to improve understandability. No new topics were added.

Demographics. Sex, age, study discipline, study level, school and class, country of origin and religion were included in the questionnaire. Country of origin of the student, and their mother and father (if applicable) was addressed by 3 questions. This item was later dichotomized into a Western or non-Western background(66). Religion was addressed by 1 question. A single-item scale for measuring religiosity is useful if religion is not the central concern of a study(67). Religiosity was measured by the question, "My religion influences my daily life"(68).

Organ donation registration. Participants were asked about their current registration status (Yes/No/Don't know) and, if applicable, the choice they registered. Nonregistered participants were then asked about their intention to register (Yes/No/Don't know) and, if applicable, the choice they would like to register. All 4 measures were dichotomized. Registration status was dichotomized into registered (Yes) and nonregistered (No/Don't know). Registration choice was dichotomized into registration as a donor (posthumous organ and tissue donor/ posthumous donor for specific organs and tissues) and registration as a non-donor (non-donor/ leave the decision to the next of kin/ leave the decision to a specific person). The same procedure was applied to the intention questions.

Beliefs regarding organ donation. Relevant beliefs for the questionnaire were identified according to the core processes of intervention mapping, starting with a brainstorm session(69). The results of this were used as input for a literature search. The meta-analysis by Newton (70) was used as a starting point after which more studies 
were added. Over 30 studies were identified varying in methods and target groups (see Appendix Tables A1 and A2). Themes and constructs were derived from those studies. Constructs were selected based on the number of studies that reported this, responses from the target group and additional literature. No additional constructs were added from theories. Finally, the chosen constructs were translated into items that were adjusted to the lower-educated target group by using simple language and short sentences.

Seven themes were translated into questions. This resulted in a total of 26 questions. All questions, except for the one on religion (as described in what follows), were answered on a 7-point Likert scale ranging from "Totally disagree" to "Totally agree".

Six questions were included on the body, of which 5 were translated from existing constructs from studies(65, 71, 72). An additional question was added (i.e., "The idea of my organs being in someone else's body gives me a feeling of discomfort"), as it was expected that the adolescents have not yet spent much time thinking about organ donation. A feeling of discomfort with organ donation could therefore be important.

Three questions were included on death, of which 2 were translated from previous studies(73-75). One additional question was included (i.e., "I still have enough time to register myself"), as this was expected to play a role for this young target group.

Mistrust in medical professionals was covered by 5 questions, all derived from previous studies(76-78); for example, "When I am an organ donor, my organs will be allocated to patients in an ethical manner."

Six questions were included regarding social environment. The importance of family was identified in nearly all studies(79-81). However, the importance of friends was rarely identified. In this particular population, friends are expected to play an important role in decision-making. At 16-18 of age, support from friends is even more important than 
parental support(82). Therefore, the questionnaire contains 2 questions on friends, 3 on family and 1 on both.

Three questions were included on recipients: 1 on helping people in need and 2 on reciprocity (e.g., "If I am an organ donor, I am happy I can help people in need")(83-85).

The theme knowledge was covered by 2 questions, of which one was derived from previous studies(86-88). One question was added in the light of a possible future intervention: "I would like to learn more about organ donation and registration."

The last theme, religion, was covered by 1 question(62, 89, 90): "What is your religion's stance on organ donation?" (Positive/Neutral/Negative/Don't know).

Finally, the questionnaire ended with an open-ended question to measure salience of beliefs. Participants were asked to mention the most important reason for them to (not) register (as an organ donor). Measuring salience can improve the insight into the structure of attitude(91). It can also give participants the opportunity to mention additional beliefs that were not included in the questionnaire(92).

\section{Statistical analyses}

Data were analysed using SPSS version 23 (IBM, Armonk, NY). Bivariate analyses (i.e., correlation coefficients) were used to assess the strength of associations between beliefs and each of the 4 outcome measurements. Component analyses were conducted to extract scales from the beliefs, as correlations between beliefs were high (i.e. multicollinearity may hinder correct interpretation). As component analyses led to a low interpretability of scales, the scales were determined based on themes (see Beliefs regarding organ donation subsection). Some themes did not show sufficiently high factor loadings of items related to that theme (i.e. no unidimensionality), so the items were included separately in logistic regression analyses. The question regarding religious stance on organ donation was not included as half of the population was not 
religious and others scored low on the religiosity scale $(2.41 \pm 1.66)$. Finally, one more scale was split up into separate items, as the internal consistency was low.

The extracted scales, separate beliefs and demographics were included in 4 multivariate logistic regression analyses, with the registration status, registration as a donor, intention to register and intention to become a donor as dependent variables. There were several issues leading to the decision not to report the results of these analyses. First, the interpretability of the results remained low. Second, the correlations between the separately added beliefs were in some cases still quite high (see Appendix Table A3). Third, the number of students who answered the questions on two outcome variables was quite low (see Figure 1), which hindered accurate parameter estimations (i.e. leading to wide confidence intervals). In the end, these analyses did not add valid information to the bivariate analyses. 
A total of 405 participants were included in the study (Figure 1). Their mean age was $18.86(S D=2.39)$ years and 31.9\% were male. Over one-fourth of the participants (26.6\%) reported to have completed a registration form, of whom $67.6 \%$ registered as a donor (with or without restrictions for certain organs or tissues). From the unregistered participants, $43.3 \%$ intended to register a decision, of whom $65.8 \%$ intended to become a donor (with/without restrictions for certain organs or tissues). Table 1 provides further demographic information.

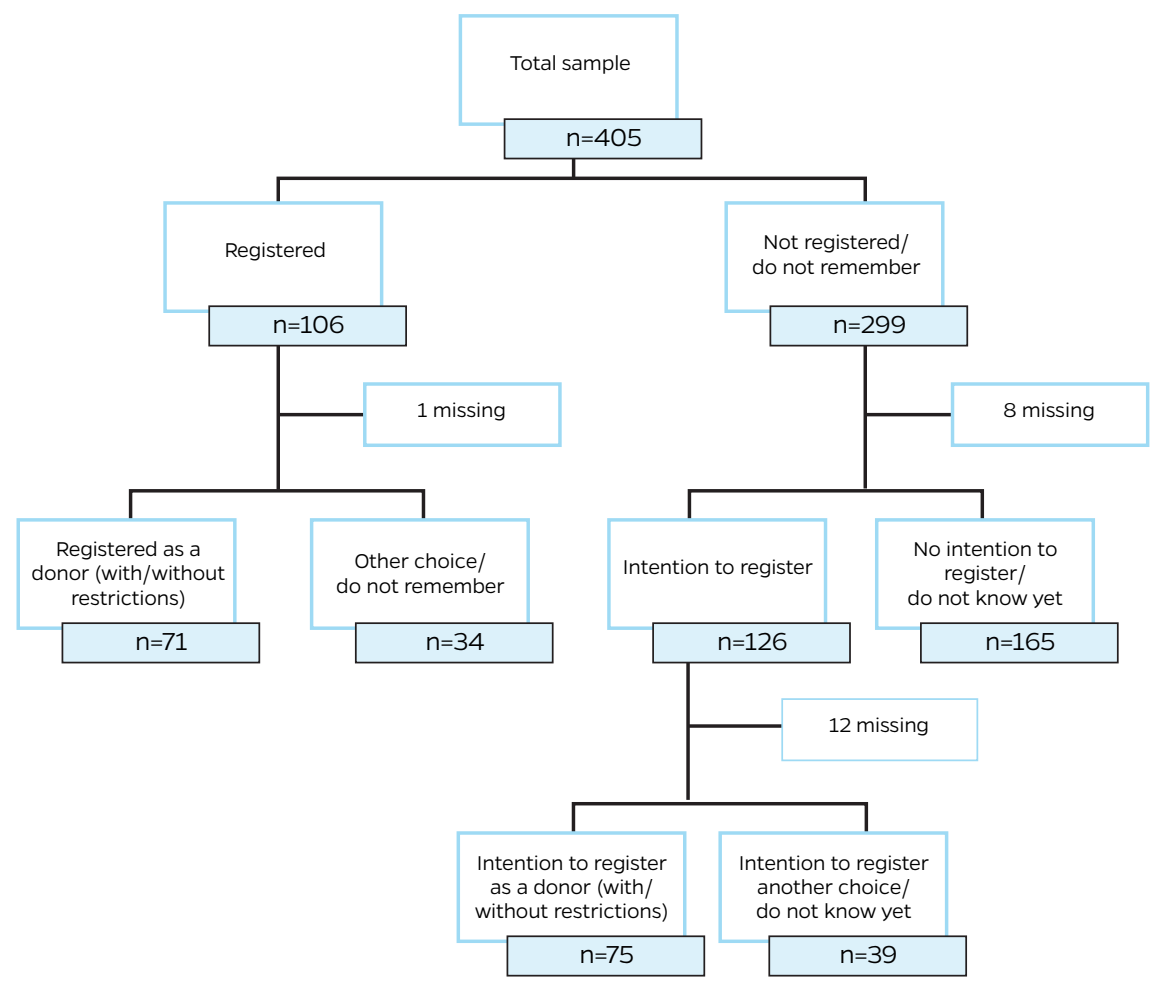

Figure 1. Flowchart participants 
Table 1. Descriptive information study sample

\begin{tabular}{|c|c|c|c|}
\hline & Male & Female & Total \\
\hline Sex & $31.9 \%$ & $68.1 \%$ & \\
\hline Age & $18.95 \pm 2.64$ & $18.82 \pm 2.27$ & $18.86 \pm 2.39$ \\
\hline \multicolumn{4}{|l|}{ Religion } \\
\hline Not religious & $70.1 \%$ & $40.8 \%$ & $49.9 \%$ \\
\hline Islam & $0.8 \%$ & $6.6 \%$ & $5.0 \%$ \\
\hline Catholic & $15.0 \%$ & $43.0 \%$ & $34.0 \%$ \\
\hline Dutch Reformed & $3.9 \%$ & $1.8 \%$ & $2.7 \%$ \\
\hline Calvinist & $3.1 \%$ & $1.1 \%$ & $1.7 \%$ \\
\hline Jewish & $0.0 \%$ & $0.7 \%$ & $0.5 \%$ \\
\hline Other & $7.1 \%$ & $5.9 \%$ & $6.2 \%$ \\
\hline Religiosity of those indicating to be religious & $2.29 \pm 1.45$ & $2.43 \pm 1.71$ & $2.41 \pm 1.66$ \\
\hline Registered a decision (yes) & $28.1 \%$ & $25.3 \%$ & $26.2 \%$ \\
\hline Donor & $48.6 \%$ & $30.4 \%$ & $37.1 \%$ \\
\hline Restricted donor & $14.3 \%$ & $39.1 \%$ & $30.5 \%$ \\
\hline Non-donor & $22.9 \%$ & $20.3 \%$ & $21.0 \%$ \\
\hline Next of kin & $14.3 \%$ & $8.7 \%$ & $10.5 \%$ \\
\hline Specific person & $0.0 \%$ & $0.0 \%$ & $0.0 \%$ \\
\hline Unknown & $0.0 \%$ & $1.4 \%$ & $1.0 \%$ \\
\hline Intention to register (yes) & $38.9 \%$ & $45.5 \%$ & $43.3 \%$ \\
\hline Donor & $51.5 \%$ & $17.5 \%$ & $27.2 \%$ \\
\hline Restricted donor & $24.2 \%$ & $45.0 \%$ & $38.6 \%$ \\
\hline Non-donor & $3.0 \%$ & $11.3 \%$ & $9.6 \%$ \\
\hline Next of kin & $15.2 \%$ & $12.5 \%$ & $13.2 \%$ \\
\hline Specific person & $0.0 \%$ & $1.3 \%$ & $0.9 \%$ \\
\hline Unknown & $6.1 \%$ & $12.5 \%$ & $10.5 \%$ \\
\hline \multicolumn{4}{|l|}{ Religious stand towards organ donation } \\
\hline Negative & $3.1 \%$ & $2.9 \%$ & $3.4 \%$ \\
\hline Neutral & $31.3 \%$ & $30.7 \%$ & $31.4 \%$ \\
\hline Positive & $28.1 \%$ & $14.3 \%$ & $16.6 \%$ \\
\hline I don't know & $37.5 \%$ & $52.1 \%$ & $48.6 \%$ \\
\hline \multicolumn{4}{|l|}{ Country of origin } \\
\hline Western & $96.0 \%$ & $83.9 \%$ & $87.3 \%$ \\
\hline Non-western & $4.0 \%$ & $16.1 \%$ & $12.7 \%$ \\
\hline
\end{tabular}

Data presented as mean \pm SD for continuous variables and percentages for categorical variables 


\section{Bivariate analyses}

Table 2 shows the results of the bivariate analyses. The high number of beliefs and outcome measurements could make it difficult to see which beliefs are more important than others. A high correlation between a belief and outcome measurement indicates that it may be an important belief to target in interventions. However, if the mean score on this belief is already close to a desired value, then there is only little room for improvement. Thus, means and correlations need to be combined in order to gain insight into the importance of beliefs for future interventions(93). Next we provide examples on how this can be applied.

\section{Examples from Table 2}

The use of the table can be illustrated by the belief, "I still have enough time to register." Participants scored medium to high on this scale (3.71-5.17), indicating that most believed they still had enough time to register. There is room for improvement, as it is desirable that persons register at this specific age. Also, the correlations between this belief and 2 of the outcome variables, registration behaviour $(r=0.34)$ and registration choice $(r=0.35)$, were high. Therefore, this could be an important belief on which to intervene.

On the contrary, beliefs with a mean score already close to the desired value and/or low or nonsignificant correlations with the outcome measures would not be important targets for an intervention. An example of this is the belief, "I find it hard to discuss organ donation with my family members." On average, participants scored low on this scale (1.52-1.68), and the belief shows very low correlations with outcome measurements ( $r=-0.06$ to $r=0.03$ ). Therefore, this belief is not among the most important ones on which to focus in future interventions.

Another example would be, "If I am an organ donor, I am happy I can help people in need," which correlates significantly with all outcomes ( $r=0.205$ to $r=0.489)$. However, when looking closer at the mean scores (5.5-6.2), one could conclude that most participants were already convinced by this statement and therefore, intervening on this 
particular belief may not be a priority. If so, the focus should be on reinforcing this specific belief.

As a final example, the belief, "If I am an organ donor, medical professionals will choose the life of a patient who needs an organ over mine," shows that there is still room for improvement. The mean score on this belief ranged from 2.98 to 3.36, meaning that some students believed medical professionals cannot be trusted in this situation. However, the belief hardly correlated with 3 of 4 outcome measurements. Thus, changing this belief is not likely to result in a change in behaviour or intention, so in cases where one has to make decisions this belief would not be a priority.

\section{General comments on Table 2}

In general, although most mean scores are around the middle of the scale, there are only few beliefs that have high correlations with outcome measurements. Most correlations are small to medium in terms of association strength(94). This could mean that none of the beliefs in this study are decisive on their own, but rather only in combination with others. Another possibility is that other factors play a role in the decision-making process.

At the start of the study we expected to find a different set of beliefs for registration (intention) and registration as a donor (intention). However, most beliefs that had any correlation with an outcome measurement were correlated with all outcome measurements, or at least 3 of 4 .

\section{Salience}

The open question, addressing participants' most important reason (not) to register (as a donor), largely confirms the results from the bivariate analyses. The main reasons for participants registering (as a donor) were to help people, to save lives, and because they do not need their organs anymore after death. No new beliefs were elicited. An uneasy or "weird" feeling about organ donation or the transplantation procedure was the most commonly mentioned reason not to register (as a donor), followed by 
statements about bodily integrity. A few additional beliefs were elicited but were only mentioned by 1 or 2 participants. The aforementioned reasons show that participants sometimes confused "registration" with "registration as a donor." 
Table 2. Correlations between beliefs and registration status, donor registration, intention to register and intention to become a donor

Registered vs. non-registered

choice
Donor vs. another

no intention to register

\begin{tabular}{|c|c|c|c|}
\hline & Pearson's r (95\% Cl) & Mean \pm SD & Pearson's r $(95 \% \mathrm{Cl})$ \\
\hline $\begin{array}{l}\text { I have enough knowledge to make a decision about } \\
\text { organ donation }\end{array}$ & $\begin{array}{l}0.33^{\star \star} \\
(0.24 \text { to } 0.42)\end{array}$ & $4.74 \pm 1.80$ & $\begin{array}{l}0.18 \\
(-0.01 \text { to } 0.36)\end{array}$ \\
\hline $\begin{array}{l}\text { I would like to know more about organ donation and } \\
\text { registration }\end{array}$ & $\begin{array}{l}-0.12^{\star} \\
(-0.22 \text { to }-0.03)\end{array}$ & $3.70 \pm 1.75$ & $\begin{array}{l}0.06 \\
(-0.14 \text { to } 0.24)\end{array}$ \\
\hline I have talked about organ donation with family members & $\begin{array}{l}0.38^{\star \star} \\
(0.29 \text { to } 0.46)\end{array}$ & $4.08 \pm 2.24$ & $\begin{array}{l}0.09 \\
(-0.11 \text { to } 0.27)\end{array}$ \\
\hline I have talked about organ donation with friends & $\begin{array}{l}0.31^{\star \star} \\
(0.22 \text { to } 0.40)\end{array}$ & $3.44 \pm 2.16$ & $\begin{array}{l}0.14 \\
(-0.05 \text { to } 0.32)\end{array}$ \\
\hline $\begin{array}{l}\text { I find it hard to discuss organ donation with family } \\
\text { members }\end{array}$ & $\begin{array}{l}-0.06 \\
(-0.15 \text { to } 0.04)\end{array}$ & $1.64 \pm 1.27$ & $\begin{array}{l}-0.05 \\
(-0.23 \text { to } 0.15)\end{array}$ \\
\hline I find it hard to discuss organ donation with friends & $\begin{array}{l}-0.03 \\
(-0.13 \text { to } 0.07)\end{array}$ & $1.67 \pm 1.31$ & $\begin{array}{l}-0.10 \\
(-0.28 \text { to } 0.10)\end{array}$ \\
\hline I rather not think about death & $\begin{array}{l}-0.12^{\star} \\
(-0.21 \text { to }-0.02)\end{array}$ & $4.04 \pm 2.08$ & $\begin{array}{l}-0.14 \\
(-0.32 \text { to } 0.05)\end{array}$ \\
\hline I still have enough time to register & $\begin{array}{l}-0.34^{\star *} \\
(-0.42 \text { to }-0.25)\end{array}$ & $4.78 \pm 1.82$ & $\begin{array}{l}-0.35^{\star *} \\
(-0.51 \text { to }-0.16)\end{array}$ \\
\hline $\begin{array}{l}\text { The idea of my organs being in someone else's body } \\
\text { gives me a feeling of discomfort }\end{array}$ & $\begin{array}{l}-0.26^{\star \star} \\
(-0.34 \text { to }-0.16)\end{array}$ & $3.06 \pm 2.10$ & $\begin{array}{l}-0.49^{* \star} \\
(-0.62 \text { to }-0.33)\end{array}$ \\
\hline Certain organs have an important value to me & $\begin{array}{l}-0.08 \\
(-0.18 \text { to } 0.01)\end{array}$ & $3.01 \pm 2.14$ & $\begin{array}{l}-0.26^{\star \star} \\
(-0.43 \text { to }-0.07)\end{array}$ \\
\hline When I die, I don't want my organs to go to waste & $\begin{array}{l}0.24^{* *} \\
(0.14 \text { to } 0.33)\end{array}$ & $4.32 \pm 2.13$ & $\begin{array}{l}0.40^{\star \star} \\
(0.23 \text { to } 0.55)\end{array}$ \\
\hline When I die, my body needs to be intact for afterlife & $\begin{array}{l}-0.09 \\
(-0.19 \text { to } 0.00)\end{array}$ & $2.59 \pm 1.83$ & $\begin{array}{l}-0.17 \\
(-0.35 \text { to } 0.02)\end{array}$ \\
\hline $\begin{array}{l}\text { Some people are more deserving to receive an organ } \\
\text { than others }\end{array}$ & $\begin{array}{l}0.10 \\
(0.00 \text { to } 0.19)\end{array}$ & $4.07 \pm 2.23$ & $\begin{array}{l}-0.02 \\
(-0.21 \text { to } 0.17)\end{array}$ \\
\hline $\begin{array}{l}\text { If I register my decision, I prevent my family from having } \\
\text { to make a difficult decision when I would die }\end{array}$ & $\begin{array}{l}0.15^{\star \star} \\
(0.05 \text { to } 0.25)\end{array}$ & $5.11 \pm 1.78$ & $\begin{array}{l}0.21^{\star} \\
(0.02 \text { to } 0.38)\end{array}$ \\
\hline $\begin{array}{l}\text { If I register my decision, medical professionals will } \\
\text { honour my wishes }\end{array}$ & $\begin{array}{l}0.10 \\
(0.00 \text { to } 0.19)\end{array}$ & $5.54 \pm 1.51$ & $\begin{array}{l}0.16 \\
(-0.03 \text { to } 0.34)\end{array}$ \\
\hline $\begin{array}{l}\text { If i register my decision, I know what happens with my } \\
\text { body when I would die }\end{array}$ & $\begin{array}{l}0.06 \\
(-0.03 \text { to } 0.16)\end{array}$ & $5.07 \pm 1.71$ & $\begin{array}{l}0.04 \\
(-0.15 \text { to } 0.23)\end{array}$ \\
\hline $\begin{array}{l}\text { If I am an organ donor, I am happy I can help people in } \\
\text { need }\end{array}$ & $\begin{array}{l}0.21^{* *} \\
(0.11 \text { to } 0.30)\end{array}$ & $5.71 \pm 1.49$ & $\begin{array}{l}.049^{* *} \\
(0.33 \text { to } 0.62)\end{array}$ \\
\hline $\begin{array}{l}\text { If I am an organ donor, I am afraid my family and friends } \\
\text { see me as a deformed person because my organs were } \\
\text { removed }\end{array}$ & $\begin{array}{l}-0.11^{*} \\
(-0.21 \text { to }-0.01)\end{array}$ & $2.42 \pm 1.79$ & $\begin{array}{l}-0.25^{\star *} \\
(-0.42 \text { to }-0.06)\end{array}$ \\
\hline $\begin{array}{l}\text { If I am an organ donor, I can find a sense of positive } \\
\text { closure }\end{array}$ & $\begin{array}{l}0.19^{\star *} \\
(0.10 \text { to } 0.29)\end{array}$ & $4.63 \pm 1.78$ & $\begin{array}{l}0.39^{* *} \\
(0.21 \text { to } 0.54)\end{array}$ \\
\hline $\begin{array}{l}\text { If I am an organ donor, I run the risk of my organs being } \\
\text { taken out before I died }\end{array}$ & $\begin{array}{l}-0.12^{\star} \\
(-0.22 \text { to }-0.02)\end{array}$ & $2.92 \pm 1.91$ & $\begin{array}{l}-0.26^{* *} \\
(-0.43 \text { to }-0.07)\end{array}$ \\
\hline $\begin{array}{l}\text { If I am an organ donor, I am afraid my body will be } \\
\text { mutilated }\end{array}$ & $\begin{array}{l}-0.15^{\star \star} \\
(-0.25 \text { to }-0.05)\end{array}$ & $3.03 \pm 1.99$ & $\begin{array}{l}-0.15 \\
(-0.33 \text { to } 0.05)\end{array}$ \\
\hline $\begin{array}{l}\text { If I am an organ donor, medical professionals will choose } \\
\text { the life of a patient who needs an organ over mine }\end{array}$ & $\begin{array}{l}-0.09 \\
(-0.12 \text { to }-0.06)\end{array}$ & $3.26 \pm 1.89$ & $\begin{array}{l}-0.23^{\star} \\
(-0.40 \text { to }-0.04)\end{array}$ \\
\hline $\begin{array}{l}\text { If I am an organ donor, I am more deserving of receiving } \\
\text { an organ in case I need one }\end{array}$ & $\begin{array}{l}0.03 \\
(-0.07 \text { to } 0.12)\end{array}$ & $4.23 \pm 1.98$ & $\begin{array}{l}0.12 \\
(-0.07 \text { to } 0.30)\end{array}$ \\
\hline $\begin{array}{l}\text { If I am an organ donor, my organs will be allocated to } \\
\text { patients in an ethical manner }\end{array}$ & $\begin{array}{l}0.03 \\
(-0.07 \text { to } 0.13)\end{array}$ & $5.03 \pm 1.53$ & $\begin{array}{l}0.37^{\star *} \\
(0.19 \text { to } 0.52)\end{array}$ \\
\hline $\begin{array}{l}\text { If I am an organ donor, I run the risk of being declared } \\
\text { dead too soon }\end{array}$ & $\begin{array}{l}-0.09 \\
(-0.18 \text { to } 0.01)\end{array}$ & $2.81 \pm 1.91$ & $\begin{array}{l}-0.17 \\
(-0.35 \text { to } 0.03)\end{array}$ \\
\hline
\end{tabular}

$\mathrm{SD}$, standard deviation; $\mathrm{Cl}$, confidence interval; * $p<.05 ;{ }^{\star \star} p<.01$ 
Intention to register vs. no intention to register
Intention to register as a

donor vs. intention to

register another choice

\begin{tabular}{|c|c|c|c|c|}
\hline Mean \pm SD & Pearson's r $(95 \% \mathrm{Cl})$ & Mean \pm SD & Pearson's r $(95 \% \mathrm{Cl})$ & Mean $\pm S D$ \\
\hline $5.75 \pm 1.31$ & $\begin{array}{l}0.17^{\star \star} \\
(0.06 \text { to } 0.28)\end{array}$ & $4.38 \pm 1.82$ & $\begin{array}{l}0.22^{\star} \\
(0.04 \text { to } 0.39)\end{array}$ & $4.70 \pm 1.70$ \\
\hline $3.34 \pm 1.79$ & $\begin{array}{l}0.27^{\star *} \\
(0.16 \text { to } 0.37)\end{array}$ & $3.83 \pm 1.71$ & $\begin{array}{l}0.15 \\
(-0.04 \text { to } 0.32)\end{array}$ & $4.35 \pm 1.58$ \\
\hline $5.49 \pm 1.52$ & $\begin{array}{l}0.38^{\star \star} \\
(0.27 \text { to } 0.47)\end{array}$ & $3.58 \pm 2.24$ & $\begin{array}{l}0.21^{\star} \\
(0.03 \text { to } 0.38)\end{array}$ & $4.57 \pm 2.10$ \\
\hline $4.58 \pm 1.95$ & $\begin{array}{l}0.36^{\star \star} \\
(0.25 \text { to } 0.45)\end{array}$ & $3.04 \pm 2.10$ & $\begin{array}{l}0.23^{\star} \\
(0.05 \text { to } 0.40)\end{array}$ & $3.91 \pm 2.15$ \\
\hline $1.52 \pm 1.17$ & $\begin{array}{l}-0.04 \\
(-0.16 \text { to } 0.07)\end{array}$ & $1.68 \pm 1.31$ & $\begin{array}{l}0.03 \\
(-0.15 \text { to } 0.21)\end{array}$ & $1.60 \pm 1.21$ \\
\hline $1.60 \pm 1.22$ & $\begin{array}{l}-0.04 \\
(-0.15 \text { to } 0.08)\end{array}$ & $1.70 \pm 1.35$ & $\begin{array}{l}-0.01 \\
(-0.19 \text { to } 0.18)\end{array}$ & $1.62 \pm 1.26$ \\
\hline $3.62 \pm 1.85$ & $\begin{array}{l}-0.18^{\star *} \\
(-0.29 \text { to }-0.06)\end{array}$ & $4.19 \pm 2.14$ & $\begin{array}{l}-0.23^{\star} \\
(-0.40 \text { to }-0.05)\end{array}$ & $3.74 \pm 2.16$ \\
\hline $3.71 \pm 2.15$ & $\begin{array}{l}0.01 \\
(-0.11 \text { to } 0.13)\end{array}$ & $5.14 \pm 1.54$ & $\begin{array}{l}0.02 \\
(-0.17 \text { to } 0.20)\end{array}$ & $5.17 \pm 1.45$ \\
\hline $2.16 \pm 1.74$ & $\begin{array}{l}-0.29^{* *} \\
(-0.39 \text { to }-0.18)\end{array}$ & $3.37 \pm 2.13$ & $\begin{array}{l}-0.48^{* *} \\
(-0.61 \text { to }-0.32)\end{array}$ & $2.66 \pm 1.89$ \\
\hline $2.72 \pm 2.16$ & $\begin{array}{l}0.01 \\
(-0.10 \text { to } 0.13)\end{array}$ & $3.12 \pm 2.13$ & $\begin{array}{l}-0.16 \\
(-0.33 \text { to } 0.03)\end{array}$ & $3.15 \pm 2.04$ \\
\hline $5.16 \pm 2.11$ & $\begin{array}{l}0.19^{* *} \\
(0.08 \text { to } 0.30)\end{array}$ & $4.02 \pm 2.05$ & $\begin{array}{l}0.36^{* *} \\
(0.18 \text { to } 0.51)\end{array}$ & $4.46 \pm 2.14$ \\
\hline $2.30 \pm 1.83$ & $\begin{array}{l}-0.17^{* *} \\
(-0.28 \text { to }-0.06)\end{array}$ & $2.69 \pm 1.83$ & $\begin{array}{l}-0.25^{\star *} \\
(-0.41 \text { to }-0.06)\end{array}$ & $2.33 \pm 1.63$ \\
\hline $4.42 \pm 2.15$ & $\begin{array}{l}0.06 \\
(-0.06 \text { to } 0.17)\end{array}$ & $3.94 \pm 2.25$ & $\begin{array}{l}0.07 \\
(-0.11 \text { to } 0.25)\end{array}$ & $4.09 \pm 2.28$ \\
\hline $5.56 \pm 1.66$ & $\begin{array}{l}0.33^{\star \star} \\
(0.22 \text { to } 0.43)\end{array}$ & $4.95 \pm 1.80$ & $\begin{array}{l}0.19^{\star} \\
(0.00 \text { to } 0.36)\end{array}$ & $5.58 \pm 1.47$ \\
\hline $5.78 \pm 1.41$ & $\begin{array}{l}0.14^{\star} \\
(0.02 \text { to } 0.26)\end{array}$ & $5.45 \pm 1.53$ & $\begin{array}{l}0.02 \\
(-0.17 \text { to } 0.20)\end{array}$ & $5.70 \pm 1.39$ \\
\hline $5.26 \pm 1.61$ & $\begin{array}{l}0.19^{\star \star} \\
(0.07 \text { to } 0.31)\end{array}$ & $5.01 \pm 1.74$ & $\begin{array}{l}0.16 \\
(-0.03 \text { to } 0.33)\end{array}$ & $5.37 \pm 1.58$ \\
\hline $6.22 \pm 1.13$ & $\begin{array}{l}0.26^{\star \star} \\
(0.14 \text { to } 0.37)\end{array}$ & $5.53 \pm 1.55$ & $\begin{array}{l}0.37^{\star \star} \\
(0.20 \text { to } 0.52)\end{array}$ & $5.98 \pm 1.39$ \\
\hline $2.09 \pm 1.58$ & $\begin{array}{l}-0.13^{*} \\
(-0.24 \text { to }-0.01)\end{array}$ & $2.53 \pm 1.85$ & $\begin{array}{l}-0.01 \\
(-0.20 \text { to } 0.17)\end{array}$ & $2.27 \pm 1.61$ \\
\hline $5.21 \pm 1.70$ & $\begin{array}{l}0.32^{\star \star} \\
(0.21 \text { to } 0.41)\end{array}$ & $4.43 \pm 1.77$ & $\begin{array}{l}0.26^{\star \star} \\
(0.08 \text { to } 0.42)\end{array}$ & $5.08 \pm 1.64$ \\
\hline $2.53 \pm 1.74$ & $\begin{array}{l}-0.05 \\
(-0.17 \text { to } 0.06)\end{array}$ & $3.06 \pm 1.95$ & $\begin{array}{l}-0.21^{\star} \\
(-0.38 \text { to }-0.02)\end{array}$ & $2.94 \pm 1.97$ \\
\hline $2.52 \pm 1.69$ & $\begin{array}{l}-0.19^{\star \star} \\
(-0.30 \text { to }-0.07)\end{array}$ & $3.21 \pm 2.05$ & $\begin{array}{l}-0.24^{\star} \\
(-0.41 \text { to }-0.05)\end{array}$ & $2.76 \pm 1.81$ \\
\hline $2.98 \pm 1.86$ & $\begin{array}{l}-0.07 \\
(-0.19 \text { to } 0.04)\end{array}$ & $3.36 \pm 1.89$ & $\begin{array}{l}-0.16 \\
(-0.33 \text { to } 0.03)\end{array}$ & $3.19 \pm 1.84$ \\
\hline $4.32 \pm 2.01$ & $\begin{array}{l}0.11 \\
\text { (-0.01 to } 0.22)\end{array}$ & $4.20 \pm 1.97$ & $\begin{array}{l}-0.01 \\
(-0.20 \text { to } 0.17)\end{array}$ & $4.42 \pm 1.88$ \\
\hline $5.11 \pm 1.34$ & $\begin{array}{l}0.20^{\star \star} \\
(0.09 \text { to } 0.31)\end{array}$ & $5.01 \pm 1.60$ & $\begin{array}{l}0.27^{\star \star} \\
(0.09 \text { to } 0.43)\end{array}$ & $5.38 \pm 1.43$ \\
\hline $2.53 \pm 1.85$ & $\begin{array}{l}-0.04 \\
(-0.15 \text { to } 0.08)\end{array}$ & $2.90 \pm 1.93$ & $\begin{array}{l}-0.09 \\
(-0.27 \text { to } 0.10)\end{array}$ & $2.84 \pm 1.97$ \\
\hline
\end{tabular}


In this study we aimed to provide insight into organ donation registration and intention among lower-educated adolescents and the associated beliefs. Of the unregistered participants (73.8\%), two thirds intended to fill out a registration form, among whom two thirds wanted to become a donor (with or without restrictions). Most beliefs showed small to medium sized correlations with 1 or more of the outcomes. In general, participants scored around the middle of the scales of the beliefs, which leaves room for improvement in future interventions for increasing the registration and donor rate among this target group.

This is one of the few studies to investigate quantitatively a large number of beliefs in relation to organ donation. This provides the opportunity to not only identify beliefs that people may have, but also show how these are related to registration behaviour in a larger sample. It also shows the complexity of registration behaviour. Registration itself may seem like a simple behaviour, but the beliefs underlying this behaviour can be deeply rooted and difficult to change. This is comparable to other types of behaviour in which many different perspectives (parents, medical professionals) are involved and about which a certain controversy exists (e.g., HPV vaccination)(95). Interventions aimed at changing these behaviours should therefore not only be aimed at increasing knowledge about the topic, but also addressing these underlying beliefs.

Surprisingly, there was no clear difference between beliefs associated with registration behaviour in general and registration as a donor. There were some correlations between beliefs and outcome measurements that seem illogical, as some of the beliefs were expected to only be associated with registration (intention) in general and others with the registration as a donor (intention). For example, the belief "If I register my decision, I prevent my family from having to make a difficult decision when I would die", could be expected to be related to registration itself, but not necessarily to becoming a donor. The data show, however, that it is associated with both registration (intention) and registration as a donor (intention). It is possible that participants had difficulties 
distinguishing between registering and registering as a donor, which then resulted in a similarity in correlation patterns across different outcomes.

This problem was foreseen, as the level of knowledge about organ donation and registration was expected to be low in this group. Moreover, during the pilot test, it became clear that it was difficult for participants to differentiate between these 2 concepts. We anticipated this and thus provided both an oral and written introduction about organ donation, including an explanation about the different options upon registration. Moreover, while students were filling out the questionnaires, there was a researcher available at all times to answer questions. This was apparently not enough for students to understand these concepts clearly. This further stresses the importance of organ donation education. It is important that people know about the possibility of registering a decision, without becoming an organ donor, as an increase in the registration rate, without an increase in donors, also has a high value - that is, it could lower the burden on medical professionals and family members when unregistered individuals die(2, 11).

We were unable to perform regression analyses as no clear, interpretable scales could be constructed. This may have been due to the fact that no validated questionnaire was used. However, it is unlikely that the problem lies in the operationalization of the items, as an extensive literature search was employed to identify specific items used in previous studies. Moreover, the salience question hardly led to new topics. Another reason could be that organ donation registration is far more complex than only a few themes or even that it is nonreasoned, in view of the wide attitude-behaviour gap. Many people have a positive attitude toward organ donation, but do not register. Stevens (96) found that peoples' explicit attitudes are not always in line with their implicit attitudes about organ donation. Models based on the coexistence of both implicit and explicit cognitions (e.g., the Reflexive-Impulsive Model(97)) could be useful in further research in this field to enrich the understanding of registration behaviour.

Another limiting factor in the regression analyses was the sample size. The total sample size was sufficient for the primary analyses focused on bivariate associations(98), 
but the questions related to the choice they registered, their intention and the specific choice they intended to register were only answered by a small proportion of the sample. For example, only 106 people answered the question about their registration choice, which is about one fourth of the sample. In combination with the large number of predictors remaining, the regression model was less likely to result in accurate parameter estimations in comparison to bivariate associations(98).

In conclusion, organ donation registration is complex and associated with many underlying beliefs. Important targets for interventions became visible, showing where there is room for improvement. However, it is plausible that, in addition to these explicit beliefs, implicit factors play a role in registration behaviour. This could be explored in future research and intervention development aimed at increasing registration rates. 
Table A1. Overview of studies and beliefs used for the questionnaire

\begin{tabular}{|c|c|c|c|c|c|c|c|c|c|c|c|c|c|c|c|c|}
\hline Beliefs & 1 & 2 & 3 & 4 & 5 & 6 & 7 & 8 & 9 & 10 & 11 & 12 & 13 & 14 & 15 & 16 \\
\hline \multicolumn{17}{|l|}{ The body } \\
\hline $\begin{array}{l}\text { Dehumanization of } \\
\text { the body }\end{array}$ & $x$ & $x$ & $x$ & $x$ & & $x$ & & & & $x$ & $x$ & & $x$ & $x$ & & \\
\hline $\begin{array}{l}\text { Ownership over the } \\
\text { body }\end{array}$ & $x$ & & & & & & $x$ & & & & & & $x$ & $x$ & & $\mathrm{x}$ \\
\hline $\begin{array}{l}\text { Special significance } \\
\text { certain organs }\end{array}$ & & & & & $x$ & $x$ & & & & & & & $x$ & & & $\mathrm{x}$ \\
\hline $\begin{array}{l}\text { Pragmatic } \\
\text { standpoint/don't let } \\
\text { organs go to waste }\end{array}$ & & & $x$ & $x$ & & $x$ & & & & & $x$ & & $x$ & & & \\
\hline \multicolumn{17}{|l|}{ Death } \\
\hline $\begin{array}{l}\text { Don't want to think } \\
\text { about death/organ } \\
\text { donation }\end{array}$ & $x$ & $x$ & & & $x$ & $x$ & & $x$ & $x$ & $x$ & & $x$ & $x$ & & $x$ & $\mathrm{x}$ \\
\hline Positive closure & & & & & & & $x$ & & & & & & & $x$ & & \\
\hline
\end{tabular}

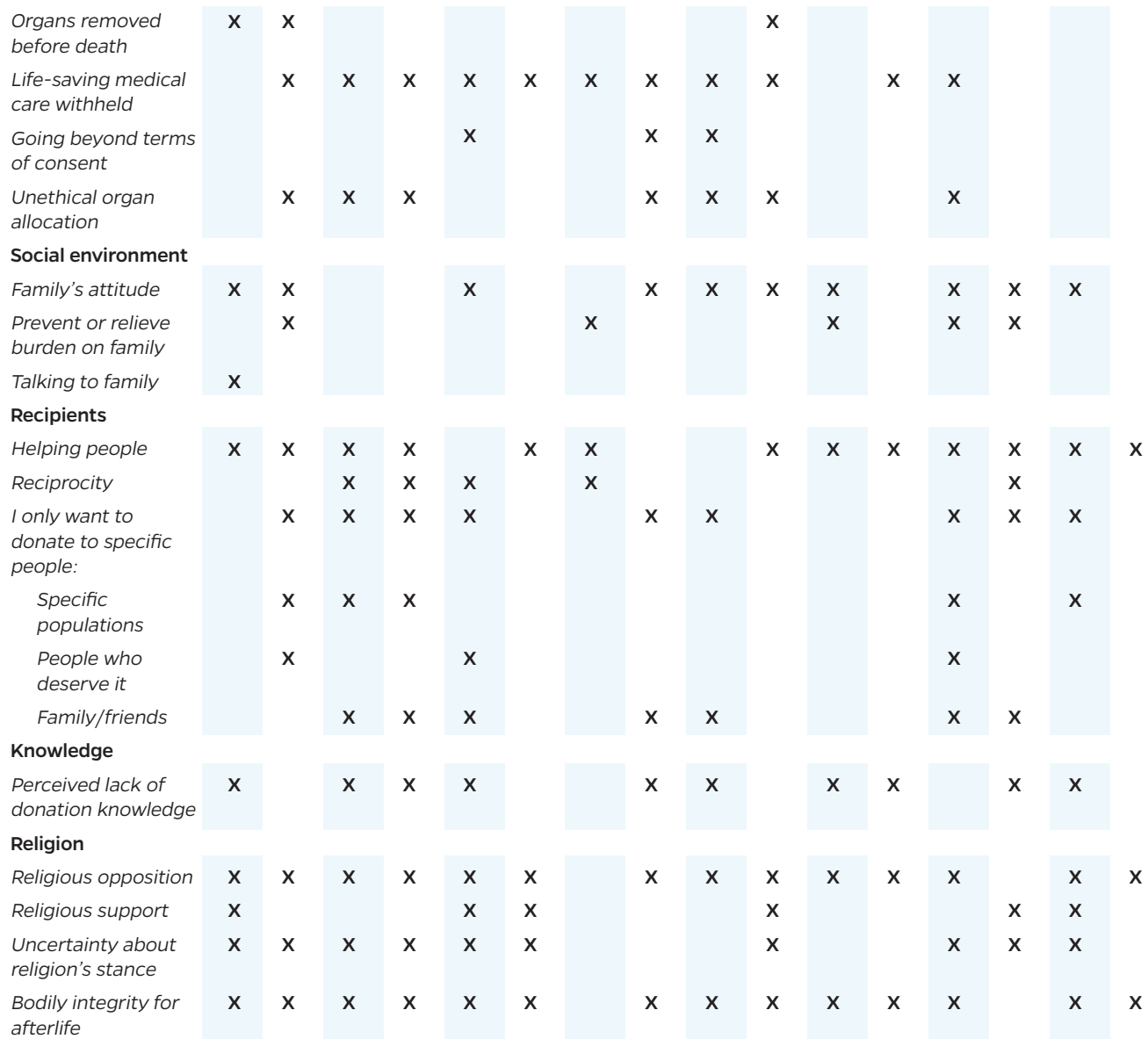

afterlife

Numbers 1-34 refer to the studies mentioned in Table A2 

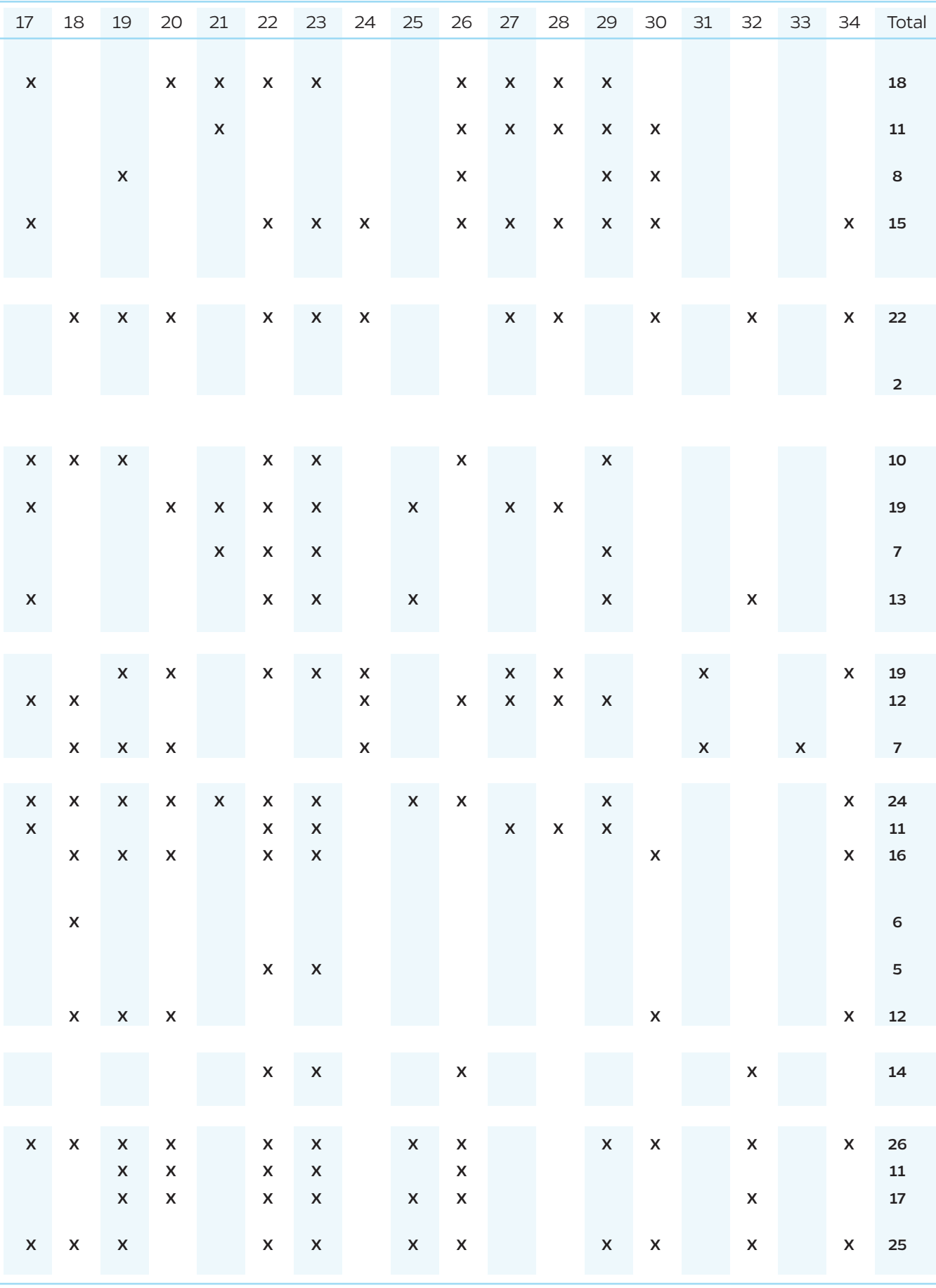
Table A2. Methods and theories used in the studies

\begin{tabular}{|c|c|c|c|c|}
\hline \multicolumn{2}{|c|}{ Study Author } & \multirow{2}{*}{$\begin{array}{l}\text { Year } \\
2005\end{array}$} & \multirow{2}{*}{$\begin{array}{l}\text { Methods } \\
\text { Focus groups }\end{array}$} & \multirow{2}{*}{$\begin{array}{l}\text { Theory } \\
\text { - }\end{array}$} \\
\hline 1 & Albright, Glanz (62) & & & \\
\hline 2 & AlKhawari, Stimson (99) & 2005 & $\begin{array}{l}\text { Semi-structured interviews \& } \\
\text { focus groups }\end{array}$ & Grounded theory methodology \\
\hline 3 & Arriola, Perryman (76) & 2005 & Focus groups & - \\
\hline 4 & Arriola, Perryman (86) & 2007 & Focus groups & - \\
\hline 5 & Bhengu and Uys (89) & 2004 & Semi-structured interviews & $\begin{array}{l}\text { Theory of Leininger } \\
\text { Model of Chrisman }\end{array}$ \\
\hline 6 & Braun and Nichols (71) & 1997 & $\begin{array}{l}\text { Semi-structured interviews \& } \\
\text { focus groups }\end{array}$ & - \\
\hline 7 & Brug, van Vugt (100) & 2000 & Questionnaires & Social Cognitive Theory \\
\hline 8 & Davis and Randhawa (78) & 2004 & Focus groups & - \\
\hline 9 & Davis and Randhawa (73) & 2006 & Focus groups & - \\
\hline 10 & Exley, Sim (74) & 1996 & $\begin{array}{l}\text { Semi-structured interviews \& } \\
\text { focus groups }\end{array}$ & - \\
\hline 11 & Fahrenwald and Stabnow (88) & 2005 & Semi-structured interviews & Ecological model (Stokols) \\
\hline 12 & Frates and Garcia Bohrer (101) & 2002 & Semi-structured interviews & - \\
\hline 13 & Hayward and Madill (102) & 2003 & Focus groups & Grounded theory methodology \\
\hline 14 & Irving, Jan (65) & 2014 & Nominal groups techniques & - \\
\hline 15 & Kennedy (87) & 2002 & Discursive interviews & - \\
\hline 16 & Lai, Dermody (103) & 2007 & Active interviews & - \\
\hline 17 & Moloney and Walker (84) & 2002 & Focus groups & - \\
\hline 18 & Molzahn, Starzomski (63) & 2004 & Semi-structured interviews & Naturalistic inquiry \\
\hline 19 & Molzahn, Starzomski (104) & 2005 & $\begin{array}{l}\text { Focus groups \& semi-structured } \\
\text { interviews }\end{array}$ & \\
\hline 20 & Molzahn, Starzomski (105) & 2005 & $\begin{array}{l}\text { Focus groups \& semi-structured } \\
\text { interviews }\end{array}$ & \\
\hline 21 & Morgan, Mayblin (83) & 2008 & Semi-structured interviews & - \\
\hline 22 & Morgan, Harrison (77) & 2008 & $\begin{array}{l}\text { Observation of communication } \\
\text { between dyads }\end{array}$ & - \\
\hline \multirow[t]{2}{*}{23} & Morgan, Harrison (106) & 2005 & $\begin{array}{l}\text { Observation of communication } \\
\text { between dyads }\end{array}$ & Theory of Reasoned Action \\
\hline & & & & $\begin{array}{l}\text { Theory of Motivated Information } \\
\text { Management }\end{array}$ \\
\hline 24 & Nizza, Britton (79) & 2016 & Semi-structured interviews & - \\
\hline 25 & Peters, Kittur (90) & 1996 & Focus groups & - \\
\hline 26 & Randhawa (72) & 1998 & Focus groups & - \\
\hline 27 & Reubsaet, Brug (107) & 2001 & Questionnaire & Social Cognitive Theory \\
\hline 28 & Reubsaet, van den Borne (80) & 2001 & Questionnaire & Social Cognitive Theory \\
\hline 29 & Sanner (85) & 1994 & Semi-structured interviews & - \\
\hline 30 & Sanner (64) & 2001 & Semi-structured interviews & - \\
\hline 31 & Sirois, Sears Jr (81) & 2005 & Questionnaires & - \\
\hline 32 & Thompson (75) & 1993 & Focus groups & - \\
\hline \multirow[t]{2}{*}{33} & Trompeta, Cooper (108) & 2012 & Questionnaire & Organ Donation Model (ODM) \\
\hline & & & & $\begin{array}{l}\text { Acculturation theory } \\
\text { Theory in adolescent } \\
\text { development }\end{array}$ \\
\hline \multirow[t]{2}{*}{34} & Wittig (109) & 2001 & Semi-structured interviews & $\begin{array}{l}\text { Theory of culture care diversity } \\
\text { and universality }\end{array}$ \\
\hline & & & & The Sunrise Model \\
\hline
\end{tabular}


Table A3. Correlations between separate beliefs

\begin{tabular}{|c|c|c|c|c|c|c|c|c|c|c|}
\hline & 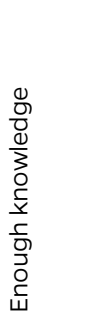 &  & 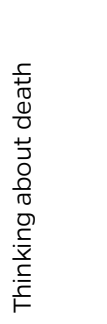 & 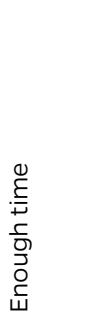 & 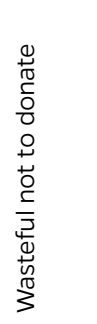 & 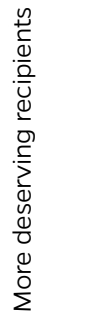 & 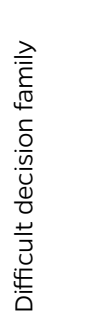 & 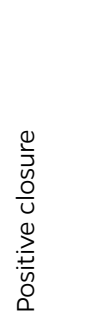 & 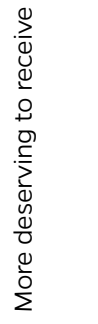 & 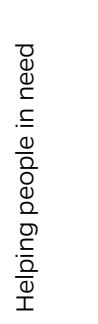 \\
\hline $\begin{array}{l}\text { Enough } \\
\text { knowledge }\end{array}$ & 1 & $-.166^{\star \star}$ & $-.236^{\star \star}$ & -.093 & $.150^{\star \star}$ & .089 & $.217^{\star \star}$ & $.223^{\star \star}$ & -.024 & $.205^{\star \star}$ \\
\hline $\begin{array}{l}\text { Want to } \\
\text { know more }\end{array}$ & $-.166^{\star \star}$ & 1 & .056 & .043 & $.101^{\star}$ & .034 & $.107^{\star}$ & $.197^{\star \star}$ & $.117^{\star}$ & $.320^{\star \star}$ \\
\hline $\begin{array}{l}\text { Thinking } \\
\text { about death }\end{array}$ & $-.236^{\star \star}$ & .056 & 1 & $.133^{\star \star}$ & -.097 & .082 & $-.128^{\star}$ & $-.105^{\star}$ & .070 & $-.208^{\star \star}$ \\
\hline $\begin{array}{l}\text { Enough } \\
\text { time }\end{array}$ & -.093 & .043 & $.133^{\star \star}$ & 1 & -.081 & -.061 & -.035 & $-.135^{\star \star}$ & $-.129 *$ & -.096 \\
\hline $\begin{array}{l}\text { Wasteful } \\
\text { not to } \\
\text { donate }\end{array}$ & $.150^{\star \star}$ & $.101^{\star}$ & -.097 & -.081 & 1 & $.124^{\star}$ & $.221^{\star \star}$ & $.296^{\star \star}$ & .082 & $.270^{\star \star}$ \\
\hline $\begin{array}{l}\text { More } \\
\text { deserving } \\
\text { recipients }\end{array}$ & .089 & .034 & .082 & -.061 & $.124^{\star}$ & 1 & $.148^{\star \star}$ & .098 & $.230^{\star \star}$ & $.110^{\star}$ \\
\hline $\begin{array}{l}\text { Difficult } \\
\text { decision } \\
\text { family }\end{array}$ & $.217^{\star \star}$ & $.107^{\star}$ & $-.128^{\star}$ & -.035 & $.221^{\star \star}$ & $.148^{\star \star}$ & 1 & $.288^{\star \star}$ & .073 & $.285^{\star \star}$ \\
\hline $\begin{array}{l}\text { Positive } \\
\text { closure }\end{array}$ & $.223^{\star \star *}$ & $.197^{\star \star}$ & $-.105^{\star}$ & $-.135^{\star \star}$ & $.296^{\star \star}$ & .098 & $.288^{\star \star}$ & 1 & $.190^{\star \star}$ & $.515^{\star \star}$ \\
\hline $\begin{array}{l}\text { More } \\
\text { deserving } \\
\text { to receive }\end{array}$ & -.024 & $.117^{\star}$ & .070 & $-.129^{\star}$ & .082 & $.230^{\star \star}$ & .073 & $.190^{\star \star}$ & 1 & .084 \\
\hline $\begin{array}{l}\text { Helping } \\
\text { people } \\
\text { in need }\end{array}$ & $205^{\star \star}$ & $.320 \star \star$ & $-.208^{\star \star}$ & -.096 & $.270^{\star \star}$ & $.110^{\star}$ & $.285^{\star \star}$ & $.515^{\star \star}$ & .084 & 1 \\
\hline
\end{tabular}

${ }^{\star}, p<.05 ;{ }^{\star *}, p<.01$ 



\section{chapter 3}

a web-based education program to encourage organ donation registration among lower-educated adolescents in the Netherlands: study protocol for a cluster randomized

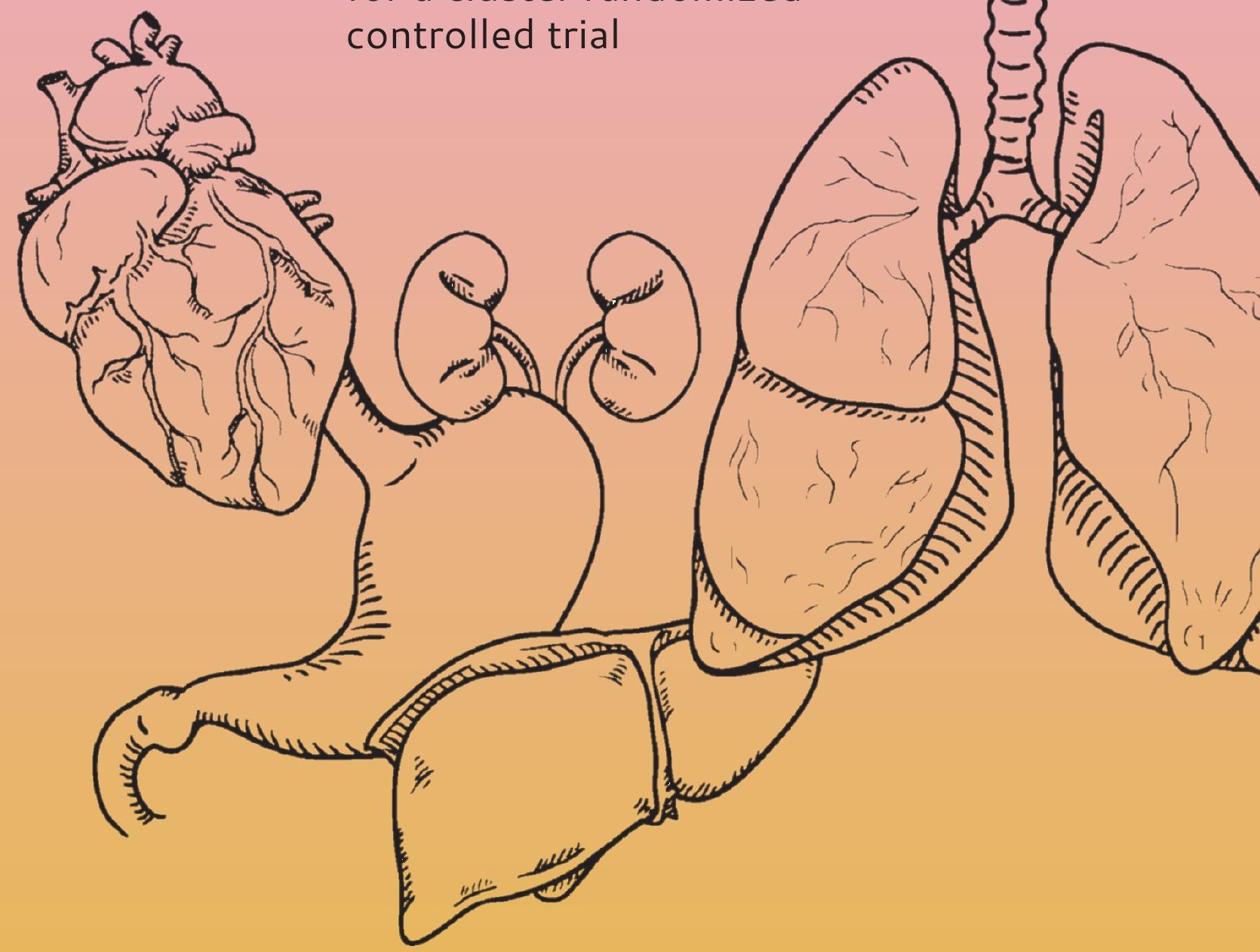

This chapter has been published as:

Steenaart, E., Crutzen, R., Candel, M. J., \& de Vries, N. K. A web-based education program to encourage organ donation registration among lower-educated adolescents in the Netherlands: study protocol for a cluster randomized controlled trial. Trials. 2018;19(1):532. 


\section{ABSTRACT}

\section{Background}

The gap between the supply and demand of organ donors is substantial, causing patients to suffer from long waiting times. Moreover, the lack of registrations places a burden on family members and medical professionals when an unregistered individual dies. This article describes a cluster randomized controlled trial (CRCT) study to assess the effectiveness and quality of implementation of a web-based program aimed at encouraging lower-educated adolescents to register a well-informed choice about organ donation, regardless of it being as a donor or not.

\section{Methods}

The program will be delivered by teachers at schools for Intermediate Vocational Education in the Netherlands. The effectiveness will be assessed in a CRCT design with post-test only using self-administered questionnaires for the primary outcome (i.e. intention to register). Classes will be matched to improve equivalence of groups. From each pair of matched classes, one class will be randomly assigned to the experimental condition, and the other assigned to the control condition. Students in the control groups will fill out the questionnaire before receiving the program, while the experimental groups will do this afterwards. A post-test design prevents the risk of testing bias. The required sample size is 14 schools, with 10 classes per school and 13 unregistered students per class. The questionnaire assesses demographics, behavioural determinants (attitude, self-efficacy, knowledge and social outcomes), intention to register (as a donor) and registration status. Six months after delivery, registration status will be assessed again. Additionally, a process evaluation will be conducted to evaluate the quality of implementation using both qualitative (i.e. semistructured interviews) and quantitative (i.e. logbooks, questionnaires, Google Analytics to track user behaviour at the website) methods. 


\section{Discussion}

Findings of the study can help to further improve the program and serve as a basis for a solid dissemination plan. Moreover, the study will provide insight into (change in) determinants of registration and donorship and the translation of research into practice of school-based health promotion interventions, which can serve as an example for others. 


\section{BACKGROUND}

Despite an increase in the number of organ donors and successful transplantations in recent years, there is still a substantial gap between the supply and demand for organ donors. As a result, patients suffer from long waiting times or even die while waiting for an organ(110).

One of the many efforts to increase the number of registrations is a yearly initiative to encourage 18-year-olds to register their choice (irrespective of whether they want to be a donor or not). In the year after adolescents turn 18, they receive a letter from the Ministry of Health, Welfare and Sport asking them to register their choice. This led to a response rate of $33.0 \%$ in 2016 , of which $73.9 \%$ gave permission for organ donation(61). In other words, many adolescents did not make a choice regarding organ donation yet, or at least did not register this choice. This lack of registration leads to several problems, including the burden on family members and medical professionals when an unregistered individual dies. For example, when no donor record of a patient is found, the next of kin will be asked for consent. This is a stressful situation for all people involved and results in a high refusal rate $(2,10,11)$. To increase the registration rate, adolescents could be supported in making a well-informed decision and be encouraged to register this choice.

Reubsaet and colleagues made an effort to educate adolescents about organ donation and registration by designing an educational program for high school students. The main aim of their program was to increase the number of registrations, not necessarily the number of organ donors. The social cognitive theory (SCT) of Bandura was the main underlying theory during the development(111). SCT describes three important factors that influence (intentions to participate in) a certain behaviour. These include people's expected consequences of performing a certain behaviour (positive/negative outcome expectations), people's expected social reactions to performing that behaviour (social outcome expectations) and beliefs about their own ability to perform this behaviour (self-efficacy expectations). Several determinant studies and pilot tests led 
to the development of the three educational components of the program: (1) videos to elicit discussion about positive and negative outcome expectations of organ donation and registration, (2) working with an interactive computer program with tailored feedback, and (3) practicing with completing a registration form(25, 26, 80, 107). This program was proven to be effective in increasing the intention to register in a large field study(24), after which the program was translated from a paper-based version into a web-based version. Web-based programs have high potential, as they can be effective in changing behavioural outcomes with low costs(112). Moreover, web-based programs enable one to reach a large group of people with information that can be tailored to the individual(113).

Another desirable adaptation regards the target group of the program. As the original program was only used among high school students, lower-educated students were not reached. Lower-educated students have left high school by the age of 16 (as opposed to 17-18 for higher-educated students) and usually continue their education at Intermediate Vocational Education (IVE) schools(114). IVE schools typically teach lower-educated adolescents from the age of 16 until their early 20s. These adolescents are all about to receive the letter about organ donation or have received it recently. The need for a program about organ donation might even be higher for this group than for high school students, as studies have shown that lower-educated individuals have a less positive attitude towards organ donation than higher-educated individuals(20, 29, 115). Moreover, the registration rate of lower-educated individuals is significantly lower than that of higher-educated individuals(31).

Adjustments had to be made to make the website suitable for lower-educated students as well. Firstly, textual changes were made, as students at IVE schools score lower on reading competencies than high school students; $20 \%$ of the students that start their IVE trajectory score even lower than the minimal reading level required for civic integration(116). Therefore, adjustments were made to improve text comprehension. Moreover, the number of questions in the interactive computer program was decreased by half. This selection was made based on a preparatory study in the target group(117). 
This study was conducted among 405 IVE students, using a questionnaire based on previous literature, identifying important beliefs regarding organ donation and registration. The selection of beliefs was based on their association strength with registration behaviour and intention and the extent to which there was room for improvement, that is, the extent to which mean scores on the beliefs are in the desired direction (e.g. in favour of organ donation registration).

Adapting the web-based educational program of Reubsaet and colleagues to lowereducated students and implementing it in IVE schools throughout the Netherlands could help reach a larger group of adolescents and therefore increase the number of registrations. As the program is now web-based and applied to a different target group, it is important to study its effectiveness. This will be done in a cluster randomized controlled trial (CRCT) with post-test only in IVE schools spread over the Netherlands. In addition, a process evaluation will be performed to determine the quality of implementation during this trial. Combining an effect and process evaluation will give insight into the effects of the program and how these effects were achieved. This article gives an overview of the different components of the program and provides a detailed protocol for the anticipated evaluation study. 


\section{METHODS}

\section{Aims}

The effect evaluation aims to give insight into the effect of the program on behavioural determinants, the intention to register (as an organ donor) and the actual registration behaviour itself. Attitude, self-efficacy, social outcomes and knowledge will be assessed as behavioural determinants.

With the process evaluation we aim to gain insight into how the program was implemented. The process evaluation relies on four different data sources: questionnaires from students, logbooks, interviews with teachers and user data from Google Analytics. The use of data triangulation enables different data sources to complement one another. This provides an overview of the implementation of the educational components on six levels: reach, dose delivered, dose received, fidelity, context and reasons for fidelity and dose. These levels are inspired by the model of Steckler and Linnan(118). Appendix Table A1 provides an overview of all constructs used, the definitions we use in this study and the instruments used to measure them.

\section{Description of the intervention}

The web-based program consists of three main elements: video fragments followed by group discussions, quizzes with tailored feedback and an exercise to fill out an organ donation registration form. The website is hosted by SIDVO, which is a foundation that aims to develop, evaluate and distribute organ donation education. The elements will be provided to the students during two 50-min lessons at school. At the end of the program, students are expected to be able to make a well-informed decision about organ donation registration and will be encouraged to register this choice.

Lesson 1 consists of four video fragments followed by group discussions. Each video deals with an aspect of organ donation and registration in which both positive and negative outcome expectations are included. The videos are designed to elicit discussion among students about brain death, the possibility to help other people by donating 
your organs, discussing the subject with others and the importance of registering in general (from the perspective of medical professionals and family members). Teachers will be provided with a manual to facilitate discussion after each video in which students have the opportunity to share their opinions and beliefs.

This activity aims to increase involvement, encourage positive beliefs and counterbalance negative beliefs. Lesson 2 combines two program elements. First, students will individually work with the website. The website provides the participants with two quizzes. One quiz will mainly focus on students' knowledge, while the other one will focus on their opinions. The knowledge quiz reveals a score on a scale from 1 to 10 and the correct answers to the questions after completion. In the opinion quiz each question will be followed by tailored feedback. Participants will receive information that is personally relevant and fits their needs. The main goal of the quizzes is to teach participants about organ donation and registration and give them tailored feedback on misconceptions they might have. The second part of the lesson will be spent on an exercise on completing an organ donation registration form in order to enhance selfefficacy. Students will be provided with a copy of an organ donation registration form or use a digital version; whatever option is most convenient. The aim is to give students an enactive mastery experience, which increases their self-efficacy and therefore increases the intention to fill out a real organ donation registration form.

\section{Study design}

This article was written in accordance with the Standard Protocol Items: Recommendations for Interventional Trials (SPIRIT) checklist. The effects of the program on registration behaviour, registration intention and beliefs regarding organ donation and registration will be evaluated in a CRCT with post-test only (see Figure 1). The program will be offered to both the control and experimental groups. Students in the control group will complete the evaluation questionnaire before receiving the program, while the experimental group will do this after receiving the program. Differential attrition can be prevented, as all participating classes will receive the program. A post-test design prevents the risk of testing bias by priming students for the program by filling 
out the questionnaire beforehand(119). The absence of a pre-test, however, might also threaten internal validity, since equivalence of the groups cannot be established. The threat of possible differences at baseline will be minimized by using a large number of randomization units and a proper randomization(120).

After agreement to participate, classes will be matched by members of the study team to improve the equivalence of the groups. The classes will be matched on study discipline, and matched classes will be from the same school. From each pair of matched classes, one class will be randomly assigned to the experimental condition, while the other class will then be assigned to the control condition. Teachers will be notified as to whether they have to hand out the questionnaire before or after delivering the program to students.

The implementation of the educational program will be evaluated using both qualitative (i.e. semi-structured interviews) and quantitative (i.e. logbooks, questionnaires, Google Analytics data) methods, both during and post-delivery. 


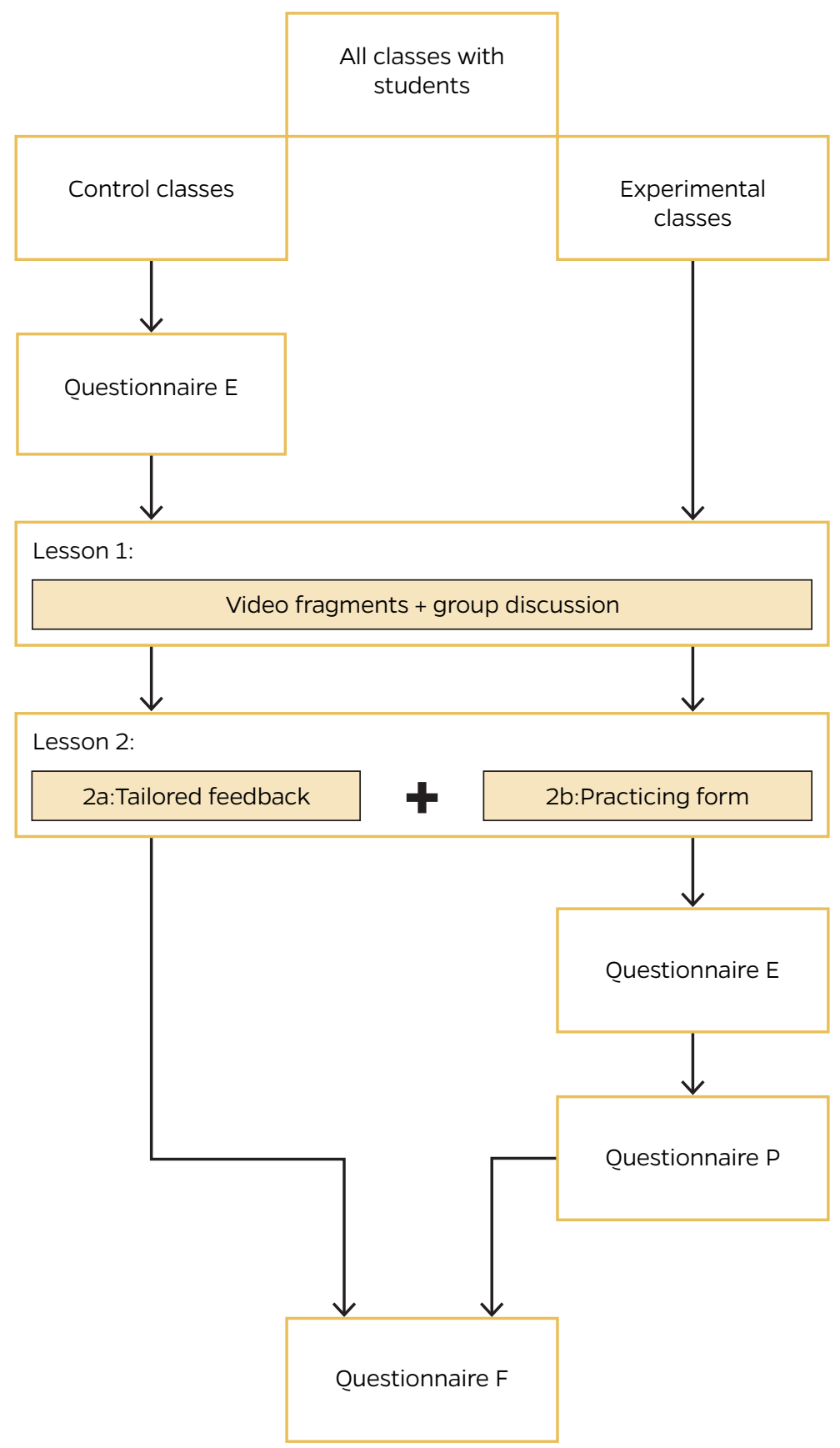

Figure 1. Design of the evaluation study

Questionnaire $P$, questionnaire process evaluation; Questionnaire E, questionnaire effect evaluation; Questionnaire $F$, questionnaire follow-up measurement 


\section{Procedure}

The educational program will be provided by the teachers in IVE schools during regular classes. They will receive a link via e-mail prior to the start of the study. With this link, both teachers and students can reach the website. Before the first lesson, the control group will complete the effect evaluation questionnaire. All participants will then receive lesson 1 , with the video fragments and group discussions. During the next session, they will both receive lesson $2 \mathrm{a}$, the quizzes with tailored feedback, and lesson $2 \mathrm{~b}$, the exercise on completing an organ donation registration form. Teachers will have the freedom to provide the lessons whenever it fits their schedule, but we expect that in most cases lesson 2 will be delivered within 1 or 2 weeks after lesson 1 . After the whole program is delivered, students in the experimental group will fill out the evaluation questionnaire. Six months after the implementation of the program, participating students (students from both the experimental and control groups) will receive a follow-up questionnaire during class to measure their registration behaviour. New control classes will then be recruited to compare the registration behaviour of students who received the program with that of students who did not. Data for the process evaluation will be gathered partly during the program delivery and partly after. During the program delivery, data will be collected on usage (e.g. by means of Google Analytics), while after the program delivery, reasons for particular usage behaviour will be assessed (e.g. by means of interviews). Moreover, students in the experimental groups will complete a process evaluation questionnaire after the program is delivered.

\section{Study setting, population and sample size}

The program will be evaluated in a school setting. More specifically, IVE schools throughout the Netherlands will be invited to participate in the program through various channels. In particular, teachers teaching the course Citizenship will be approached, as organ donation fits with the content of this course. IVE schools typically teach lowereducated adolescents from the age of 16 until the early 20s, but students from all ages are welcome. Older students will therefore be automatically included in the sample as well. Students in IVE can choose from a variety of disciplines, both manual and non- 
manual. There are four levels within IVE, but the educational level is generally low as opposed to college or university education.

As participants will be recruited via their schools, they are not approached individually. Therefore, no inclusion or exclusion criteria are set on the individual level. On the class level, only students in IVE levels 2, 3 and 4 are included in the study. Level 1 is also known as entry training. Students in this level did not graduate from high school; therefore, we cannot guarantee they will be able to participate properly in the program due to a large variety in cognitive abilities at this level.

Data from a preparatory study in the same target group(117) and the evaluation of a similar study in a slightly different target group(24) were used in simulations to calculate the sample size for the current study. The calculations were performed using a Monte Carlo simulation study with MLPowSim and are therefore not based on design effects, but on the expected percentage of registration in the control and experimental groups as well as the variances of the random effects from the logistic multilevel model and intraclass correlations (ICCS)(121). The calculations were based on an expected increase in the primary outcome, expected class size, the ICC and the power of the test. The matching was not taken into account, as this will only increase the power. Therefore, the chosen power level (80\%) is a safe choice(122). A relative increase of $20 \%$ of the primary outcome was minimally expected based on the results of the study by Reubsaet et al.(24). In the preparatory study, the average number of students per class was 16.2, of which $73.8 \%$ were not registered yet (our target group). The average cluster size is therefore 11.95 , or 12 unregistered students per class. In order to be able to detect a difference of $20 \%$ with $80 \%$ power in a two-sided test with $\alpha=0.05$, taking into account an ICC of 0.02 at class level and 0.01 at school level, the required sample size is 12 schools, with an average of 10 classes per school and 12 un-registered students per class, leading to a power level of 0.839. However, as there is a high range of the number of students per class, the number of schools is increased by $15 \%(123)$, resulting in a minimum of 14 schools(and thus 140 classes, of which 70 
are assigned to the control condition and 70 to the intervention condition, with a total of 1680 unregistered students).

\section{Ethical approval}

The study was approved by the Ethics Committee of the Faculty of Health, Medicine and Life Sciences on 23 October 2017 (reference number Steenaart/231017) and registered at the Dutch Trial Register (NTR6771; http://www.trialregister.nl/trialreg/admin/ rctview.asp?TC=6771). Participation of teachers and students is voluntary, and they will provide written (students) or verbal (teachers) informed consent. Participants will be informed about the study, the opportunity to withdraw their consent at any time and the anonymity of the study and will be provided with contact information in case they have any further questions.

\section{Measurements}

Four different measurement instruments will be used to gather data; questionnaires from students, logbooks, interviews with teachers and user data from Google Analytics.

\section{Questionnaires}

All students will participate in the evaluation study by completing a total of two or three questionnaires depending on the condition: one for the process evaluation (questionnaire P; experimental condition only), one for the effect evaluation (questionnaire E) and one follow-up questionnaire (questionnaire F). For the process evaluation, only students in the experimental condition will receive a questionnaire (questionnaire $P$ ) in which they are asked to evaluate the program after the second session. This questionnaire will assess the dose received and reasons for fidelity and dose. Dose received will be measured by assessing their appreciation for the program. The appreciation of the program as a whole as well as the three components will be assessed by asking the students how much they learned from each component and how much they enjoyed working with the component. Also, reasons for fidelity and dose will be assessed by asking students what parts they liked and what parts could be improved. 
The questionnaire for the effect evaluation (questionnaire E) will be completed before (control condition) or after (experimental condition) the program delivery. The primary outcome will be the students' intention to register (yes/no). Students who answered "yes" to this question will be asked to specify the decision they would like to make (registering as a posthumous organ and tissue donor, a posthumous donor for specific organs and tissues or a non-donor; leaving the decision to the next of kin; or leaving the decision to a specific person), which will be dichotomized into intention to become a donor or not. All students will also be asked about whether they already registered a decision (yes/no) and, if yes, the choice they made (see the above-mentioned options). Only unregistered participants will fill out the intention question. Additionally, questions are included to measure attitude, self-efficacy, knowledge and social outcomes. These behavioural determinants are the main focus of the educational program.

Finally, all participants will receive a follow-up questionnaire (questionnaire F) after a period of approximately 6 months to measure their registration behaviour. As official registration records are private, participants will be asked whether they registered their choice since receiving the program and, if so, what choice they registered.

\section{Logbooks}

Teachers will be asked to keep track of a logbook during the two sessions. This logbook will consist of a simple checklist in which they can tick the boxes of the components they delivered during the session. Moreover, they will be asked to indicate the time spent on the components and rate their satisfaction with the lesson. Finally, there will be room for additional comments in case they encountered difficulties during the implementation of the lessons.

\section{Interviews}

All participating teachers will be invited to elaborate on the facilitators and barriers of implementation of the lessons during a semi-structured interview. Data from the logbooks will be used as an input for the interview guide, as well as the diffusion of innovations theory(124). The topics that will be addressed include teachers' experiences (e.g. 
"How did you experience working with the program?" or "How did you like working with the manual?"), dissemination (e.g. "Would you be interested in using the program again in the future?") and innovation characteristics (e.g. "To what extent does the program fit in your schools' curriculum?" or "How complex was it for you to work with the program?"). The interviews are expected to last between 15 and 30 min, will be audiorecorded and will be transcribed verbatim.

\section{Google Analytics}

The usage of the website will be monitored by Google Analytics. This quantitative measure gives us the opportunity to assess participants' behaviour on the website objectively. The potential of using this method in the process evaluation of Internetdelivered interventions has been demonstrated before(125). The data will give us information on when the website is visited and by whom, how participants then behave on the website, whether they complete all elements and, if not, when they quit. This also gives us the opportunity to check whether matched classes in different arms received the program in the same period of time. As emphasized in the previous Internetdelivered interventions study(125), it is important to combine objective user data with qualitative measures. Google Analytics cannot provide an explanation for certain user behaviour, which will therefore be assessed using interviews, logbooks and questionnaires. As Google Analytics can only trace users back to their zip code, teachers will be provided with a link to be able to trace the user behaviour back to specific schools and even classes. User behaviour cannot be traced back on the individual level; only data at the aggregate class level are accessible and used for evaluation purposes.

\section{Statistical analyses}

The first aim of this study is to investigate the effectiveness of the educational program on the intention to register a choice (i.e. the primary outcome in the study at hand, measured as yes or no). All data for the effectiveness evaluation are gathered from questionnaire E. Secondary outcomes will be the choice students intend to make (yes or no donation), behavioural determinants and finally their actual registration behaviour 6 months after receiving the intervention. The differences in outcomes 
between the intervention and the control group will be analysed using multilevel regression models, taking into account that students are nested within classes which in turn are nested within schools. Besides intervention group, several demographic characteristics are included in these models (i.e. sex, study discipline, age, religion and educational level), as they are expected to be associated with the outcomes.

As a post-test only design was used, there are no missing data in terms of participants dropping out in between measurements. Therefore, when comparing the experimental and control groups, missing data will not be an issue-we have all data from participants who agreed to participate. The mixed model analysis is then valid under the assumption of missing at random (MAR). However, when correcting for covariates, missing could become an issue, as participants can skip items in the questionnaire. This will be dealt with using multiple imputation (MI).

The second aim is to analyse the implementation of the program. Interviews will be audio-recorded, and a transcript will be written from each interview. The transcripts will be marked with labels using open coding. These codes will be categorized (selective coding), resulting in matrices in which facilitators and barriers of the implementation will be identified. Quantitative data from Google Analytics, the teachers' logbooks and students' questionnaires (questionnaire P) will be used for descriptive analyses to provide insight into how the program was used, delivered and received.

All data will be stored on a secured service and will only be accessible by the study team. A data entry check will be performed on the data from the questionnaires; range checks will also be performed. The interviews will be coded independently by two researchers. 


\section{DISCUSSION}

This protocol describes a study to evaluate both the effectiveness and implementation of a program aimed at encouraging lower-educated adolescents to make a well-informed decision about organ donation and to register this choice. The study is strong in combining several methods and a variety of data sources. The data triangulation serves two main goals: confirmation of findings and completeness(126). The combination of qualitative and quantitative methods is valuable, as both methods separately will not be sufficient(118). By combining the methods, flaws can be neutralized and benefits can be strengthened(127). This leads to a higher validity of conclusions.

There are also possible pitfalls of the study. However, by acknowledging them beforehand and taking them into account during the execution, risks can be limited. A threat during the execution of the program is the possibility of contamination. If students in the experimental group receive the program before students in the control group, students in the control group could hear about the content, biasing their answers on the evaluation questionnaire. Ideally, students from both groups (within one school) will receive the program simultaneously. However, in many cases, we expect this to be difficult due to organizational reasons and because often these classes are being taught by the same teacher. If students in the control group hear about the content before filling out the baseline questionnaire, this could influence their answers in the direction of expected intervention effects and therefore most probably lead to an underestimation of the program effect in the end.

Finally, the effectiveness of the program in terms of registration behaviour is difficult to measure. As official organ donation registration records are private, no objective data can be gathered regarding the actual registration numbers of participants. The intention to register will be measured directly after receiving the program. To gain some insight into the registration behaviour, participants will be asked about their registration status 6 months after receiving the program. The registration behaviour will thus be 
based on self-reported registration status. This is, however, the best possible option concerning the circumstances.

The findings of the study can help further improve the program and function as a guideline for a solid dissemination plan. Results from the process evaluation will show how the program was implemented and how this can be improved in the future. The interviews with teachers give further details on circumstances that should be taken into account when disseminating the program to a larger scale. Moreover, the study will provide insight into the translation of research into practice of school-based health promotion interventions, which can serve as an example for others. 


\section{APPENDIX CHAPTER 3}

Table A1. Evaluation framework

\begin{tabular}{|c|c|c|}
\hline \multicolumn{3}{|l|}{ Effect evaluation } \\
\hline Construct & Definition & Measurement instrument \\
\hline Intention & $\begin{array}{l}\text { - Intention to fill out an organ donation registration form } \\
\text { - Intention to become an organ donor }\end{array}$ & Questionnaire E \\
\hline Attitude & (Mis)beliefs regarding organ donation and registration & Questionnaire E \\
\hline Self-efficacy & $\begin{array}{l}\text { - The extent to which students feel confident in having } \\
\text { enough knowledge to make a decision } \\
\text { - The extent to which students find it difficult to discuss } \\
\text { the topic with others }\end{array}$ & Questionnaire E \\
\hline Knowledge & $\begin{array}{l}\text { The extent to which students perceive their knowledge } \\
\text { about organ donation and whether they are interested } \\
\text { in learning more }\end{array}$ & Questionnaire E \\
\hline Social outcomes & $\begin{array}{l}\text { The extent to which students intend to discuss organ } \\
\text { donation and registration with others: } \\
\text { - Intention to discuss with friends } \\
\text { - Intention to discuss with parents }\end{array}$ & Questionnaire E \\
\hline $\begin{array}{l}\text { Registration } \\
\text { behaviour }\end{array}$ & Actual registration of a participant & Questionnaire F \\
\hline \multicolumn{3}{|l|}{ Process evaluation } \\
\hline Construct & Definition & Measurement instrument \\
\hline Reach & $\begin{array}{l}\text { The extent to which the target group is reached: } \\
\text { - Number of schools reached } \\
\text { - Number of participants reached }\end{array}$ & Google Analytics \\
\hline \multirow[t]{2}{*}{ Dose delivered } & $\begin{array}{l}\text { The proportion of program components actually delivered } \\
\text { by teachers: }\end{array}$ & Logbooks teachers \\
\hline & - Number of components delivered & Interviews teachers \\
\hline Dose received & $\begin{array}{l}\text { The extent to which students engage with the program: } \\
\text { - Active participation during the lessons } \\
\text { - Appreciation of the program (components) } \\
\text { - Completing quizzes } \\
\text { - Watching full videos }\end{array}$ & $\begin{array}{l}\text { Logbooks teachers } \\
\text { Interviews teachers } \\
\text { Questionnaire P } \\
\text { Google Analytics }\end{array}$ \\
\hline Fidelity & $\begin{array}{l}\text { The extent to which the program was implemented as intended: } \\
\text { - Compliance to the manual } \\
\text { - Completeness of deliverance of the components }\end{array}$ & $\begin{array}{l}\text { Logbooks teachers } \\
\text { Interviews teachers } \\
\text { Google Analytics }\end{array}$ \\
\hline Context & $\begin{array}{l}\text { Environmental aspects that could affect the implementation: } \\
\text { - Compatibility with the existing curriculum } \\
\text { - Teachers' capacity to implement the program } \\
\text { - Support by the schools' board or colleagues }\end{array}$ & Interviews teachers \\
\hline \multirow[t]{2}{*}{$\begin{array}{l}\text { Reasons for } \\
\text { fidelity and dose }\end{array}$} & $\begin{array}{l}\text { Reasons for (not) implementing the program (components) } \\
\text { as intended: }\end{array}$ & Logbooks teachers \\
\hline & $\begin{array}{l}\text { - Facilitators to implementation } \\
\text { - Barriers to implementation }\end{array}$ & $\begin{array}{l}\text { Interviews teachers } \\
\text { Ouestionnaire P }\end{array}$ \\
\hline
\end{tabular}

Questionnaire P, Questionnaire process evaluation; Questionnaire E: Questionnaire effect evaluation; Questionnaire F, Questionnaire follow-up measurement 



\section{chapter 4}

the effectiveness of an interactive organ donation education intervention for Dutch lower-educated students: a cluster

randomized controlled trial



This chapter has been published as:

Steenaart, E., Crutzen, R., Candel, M. J., \& de Vries, N. K. The effectiveness of an interactive organ donation education intervention for Dutch lower-educated students: a cluster randomized controlled trial. Trials. 2019;20(1):1. 


\section{ABSTRACT}

\section{Background}

Organ donation registration rates remain low, especially among people with lowereducational levels. An interactive educational intervention was developed to prepare lower-educated students in the Netherlands for making a well-informed decision about organ donation. This article reports on the effects of this intervention on the intention to register (i.e., the primary outcome in the study at hand) and beliefs regarding organ donation.

\section{Methods}

The effectiveness was investigated in a post-test only cluster randomized controlled trial, in which the intervention was offered to the experimental group and after measurement also to the control group. Randomization to the experimental and control groups took place at a class level. Teachers of schools for Intermediate Vocational Education who taught a course on Citizenship delivered three intervention elements (i.e., video fragments and discussion, quizzes with tailored feedback and exercise filling out a registration form) to their students during two 50-min lessons.

\section{Results}

A total of 1170 students participated in the trial and filled out a questionnaire (45 experimental and 43 control classes). Compared to the control group, students in the experimental group had higher odds of having positive registration intentions $(\mathrm{OR}=1.81 ; 95 \% \mathrm{Cl}$ [1.10-2.96]), their perceived knowledge was higher $(\mathrm{B}=0.62 ; 95 \% \mathrm{Cl}$ [0.23-1.01]) and they had higher intentions to talk to family members $(B=0.68$; $95 \% \mathrm{Cl}[0.28-1.08])$ and friends $(\mathrm{B}=0.36 ; 95 \% \mathrm{Cl}$ [0.07-0.66]) about organ donation. There were no effects on the choice students intended to register $(\mathrm{OR}=1.08 ; 95 \% \mathrm{Cl}$ $[0.67-1.73])$. 


\section{Conclusion}

Providing education in a classroom setting is an effective tool in increasing registration intentions. Despite uncertainties about the effects on actual registration behaviour, a larger-scale dissemination of this intervention is recommended. Providing clear information and opening the discussion about organ donation is an important and promising first step towards higher registration rates. 
Despite many efforts to increase donor rates in the Netherlands, the high demands for organs and tissues are not met. An important reason is that registration numbers remain low. The Dutch registration system allows persons to register several options, among which also registration as a non-donor. Only $42 \%$ of the Dutch population has registered their preference regarding organ donation, of which $58 \%$ registered as a donor(9). This results in long waiting lists(110), but also places a high burden on family members and medical professionals(2, 10, 11). In case someone dies without being registered, family members are asked for consent. This is often an overwhelming experience in sad circumstances(11). Moreover, medical professionals expressed having difficulties talking to families about organ donation(2). Up to $10 \%$ of the families are not even approached to ask for consent(10). This all leads to a high refusal rate (67\%) in cases where no consent or objection is registered(11).

Raising awareness about organ donation (registration) and encouraging people to make a decision is important to increase the registration rates. An important strategy, designed to reach abovementioned goals, is aimed at youngsters who come of age. Every year, the Dutch Ministry of Health, Welfare and Sports sends a letter to adolescents who just turned 18 years asking them to register a decision. This leads to a response rate of about one in three (including the people who already registered before receiving that letter)(61). This shows that the majority of the 18-year-olds has not made a decision yet or did not register this. Studies show that there are many false beliefs about organ donation that could stand in the way of informed decision-making(117). Youngsters should be supported in their decision process in order to increase the number of registrations.

Especially lower-educated adolescents could benefit from this support as a lower educational level is associated with lower registration rates(31). Moreover, low literacy is a serious problem among this group(40), leading to difficulties with understanding written information about health and filling out forms(128). Filling out a registration form 
and understanding and processing all information in the accompanied letter are, therefore, challenging. Therefore, we developed an educational program to prepare lowereducated students in the Netherlands for a well-informed decision about organ donation. It concerns an adapted version of an existing program aimed at high school students, which was already proven to be effective(24). The original program was based on the concepts of the Social Cognitive Theory extended with factors from other theoretical perspectives. A recent determinants study among lower-educated adolescents was used as an input to tailor the program to a lower-educated target group(117). Disseminating this adapted version to lower-educated students through schools for Intermediate Vocational Education (IVE) could help in reaching a larger group of adolescents and possibly increase the number of registrations. However, prior to dissemination it is important to study the program's effectiveness. This will be done in a cluster randomized controlled trial (CRCT) to evaluate the effects of the intervention on beliefs regarding organ donation and the intention to register in classes that received the program compared to classes that did not. This effect evaluation is combined with a process evaluation. This article focuses on the effectiveness of the intervention; the results of the process evaluation will be reported elsewhere. 


\section{MATERIALS AND METHODS}

\section{Aims}

The effect evaluation provides insight into the effectiveness of the intervention on beliefs regarding organ donation and the intention to register (as donor or non-donor).

\section{Design}

This article adhered to the Consolidated Standards of Reporting Trials (CONSORT) 2010 Checklist of information to include when reporting a cluster randomized trial (see Figure 1). The effectiveness of the intervention was investigated in a post-test only CRTC, in which the intervention was offered to the experimental group and, after measurement, also to the control group. This design was most suitable in a school setting to ensure that all students would receive the intervention. Participants in the control group filled out the evaluation questionnaire just before receiving the intervention, while participants in the experimental groups did this at the end of the second lesson. Randomization to the experimental and control groups took place at the class level. More details on the content of the intervention, study design and methodology can be found in the protocol article(129).

\section{Recruitment and procedure}

Recruitment started in September 2017 and stopped in June 2018, as the summer vacation started in July. Teachers of Dutch schools for IVE who taught a course on Citizenship were invited by e-mail to use the intervention and participate in the study. Different methods were used to identify these teachers, including the use of contact persons from earlier studies in our department (not focused on organ donation, but other health-related topics), recruitment via key persons from a national IVE organization and using e-mail addresses that were provided on the schools' websites. Region and study discipline (Health and Well-Being, Engineering, Economic, Social Services, Green and Security) were taken into account to ensure a good representation of the target group. Within IVE, there are four educational levels (where 4 is the highest level), but these are all considered low as opposed to college or university level. On class 
level, only students from levels 2 to 4 were included. Students in level 1 (also known as entry training) did not graduate from high school and have a large variety in cognitive abilities. Therefore, we cannot guarantee that they will be able to participate properly in the program. No additional inclusion or exclusion criteria were set as students were recruited via their teachers. Students were typically in the age group of 15 years to early 20s, but older students were no exception nor excluded.

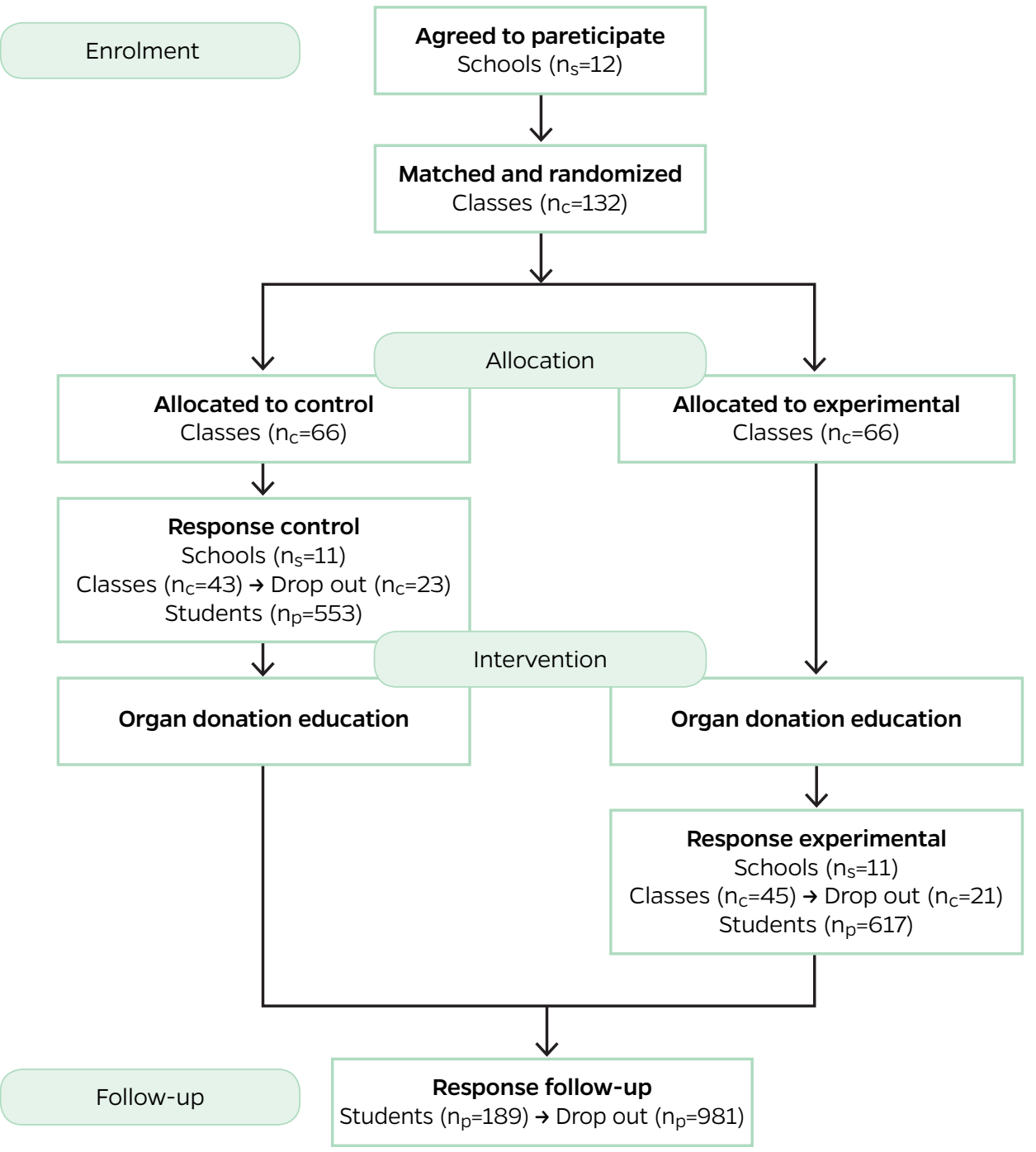

Figure 1. Flowchart of the participants

$n_{s}$, number of schools; $n_{c}$, number of classes, $n_{p}$, number of participants (students) 
Teachers who accepted the invitation were asked to draw up an inventory of the number of classes for participation, either being taught by themselves or by colleagues. This led to the inclusion of 132 classes in 12 schools. Classes were matched by a member of the study team to improve equivalence of the groups. Classes were (where possible) matched on study discipline and educational level, and matched classes were from the same school. From each pair of matched classes, one class was randomly assigned to the experimental condition by computer software, while the other class was then assigned to the control condition ( $n=66$ classes in the experimental group, $n=66$ classes in the control group) (Figure 1).

Teachers received a personalized link via e-mail to reach the website with the educational program. This link was used by both the teacher and the students of that class. Further, they received the questionnaires, instructions and a manual in paper form. Teachers were instructed to either distribute the questionnaires prior to delivering the intervention (control groups) or the other way around (experimental groups). The control classes completed the questionnaires before the first lesson. All participants then received the intervention, taught by their own teachers. The intervention consisted of two 50-min lessons addressing three elements. The first lesson focused on increasing involvement, encouraging positive beliefs and counterbalancing negative beliefs. This was done by watching video fragments followed by plenary discussions. In the second lesson, students first received tailored feedback on misconceptions they might have had by individually working with two quizzes on the website. Moreover, they did an exercise on filling out a simulated organ donation registration form to enhance their self-efficacy. Immediately after the intervention was delivered, students in the experimental classes filled out the questionnaires.

Teachers were asked to return the forms afterwards. Not all forms were returned, leading to a drop-out of $n=44$ classes, of which one was an entire school (with $n=22$ classes) (Figure 1). Drop-out was due to problems with planning the lessons or staff turnover, leaving $N=88$ classes ( $n=45$ in the experimental group, 617 students, $n=43$ in the control group, 553 students). 
Six months to 1 year after implementation, teachers were contacted for a follow-up measurement. This entailed an online questionnaire for students who received the intervention. We decided not to recruit new control groups (while this was indicated in the protocol article(129)), as this appeared unfeasible. Instead, we compared registration rates of the follow-up measurement with the original control group. The follow-up measurement led to a response of $n=189$ students. High drop-out rates were found because of multiple reasons such as students graduating the year before, being spread over new classes, and conducting an internship (and, therefore, not being present at school).

\section{Ethical approval}

The study was approved by the Ethics Committee of the Faculty of Health, Medicine and Life Sciences, Maastricht University, on 23 October 2017 (reference number: Steenaart/231017) and registered at the Dutch Trial Register (NTR6771; https://www. trialregister.nl/trial/6557). Students provided informed consent (after randomization) after explanations about the study, the opportunity to withdraw their consent at any time, and the anonymous way in which their data would be processed. They were provided with contact information in case they had any further questions.

\section{Measurements}

The questionnaire in this study was largely based on the questionnaire used in a preparatory study(117). The questionnaire assessed demographics, registration behaviour, registration intention and beliefs regarding organ donation. The full questionnaire is available at https://osf.io/2jf7v/.

\section{Demographics}

Demographic variables included sex, age, study discipline, study level, country of origin and religion. Country of origin of the student, mother and father were assessed and combined into one item; having a western or non-western background. Students for whom one or more parents were from a non-western country, or who were born in a non-western country themselves, were labelled as non-western, while students from whom both parents were from a western country and who were born in a western 
country themselves were labelled as western(66). Religion was also dichotomized into being religious or not.

\section{Registration behaviour and intention}

Participants were asked whether they had already registered a decision regarding organ donation (yes/no/don't know) and, if applicable, what choice they registered (posthumous organ and tissue donor/posthumous donor for specific organs and tissues/non-donor/leave the decision to the next of kin/leave the decision to a specific person). Unregistered participants were then asked whether they intended to register a decision (yes/no/don't know) and, if applicable, the choice they would like to register (see the abovementioned options). The intention to register was the primary outcome measurement. All registration-related questions were dichotomized. Registration status was dichotomized into registered (yes) and not registered (no/don't know), while registration choice was dichotomized into being a donor (posthumous organ and tissue donor/posthumous donor for specific organs and tissues) and not being a donor (nondonor/leave the decision to the next of kin or leave the decision to a specific person/ don't know). The intention questions were dichotomized in the same manner.

\section{Beliefs regarding organ donation}

The beliefs regarding organ donation included items related to attitude, self-efficacy, knowledge and social outcomes. The questionnaire contained 25 questions on beliefs, all answered on a 7-point Likert scale (totally disagree to totally agree). These questions were based on constructs from over 30 (mainly qualitative) existing studies and have been used before(117).

The 1-year follow-up measurement consisted of a short online questionnaire, primarily assessing registration status (yes/no/l don't know) and if applicable, the choice they registered (see the earlier-mentioned options). However, as the response rate at follow-up was very low ( $n=189$ ) and over 50\% of these participants did not remember receiving the program, the results of this follow-up measurement will not be reported, as no valid conclusions can be drawn from this. 


\section{Statistical analyses}

All data were analysed using SPSS 24 and a two-sided P value $\leq .05$ was considered significant for all analyses. The first aim of this study was to investigate the effectiveness of the intervention on the intention to register a decision regarding organ donation (i.e., the primary outcome in the study at hand). These analyses were only done among people who were not registered yet or did not remember $(n=916)$ (Figure 2). Secondary outcomes were the choice that students intend to make and beliefs regarding organ donation. Since students were nested within classes within schools, multilevel analyses were used to examine the relationship between the intervention and (determinants of) organ donation registration intentions. For each analysis a step-by-step procedure was used to find the best model fit, starting with the most complex model (unstructured). The structure of the random-effect model was simplified where needed, by first removing the random slope and then the random intercept at the class level and/ or school level. For more details about each model, the full syntax that was used can be found on OSF: https://osf.io/2jf7v/.

The effects of the intervention on the primary outcome were examined using multilevel nominal regression analyses, in which intervention group (control/experimental) was the main independent variable. Two different analyses were run; one for the dichotomized outcome (yes/no) and one for the original outcome (yes/no/don't know). Both analyses were adjusted for several demographic characteristics (i.e., sex, age, educational level, religion, migration background and having had organ donation education before) as they were expected to be associated with the outcomes. To identify possible interaction effects, interaction terms of age, sex and educational level with the intervention variable were separately added to the analysis model in case of the dichotomized outcome (as this was our primary focus).

The effects of the intervention on the choice that students intended to make was done in a similar analysis. However, only the dichotomized outcome (donor/non-donor) was used, as some categories of the original outcome were chosen by too few students (e.g., I want to leave the decision to a specific person was chosen by only three 
students) to allow for reliable analyses. The model was adjusted for the same demographic characteristics as were used for the primary outcome.

Differences in beliefs regarding organ donation were examined with multilevel linear regression analyses, in which the intervention group (control/experimental) was again the main independent variable. A total of 25 analyses were run, one for each belief separately. These models were again adjusted for the same set of demographic characteristics. Seven beliefs were strongly skewed to the right. When the distribution of continuous outcomes is not symmetric and the values are always positive, a gamma distribution could be a better representation than the normal distribution. Therefore, for these beliefs, a gamma regression model was used(130). To control for multiple testing, the Benjamini-Hochberg procedure was used with a false discovery rate of 5\%(131). An Excel template was used to calculate the adjusted significance levels.

The data file, syntax and excel templates used are available at https://osf.io/2jf7v/. These efforts are taken to maximize scrutiny, foster accurate replication, and facilitate future data syntheses (e.g., meta-analyses)(132). 


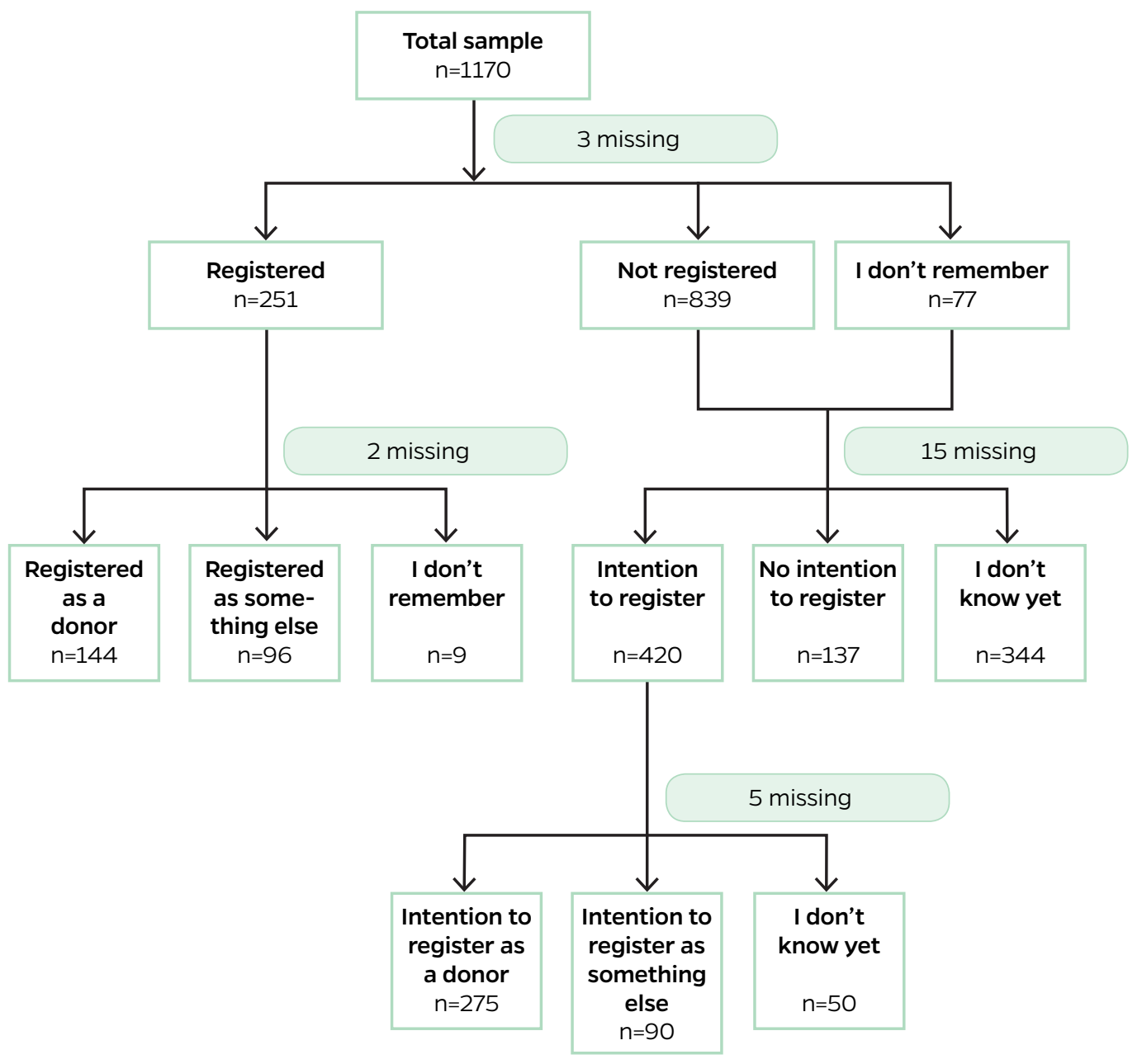

Figure 2. Flowchart regarding the outcomes 


\section{RESULTS}

\section{Participants}

Participants in the trial had a mean age of 18.05 years (standard deviation $(S D)=2.02$ ) and $31.6 \%$ were male. Students from six different study disciplines were included, of which most were enrolled in a Health and Well-Being program (44.9\%). Students from levels $4(67.7 \%), 3(19.5 \%)$ and $2(12.8 \%)$ participated, which is representative of the population of IVE students in the Netherlands(133). The majority was not religious (62.0\%) and had a western background (81.6\%). Students (or parents from students) born in 75 different countries participated in the evaluation study. About one in five students said that they had already registered a decision regarding organ donation (21.5\%), of whom 57.9\% registered as a donor (with or without restrictions). Of those who did not register yet, $46.6 \%$ had the intention to make a decision, of which $66.3 \%$ would like to register as a donor (Figure 2). There were large differences in intention rates between schools, ranging from 32.9 to $60.9 \%$, emphasizing the importance of using mixed models. An overview of the demographic characteristics of the study sample can be found in Table 1.

\section{Registration intentions}

The intra-cluster coefficient (ICC) for registration intention was 0.10 at class level and 0.03 at school level(134). Students in the experimental group had higher odds of having positive registration intentions, compared to students in the control group (OR=1.81; 95\% Cl [1.10-2.96]) (Table 2). After adjusting for sex, age, educational level, migration background, religion and having had education about organ donation before, the effect of the intervention on registration intentions was comparable $(\mathrm{OR}=1.74 ; 95 \% \mathrm{Cl}[1.11-$ 2.73]) (Table 3). No interaction effects were found for sex, age and educational level (see Appendix Tables A1, A2 and A3, respectively).

A comparable effect was also found for the categorical outcome for registration intention (yes versus no and I don't know versus no) when comparing having the intention to register to not having the intention to register ( $\mathrm{OR}=1.93,95 \% \mathrm{Cl}[1.30-2.85])$, but this 
was not significant when comparing students who did not know whether they intended to register to students not having the intention to register (OR=1.22; 95\% CI [0.82-1.82]). These effects were similar when adjustment was made for the demographic factors. 
Table 1. Demographic information of participants

\begin{tabular}{|c|c|c|c|}
\hline & $\begin{array}{l}\text { Control condition } \\
(n=553)\end{array}$ & $\begin{array}{l}\text { Experimental condition } \\
(n=617)\end{array}$ & $\begin{array}{l}\text { Total } \\
(\mathrm{n}=1170)\end{array}$ \\
\hline Sex (male) & $29.5 \%$ & $33.8 \%$ & $31.6 \%$ \\
\hline Age & $18.04 \pm 2.06$ & $18.05 \pm 1.99$ & $18.05 \pm 2.02$ \\
\hline Younger than 18 & $47.1 \%$ & $48.9 \%$ & $48.1 \%$ \\
\hline 18 & $24.9 \%$ & $21.9 \%$ & $23.3 \%$ \\
\hline Older than 18 & $28.0 \%$ & $29.2 \%$ & $28.6 \%$ \\
\hline \multicolumn{4}{|l|}{ Study discipline } \\
\hline Health and Well-Being & $50.8 \%$ & $39.5 \%$ & $44.9 \%$ \\
\hline Engineering & $7.6 \%$ & $11.8 \%$ & $9.8 \%$ \\
\hline Economics & $25.5 \%$ & $31.4 \%$ & $28.6 \%$ \\
\hline Social Services & $7.1 \%$ & $7.6 \%$ & $7.4 \%$ \\
\hline Green & $6.0 \%$ & $6.3 \%$ & $6.2 \%$ \\
\hline Security & $3.1 \%$ & $3.2 \%$ & $3.2 \%$ \\
\hline \multicolumn{4}{|l|}{ Educational level } \\
\hline Level 2 & $15.2 \%$ & $10.7 \%$ & $12.8 \%$ \\
\hline Level 3 & $20.8 \%$ & $18.3 \%$ & $19.5 \%$ \\
\hline Level 4 & $64.0 \%$ & $71.0 \%$ & $67.7 \%$ \\
\hline \multicolumn{4}{|l|}{ Religion } \\
\hline Not religious & $59.0 \%$ & $64.6 \%$ & $62.0 \%$ \\
\hline Islam & $12.1 \%$ & $9.5 \%$ & $10.7 \%$ \\
\hline Catholic & $11.9 \%$ & $10.9 \%$ & $11.3 \%$ \\
\hline Dutch Reformed & $2.9 \%$ & $3.3 \%$ & $3.1 \%$ \\
\hline Calvinist & $3.5 \%$ & $4.3 \%$ & $3.9 \%$ \\
\hline Jewish & $0.5 \%$ & $0.3 \%$ & $0.4 \%$ \\
\hline Other & $10.1 \%$ & $7.1 \%$ & $8.5 \%$ \\
\hline Migration background (western) & $79.7 \&$ & $83.4 \%$ & $81.6 \%$ \\
\hline \multicolumn{4}{|l|}{ Registration status } \\
\hline Not registered & $73.3 \%$ & $70.6 \%$ & $71.9 \%$ \\
\hline Registered & $18.9 \%$ & $23.9 \%$ & $21.5 \%$ \\
\hline Don't know & $7.8 \%$ & $5.5 \%$ & $6.6 \%$ \\
\hline \multicolumn{4}{|l|}{ Registration choice } \\
\hline Donor & $31.1 \%$ & $28.1 \%$ & $29.3 \%$ \\
\hline Restricted donor & $24.3 \%$ & $31.5 \%$ & $28.5 \%$ \\
\hline No donor & $40.8 \%$ & $26.0 \%$ & $32.1 \%$ \\
\hline Next of kin & $1.0 \%$ & $7.5 \%$ & $4.8 \%$ \\
\hline Specific person & $1.0 \%$ & $2.1 \%$ & $1.6 \%$ \\
\hline Don't know & $1.9 \%$ & $4.8 \%$ & $3.6 \%$ \\
\hline \multicolumn{4}{|l|}{ Intention to register } \\
\hline Yes & $40.1 \%$ & $52.8 \%$ & $46.6 \%$ \\
\hline No & $18.1 \%$ & $12.4 \%$ & $15.2 \%$ \\
\hline Don't know & $41.7 \%$ & $34.8 \%$ & $38.2 \%$ \\
\hline \multicolumn{4}{|l|}{ Intention to become a donor } \\
\hline Donor & $32.2 \%$ & $23.2 \%$ & $27.0 \%$ \\
\hline Restricted donor & $33.3 \%$ & $43.6 \%$ & $39.3 \%$ \\
\hline No donor & $12.1 \%$ & $21.2 \%$ & $17.3 \%$ \\
\hline Next of kin & $5.2 \%$ & $2.5 \%$ & $3.6 \%$ \\
\hline Specific person & $1.7 \%$ & $0.0 \%$ & $0.7 \%$ \\
\hline Don't know & $15.5 \%$ & $9.5 \%$ & $12.0 \%$ \\
\hline
\end{tabular}

Data presented as mean \pm SD for continuous variables and percentages for categorical variables

No significant effects were found of the intervention on the intention to register as a donor (versus as a non-donor) $(\mathrm{OR}=1.08 ; 95 \% \mathrm{Cl}[0.67-1.73])$. This was also the case after adjustment for demographic variables. 
Table 2. Effect of organ donation education on students' registration intentions

\begin{tabular}{|c|c|c|c|c|}
\hline & \multirow{2}{*}{\multicolumn{2}{|c|}{$\begin{array}{l}\text { Intention to register dich } \\
\text { (odds of yes versus no) }\end{array}$}} & \multirow{2}{*}{\multicolumn{2}{|c|}{$\begin{array}{l}\text { Intention to register } \\
(\mathrm{O}=\mathrm{no} / 1=\mathrm{yes} / 2=\text { don't know) }\end{array}$}} \\
\hline & & & & \\
\hline & OR $(95 \% \mathrm{Cl})$ & $P$ & OR $(95 \% \mathrm{Cl})$ & $P$ \\
\hline $\begin{array}{l}\text { Intervention group } \\
\text { (experimental versus control) }\end{array}$ & $1.81(1.10-2.96)$ & .02 & $1.93(1.30-2.85)$ & .001 \\
\hline
\end{tabular}

$P$ values $<.05$ are printed in bold

Table 3. Effect of organ donation education on students' registration intentions, adjusted fo demographic variables

\begin{tabular}{|c|c|c|c|c|}
\hline \multirow{3}{*}{ Predictor } & \multirow{2}{*}{\multicolumn{2}{|c|}{$\begin{array}{l}\text { Intention to register dich } \\
\text { (odds of yes versus no) }\end{array}$}} & \multirow{2}{*}{\multicolumn{2}{|c|}{$\begin{array}{l}\text { Intention to register } \\
(\mathrm{O}=\mathrm{no} / 1=\mathrm{yes} / 2=\text { don't know) } \\
\text { (odds of yes versus no) }\end{array}$}} \\
\hline & & & & \\
\hline & OR $(95 \% \mathrm{Cl})$ & $P$ & OR $(95 \% \mathrm{Cl})$ & $P$ \\
\hline $\begin{array}{l}\text { Intervention group } \\
\text { (experimental versus control) }\end{array}$ & $1.74(1.11-2.73)$ & .02 & $1.84(1.18-2.85)$ & .01 \\
\hline $\begin{array}{l}\text { Sex } \\
\text { (male versus female) }\end{array}$ & $0.64(0.51-0.81)$ & $<.001$ & $0.31(0.20-0.48)$ & $<.001$ \\
\hline \multicolumn{5}{|l|}{ Age } \\
\hline 18 versus $<18$ & $0.81(0.54-1.20)$ & .29 & $0.77(0.45-1.31)$ & .33 \\
\hline$>18$ versus $<18$ & $0.57(0.39-0.83)$ & .003 & $0.62(0.35-1.08)$ & .09 \\
\hline \multicolumn{5}{|l|}{ Educational level } \\
\hline level 3 versus level 2 & $2.82(1.64-4.84)$ & $<.001$ & $5.03(2.38-10.61)$ & $<.001$ \\
\hline level 4 versus level 2 & $2.97(2.18-4.04)$ & $<.001$ & $5.67(3.08-10.43)$ & $<.001$ \\
\hline $\begin{array}{l}\text { Religion } \\
\text { (religious versus not religious) }\end{array}$ & 1.13 (0.78-1.63) & .52 & $0.75(0.46-1.24)$ & .26 \\
\hline $\begin{array}{l}\text { Migration background } \\
\text { (non-western versus western) }\end{array}$ & $0.46(0.28-0.74)$ & .001 & $0.28(0.16-0.50)$ & $<.001$ \\
\hline $\begin{array}{l}\text { Other organ donation education } \\
\text { (yes versus no) }\end{array}$ & $1.14(0.91-1.42)$ & .26 & $0.98(0.56-1.61)$ & .94 \\
\hline
\end{tabular}

$P$ values $<.05$ are printed in bold 
Intention to register as a donor dich (odds of yes versus no)

(odds of don't know versus no)

\begin{tabular}{llll} 
OR $(95 \% \mathrm{Cl})$ & $P$ & OR $(95 \% \mathrm{Cl})$ & $P$ \\
\hline $1.22(0.82-1.82)$ & .33 & $1.08(0.67-1.73)$ & .76
\end{tabular}

Intention to register as a donordich (odds of yes versus no)

(odds of don't know versus no)

\begin{tabular}{|c|c|c|c|}
\hline OR $(95 \% \mathrm{Cl})$ & $P$ & OR $(95 \% \mathrm{Cl})$ & $P$ \\
\hline $1.12(0.72-1.73)$ & 61 & $1.10(0.61-1.99)$ & .75 \\
\hline $0.41(0.26-0.64)$ & $<.001$ & $0.80(0.52-1.24)$ & .31 \\
\hline $0.87(0.52-1.47)$ & .60 & $1.29(0.71-2.34)$ & .41 \\
\hline $0.95(0.55-1.64)$ & .85 & $0.62(0.56-1.54)$ & .86 \\
\hline $2.17(1.09-4.30)$ & .03 & $1.89(0.89-4.01)$ & .10 \\
\hline $2.57(1.50-4.40)$ & .001 & $2.80(1.84-4.21)$ & $<.001$ \\
\hline $0.56(0.34-0.93)$ & .03 & $0.90(0.59-1.36)$ & .61 \\
\hline $0.61(0.36-1.06)$ & .08 & $0.45(0.21-0.98)$ & .04 \\
\hline $0.80(0.48-1.33)$ & .39 & $0.68(0.49-0.94)$ & .02 \\
\hline
\end{tabular}




\section{Organ donation beliefs}

In general, the intervention had small effects on beliefs regarding organ donation. Most scores on positive beliefs were a little higher in the experimental group compared to the control group, while scores on negative beliefs were lower. For 11 beliefs that were measured (12 after adjustment), no significant differences were found. See Table 4 for all (adjusted) regression coefficients. Important results are that students in the experimental group felt confident in having enough knowledge to make a decision about organ donation $(\mathrm{B}=0.62 ; 95 \% \mathrm{Cl}[0.23-1.01])$ and were more likely to talk to family members $(\mathrm{B}=0.68 ; 95 \% \mathrm{Cl}$ [0.28-1.08]) and friends $(\mathrm{B}=0.36 ; 95 \% \mathrm{Cl}[0.07-0.66])$ about organ donation, compared to the control group. They also found it slightly more difficult to talk to family members $(B=0.08 ; 95 \% \mathrm{Cl}[0.01-0.16])$ or friends $(B=0.13$; $95 \% \mathrm{Cl}$ [0.04-0.23]), but the scores remained low (family 2.09 \pm 1.6 ; friends $2.28 \pm 1.72$ ).

\section{Exploratory results}

Table 3 shows some additional interesting findings. However, as no hypotheses were formulated for these analyses, the results are purely exploratory. Female students $(\mathrm{OR}=0.64 ; 95 \% \mathrm{Cl}[0.51-0.81)$ and students with a western background (OR=0.46; $95 \% \mathrm{Cl}[0.28-0.74])$ had higher odds of having a positive registration intention, and so did students younger than 18 years of age $(\mathrm{OR}=0.57 ; 95 \% \mathrm{Cl}$ [0.39-0.83] (compared to students older than 18 years of age). Also, differences can be observed in terms of educational level. When compared to level-2 students, students in level 4 (OR=2.82; [1.644.84]) and level $3(\mathrm{OR}=2.97 ; 95 \% \mathrm{Cl}$ [0.28-0.74]) had higher odds of having the intention to register a decision. 
Table 4. Effect of organ donation education on students' beliefs about organ donation

Outcome measurement

$\begin{array}{ll}\text { Control } & \text { Experimental } \\ \text { condition } & \text { condition } \\ \text { Mean } \pm S D & \text { Mean } \pm S D\end{array}$

I have enough knowledge to make a decision about organ donation I would like to know more about organ donation and registration I intend to talk about organ donation with family members I intend to talk about organ donation with friends

I find it hard to discuss organ donation with family members

I find it hard to discuss organ donation with friends

I rather not think about death

I still have enough time to register

The idea of my organs being in someone else's body gives me a feeling of discomfort

Certain organs have an important value to me

When I die, I don't want my organs to go to waste

After I die, my body needs to be intact

Some people are more deserving to receive my organ than others

If I register my decision, I prevent my family from having to make a difficult decision when I would die

If I register my decision, medical professionals will honour my wishes

If I register my decision, I know what happens with my body when I would die

If I am an organ donor, I am happy I can help people in need

If I am an organ donor, I am afraid my family and friends see me as a deformed person because my organs were removed

If I am an organ donor, I can find a sense of positive closure

If I a man organ donor, I run the risk of my organs being taken out before I died

If I am an organ donor, I am afraid my body will be mutilated

If I am an organ donor, medical professionals will choose the life of a patient who needs an organ over mine

If I am an organ donor, I am more deserving of receiving an organ in case I need one

If I am an organ donor, my organs will be allocated to patients in an ethical manner

If I am an organ donor, I run the risk of being declared dead too soon

\begin{tabular}{|c|c|}
\hline $4.53 \pm 1.90$ & $5.11 \pm 1.61$ \\
\hline $3.90 \pm 1.81$ & $3.57 \pm 1.72$ \\
\hline $3.86 \pm 1.98$ & $4.47 \pm 1.85$ \\
\hline $3.27 \pm 1.85$ & $3.57 \pm 1.91$ \\
\hline $1.91 \pm 1.50$ & $2.09 \pm 1.61$ \\
\hline $2.00 \pm 1.56$ & $2.28 \pm 1.72$ \\
\hline $4.28 \pm 2.18$ & $4.41 \pm 2.08$ \\
\hline $4.98 \pm 1.81$ & $4.86 \pm 1.92$ \\
\hline $3.46 \pm 2.13$ & $3.43 \pm 2.08$ \\
\hline $3.24 \pm 2.12$ & $3.33 \pm 2.08$ \\
\hline $3.94 \pm 2.11$ & $4.19 \pm 2.09$ \\
\hline $4.02 \pm 2.03$ & $4.18 \pm 2.00$ \\
\hline $4.17 \pm 2.18$ & $4.17 \pm 2.13$ \\
\hline $5.26 \pm 1.75$ & $5.60 \pm 1.62$ \\
\hline $5.50 \pm 1.63$ & $5.86 \pm 1.43$ \\
\hline $5.07 \pm 1.88$ & $5.36 \pm 1.79$ \\
\hline $5.50 \pm 1.68$ & $5.70 \pm 1.64$ \\
\hline $2.70 \pm 1.89$ & $3.04 \pm 1.98$ \\
\hline $4.42 \pm 1.80$ & $4.68 \pm 1.75$ \\
\hline $3.20 \pm 1.96$ & $3.19 \pm 1.90$ \\
\hline $3.39 \pm 1.98$ & $3.52 \pm 1.96$ \\
\hline $3.46 \pm 1.85$ & $3.26 \pm 1.87$ \\
\hline $4.07 \pm 1.99$ & $4.07 \pm 2.01$ \\
\hline $4.93 \pm 1.60$ & $5.22 \pm 1.58$ \\
\hline $3.23 \pm 1.97$ & $.17 \pm 1.62$ \\
\hline
\end{tabular}

$P$ values $<.05$ are printed in bold

a Significant $p$ values after correction for multiple comparisons according to the Benjamini-Hochberg procedure(131). 


\begin{tabular}{|c|c|c|c|}
\hline \multicolumn{2}{|c|}{$\begin{array}{l}\text { Regression weight of } \\
\text { experimental (1) versus control (0) }\end{array}$} & \multicolumn{2}{|c|}{$\begin{array}{l}\text { Adjusted regression weight of } \\
\text { experimental (1) versus control (0) }\end{array}$} \\
\hline B $(95 \% \mathrm{Cl})$ & $P$ & B $(95 \% \mathrm{Cl})$ & $P$ \\
\hline $0.62(0.23-1.01)$ & $.002 \mathrm{a}$ & $0.57(0.18-0.95)$ & $.004 a$ \\
\hline$-0.31(-0.48--0.14)$ & $<.001_{a}$ & $-0.36(-0.61--0.10)$ & $.01_{a}$ \\
\hline $0.68(0.28-1.08)$ & $.001_{a}$ & $0.65(0.27-1.02)$ & $.001_{a}$ \\
\hline $0.36(0.07-0.66)$ & $.02 a$ & $0.33(0.01-0.65)$ & .04 \\
\hline $0.08(0.01-0.16)$ & .02 & $0.09(0.00-0.18)$ & .04 \\
\hline $0.13(0.04-0.23)$ & $.01_{\mathrm{a}}$ & $0.14(0.05-0.23)$ & $.002_{a}$ \\
\hline $0.11(-0.07-0.28)$ & .23 & $0.07(-0.11-0.26)$ & .44 \\
\hline$-0.17(-0.31--0.02)$ & .02 & $-0.23(-0.45--0.01)$ & .05 \\
\hline$-0.04(-0.31-0.23)$ & .77 & $-0.00(-0.28-0.27)$ & .98 \\
\hline $0.11(-0.17-0.39)$ & .45 & $0.19(-0.13-0.50)$ & .24 \\
\hline $0.26(-0.03-0.54)$ & .08 & $0.18(-0.10-0.46)$ & .21 \\
\hline $0.15(-0.12-0.43)$ & .28 & $0.21(-0.06-0.48)$ & .13 \\
\hline$-0.03(-0.26-0.21)$ & .82 & $-0.11(-0.41-0.18)$ & .45 \\
\hline $0.13(0.03-0.23)$ & $.01_{\mathrm{a}}$ & $0.12(0.00-0.23)$ & .05 \\
\hline $0.15(0.04-0.26)$ & $.01_{a}$ & $0.13(0.05-0.21)$ & $.002_{a}$ \\
\hline $0.10(0.01-0.20)$ & .08 & $0.11(0.01-0.21)$ & .03 \\
\hline 0.09 (0.01-0.17) & .03 & $0.06(-0.03-0.15)$ & $<.001_{a}$ \\
\hline $0.12(0.05-0.19)$ & $.001_{a}$ & $0.13(0.03-0.23)$ & .01 \\
\hline $0.26(0.00-0.49)$ & .03 & $0.21(-0.02-0.43)$ & .07 \\
\hline $0.05(-0.21-0.30)$ & .71 & $0.04(-0.25-0.32)$ & .79 \\
\hline $0.16(-0.12-0.43)$ & .26 & $0.19(-0.13-0.51)$ & .24 \\
\hline$-0.19(-0.37--0.01)$ & .04 & $-0.16(-0.37-0.04)$ & .12 \\
\hline$-0.00(-0.22-0.22)$ & .99 & $0.04(-0.14-0.23)$ & .63 \\
\hline 0.29 (0.08-0.49) & $.01_{a}$ & $0.26(0.04-0.47)$ & .02 \\
\hline$-0.03(-0.25-0.19)$ & .78 & $-0.03(-0.23-0.17)$ & .78 \\
\hline
\end{tabular}


This paper describes the evaluation of a web-based and classroom-based organ donation education program aiming to encourage lower-educated adolescents to register their preference regarding organ donation. Compared to the control group, more students in the experimental group were intending to register a decision, their perceived knowledge was higher and they expressed greater intentions to talk to others about organ donation. There were no effects of the intervention on the intention to register as an organ donor. These effects are in line with our expectations as the purpose of the intervention was to support decision-making, not to convince students to register as organ donors. Moreover, no adverse effects of the intervention were found on the beliefs or uncertainty regarding their intentions. Finally, sex, age, educational level and migration background are possibly related to students' intention to register a decision. These results are exploratory in nature and could be used for developing research questions for future studies.

The intervention evaluated in this study concerns an updated and simplified version of an intervention developed and evaluated by Reubsaet and colleagues(24). The results of the present study are comparable to those of the first version of the intervention, where an increase in registration intention of 33\% was found (compared to $32 \%$ in the present study). This suggests that organ donation education, when carefully adapted to a specific target group, has the potential to increase registration rates. Moreover, as no significant interactions were found between sex, educational level, age on the one hand and intervention condition on the other, the intervention seems suitable for a wide range of lower-educated students.

As only small differences were found on the beliefs in this study, this might indicate areas in which the intervention can improve further. However, a preparatory determinants study already showed that none of the beliefs are decisive individually and decision-making about organ donation is far more complex(117). This seems a possible explanation for the findings in this study as the effects on beliefs are small, but a relatively large difference was found in registration intention. This suggests that the effects of the 
intervention might not be mediated by the explicit beliefs in the questionnaire, but by more complex processes.

Several other studies have shown that organ donation education can be effective in increasing knowledge(135-138), willingness/intention to register(135-138) and willingness to talk to family members among adolescents $(135,136,139)$. In that sense, the results of this study are in line with previous work. However, organ donation education is usually provided in a high school setting or among students in higher levels of secondary education, without paying attention to lower educational levels (and also lower literacy levels). Especially with a sensitive and difficult topic like organ donation, a one-size-fits-all approach might not work. Even within this study among IVE students, teachers emphasized that students from level 2 and level 4 cannot be compared and should be treated differently(140). Preliminary results of the process evaluation also showed that teachers made on-the-spot adaptations when delivering the intervention. It is, therefore, important to recognize that not all students are the same and organ donation education should be tailored to match students' abilities.

There were some difficulties regarding the follow-up measurement. As registration records are private, we had to rely on self-reported registration behaviour. The response on this follow-up measurement was low. This makes the effects of the intervention on registration behaviour doubtful. A systematic review on classroom organ donation education found that none of the 15 included studies measured actual registration behaviour(23). The attempt we made in the current study shows the difficulties with assessing actual registration behaviour and thus still leaves us with uncertainties about a possible intention-behaviour gap regarding organ donation registration.

The number of participants during the intervention was also lower than planned (see the protocol article for the sample size calculation(129)). However, a very conservative estimation of the effect on intention to register was used in this calculation (i.e., a relative increase of 20\%), while the actual effects of the original version of the intervention (33\%) and the version used in this study (32\%), are much higher. Moreover, we still managed to 
acquire a representative sample with a high diversity of geographical areas, study disciplines, educational levels and migration backgrounds.

\section{New donor law}

In February 2018, a new donor law was approved by the Dutch Senate. This law, to be implemented in the summer of 2020, entails a variation on an opt-out system instead of the current opt-in system. Everyone aged over 18 years, who has not made a decision yet, will receive a letter asking them to register a decision. Failure to respond to this letter, or the reminder that will be sent 6 weeks later, results in a no-objection registration in the donor register. With this upcoming law change, the need for education increases(141).

The main goal of this law is to have more people make an explicit decision, but many people are not ready for this, do not know enough about the topic or might not understand how the new law works. This could potentially lead to many people with a noobjection registration, instead of an explicit "yes" or "no,", in which cases the decision will still come down to the relatives. Supporting people in the decision-making process is, therefore, crucial, as well as encouraging people to talk to family members. Studies have shown that relatives feel more confident in making a decision when they know what the deceased person wanted(142). If not, they usually feel hesitant and indecisive, which in many cases leads to refusal(10). So, even if adolescents are not ready to make a decision yet, talking about it at home should be encouraged. Students in this study expressed the view that they did not find it difficult to talk to family members or friends, but this might not translate into actually discussing donorship at home. Tamburlin and colleagues found that this can be very difficult, especially starting the conversation(139). The intervention could benefit from more practical guidance in this.

The vote about the new donor law in February 2018 has been preceded by both public and political debates and has received a lot of media attention. As a response to this change in law, more people registered as a non-donor, especially more young people said "no" to organ donation in the last year(9). This all happened during the trial period of the intervention and could, therefore, have influenced students' attitudes towards organ donation registration. 


\section{CONCLUSION}

It is clear that supporting decision-making about organ donation is important, especially when it concerns lower-educated groups. This has been one of the first efforts to educate this underrepresented group. It became evident that providing education in a classroom setting is effective in increasing registration intentions. Despite uncertainties about the effects on actual registration behaviour, a larger-scale dissemination of this intervention is recommended. As Cárdenas and colleagues pointed out, decision-making regarding organ donation is very complex and is usually a process that evolves over time(137). Providing clear information and opening the discussion about organ donation is an important and promising first step towards higher registration rates. 
Table A1. Effect of organ donation education on students' intention to register, adjusted for demographic variables and intervention group*sex interaction

\begin{tabular}{|c|c|c|}
\hline \multirow[t]{2}{*}{ Predictor } & \multicolumn{2}{|c|}{$\begin{array}{l}\text { Intention to register dich } \\
\text { (odds of yes versus no) }\end{array}$} \\
\hline & OR $(95 \% \mathrm{Cl})$ & $P$ \\
\hline Intervention group (experimental versus control) & $1.77(1.17-2.69)$ & .01 \\
\hline Sex (male versus female) & $0.66(0.44-1.00)$ & .05 \\
\hline \multicolumn{3}{|l|}{ Age } \\
\hline 18 versus $<18$ & $0.81(0.54-1.20)$ & .29 \\
\hline$>18$ versus $<18$ & $0.57(0.39-0.83)$ & .003 \\
\hline \multicolumn{3}{|l|}{ Educational level } \\
\hline level 3 versus level 2 & $2.80(1.60-4.91)$ & $<.001$ \\
\hline level 4 versus level 2 & $2.96(2.15-4.08)$ & $<.001$ \\
\hline Religion (religious versus not religious) & $1.13(0.78-1.63)$ & .52 \\
\hline Migration background (non-western versus western) & $0.46(0.28-0.73)$ & .001 \\
\hline Other organ donation education (yes versus no) & $1.14(0.91-1.42)$ & .26 \\
\hline Intervention group*sex & $0.95(0.59-1.54)$ & .84 \\
\hline
\end{tabular}

$P$ values $<.05$ are printed in bold

Table A2. Effect of organ donation education on students' intention to register, adjusted for demographic variables and intervention group*age interaction

\begin{tabular}{|c|c|c|}
\hline \multirow[t]{2}{*}{ Predictor } & \multicolumn{2}{|c|}{$\begin{array}{l}\text { Intention to register dich } \\
\text { (odds of yes versus no) }\end{array}$} \\
\hline & OR $(95 \% \mathrm{Cl})$ & $P$ \\
\hline Intervention group (experimental versus control) & $1.65(0.93-2.91)$ & .09 \\
\hline Sex (male versus female) & $0.65(0.51-0.81)$ & $<.001$ \\
\hline \multicolumn{3}{|l|}{ Age } \\
\hline 18 versus $<18$ & $0.76(0.44-1.30)$ & .32 \\
\hline$>18$ versus $<18$ & $0.53(0.31-0.89)$ & .02 \\
\hline \multicolumn{3}{|l|}{ Educational level } \\
\hline level 3 versus level 2 & $2.82(1.62-4.92)$ & $<.001$ \\
\hline level 4 versus level 2 & $2.99(2.20-4.05)$ & $<.001$ \\
\hline Religion (religious versus not religious) & $1.12(0.77-1.63)$ & .54 \\
\hline Migration background (non-western versus western) & $0.46(0.28-0.74)$ & .002 \\
\hline Other organ donation education (yes versus no) & $1.13(0.89-1.43)$ & .33 \\
\hline \multicolumn{3}{|l|}{ Intervention group ${ }^{\star}$ age } \\
\hline 18 versus $<18$ & $1.12(0.60-2.08)$ & .72 \\
\hline$>18$ versus $<18$ & $1.18(0.61-2.28)$ & .63 \\
\hline
\end{tabular}

$P$ values $<.05$ are printed in bold 
Table A3. Effect of organ donation education on students' intention to register, adjusted for demographic variables and intervention group*educational level interaction

\begin{tabular}{|c|c|c|}
\hline \multirow[t]{2}{*}{ Predictor } & \multicolumn{2}{|c|}{$\begin{array}{l}\text { Intention to register dich } \\
\text { (odds of yes versus no) }\end{array}$} \\
\hline & OR $(95 \% \mathrm{Cl})$ & $P$ \\
\hline Intervention group (experimental versus control) & $2.50(0.72-8.62)$ & .15 \\
\hline Sex (male versus female) & $0.64(0.50-0.81)$ & $<.001$ \\
\hline \multicolumn{3}{|l|}{ Age } \\
\hline 18 versus $<18$ & $0.80(0.54-1.19)$ & .27 \\
\hline$>18$ versus $<18$ & $0.57(0.40-0.83)$ & .004 \\
\hline \multicolumn{3}{|l|}{ Educational level } \\
\hline level 3 versus level 2 & $3.60(2.14-6.07)$ & $<.001$ \\
\hline level 4 versus level 2 & $3.62(2.00-6.56)$ & $<.001$ \\
\hline Religion (religious versus not religious) & $1.13(0.78-1.63)$ & .53 \\
\hline Migration background (non-western versus western) & $0.46(0.28-0.74)$ & .001 \\
\hline Other organ donation education (yes versus no) & $1.14(0.91-1.42)$ & .26 \\
\hline \multicolumn{3}{|l|}{ Intervention group^educational level } \\
\hline level 3 versus level 2 & $0.62(0.22-1.73)$ & .36 \\
\hline level 4 versus level 2 & $0.69(0.20-2.41)$ & .56 \\
\hline
\end{tabular}

$P$ values $<.05$ are printed in bold 



\section{chapter 5}

implementation of an interactive

organ donation education program for

Dutch lower-educated students:

a process evaluation



This chapter has been published as:

Steenaart, E., Crutzen, R., \& de Vries, N. K. Implementation of an interactive organ donation education program for Dutch lower-educated students: a process evaluation. BMC Public Health. 2020;20:739. 


\section{ABSTRACT}

\section{Background}

As organ donation registration rates remain low, especially among lower-educated people, it is important to support this group in making their registration decision. To prepare lower-educated students in the Netherlands for making a well-informed decision, an interactive educational program was developed. We aim to understand both the (quality of) implementation as well as to contextualize the effects of this program in a lower-educated school setting.

\section{Methods}

The process evaluation was part of a cluster randomized controlled trial, in which 11 schools for Intermediate Vocational Education throughout the Netherlands participated. Teachers who taught a course on Citizenship delivered three intervention elements (i.e. video fragments and discussion, quizzes with tailored feedback and an exercise filling out a registration form) to their students. Implementation was assessed by interviews with teachers, questionnaires from students, logbooks from teachers and user data from Google Analytics.

\section{Results}

The program was well received and implemented, but on-the-spot adaptations were made by teachers to fit their students better. Within the lower-educated target group, differences between students are high in terms of active participation, reading abilities, knowledge and attention span. The program fit well within their regular teaching activities, but the topic of organ donation is not always prioritized by teachers. 


\section{Conclusions}

We see opportunities to disseminate the program on a larger scale and reach a group that has been neglected in organ donation education before. Within the program, there are possibilities to increase the effectiveness of the program, such as alternative delivery methods for the elements with a lot of text, the addition of booster sessions and guidelines for teachers to adapt the program to students of different levels within Intermediate Vocational Education. Moreover, in order to have an impact on a national level, strategies need to be employed to reach high numbers of students and, therefore, support on a higher level is needed (both within schools and at policy level). 


\section{BACKGROUND}

Shortage in the availability of organs for transplantation is an important public health challenge. Even though organ donation rates vary dramatically from country to country (due to e.g. registration systems or transplant coordination), there is a universal shortage and the global need for organs continues to $\operatorname{grow}(3,4)$. In the Netherlands, the number of people that are waiting for an organ is also growing, causing patients to die or suffer other consequences while waiting(143). While these problems are no different than in many other countries, the Dutch situation is quite unique. The donor legislation is different from other countries, and so are policy and education initiatives.

Currently, an opt-in registration system is used in the Netherlands. Next to registration as a donor, people also have the opportunity to register another decision, such as registration as a non-donor or leaving the decision to next of kin. However, as an opt-in system is based on voluntary registration, people also have the option not to choose, and a large proportion of the population still makes use of this option(9). Many efforts have been taken to encourage people to make a decision regarding their donor record and actually register their decision. Increasing the number of registrations is important to help more patients and can also take away uncertainties around the death of someone without a donor record. Siminoff and Lawrence showed that having knowledge of a patient's preference to donate, increases the likelihood of donating and the family's satisfaction with the decision(12).

At the age of 18, Dutch citizens are asked to make a decision about their donor status by the Ministry of Health, Welfare and Sports. As only about 1 in 3 adolescents respond every year, there is clearly a need for support in this decision-making process(61). Teaching adolescents about organ donation has the potential to fulfil this role and increase registration rates. Several studies have shown higher levels of knowledge, a more positive attitude towards organ donation, a higher willingness to donate and/or higher intentions to register a decision in participants of such programs(137) $(24,144)$. However, these programs have mostly been directed at schools for higher 
educational levels. The school system for lower levels of education is different (in terms of students, teachers, and organizational structure) and existing organ donation education programs have not reached these specific schools so far (and might also not be suitable for this setting). This is worrying, as lower-educated people are found to have a less positive attitude about organ donation(20, 29, 30), spend less time looking for information about organ donation on the Internet, talk less about organ donation with others, are less aware of news coverage on organ donation(29) and are less often registered(31). Therefore, we designed an interactive educational program, especially for a lower-educated target group and school setting, focused on supporting adolescents in making a well-informed decision about organ donation and encouraging them to register this decision.

This program was implemented in a school setting and delivered by teachers. Teachers, therefore, play a large role in the quality of implementation. Next to evaluating program effects, a process evaluation has become an increasingly important part of a comprehensive program evaluation(118) to understand both the (quality of) implementation as well as to contextualize the possible effects of the program. The current study focuses on describing and evaluating the implementation of this educational program for lower-educated adolescents, using multiple methods. 


\section{METHODS}

A process evaluation was conducted of an educational program about organ donation at 11 schools that implemented the program. This process evaluation is part of a cluster randomized controlled trial (CRCT) evaluating the effectiveness of the organ donation program. More details about the development of the program, the study design and methods(129) and the effect evaluation(145) can be found elsewhere. The study was approved by the Ethics Committee of the Faculty of Health, Medicine and Life Sciences on 23 October 2017 (reference number: Steenaart/231017) and prospectively registered at the Dutch Trial Register (NTR6771; https://www.trialregister.nl/trial/6557). This article was written in accordance with the COREQ checklist.

\section{Program}

The original program was designed by Reubsaet and colleagues to support high school students in making a decision about organ donation (regardless of this being as a donor or not) and to encourage them to register this decision(24-26). The program was developed based on the social cognitive theory of Bandura(146). Several formative studies focusing on determinants and pilot tests led to the final educational program, which was then successfully implemented in a high school setting. Later, the program was translated from a paper-based to a web-based version. This version was adjusted to make it suitable for a lower-educated target group, based on a determinant study among this group(117). This lower-educated target group concerns students that left high school after four years and continue their education in Intermediate Vocational Education (IVE). In principle, these students are above the age of 16 , so written informed consent was only obtained from the students themselves, not from their parents, as approved by the Ethical Committee. Within IVE, students can choose from a variety of disciplines. There are four levels (of which level 1 is the lowest and level 4 is the highest) and the educational level of this group in general is lower as opposed to college or university education. The effectiveness of this adjusted program was evaluated in a CRCT with post-test only (Figure 1). 


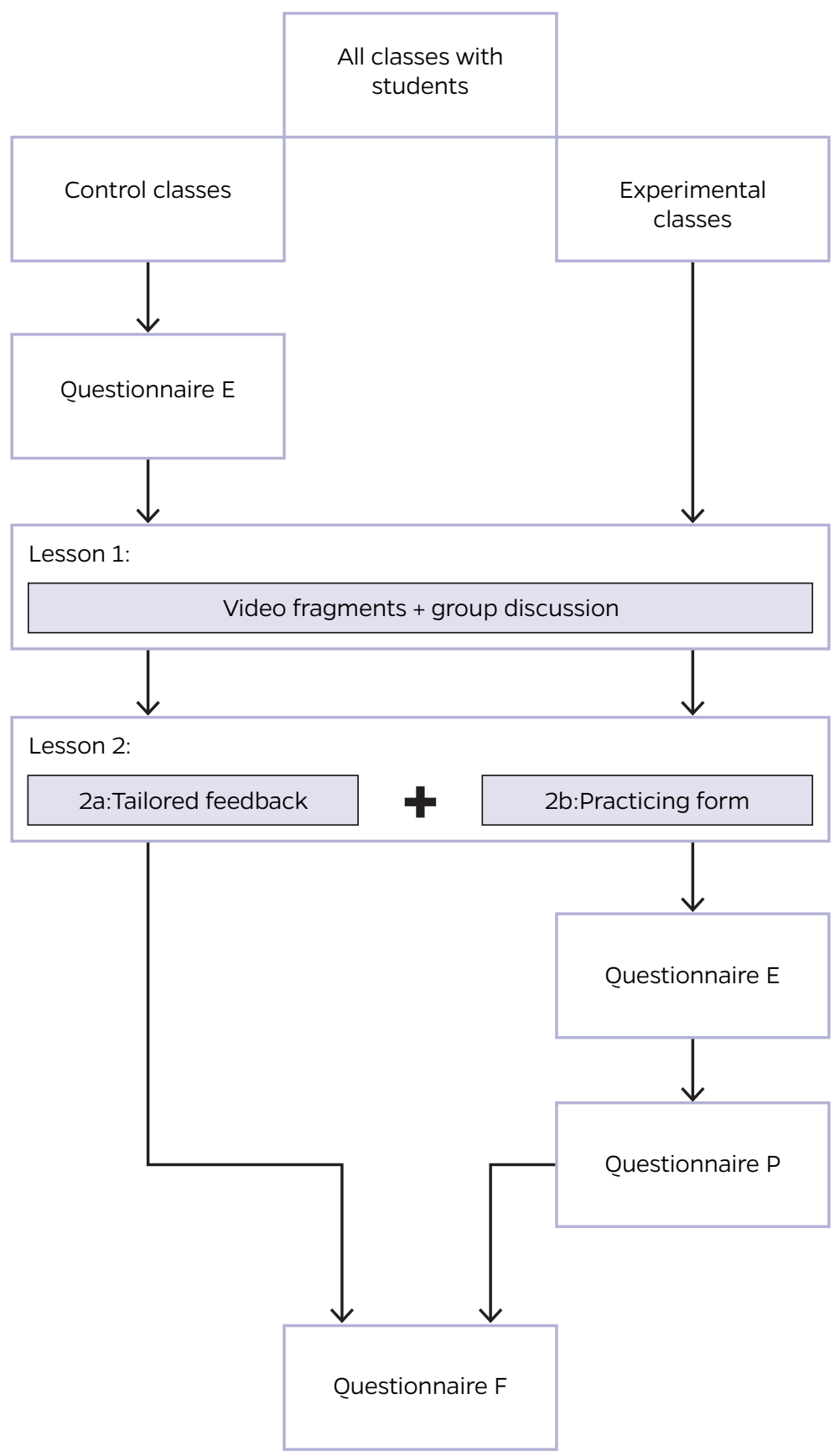

Figure 1. Design of the evaluation study

Questionnaire $P$, questionnaire process evaluation; Questionnaire E, questionnaire effect evaluation; Questionnaire F, questionnaire follow-up measurement 
The program consisted of a website with three elements to be completed in a school setting during two 50-min-lessons. A combination of individual and plenary activities was used. Figure 2 provides an overview of the lessons and goals of the program.

\section{Web-based program on organ donation}

\section{Lesson 1}

4 video fragments with positive and negative outcome expectations

- Deciding about organ donation when someone is brain dead

- Helping other people

- Discussing organ donation with others

- Importance of registration

Discussion after each video fragment

Goal: Increasing involvement, encourage positive beliefs, counterbalancing negative beliefs

\section{Lesson $2 a$}

Individually answer quiz questions on the website

- Knowledge: score and correct answers after completion

- Opinions: tailored feedback after each question

Goal: Teaching about organ donation, giving them tailored feedback on misconceptions

\section{Lesson $\mathbf{2 b}$}

Exercise on completing an organ donation registration form

Goal: Giving students an enactive mastery experience to increase their self-efficacy and therefore their intention to fill out a real organ donation registration form

Figure 2. Content of the educational program about organ donation 


\section{Recruitment and participants in trial}

Teachers from schools for IVE were invited to participate in the study by e-mail. These were typically teachers providing a course on Citizenship. Teachers that agreed to participate were asked to draw up an inventory of their classes in terms of the number of students, educational level and study discipline. The classes were randomized into control and experimental, after which the teachers received all materials (questionnaires for the students, logbooks and teacher manual) and a personalized link for every class. The program was offered to the experimental group and after measurement also to the control group. At the individual level, no inclusion or exclusion criteria were set, only on class and school level, so everyone participated in the program, regardless of age. After receiving the data, there appeared to be 5 students of 15 years old in our data (out of 1170 in total). They were excluded from the data analysis. At class level, a variety of study disciplines and levels of education were included. Classes from level 1 (entry level) were excluded from participation because of the large variety in cognitive abilities at this level. Later, teachers from all schools who completed the program and returned the questionnaires and logbooks were invited over e-mail for a telephone interview to elaborate on their experiences in the classroom. No additional exclusion criteria were set.

\section{Data collection}

Data collection took place between October 2017 and October 2018. The implementation of the program was evaluated both during and after the delivery of the program. During the delivery, user data were collected by means of Google Analytics. After delivery, students in the experimental groups filled out a questionnaire about the program they received. All other data was collected in both experimental and control groups. Teachers were asked to fill out a logbook after each lesson. Teachers who returned the logbooks were invited to participate in a telephone interview. Reasons not to participate were related to a lack of time.

The interviews were conducted by researcher ES. ES was a female PhD researcher, trained in doing qualitative research. Teachers were familiar with her as she also provided 
the support during recruitment and implementation. In the beginning of the interview ES informed the teachers about the goals of the interview. The interviews lasted approximately $20 \mathrm{~min}$ and were the main data source for this study. Interviews usually took place within a few weeks after implementation, but near the end of the trial (and also the end of the school year), recruiting for participation in an interview became more difficult. One interview was planned after the summer vacation, but this teacher clearly had difficulties remembering details of the implementation, which was a natural moment to stop recruiting.

\section{Measurements}

Implementation of the educational components was measured using six constructs, inspired by the model of Steckler and Linnan(118). Table 1 provides an overview of abovementioned constructs, the definitions used and the instruments used to measure these. The interviews were the main data source in this study, complemented by user data from Google Analytics, logbooks from teachers and student questionnaires.

Table 1. Constructs of implementation with their definitions and instruments

\begin{tabular}{|c|c|c|}
\hline Construct & Definition & Measurement instrument \\
\hline Reach & $\begin{array}{l}\text { The extent to which the target group is reached: } \\
\text { - Number of schools reached } \\
\text { - Number of participants reached }\end{array}$ & Google Analytics \\
\hline Dose delivered & $\begin{array}{l}\text { The proportion of program components actually delivered } \\
\text { by teachers: } \\
\text { - Number of components delivered }\end{array}$ & $\begin{array}{l}\text { Logbooks teachers } \\
\text { Interviews teachers }\end{array}$ \\
\hline Dose received & $\begin{array}{l}\text { The extent to which students engage with the program: } \\
\text { - Active participation during the lessons } \\
\text { - Appreciation of the program (components) }\end{array}$ & $\begin{array}{l}\text { Logbooks teachers } \\
\text { Interviews teachers } \\
\text { Questionnaire } \\
\text { Google Analytics }\end{array}$ \\
\hline Fidelity & $\begin{array}{l}\text { The extent to which the program was implemented as intended: } \\
\text { - Compliance to the manual } \\
\text { - Completeness of deliverance of the components }\end{array}$ & $\begin{array}{l}\text { Logbooks teachers } \\
\text { Interviews teachers } \\
\text { Google Analytics }\end{array}$ \\
\hline Context & $\begin{array}{l}\text { Environmental aspects that could affect the implementation: } \\
\text { - Compatibility with the existing curriculum } \\
\text { - Teachers' capacity to implement the program } \\
\text { - Support by the schools' board or colleagues }\end{array}$ & Interviews teachers \\
\hline $\begin{array}{l}\text { Reasons for } \\
\text { fidelity } \\
\text { and dose }\end{array}$ & $\begin{array}{l}\text { Reasons for (not) implementing the program (components) } \\
\text { as intended: } \\
\text { - Facilitators to implementation } \\
\text { - Barriers to implementation }\end{array}$ & $\begin{array}{l}\text { Logbooks teachers } \\
\text { Interviews teachers } \\
\text { Questionnaire }\end{array}$ \\
\hline
\end{tabular}




\section{Interviews}

To learn more about teachers' experiences and barriers and facilitators to the implementation, semi-structured interviews were used. Data from the logbooks were used during the interview with that particular teacher, to give them the opportunity to elaborate on answers they gave. The interviews were based on a topic list, focusing on teachers' experiences, dissemination and innovation characteristics (the latter derived from the Diffusion of Innovations Theory by Rogers(124)). The full topic list can be found in the Open Science Framework repository (https://osf.io/sk6mr/).

\section{Google Analytics}

Participants' behaviour on the website (at an aggregate level) was assessed by Google Analytics. Teachers were provided with a personalized link per class, which enabled us to trace user behaviour back to specific classes (i.e., not to individuals within that class). The user data gave us insight in when the website was visited by which classes, how participants behaved on the website (e.g. how long they stayed on a certain page), whether all elements were completed and gave us an indication whether elements were used in an individual or plenary session. User data cannot explain why teachers and students behaved in a certain way. This was mainly explored during the interviews.

\section{Logbooks}

Teachers were asked to fill out a logbook after each lesson to learn more about what components they delivered, how much time they spent on the different components, how satisfied they were with the components and any other comments they wanted to share. Whether components were delivered, was assessed by a simple yes/no checklist. Each component was scored on a scale from 1 to 10.

\section{Questionnaires}

To include students' experiences in the evaluation as well, students in the experimental groups filled out a questionnaire after completing the program. They first indicated whether they were present during lesson 1 and 2 . Their appreciation for the different components was then assessed on a 7-point Likert scale (totally disagree to totally 
agree), by asking them whether they felt a particular component was fun and whether they felt that component was informative. They also scored the program as a whole on a scale from 1 to 10 (in line with the Dutch grading system). Finally, they had the opportunity to mention things they specifically liked about the program and give recommendations for improving the program.

\section{Analyses}

The interviews were audio-taped, notes were made during the interview and a transcript was written from each interview afterwards. NVivo was used to code and group the qualitative data from the interviews and the open-ended questions in the logbooks and questionnaires. Thematic analysis was used to analyse the data(147). After getting familiar with the data, a code tree was made based on which the first interviews were coded. After this first round, themes in the code tree were reviewed by two researchers and adaptations were made. All interviews were then coded based on this new code tree. The final code tree can be found on OSF: https://osf.io/sk6mr/. The coding of the interviews was individually done by two independent researchers, after which the differences were identified and consensus was reached. The quantitative data (logbooks, questionnaires and Google Analytics) were analysed using SPSS24, by means of frequencies and descriptives. 


\section{RESULTS}

\section{Reach}

A total of 11 schools with 1170 students participated in the study. Of those students, 601 (i.e., those in the experimental group) filled out the process evaluation questionnaire. Of these, $67.1 \%$ was female and $40.6 \%$ were enrolled in a study in the area of health care and well-being. They were on average 18.09years old. Thirty teachers kept track of a logbook during and after the implementation of the program, leading to a total of 72 logbooks being returned. Ten teachers were interviewed after completing the implementation of the program. The interviewed teachers were from eight different schools from different geographical regions. Three were male, seven were female, and their age ranged from 23 to 62. Their teaching experience varied from 1 year to 30 years. As not all teachers made use of the right link (i.e. to allow tracing back to class-level), results on reach were only derived from returned forms and interviews and not based on Google Analytics.

\section{Dose delivered}

Logbooks from teachers showed that the video fragments and group discussions were delivered by $98.6 \%$ of them (Table 2). Deliverance of the second lesson was a little lower, with $87.7 \%$ of the teachers letting their students work with the quizzes on the website. Finally, 55.1\% let the students practice with a paper-based registration form in lesson $2 \mathrm{~b}$, while $39.6 \%$ used the digital form, and $88.5 \%$ provided the students with information about the registration form. In total, $96.2 \%$ of the teachers delivered at least one element of lesson $2 \mathrm{~b}$. Teachers were divided on whether paper-based or digital materials work better. One teacher commented that everything an IVE student does, is online nowadays. On the other hand, teachers mentioned that students benefit from physical materials as well:

"And in the end I printed the registration form, because that often helps, that they then have something tangible." - Teacher, 38, female. 
Table 2. Deliverance of each lesson according to teachers' logbooks

\begin{tabular}{lll}
\hline Lesson & & Component delivered (\% yes) \\
\hline Lesson 1 & - Showing video fragments & \\
& - Facilitating group discussion & $98.6 \%$ \\
Lesson 2a & - Let students make quizzes & $98.6 \%$ \\
Lesson 2b & - Practicing on paper & $87.7 \%$ \\
& - Practicing online & $55.1 \%$ \\
& - Provide information about form & $39.6 \%$ \\
& & $88.5 \%$ \\
\hline
\end{tabular}

\section{Dose received}

\section{Active participation}

Teachers were divided about the active participation of their students. In some classes, students were very enthusiastic, had vivid discussions and asked a lot of questions:

"They were all very interested and then of course there is a group that says, "We are not allowed to donate because of our religion". But then they really discuss it respectfully and that leads to very nice conversations. (...) So you have really nice questions and discussions." - Teacher, 45, female.

"The atmosphere in the class was very quiet and attentive." - Student, 16, female, level 2.

In other classes, it was harder to motivate students, as they were not convinced of the relevance of (education about) the topic or simply not interested. Some teachers suggest that this depends on the study discipline. Students enrolled in a health care program were more interested in the topic than some other classes:

"Well, what should be noted; these are technical guys, so they are - they just want to know how something works, that's it. They are not going to philosophize for a long time about feelings and things like that. I can imagine that this is different in other groups." - Teacher, 52, female. 
Some teachers said personal relevance was very important to motivate their students as well. They suggested that this could be embedded more in the program, but also personal stories from teachers or students led to more active participation:

"And I have to say, I have a friend, for example, who has a new kidney, so I also told them some of my own stories and they listened carefully to that. So that then makes it easier for me, and well, the involvement of students as well I think, when you have your own stories." - Teacher, 38, female.

\section{Appreciation of the program (components)}

In the interviews, teachers were in general enthusiastic about the program. They saw the relevance of teaching about organ donation, especially for the age group (around 18 years old) they work with. Moreover, the program was easy to use for them as teachers, but also easy to understand for the students. Further, they liked the variety of components and the fact that the program was ready-to-use. Students rated the program as a whole with a 7 out of 10 , which is considered a very adequate mark in the Netherlands. They also appreciated the variety of components:

"I liked that there was a lot of variety and that they asked about your opinion a lot and that it makes you think about it." - Student, 16, female, level 4.

\section{Lesson 1}

Teachers were most positive about lesson 1, scoring it a 7.5 out of 10 . Students were also most enthusiastic about this lesson (Table 3). Teachers said the video fragments were appealing and they liked that they involved different perspectives on organ donation (patient, surviving relative, etc). Using videos works well with their students and the actors and stories were easy to relate to:

"The videos worked well. I remember them leaving an impression. Especially one, I remember, that they, I believe it was an interview at a cemetery, or a grave, that someone said "Well, this is a nice way to start a lesson". But then 
they were like: "But why? Why is this on the screen?" So I immediately had their attention. And it made use of three people with different perspectives. (...) That was just very good and worked fine." - Teacher, 38, female.

Students were in general positive about the videos and liked the discussions followed by these.

"I liked that different people were interviewed, to make us hear different stories.” - Student, 17, male, level 4.

However, they also commented on the quality of the videos, the presenter and editing of the videos:

"I found repeating the text with white words on the screen a little childish." Student, 21, male, level 4.

Table 3. Students' evaluations of the different components and the program as a whole

\begin{tabular}{|c|c|c|}
\hline \multicolumn{2}{|l|}{ Lesson } & Score (1-7 scale) \\
\hline \multicolumn{3}{|l|}{ Lesson 1} \\
\hline \multicolumn{3}{|c|}{ Video fragments } \\
\hline & - Fun & $4.4 \pm 1.6$ \\
\hline & - Informative & $4.6 \pm 1.6$ \\
\hline \multicolumn{3}{|c|}{ Group discussion } \\
\hline & - Fun & $4.8 \pm 1.6$ \\
\hline & - Informative & $4.5 \pm 1.6$ \\
\hline \multicolumn{3}{|l|}{ Lesson 2} \\
\hline \multirow[t]{2}{*}{ Quizzes } & - Fun & $4.2 \pm 1.6$ \\
\hline & - Informative & $4.1 \pm 1.6$ \\
\hline \multicolumn{3}{|c|}{ Registration exercise } \\
\hline & - Fun & $3.9 \pm 1.8$ \\
\hline & - Informative & $3.9 \pm 1.8$ \\
\hline Entire pro & $(1-10)$ & $7.0 \pm 1.2$ \\
\hline
\end{tabular}




\title{
Lesson $2 a$
}

The second lesson (2a) was rated with a 6.3 by teachers and received critical comments during the interviews. Students were moderately positive about this component (Table 3). The main problem that teachers described was that students did not read the questions or answers properly and therefore finished within a few minutes. Moreover, some teachers found it difficult that they had no idea what their students were doing, which made it hard for them to follow up on it or answer questions. Finally, they believed the entire second lesson was too theoretical and could benefit from some more interaction.

\begin{abstract}
“Only the quiz didn't reach its full potential, I wrote that down a couple of times. (...) I have no idea what they do with the questions. So you can't $r$ eally follow up on that. And for them it sometimes was unclear what the results actually meant. And they passed through it quickly. It took them less than 10 minutes per quiz." - Teacher, 23 , female.
\end{abstract}

\section{Lesson $\mathbf{2 b}$}

Lesson $2 \mathrm{~b}$ was rated with a 6.9 by the teachers, and least appreciated by the students (Table 3). Most teachers did see the added value of paying attention to the registration form but found it hard to motivate the students. They mentioned that students sometimes felt that they already knew how it worked or did not understand why they had to actually fill it out, as it was not for real. Further, as it was the last component, at the end of a lesson, students were not able to maintain their focus. A few teachers shared examples of things that went wrong when filling out the form, emphasizing the importance of the lesson:

\footnotetext{
"There was even a boy who said he filled out the form on paper at home and that his father did a final check and that he then appeared to have made a mistake. So that was very nice. ( ...) Because the question "which organs do you want to donate or not", well, he mixed those up." - Teacher, 52, female.
} 
"We have that registration form - for level 2 students, that's a really good exercise, as they don't even know their social security number or even their zip code so to speak, really, sometimes they are so ignorant." - Teacher, 26, female.

\section{Fidelity}

\section{Compliance to manual}

All teachers that were interviewed expressed being happy with the manual. It gave them clear guidance, some knowledge about the topic and some said it made them more confident. Most said they took the time beforehand to read it thoroughly. Moreover, the frequently asked questions that were added in the manual were appreciated.

$$
\begin{aligned}
& \text { "I found the guidelines, the manual that was added, very nice. Also with } \\
& \text { all information, a few of the most frequently asked questions. A few times I } \\
& \text { thought, "oh I have some additional questions", but then I didn't e-mail the } \\
& \text { contact persons that were in there, but I could have. But no, that was very } \\
& \text { nice. Also the extra bits of information. Yes, that gave sufficient guidance." } \\
& \text { - Teacher, 29, female. }
\end{aligned}
$$

Even though all teachers made use of the manual, not all components were implemented as intended. Teachers made on-the-spot adaptations to make it fit their group or schedule better. Some teachers fit all information in 1 lesson and some spread it out over 3 lessons. Especially differences in the level of education of the students seemed to be an important reason to make adaptations. For the higher educated classes within IVE, teachers sometimes added extra components themselves (e.g. a more elaborate discussion based on statements they found online or asking students to write a summary of what they learned), while for the lower-educated classes, they made the lessons shorter (e.g. by watching less videos or only explaining the registration form instead of making them practice with it). 
"Yes, it's too many, 4 [videos] is really too many. The attention span of IVE students is not that big, so at some point, when you also want to do those discussions afterwards, (...) so I intentionally shortened these because otherwise I would've lost them at the third video already. So the first 3 are great, the one with the doctor as well, but that one is just, it also takes like 5 minutes or so, that one is too long. At least, for my classes, they are too long." - Teacher, 29, female.

"The lessons could have been shorter, because at some point I didn't have any concentration left, while the topic was very interesting."

- Student, 19, female, level 3.

\section{Completeness of deliverance of components}

Also from the information from the logbooks and Google Analytics it became apparent that not all components were delivered in a complete manner (Table 4). According to the logbooks, teachers spent 50 min on the first lesson, which was exactly as intended. However, Google Analytics showed that the average time spent on the page with the video fragments was slightly under $20 \mathrm{~min}$ (Table 5). This might mean that teachers spent more time on introducing the topic and the group discussions and thus chose not to show all videos. This also was confirmed by some teachers in the interviews:

"I did watch a few of the videos, but not all of them. So I gave a few as an example, and then of course especially the ones where youngsters were involved, because that fits their experience world." - Teacher 37, male.

Table 4. Time spent on each component according to teachers' logbooks

\begin{tabular}{ll}
\hline Lessons & Time spent \\
\hline Lesson 1 & 50 minutes \\
Lesson $2 a$ & 24 minutes \\
Lesson $2 b$ & 17 minutes \\
\hline
\end{tabular}


Table 5. Time spent on each page and number of page views according to Google Analytics

\begin{tabular}{lll}
\hline Page & Number of page views & Average time per page \\
\hline Video fragments & 438 & $19: 24$ \\
Introduction page quizzes & 1238 & $00: 12$ \\
Explanation page quizzes & 1172 & $00: 14$ \\
Quiz 1: What do you know about organ donation? & 1973 & $2: 19$ \\
Quiz 2: What is your opinion about organ donation? & 1967 & $1: 05$ \\
Practicing with registration form & 476 & $9: 14$
\end{tabular}

Teachers said lesson 2a took 24 min on average, but the Google Analytics data showed that the time actually spent on the quizzes was much lower. The first quiz took students 2:19 min to complete, while the second quiz only took them 1:05 min to finish. This suggests that students did not read the questions properly, did not think about their answers and/or did not read the tailored feedback. Teachers mentioned this in the interviews as well:

"Then I think they didn't really read what the outcome was, only the score they got and that's it. Students don't read any more these days, it's really useless." - Teacher, 28 , female.

Teachers indicated they spent on average $17 \mathrm{~min}$ on lesson $2 \mathrm{~b}$. As this lesson is not necessarily done on the web page, it is difficult to confirm this. The way in which lesson $2 \mathrm{~b}$ was delivered differs between teachers, as some used the paper-based version, others the digital version and others only showed it to them, without making them do the exercise.

The number of page views gives an indication of whether components were delivered in a plenary or individual session (Table 5). It seems like most teachers delivered the video fragments and registration form in a plenary session, while the quizzes were done individually. 


\section{Context}

\section{Compatibility with existing curriculum}

Teachers agree that the program fits very well within the course Citizenship and then especially within the Vitality dimension, but also other options were suggested, such as linking it to their age (what changes in your life when you turn 18?) or the political dimension (as in 2018 a law change on organ donation was accepted). Many teachers mentioned that Citizenship does not have a lot of requirements, which can both be a positive and negative thing. It means that there is quite some room for topics of choice, but on the other hand, there are so many topics to choose from, that organ donation is not always a priority:
"At the moment we have - here I go again with my schedule - but we limited ourselves with the dimension of Vitality, because of time constraints. So we discuss alcohol, and that is - well, I teach technical boys who on top of that want to become car mechanics, so that is an important topic. (...) And another topic we chose is STDs and, well, I always try to find some time for a healthy diet, but then often my time is up." - Teacher, 52, female.

Some teachers found it very easy to find time for two lessons, while others mentioned that they have very limited time for Citizenship in general and therefore two hours was too much. This probably highly depends on the school and curriculum. Most teachers said that if they know about the program in advance, it is not too difficult to find time for it.

At the moment, there is no program or information about organ donation in the regular Citizenship methods, but some teachers already spent time on it in previous years, as they find it an important topic. In those cases they usually shared a personal story with the students or invited a guest speaker.

"It's not a topic that is usually part of Citizenship so to say, it's not part of the requirements within the domain, but yes, I always discuss it. So I think it's definitely useful to do something with that." - Teacher, 45, female. 


\section{Teachers' capacity to implement the program}

Teachers generally see themselves as being capable to implement the program. They said the program was easy to use and the instructions were clear. However, as organ donation is not their expertise, they also encountered some challenges. Teachers sometimes got questions from students they did not know the answer to. They handled these questions very differently:

"It [eligibility for donation] depends on age and some other factors. And then they were quite interested, like, where can I find that? I said, well I think you should just Google it. I mean, you can just find that on the Internet." - Teacher, 62, male.

"And I just said in the beginning, like "Guys, I did go through a couple of frequently asked questions beforehand, but I also don't know everything, so maybe l'll look something up." - Teacher, 52, female.

Teachers were also aware that organ donation is a sensitive topic to discuss. Most teachers did not necessarily see this as a problem, but all dealt with it in their own way. Some teachers found it difficult to get a feeling of how far they could push and talk about taboos. Others said that the sensitivity of the topic led to very open discussions:

"Well, I know that one girl knows she needs a donor lung to prevent her from dying young. But we've talked about that in the past as well. So, it is tough, but doable. I am at least - but that also depends on the teacher I think, how he/she deals with that - I am just very relaxed and open about it and I'm also very young. So I'm very close to them. So that makes a difference. So you will get those questions or comments any way, but if you open up and are vulnerable, students will do the same." - Teacher, 28, female. 


\section{Support by the schools' board or colleagues}

As mentioned before, Citizenship is a course in which teachers have a lot of freedom to teach about topics they find important. Implementing it on a school level might therefore be challenging. However, some teachers commented that they think it would be of added value to implement the program on a school level.

“Yes, well actually, I don't know how much power you have (...) But I think that if you want it to be very powerful, it is utopian what l'm going to say now, but that it will become an obligatory component of the curriculum.

(...) So the government needs to invest in that, in education, like hey, there's one period in their entire school career, that when they're 18, we are going to spend time on that." - Teacher, 37, male.

No other teachers mentioned involvement of the school board, but sometimes discussed it among colleagues or in Citizenship meetings.

\section{Reasons for fidelity and dose}

\section{Facilitators to implementation}

If both students and teachers saw the relevance of learning/teaching about organ donation, this facilitated the implementation. There were several ways in which the program became more relevant. For instance, one teacher chose to deliver the program around Christmas and another teacher suggested that it might be good to link it to the yearly national Donor week. Further, around the time of implementation, an upcoming new donor law got a lot of media attention:

"For me, it was a godsend at that time. Because it was very topical then.

So I thought like, how am I going to address that in my Citizenship classes? Because, coincidentally, we were also just dealing with Vital Citizenship, so yes, that fits fine of course. (...) So in that sense: timing was perfect." - Teacher, 38, female. 
Another factor that helped in making it relevant for the students is their age. During the year after they turn 18, they receive a letter in which they are asked to make a choice regarding organ donation.

"Because it's of course also the age that fits this very well. So there are 16, 17, 18 year-olds in the first year, that's where I implemented it, and yes, for 16-year-olds it might not concern them yet, but then there's also 18-year-olds there, so you can ask "Who is already 18 here? Do you remember getting that letter?" And to a 16 or 17-year-old you could say: "Well, now you know what to expect when you turn 18". So that's a nice preparation, fits their age as well. So also without topicality, you could make it relevant to address." - Teacher, 38, female.

Other facilitating factors for implementation were that the program was easy to use for both students and teachers and that effects were observable. They mentioned that they had interesting discussions about it, students clearly had more knowledge after, that they sometimes said they talked about home or even registered:

"Yes, some of them changed their opinions. In the beginning they often said "Oh I don't want that", and now they started thinking "Oh well, maybe I do". Like: "I don't know yet", but it's not a harsh no at least. So that's really nice to see, that they start thinking critically. (...) They at least became aware of the fact that they have a choice. And that they have to think about it themselves, if you want to influence the outcome. That's one thing. And secondly, that they started thinking critically. So they might not have an answer yet, but are dealing with it." - Teacher, 38, female.

"I learned a lot and now I know more about donor registration and what happens after that with your organs and body." - Student, 17, female, level 4. 


\section{Barriers to implementation}

One of the most important barriers to implementation, as mentioned before, was the fact that IVE students do not read materials that well. Some teachers said that they just forget and immediately want to do things instead of reading about it. Others are just discouraged when seeing a lot of text. Sometimes this is because of more serious problems such as low literacy:

"In level 2, and especially in level 1 but we don't even teach them, there are many people with low literacy." - Teacher, 52, female.

Teachers therefore recommend to stick to the content of the quizzes, but then delivering it in a more interactive way. This could also help overcoming another barrier, which is the low attention span of students in IVE (see: Fidelity: compliance to manual).

Two practical issues were mentioned by teachers, that made the implementation more difficult. One teacher mentioned she had a large group, which made it hard to involve everyone, while another teacher mentioned that she struggled with absenteeism of students during the first lesson. These are issues that cannot be prevented, but suggestions on how to deal with this could be added to the manual.

Finally, different cultural or religious backgrounds were mentioned as being either a facilitator or a barrier. One teacher said that having more students with a migration background made things a little bit more challenging, while others said that the mixed backgrounds of their students facilitated lively discussions:

"I have to say that I found it very interesting because our school is very mixed, so we have around, well I don't know, maybe 40 to 50 different cultures here. So that leads to very nice discussions." - Teacher, 45, female. 


\section{Future use}

All teachers were positive towards future use, sometimes even actively asking questions about this in the end of the interviews themselves. They seem willing to make time available for this topic in the future. Some of them want to follow up in the same classes as well. There was also a specific request by some teachers to make a follow-up lesson to be able to repeat some things and elaborate in the same classes some time later.

"Look, this time I had a gap to fill, but I think that I'll make time for this in the future." - Teacher, 29, female.

They believed that especially colleagues teaching Citizenship would be interested in using the program as well. However, they also mentioned that you probably highly depend on the teacher that you encounter. Some teachers prefer to spend time on other topics, or might just not be enthusiastic about organ donation themselves.

"I think colleagues in Citizenship would [be interested in using the program], yes. However, it does depend on the teacher. Because I'm a little bit more involved in those things, that I find these things important and others have their focus on other topics. That's a thing with this subject [Citizenship]. That it's very dependent on the teacher." - Teacher, 23, female.

One teacher (with a background in health care) was afraid that the program might be difficult to teach for people without a background in health care, but other teachers did not conform that. One other teacher recommended to send reminder e-mails, as teachers tend to run from pillar to post.

\section{Recommendations}

Both teachers and students gave recommendations for further improvement of the program. Teachers mainly emphasized the need of different versions or options for the different educational levels within IVE. They argued that level 2 classes cannot be compared to level 4 classes in terms of active participation, attention span, reading and knowledge. 
"I personally solemnly believe in different programs, with the same subjects and the same goals for both groups. Because for level 2, these kind of topics don't concern them yet, unless they have personal experiences with it." - Teacher, 52, female.

In practice, this could mean that students in level 2 classes need some more (inter) active methods and something that makes it personally relevant for them. For level 4 classes this could mean that there are optional assignments or more in-depth information for those who are interested. Teachers commented that the program was not challenging enough for the higher achieving classes or students:
"Maybe it would be nice - because I talked about that with colleagues recently, we are working with differentiation in our classes, that especially those lessons with the quizzes and information that many students were like "I already knew that", that you might be able to add a bonus component or so. (...) Many students said at the beginning of the program "Yes, I have an opinion and I can support that because it is what it is". So it would be a challenge to pose some questions about that. That would be nice." - Teacher, 29, female.

This also became clear from the comments that students added to their evaluation form. For some students the program was elaborate enough (or even too long). On the other hand, many students commented that they would have liked even more information:

"I'd like more information about the process of organ donation, how it actually works." - Student, 21, female, level 4.

Students also commented that the program was very serious and sometimes even boring.

"Maybe it can be delivered in a more playful way. It was very formal and serious." - Student, 24, female, level 3. 
Teachers gave some suggestions to make the program more attractive for students. One teacher suggested involving a celebrity in the videos, who spoke about organ donation on a television show earlier.

Finally, some students found the program too much pro-donation. They liked having different perspectives on the topic, but suggested that the perspective of someone who is against it or decided not to become a donor could be added.

"The videos and registration form make you feel bad if you don't want to be an organ donor." - Student, 16, female, level 4.

"The only comment some students had was that they felt it was a I ittle bit forced on them. That's what one or two students said. But I said "Any way you slice it, they ask you to think about it and about the choice you'll make." - Teacher, 37, male. 


\section{DISCUSSION}

An interactive organ donation education program was developed to support lowereducated adolescents in making a well-informed decision about organ donation. The program proved to be successful in increasing (determinants of) registration intentions. The present study focused on the process of implementation of this program in an IVE school setting. While the teachers' perspective was the most important data course, also the students' perspective and user data from the website were taken into account. By combining different measurement tools, a complete overview of the implementation process was given and findings could be confirmed, leading to a higher validity of conclusions $(118,126,127)$.

The program as a whole was delivered quite well by the teachers. Lesson 1 was implemented with high fidelity and appreciated by both teachers and students. Lesson 2 (both the quizzes and registration forms) was appreciated less and also not used as intended. Teachers and students commented that it was too theoretical and that more interaction would be appreciated. It was noted that the second lesson required a lot of reading, which appeared to be a problem for the lower-educated target group. This could partly be due to high rates of low literacy within IVE: 1 out of 3 students in level 2 and 1 out of 7 in level 3 (there is no data available regarding level 4) (40).

During the implementation of a similar program in a high school setting, Reubsaet and colleagues also saw that lesson $2 b$ was implemented least often(24). Most important reasons for this were a lack of time and the fact that teachers did not seem to see the usefulness and importance of the training. These results were taken into account when adapting the program to a lower-educated target group by shortening the quizzes to ensure there was time left for the registration exercise and by adding a section about the importance of this lesson in the manual. It seems that these changes were successful in overcoming the barriers as teachers did not mention these issues during the interviews anymore. 
However, during the implementation in a lower-educated target group, new barriers emerged. While teachers were convinced of the importance, students were not. Moreover, not all students were capable to fill out the form themselves and their attention span was low at the end of the lesson. This probably explains why some teachers only gave an explanation about the form, but did not do the exercise. So, even though giving students an enactive mastery experience is traditionally seen as most influential to increase self-efficacy(111), this might not play out in this context and target group. While the content of the lesson is still very relevant, the way of delivering this should be reconsidered.

Overall, relevance of the topic and the program (elements) for both teachers and students appeared to be an important factor for implementing the program (well). When conducting the study, the relevance of teaching about organ donation was high as a law change about organ donation (to be implemented in 2020) was widely discussed in the news. However, teachers commented that in the future, it might be difficult to prioritize teaching about organ donation over other important (healthrelated) topics, such as safe sex or drug use. This can be challenging as organ donation registration serves the society as a whole, but does not directly impact the well-being of their students, especially not in the short run. Therefore, for future dissemination of the program, support on a higher level should be explored.

To increase the attractiveness and relevance of the program for students, different options are open. One option could be a collaboration with a celebrity, with the main goal of attracting students' attention. When combined with accurate and balanced information, celebrity advocacy has the potential to influence health behaviour(148, 149), and is seen as a powerful tool for both health literacy and health promotion(150). As young adults have a more positive attitude regarding celebrity engagement than older people(151), this could be a promising addition to a program in an adolescent target group. It is important to then choose a celebrity that students can easily identify with, as this is an important mediator of celebrity effects on students' attitudes and 
behaviours(152, 153). Attitudes, values and behaviours are likely influenced by celebrity issues, when someone feels personal identification with that celebrity(154). As the target group is very diverse, it will be a challenge to choose a person that most students feel connected to.

This diverse target group gave us an important insight: even when tailoring a program to a specific target group, there might be differences within this group that cannot be ignored. Teachers made on the spot adaptations, which is inevitable when implementing school-based interventions $(155,156)$. In this real life setting, an intervention needs to fit the context and the students (in this case especially different educational levels and study disciplines)(157, 158). Moreover, teachers might make adaptations to fit their own pedagogical approach or to incorporate their own stories and experiences(159). This brings us to the ongoing fidelity-adaptation debate. While traditionally fidelity is seen as critical for success, adaptations also seem beneficial. It increases local ownership and sustainability(160), may improve the engagement of students and teachers who adapt are possibly more motivation(161), creative and effective in implementing(162). Adaptations should therefore not be discouraged, but guidelines on how and where to make those adaptations in order to still ensure effectiveness of the program are needed(160, 163).

Another desirable adaptation could be the addition of follow-up interventions, or so called "booster" interventions. In the effectiveness study of the same program, it was already noted that decision-making regarding organ donation takes time and is very complex(137). Especially in this situation, where for most students it was their first encounter with the topic of organ donation, it takes time to form an opinion and act on it. In this process evaluation, several teachers asked for extra materials as they also felt the need to revisit the topic later or to come to more in-depth understanding and discussion. Booster interventions give the opportunity to reinforce and build on information to suit students' age and development(164). Booster sessions are common in the field of health promotion, including education about drugs(165), life style programs(166) or worksite interventions(167). However, as organ donation registration 
is a one-time behaviour, booster sessions are not relevant anymore for students who already registered their decision. This was also mentioned by some students who were already registered during the initial implementation of the program. The application of booster sessions in the context of organ donation education should therefore be further investigated, to ensure relevance for all students.

\section{Limitations}

Overall, when reading the results, one should be aware that there was a risk of sample bias in this study. Teachers who are enthusiastic about the topic of organ donation and who are open to new educational programs might be more likely to use the program and to agree to the interview afterwards. This was also stressed by teachers themselves during the interviews, by explaining that implementation of such programs highly depends on the individual teacher. It is important to keep in mind that teachers who are against organ donation or the upcoming law change might not be willing to teach about it or influence the implementation in a negative way.

Another possible limitation concerns the variability in time between the implementation and the interviews with teachers. Often, the interviews were conducted within a short amount of time after the implementation, but sometimes this was not possible due to busy schedules. Recall bias could have occurred, which possibly led to the loss of details. While this limitation should be acknowledged, this is not likely to have influenced the results in general, as the overall experience will not have changed over a few weeks. It might however have influenced the richness of interviews in the cases with a longer time interval.

\section{Conclusion}

This interactive organ donation education program was well received and implemented within a lower-educated school setting. Therefore, we see opportunities to disseminate the program on a larger scale and reach a group that before has been neglected in organ donation education. Within the program, there are possibilities to increase the effectiveness of the program, such as alternative delivery methods for the elements 
with a lot of text, the addition of booster sessions and guidelines for teachers to adapt the program to students of different levels within IVE. Moreover, in order to have an impact on a national level, strategies need to be employed to reach high numbers of students and therefore support on a higher level is needed (both within schools and at policy level). 



\section{part $2_{\text {organ donation registration systems }}$}

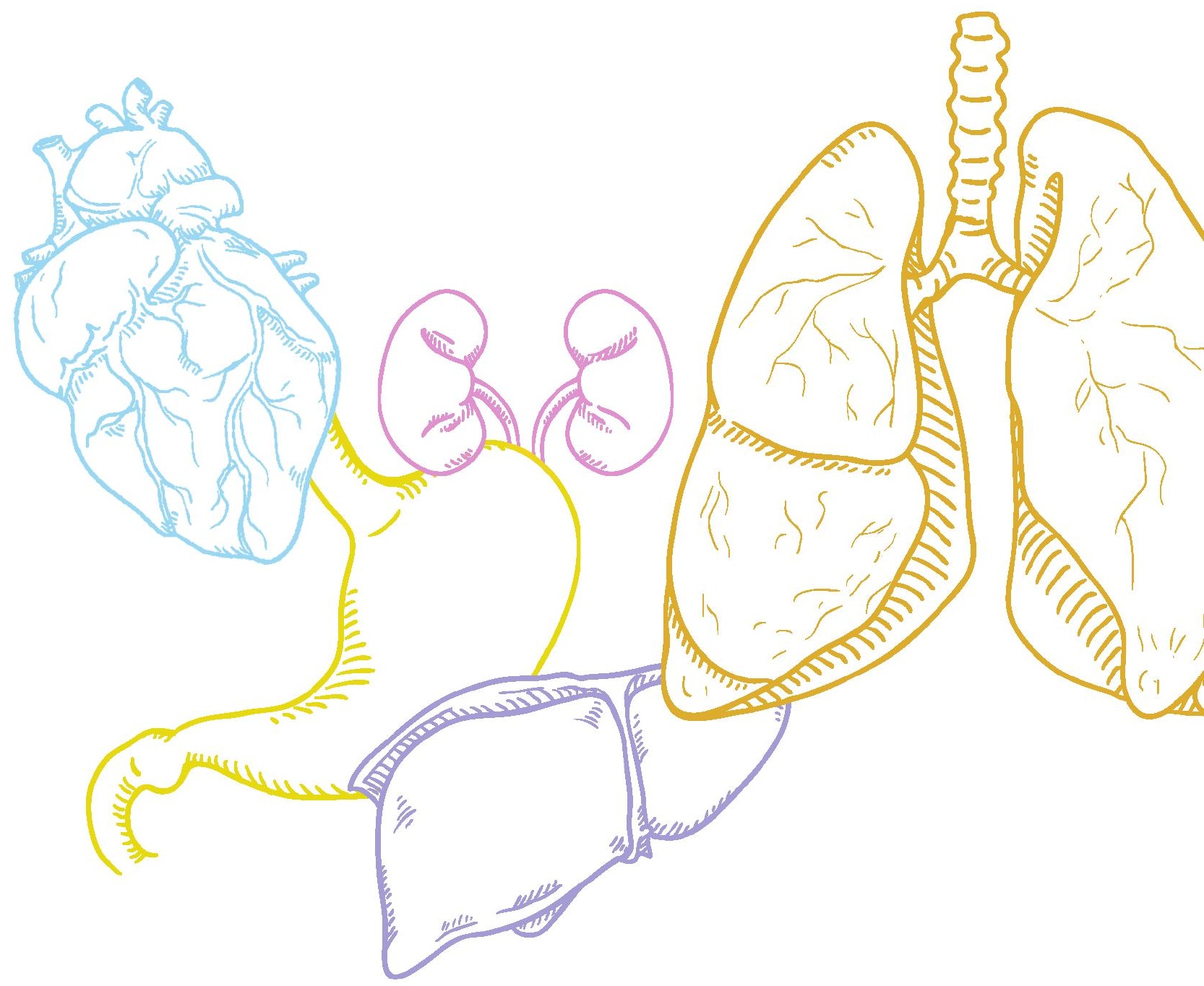





\section{chapter 6 \\ no objection against the new donor law, but even more responsibilities}

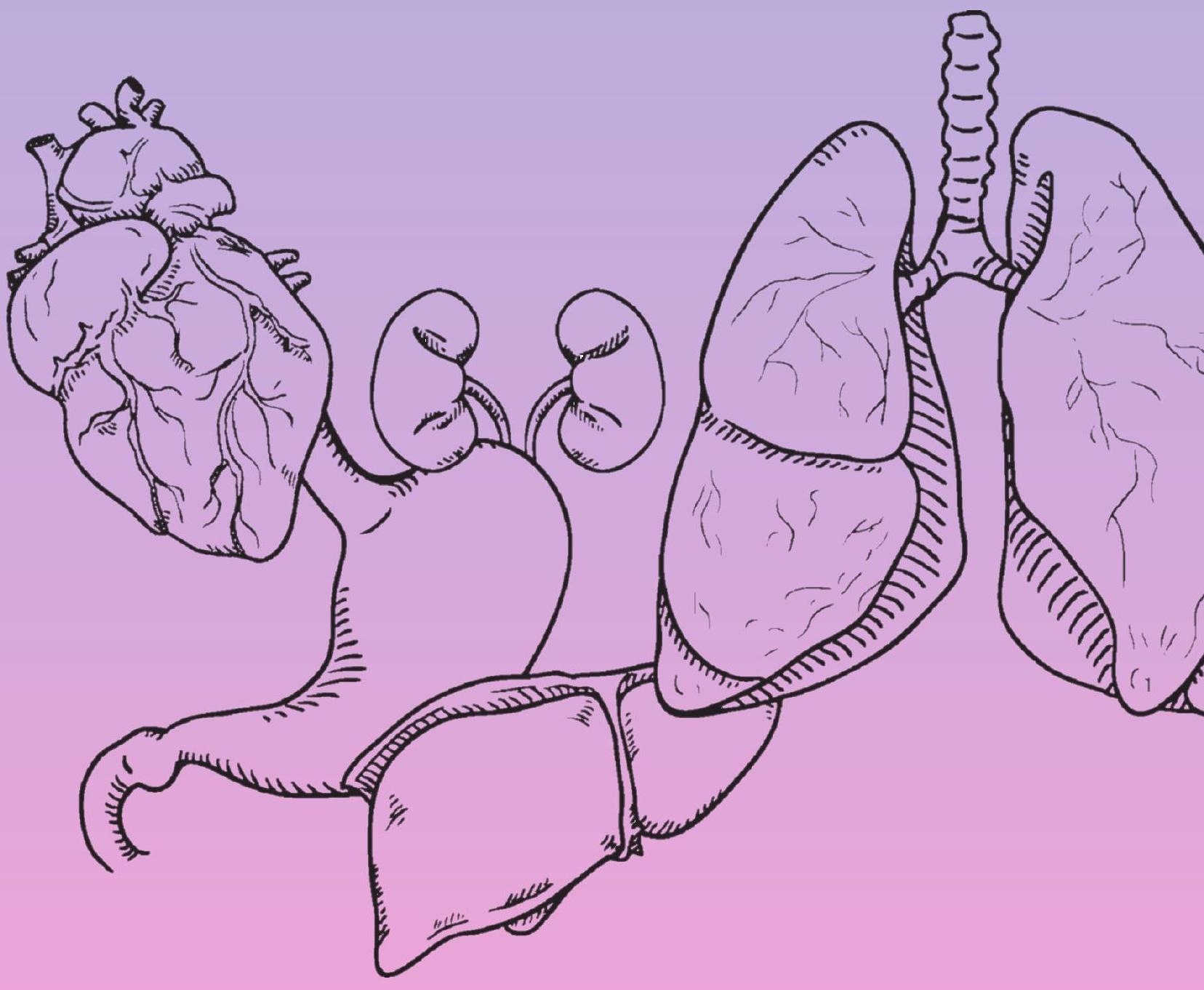

This chapter concerns a translation of the original article.

This chapter has been published in Dutch as:

Steenaart, E., Crutzen, R., \& de Vries, N. K. Geen bezwaar tegen de nieuwe donorwet, maar wel nog meer verantwoordelijkheid.

Tijdschrift voor Gezondheidswetenschappen. 2018;96(3-4):134-135. 
On the 13th of February 2019, there was finally a breakthrough in the Pia Dijkstra bill (D66). Contrary to all expectations, the new donor law was adopted by both the House of Representatives and the Senate of the Dutch parliament by a narrow majority. This new law was created to bridge to gap between the supply and demand of organs and is supposed to spare relatives when their loved one dies. However, before this law can be implemented in 2020 and result in the desired effects, a lot still needs to be done. The law divided the country, both in terms of political and societal discussions. Is the Netherlands ready for this step? And if not, how do we make sure that we are in 2020 ?

\section{The new donor law}

The new donor law implies that in 2020 all non-registered Dutch people, aged 18 and older, will receive a letter from the government asking them about their preferences regarding organ donation after death. After this first large mailing, this letter will be sent yearly to everyone who turns 18 in that year. This does not differ from the current situation as also in the current system, an annual mailing is sent to 18-year-olds asking them to make a decision. However, the difference is that in the current situation, not making a choice has no consequences, while in the new situation, this person will be recorded with a no-objection registration in the national donor register when he/she fails to respond within 6 weeks after a reminder letter. This no-objection registration is a new registration possibility next to the current "no" and "yes" (with or without the restriction on certain organs/tissues), and no replacement of "yes".

So what does this no-objection registration actually mean? When someone is recorded with this registration and dies, relatives will be told that this person "had no objection against organ donation." Relatives still have the opportunity to oppose the transplantation, if they can make a reasonable case that their loved one actually did not want this. How this will work in practice, will be figured out in the upcoming period. The only thing we know for sure, is that this does not provide us with a lot of clarity. 


\section{Relatives}

Next to increasing the number of donors and transplantations, the new law is also supposed to relieve pressure on relatives. Currently, the conversation about organ donation around someone's death is very difficult when that person did not register a decision $(2,11)$. Relatives then get to decide what should happen to the organs. That is a very tough decision, especially as the situation is already emotionally charged. The rationale behind the new donor law is that everyone will have a registration behind their name, meaning that relatives will always know what their loved one's preferences were. The question is, however, whether a no-objection registration will actually lead to more clarity than no registration at all, as it is still no active decision by the deceased person. Relatives will thus still not know what their loved one actually wanted and will still be faced with that difficult decision. It is therefore of great importance that the number of no-objection registrations will be limited and people start registering an actual "yes" or "no". In other words; that they make an active decision. But can we expect everyone to do this based on only a letter? And do people have the skills to do so?

\section{Importance of education}

At the moment, the response on the yearly mailing to 18-year-olds is about one out of three. This also means that two out of three cannot make that decision at this time, do not want to do that or simply do not get to it. For many youngsters, that letter is the first time they get confronted with organ donation. Also, the letter is often not read or understood. This leads to them not filling out the registration form and thus becoming a person without a registration in the donor register. From 2020 onwards, this means that this person will get a no-objection registration and might not even understand what this entails. It is possible that some people think "no objection" entails the same thing as "yes", causing the number of active "yes" registrations to decline.

During the debate in the Dutch Senate, the complexity of the law got a lot of attention. Politicians worried about vulnerable groups in our society, such as people with low literacy levels. They asked Dijkstra to guarantee that everyone would understand the new law, some sort of warranty. Her response - "vacuum cleaners come with a warranty" 
- was not received well by others. Very understandable, as low literacy is a problem in the Netherlands, also among youngsters. One in three students in vocational education level 2 and one in seven in level 3 score below the low literacy threshold(40), while they constitute a large part of the Dutch population.

Dijkstra emphasizes the importance of a "very good information campaign" prior to the commencement date of the new law. Every Dutch citizen should be informed about the new law, the choices that can be made and the consequences of not registering your preferences. However, education should not only take place prior to the commencement date but should reach the new group of 18-year-olds each year. If not making a choice is not an option anymore, there should be better education, which exceeds information campaigns. Further, repetitive exposure to rules and consequences is needed for the entire population and should include accessible, understandable information for everyone who would like to register their decision at a later date or wants to change their registration.

Education about organ donation and everything related to the registration choice, has always been important. This has to do with the fact that it is a very personal decision, which is associated with deeply rooted beliefs and feelings. In current education campaigns (often mass media) there is usually little attention for these personal feelings and consideration of the pros and cons. To limit the number of no-objection registrations and to encourage people to make a well-informed decision, this should be embedded better in the upcoming education initiatives. This should not be limited to only giving information but requires active involvement of and support for citizens when making their organ donation decision.

\section{Who is responsible for what?}

It is difficult to decide who is responsible in this situation. Currently, when no registration is recorded, relatives have the responsibility to decide about that person's organs. Next, there is a large role for the medical professionals who have to inform the relatives about the options. In the new donor law, the responsibility will be shifted more towards 
to "owner" of the organs, who will be deemed to make a decision when still alive. While the idea of shifting this responsibility from the relatives to the owner is good, it is important for the government to realize that their responsibilities are also extended. The responsibility to provide enough guidance in making a decision should not be underestimated. In the upcoming years, there should therefore not only be attention to the first group that will receive a letter in 2020 , but also a more personal approach for the future, to prepare both youngsters and adults for making this important decision. 



\section{chapter 7 \\ beyond the ticked box: organ donation decision-making under different registration systems}

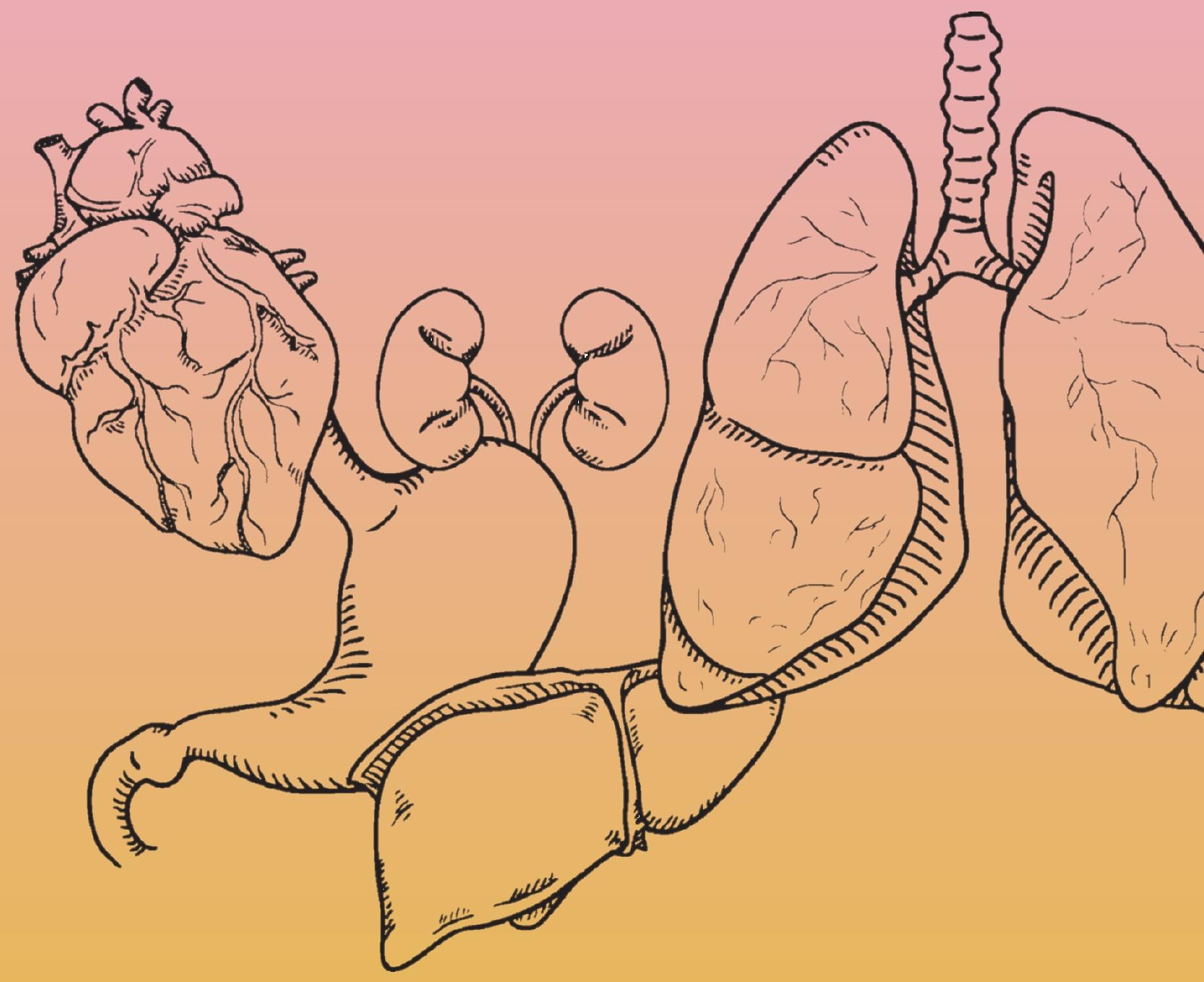

This chapter has been accepted for publication as:

Steenaart, E., Crutzen, R., \& de Vries, N. K. Beyond the ticked box: organ donation decision-making under different registration systems. Psychology and Health. Forthcoming 2020. doi:10.1080/08870446.2020.1811867 


\section{ABSTRACT}

\section{Objective}

To explore how people experience organ donation decision-making under the conditions of an opt-in, opt-out or no-objection registration system.

\section{Design}

A between-subjects experimental $3 \times 2$ design (registration system $\times$ preselection). Participants ( $\mathrm{N}=1312)$ were presented with a description of one of the three registration systems and went through a mock donor registration process. In half of the conditions, the default option of the system was visualized by a ticked box. After, participants answered questions about their perceived autonomy and perceived effective decision-making.

\section{Main outcome measurements}

Perceived autonomy, perceived decision effectiveness and registration choice.

\section{Results}

The preselected box did not impact any of the outcomes. Participants had higher perceived autonomy under the conditions of an opt-in system. There were no differences in effective decision-making across conditions. Registration choices did differ across conditions and educational levels. In the opt-in system, participants more often made an active decision. Lower-educated participants were more likely to choose to do nothing, while higher-educated people more often made an active decision, especially in the no-objection system.

\section{Conclusion}

Where the opt-out system potentially leads to the highest number of donors, the opt-in system seems better in terms of preserving people's autonomy and motivating people to make an active decision. 


\section{BACKGROUND}

The universal shortage of organs that are available for transplantation remains a public health challenge. While the majority of people are willing to donate their organs when they die, or at least have a positive attitude towards donation, many of them fail to take the necessary steps to actually register a decision $(168,169)$. The implementation of an opt-out donor registration system is a commonly suggested strategy to tackle this issue. A default option is used in such a system, meaning that people automatically become an organ donor unless they register otherwise. Countries with an opt-out system, as opposed to an opt-in system in which people have to give explicit consent for organ donation, usually have higher donation rates(44). This partly has to do with the fact that people often choose the preset option when being presented with a default. There are numerous other examples where default options influence people's decision-making in that way, such as living will completion (170), healthcare flexible spending accounts(171), using generics in a pharmacist setting(172), and HIV screening in health care(173).

Presenting people with a default is basically a change in the choice environment to stimulate a certain choice; also called a nudge. Nudges can be important to bridge the intention behavior gap between what people want to do and what they actually do(174). People generally prefer to stick to the status quo in terms of behavior, rather than doing something different or involving in an effortful choice(175). People tend to go with the flow because it is simply the most convenient option requiring the least or even no efforts (e.g., cognitively, practically). For instance, when registering a different decision regarding organ donation than the default, this usually involves the decisionmaking itself, but also completing a registration form and sending it. Finally, not choosing the default option could lead to people being uncomfortable with their decision, because defaults imply that there is a norm with regard to this default.

\section{Potential issues when using organ donation defaults}

Defaults can make people choose the desired behavior, which could result in more 
registered organ donors. However, the choice itself cannot be regarded as the only outcome, because, especially in the context of healthcare, decisions are often valueladen and can therefore not be right or wrong(176). People could be hesitant to optout for many reasons, including the fear to being regarded as ungenerous, selfish, and uncaring(177). While nudges might steer the majority of the people towards a behavior that aligns with their intentions, they sometimes lead to people making choices that are inconsistent with their actual preferences(178). Nudges that benefit the society at large, might therefore be at the expense of some. So, while defaults can be useful, they are also criticized as they make it more difficult to ensure that everyone makes a decision that reflects their wishes. This does not make nudges unjustifiable, but it is important to know what and how large this expense exactly is.

Next, people could be faced with high barriers in case they want to opt-out. Nudges are defined as being easily avoidable, but that is often not the case(179). There are several steps in opting-out, that might not seem too difficult, but could be problematic for many people. First, they have to be aware of the policy and, second, they should have the knowledge and capabilities to opt-out(172). This is especially an issue when it comes to people with vulnerabilities (e.g., lower educational levels or low literacy). It is known that people with lower levels of education less often look for information about organ donation on the Internet, talk less about organ donation with others and are less acquainted with media coverage on this topic(29). These people might therefore struggle even more with understanding what they have to do and understanding what making a choice (or not making one) actually means.

\section{Autonomy}

Autonomy is another commonly raised issue when it comes to using defaults (in organ donation). Advocates of an opt-out system usually argue that people's autonomy is not violated in such system. The rationale being that in defaults, options generally do not change and therefore the freedom of choice should not change. However, previous studies suggest otherwise and show that nudges can in fact undermine people's autonomy (180). This is an ethical concern and it could also influence the success of an opt-out 
system in terms of donors, as frustration about the unmet need for autonomy could even lead to reactance (e.g., registering as non-donor as a form of protest)(181). The first aim of this study, therefore, is to explore what organ donation defaults do to people's feeling of autonomy satisfaction and frustration about unmet needs. We hypothesize that even though the freedom of choice does not change, people perceive a lower feeling of autonomy when presented with an opt-out system and have higher levels of frustration about unmet needs.

\section{Effective decision-making}

In the end, it is questionable to what extent people are able to make an effective decision when presented with a default. According to O'Connor, effective decision-making is defined as the extent to which a person agrees that their decision was informed, consistent with personal values, acted upon and to which extent that person is satisfied with that decision(176). Difficulties in decision-making are found more often when people feel uninformed about options, feel pressured to select a certain option, or when they are not ready or skilled for decision-making(182).

While these feelings apply to decision-making (about organ donation) in general, these could be even more relevant and affected when there is an opt-out default. This could partly be due to the fact that people tend to reject a default when it regards a decision with a high degree of moral sensitivity(183). People generally feel that active choosing is better when the outcome of a default could be morally troubling (to them). The effectiveness of decision-making could therefore be lower in an opt-out system compared to an opt-in system, which would be an undesirable side effect. However, this could as well be the other way around, as the default option in an opt-in system (meaning you will not be registered, which in turn often means that your organs will not be transplanted) could also be morally troubling, as patients could die. The second aim of this study, therefore, is to gain insight into the effectiveness of decision-making under different defaults. It is expected that people's decision-making is less effective when being presented with an opt-out system. 
A third - more explorative - aim concerns the possible association between satisfaction and frustration of the need for autonomy and effective decision-making. As the basic psychological needs of the Self-Determination Theory (of which autonomy is one) facilitate the natural tendency of people to internalize values and regulations of their social groups(184), satisfaction of these needs could possibly increase effective decision-making. As very little is known about satisfied needs and decision-making in general, this will be done in a more explorative fashion. We would expect that a lower autonomy satisfaction and higher levels of frustration about unmet needs, is associated with lower levels of effective decision-making regarding organ donation.

\section{New Dutch organ donation law}

Differences between opt-in and opt-out systems regarding organ donation have been studied before. In the Netherlands, where the current study is carried out, a new kind of system will be introduced in July 2020; the so-called no-objection system. Within the no-objection system, every unregistered citizen in the Netherlands will receive a letter asking them to make a decision about organ donation. They could choose to become an organ donor, to become a non-donor or to leave the decision to next of kin (same options as the current opt-in system). When they fail to respond, they receive a reminder six weeks later. When still no decision is made, they will automatically be registered in the donor registry with a no-objection registration.

In case someone with this no-objection registration dies, the medical professional will tell the family that this person has not registered an objection against organ donation (which is different from being registered as a donor) and will then ask them for consent to transplant the organs. The family members always have the final say in this. This is not very different from the current opt-in policy, in which family members are also asked for consent when no donor record in available.

While the new no-objection system is seen as a form of a (soft) opt-out system, it has many similarities to an opt-in system as well (e.g., family members are asked for consent 
when no active decision was made). In other words, it is a compromise between an optin and an opt-out system. By implementing this system, policy makers hope to increase the donor rates, while preserving people's freedom of choice. Little is known about the decisions that people might make under the conditions of this system and if these are different from a hard opt-out system and the currently used opt-in system. A fourth aim is therefore to explore what choices people make under these different systems.

As the no-objection system is a new system, we can also predict what the effects of this will be on how people make a decision about organ donation. After years of political discussion, the general public is also not unanimously positive about the law change. Within one day after the acceptance of this new law in the Dutch parliament in 2018, 30,000 people decided to register as a non-donor and over 6,000 people changed their current registration into a hard "no" (51). This could be due to many people rejecting the idea of something being presumed in general, especially when it comes to such a sensitive topic. So, while policy makers see the no-objection system as a compromise, this might not be the perception of Dutch citizens. Next to comparing a traditional optin and opt-out system in terms of feelings of autonomy satisfaction and frustration and effective decision-making, it would therefore be interesting to also compare these systems to the new Dutch system as well. It is said that people's autonomy will be preserved in this new system, but it is unknown how this holds up against a traditional optin or opt-out system. Is this really an optimum balance between the opt-in and opt-out system? Or does it lead to more frustration and confusion in the end?

Finally, it is important to realize that in the context of organ donation, defaults are implied without actually being visible to the public. When they fill out a registration form, whether this is on paper or online, there is not an actual ticked box present. There are examples of studies about organ donation defaults, in which a ticked box is used to represent the default(185). The impact of the physical presence of this ticked box compared to only explaining what the default option is, is unknown. Therefore, different systems will be included in this study both with and without a preselected box. In other words, with and without visualizing the default within that system. 


\section{MATERIALS AND METHODS}

A between-subjects experimental design, in which participants were presented with a description of either an opt-in system, an opt-out system or a no-objection system, with either the default option visually being ticked or not. So, in total there were six conditions, varying in two factors (3x2; system $x$ preselection). The study was preregistered on Open Science Framework (OSF) (https://osf.io/mnqxc) on February 17, 2020.

\section{Participants}

A representative sample of the Dutch population above the age of 18 was recruited to participate in the study. The sample included people from different regions, sexes, age categories and educational levels. They were recruited through the Flycatcher panel. Flycatcher is a consumer panel, which started in 2000 as a spin-off of Maastricht University. This panel complies with strict quality requirements for research and submits itself to audits by an independent auditing committee. These requirements were laid down in the ISO 20252 standard for market research and opinion polls and ISO 26362 for research panels. As information and data constitute the core of their business, they have also obtained ISO 27001 certification, the internationally recognized standard for information security. Flycatcher makes use of a reward system, in which participants receive points when filling out a questionnaire, which they can later use to get a voucher or donate the money to charity. As the questionnaire is short, they will receive a small number of points.

A sample size calculation was done using G*Power 3.1(185). A total of 1290 participants was required, based on a small effect size (Cohen's f: 0.1), a power of .8 and an alpha of .05. As participants were randomly assigned to one of six conditions, each condition should consist of approximately 215 participants.

\section{Ethics approval}

This study was approved by the ethics committee of the Faculty of Health, Medicine and Life Sciences on February 14, 2020 (reference number: FHML-REC/2020/013). 


\section{Procedure}

People voluntarily register as panel members and sign a generic informed consent when they register. They get invited to participate in research over e-mail on a regular basis. They get an e-mail when new questionnaires are available for them. They always have the choice whether they would like to participate or not. The participants in the current study also received an email. They were randomly assigned to a condition when they agreed to participate. When the total number of participants was achieved, the questionnaire was closed and could not be completed anymore by panel members.

Participants were first asked to read a short, neutral description of one of the three registration systems. A timer prohibited participants to continue to the questions for 15 seconds, to give them time to read the text. Participants were then asked to make a decision about their organs under this system (I do nothing/l actively register as a donor/I actively register as a non-donor). This was a hypothetical decision, not an actual registration - a so-called vignette study. The default option in every system was 'not making a decision', however, with different consequences depending on the system. In three conditions, the box of the default option was already ticked to visualize the default explicitly (see Figure 1). Participants always had the freedom to make any choice they wanted. After, they answered questions related to their feelings of ASF and EDM. Demographic information was obtained from their accounts, which they are asked to update yearly.

Data collection took place in the first week of March 2020, four months before the actual implementation of the law change in the Netherlands. During this week a reminder was sent to participants who did not respond yet. We received the data with regard to the measured variables specified below as well as demographic information of the people who participated. The data we received is non-traceable. The data file and syntax can be found on https://osf.io/kt76z/. These efforts are taken to maximize scrutiny, foster accurate replication, and facilitate future data syntheses (e.g., metaanalyses)(132). 


\begin{tabular}{|c|c|}
\hline $\begin{array}{l}\text { No-objection system with default option } \\
\text { preselected }\end{array}$ & $\begin{array}{l}\text { No-objection system without default op- } \\
\text { tion preselected }\end{array}$ \\
\hline $\begin{array}{l}\text { What would be your choice when a } \\
\text { 'no-objection' system would be used? }\end{array}$ & $\begin{array}{l}\text { What would be your choice when a } \\
\text { 'no-objection' system would be used? }\end{array}$ \\
\hline $\begin{array}{l}\text { You only make this choice for this ques- } \\
\text { tionnaire; it will not be recorded as an } \\
\text { actual registration! }\end{array}$ & $\begin{array}{l}\text { You only make this choice for this ques- } \\
\text { tionnaire; it will not be recorded as an ac- } \\
\text { tual registration! }\end{array}$ \\
\hline $\begin{array}{l}\vee \quad \text { I do nothing and will be recorded } \\
\text { in the donor register with a } \\
\text { 'no-objection' registration }\end{array}$ & $\begin{array}{l}\square \quad \text { I do nothing and will be recorded } \\
\text { in the donor register with a } \\
\text { 'no-objection' registration }\end{array}$ \\
\hline$\square \quad$ I actively register as a donor & $\square \quad$ I actively register as a donor \\
\hline$\square \quad$ I actively register as a non-donor & $\square \quad$ I actively register as a non-donor \\
\hline Please tick the box of your choice & Please tick the box of your choice \\
\hline
\end{tabular}

Figure 1. Example of the no-objection system with and without the preselected default option

\section{Measurements}

The online questionnaire assessed people's registration decision, autonomy satisfaction and frustration (ASF) and effective decision-making (EDM). The questionnaire was pilot tested ( $n=22)$ among employees of Maastricht University after which slight changes were made in the formulation of the introduction text and questions. Demographic information was obtained from participants' accounts, which is updated yearly.

Demographics: Sex (male/female), age (in categories), and level of education (low/ medium/high) were included as demographic variables.

Registration decision: Hypothetical decision based on the registration system they were randomly assigned to (I do nothing/I actively register as a donor/I actively register as a non-donor). So, regardless of the registration system, people always had the option to actively register a yes or no next to the default option of that system.

ASF: ASF are part of the Basic Psychological Need Satisfaction and Frustration Scale (BPNSNF). This scale includes not only the degree to which needs are satisfied, but also 
the degree of need frustration. The latter is included as the absence of needs does not necessarily imply frustration. The most applicable BPNSNF scale for this particular study was the vignette/situation version, as the participants were being presented with one of three organ donation registration systems. The Dutch version of this scale was used. The short version of this scale was chosen for this study, which consists of 4 questions instead of 8 (two on autonomy satisfaction and two on frustration)(187). The autonomy frustration items were reversed, after which a mean score of ASF was computed $(\omega=.83)$.

EDM: EDM is one of the three subscales of the Decisional Conflict Scale (DCS)(176). EDM concerns questions related to the feeling that the choice is informed, valuesbased, likely to be implemented and expressing satisfaction with the choice. This subscale includes 4 statements to be answered on a 5-point-likert scale. These statements were translated to Dutch. A mean score of EDM was computed $(\omega=.91)$.

\section{Statistical analyses}

Data were analyzed using SPSS version 25. Descriptive analyses were done for all variables. As skipping questions was not allowed in the online questionnaire, there were no missing values. Two-way analyses of variance (ANOVA) were performed, to test for the main effects of registration system (opt-in versus opt-out versus no-objection) and preselection (yes versus no), and their interaction, on ASF and EDM. Both the interaction and the main effect of preselection were not statistically significant ( $p$-value > .05) for both ASF and EDM (see Results for more details). Post hoc Tukey HSD tests were used to specify between which registration systems the differences occurred. In order to identify whether an association exists between ASF and EDM, a bivariate analysis (i.e. correlation coefficient) was used. Additional analyses were done to gain insight in the choices people made under the different registration systems, to be able to make a prediction of the effects of the Dutch law change in terms of registration behavior. Descriptive analyses were used to explore these differences. Next, these descriptive statistics were stratified by educational level, to gain insight in differences in the choices people make with different educational levels, as differences in (understanding) registration systems could result in different choices. 


\section{RESULTS}

The sample in this study included 1312 participants, randomized over 6 conditions (ranging from 216 to 222 participants per condition). Fifty percent was male, and the mean age was 49.8 (SD=17.2). A representative distribution was found in terms of educational level. See Table 1 for detailed information.

Table 1. Descriptive information study sample

\begin{tabular}{ll}
\hline Total sample & $\mathrm{N}=1312$ \\
Sex (male) & $50.0 \%$ \\
Age & $49.8 \pm 17.2$ \\
$18-24$ & $9.0 \%$ \\
$25-29$ & $8.0 \%$ \\
$30-34$ & $7.5 \%$ \\
$35-39$ & $7.4 \%$ \\
$40-44$ & $7.2 \%$ \\
$45-49$ & $8.2 \%$ \\
$50-54$ & $9.0 \%$ \\
$55-59$ & $9.8 \%$ \\
$60-64$ & $9.5 \%$ \\
$65+$ & $24.5 \%$ \\
Level of education & \\
Low & $26.5 \%$ \\
Medium & $42.9 \%$ \\
High & $30.6 \%$ \\
\hline
\end{tabular}

Data presented as mean \pm SD for continuous variables and percentages for categorical variables

Table 2 shows the mean scores on ASF and EDM per condition. No significant interactions were found between registration system and preselection for ASF $(F=1.90$, $\mathrm{p}=.15)$. Also, the effect of preselection was not significant $(F=0.57, p=.45)$, indicating that the presence of a ticked box does not affect people's ASF. The two-way ANOVA did reveal significant differences in ASF for different registration systems ( $F=18.11, p<.001)$. A Tukey HSD test showed that an opt-in system is associated with a higher ASF score compared to an opt-out system or a no-objection system ( $p<.001)$ but the opt-out system and no-objection system did not differ significantly ( $p=.52)$ (Figure 2).

For EDM, the interaction between registration system and preselection was also not significant $(F=0.06, p=.95)$. There were also no significant differences in EDM for the 
different registration systems $(\mathrm{F}=0.42, \mathrm{p}=.66)$ or preselection $(\mathrm{F}=1.70, \mathrm{p}=.19)$ (Figure 3). This suggests that different registration systems and the presence of the ticked box both do not influence people's EDM.

A medium-sized correlation was found between ASF and EDM $(r=.34 ; 95 \% \mathrm{Cl}=[0.29$ 0.39]).

Table 2. Mean scores on ASF and EDM per condition

\begin{tabular}{|c|c|c|c|c|c|}
\hline Total & $\begin{array}{l}\text { Opt-in } \\
\text { (preset) }\end{array}$ & Opt-in & $\begin{array}{l}\text { Opt-out } \\
\text { (preset) }\end{array}$ & Opt-out & $\begin{array}{l}\text { No-objection } \\
\text { (preset) }\end{array}$ \\
\hline
\end{tabular}

$\begin{array}{lllllll}N & 1312 & 216 & 217 & 219 & 222 & 217 \\ \text { ASF } & 3.60 \pm 1.00 & 3.84 \pm 0.85 & 3.81 \pm 0.88 & 3.35 \pm 1.09 & 3.54 \pm 1.03 & 3.54 \pm 1.07 \\ \text { EDM } & 4.18 \pm 0.82 & 4.17 \pm 0.89 & 4.14 \pm 0.82 & 4.22 \pm 0.85 & 4.16 \pm 0.84 & 4.24 \pm 0.75\end{array}$

Data presented as mean \pm standard deviation

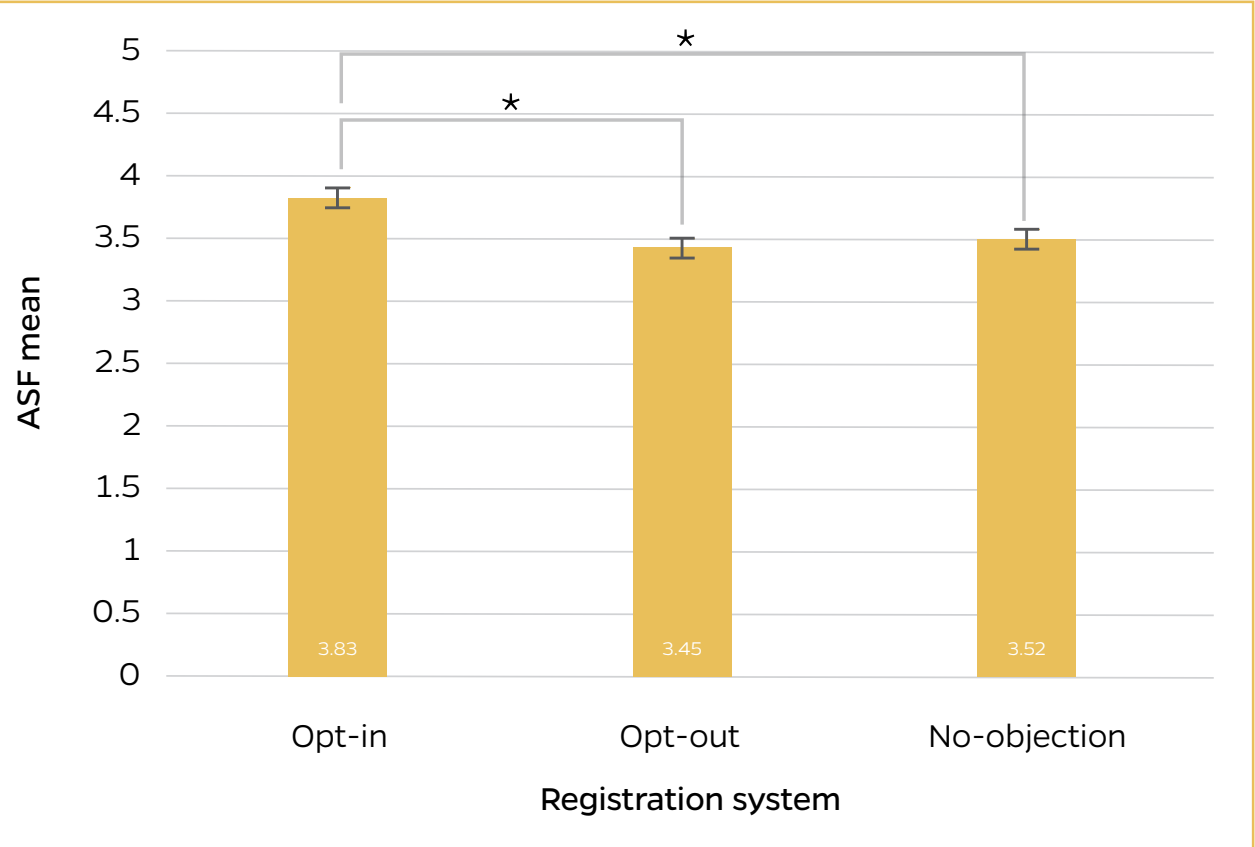

Figure 2. Mean (with 95\% Cl) ASF for different registration systems

Two-way ANOVA, asterisks indicate significant differences between registration systems 
No-objection

Preselection $\mathrm{x}$

Preselection

Registration system registration system

Partial $n^{2} \quad p$

Partial $\eta^{2} \quad p$

Partial $\eta^{2} \quad p$

221

$3.50 \pm 1.00$

.003

.15

.000

.45

0.027

$<.001$

$4.17 \pm 0.79$

.000

.95

.001

.19

.001

.66



Figure 3. Mean (with 95\% Cl) EDM for different registration systems Two-way ANOVA 
When looking at the registration choices people would make under the different registration systems, the potential effect of the enforcement of the no-objection law in the Netherlands becomes visible. Figure 4 shows the descriptive statistics of the choices that were made (including confidence intervals). It appears that people make very similar choices when being presented with an opt-out and a no-objection system (Table 1). Compared to the opt-in system, which is currently used in the Netherlands, the new no-objection system could potentially lead to less active registrations $(70.8 \%$ versus $76.0 \%)$ and active yeses (46.6\% versus 58.7\%). The proportion of people choosing to actively register a 'no' is highest in the no-objection system (24.2\% versus $20.4 \%$ in opt-out and $17.3 \%$ in opt-in) ${ }^{1}$.

Another interesting observation concerns the high percentage of participants who choose to actively register a yes or no under the conditions of the current opt-in system (76\%). This is much higher than the actual registration rate in the Netherlands (42\%) (188), showing the intention-behavior gap between registration intentions/willingness and actual registration behavior.

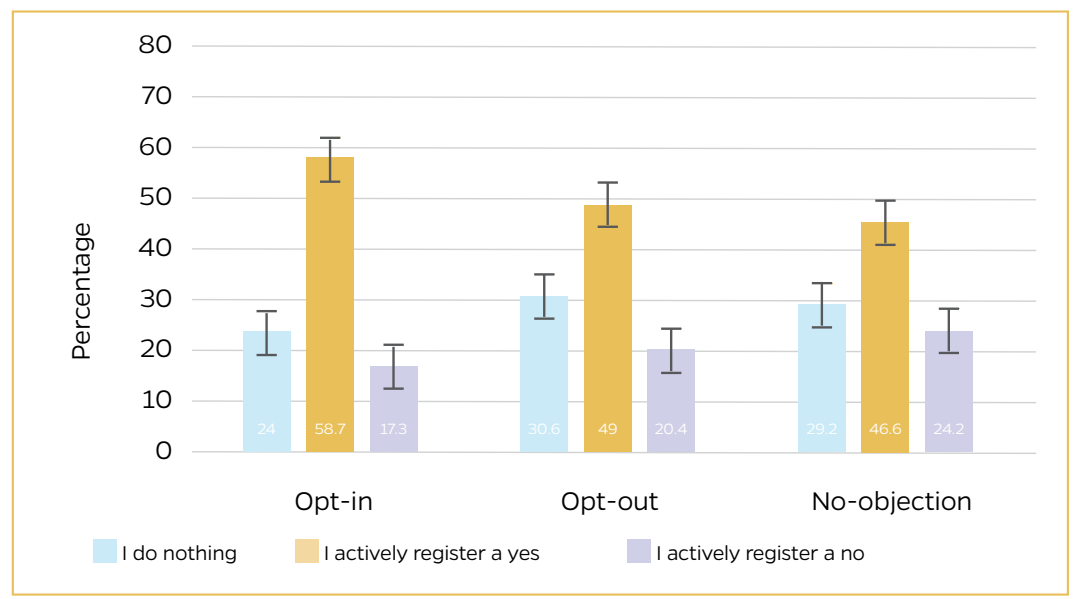

Figure 4. Percentage (with $95 \% \mathrm{Cl}$ ) of registration choices under different registration systems 
Stratifying these percentages by level of education reveals clear differences between these subgroups in terms of the decisions that are made (Table S2, Figure 5). Regardless of the registration systems they were presented with, these groups make different registration choices. Low-educated people (Figure 5; left) in general choose more often for a passive registration (doing nothing) (33.0\% versus $28.4 \%$ in intermediateeducated and $22.9 \%$ in high-educated). People with a high educational level (Figure 5; right) more often choose to actively register a decision (yes or no) compared to lower educational levels $(77.1 \%$ versus $71.6 \%$ in intermediate-educated and $66.9 \%$ in low-educated). The pattern for intermediate-educated people (Figure 5; middle) is quite comparable to the higher-educated group, but they less often choose an active yes (42.2\% in intermediate-educated versus $59.1 \%$ in high-educated).

When looking more closely at the different registration systems, the largest differences between groups are found in the no-objection system. The majority of the low-educated group (Figure 5; left) chooses for a passive registration (doing nothing) (38.1\% versus $36.4 \%$ active yeses and $25.4 \%$ active noes), while in the high-educated group this choice is made least often (19.2\% versus 56.8\% active yeses and $24.0 \%$ active noes). The intermediate-educated group (Figure 5; middle) is in between the low and higheducated group (30.3\% chooses to do nothing).

1 Based on a reviewer suggestion we ran a post-hoc analysis to assess the relationship between making an active choice and ASF and EDM. There was no difference in ASF between those who made an active choice versus those that did not ( $M 1$ vs $M 2, t=x, p=x$ ), but those that made an active choice scored higher on EDM (M1 vs M2, $t=x, p=x$ ). 



Figure 5. Differences in percentage (with 95\% Cl) of registration choices under different registration systems between different educational levels 


\section{DISCUSSION}

The current study aimed to gain insight in how different organ donation registration systems are related to ASF and EDM, whether ASF and EDM are correlated and what choices people make in the end. Further, half of the conditions included a preselected box to research the implicit or explicit presence of a default. Next to a traditional opt-in and opt-out system, the new Dutch no-objection system was included in this study. ASF was found to be higher when people were presented with an opt-in system compared to the other registration systems. The difference was small but significant. In terms of EDM, no significant differences were found. ASF and EDM showed to have a medium-sized correlation.

First of all, the preselected box did not impact any of the outcomes, so the three registration systems were compared regardless the preselection. In a real-life organ donation default, the ticked box will usually not be visible, but the default is always there. As organ donation registration is moving from paper-based registration to digital registration, this opens up possibilities for adding a visible default in the form of a ticked box in the registration procedure. In that respect, it was interesting to find out that the visible ticked box was not significantly associated with both ASF and EDM, suggesting that people do not have different decision-making experiences with an implicit default compared to a visible default.

Many articles discuss the ethical considerations around organ donation systems, of which autonomy is an important one(189-192). There is still a debate whether defaults undermine autonomy or not and whether that is important or not. Few studies researched whether people actually perceive different levels of autonomy under different organ donation systems. The current study showed that the perceived autonomy is in fact higher in an opt-in system, compared to the other systems. However, differences are small. During the debates around the new Dutch registration system, preserving people's autonomy appeared to be an important reason not to implement a hard optout system. The current study shows that people do not perceive different levels of 
autonomy when being presented with a hard opt-out system or the no-objection system, which was supposed to preserve people's autonomy better.

In terms of EDM, no differences were found between the different registration systems, which was not in line with our expectations. The validation of the DCS showed that the perceived EDM is associated with being clear about personal values and feeling informed about options, risks and benefits(176). The absence of an association between the systems and EDM could be explained by the fact that participants did not receive much information and all information was very similar for all systems. Further, the EDM subscale of the DCS is different than the other subscales at it can only be used after a decision has been made, while the others can also be used during the deliberation(176). In the current study, participants had to determine their EDM right after making their decision. In order for EDM to change, people might need more information and more time to process that, to consider the options and to clarify their values.

A medium-sized correlation was found between ASF and EDM. Previous research already showed that people who experienced decisional conflict, reported lower levels of autonomy (and relatedness and competence, i.e. the other basic psychological needs from the Self-Determination Theory) compared to people who did not(193). This is in line with the correlation that was found in the current study. This suggests that a better satisfaction of the basic psychological needs is associated with less decisional conflict, and thus higher EDM. In that respect, one would have expected significant differences in EDM for the different registration systems in this study, as the levels of autonomy also differed for the different registration systems. However, as the association between ASF and EDM is only of moderate strength and the differences in ASF were also small, these might not have been detected. It is however difficult to draw conclusions on this, as the current study only included one subscale of decisional conflict and one of the basic psychological needs. More research will be needed to understand these associations better.

The choices that people made under the systems were very similar for people presented with an opt-out and no-objection system. In the opt-in system, people more often 
chose to actively register in general and also chose more often to register an active 'yes'. The no-objection system showed the most active 'no' registrations. While the differences in ASF and EDM were (very) small for the different systems, there were larger differences in registration behavior. The differences between the no-objection and optout system were small, but the opt-in system seems to lead to different registration behavior. Where the opt-in system yields the most active yeses, the no-objection system leads to more active noes. This could partly be caused by reactance due to autonomy frustration(181). However, the differences in ASF between the different systems are too small to draw conclusions on that.

A previous study suggested that a presumed consent system (opt-out) system and mandated choice system were most effective in increasing the number of registered donors, compared to an explicit consent system (opt-in)(194). When strictly looking at potential donors, the opt-out system also seems most effective in the current study, as about $80 \%$ chose to do nothing (and thus become a donor) or register an active yes under the conditions of this system. With about $76 \%$, the no-objection system is not far behind, but doing nothing (and thus having a no-objection registration) does not necessarily lead to an extra potential donor. In an opt-out system, a passive registration is in principle the same as an active yes, and thus means an extra potential donor. However, in a no-objection system, family members are still consulted, and their wishes are decisive. The impact of these registrations on the number of transplantations is therefore still difficult to predict.

An important question for the Dutch context, is what these results mean for the new donor law. This study suggests that there is a possibility that the proportion of active registrations will decrease and the proportion of noes will increase. It is important that people are aware of the law change and understand that actively registering is important. Especially the registration behavior in the low-educated group suggests that this group does not fully understand this. This is in line with a recent report about the evaluation of the organ donation campaign around the new donor law in vulnerable groups(195). This report showed that the current campaign does not provide this group 
with enough support and that more proactive activities are needed to reach this group better. The current study emphasized the need for better strategies for these groups.

\section{Limitations}

Participants made hypothetical choices in this study about their registration behavior and were asked to imagine what that would do to their autonomy and then report on how effective that decision felt for them. In the comments section at the end of the measurements, some participants also mentioned that it was difficult for them to answer the questions, as they already registered in real-life. One should realize that hypothetical choices do not equal their actual registration behavior or their experiences. After the implementation of the no-objection system, further research is recommended to learn more about people's experiences in a real-life setting. Further, this could answer questions relating to changes in people's decision-making behavior over a longer period of time.

The main difference between the results of study and the real-life situation is the amount of effort that is required from people to register an active decision. In this study, participants were presented with information, had to read that information and had to make a decision right after (as part of this study to which they already agreed to participate). This is different compared to the real-life situation, where people receive a letter from the government and can decide for themselves whether they want to open it, whether they want to read it and whether they want to act on the information. In the end, choosing to actively make a decision and to register this requires some effort. One could even say that this study shows the potential of a mandated choice system, as people did not have the opportunity to skip the question.

Showing intentions in a study and performing the actual behavior in real life are two different things(196). There is quite a large intention-behavior gap in organ donation registration behavior (197). This is also clearly visible when comparing the reported behavior of the opt-in system in this study with the current registration rates $(42 \%$ actively registered in real-life, versus $76 \%$ in this study)(188). After the implementa- 
tion of the no-objection system, it is likely that a similar gap is found in terms of active registrations. The possible effects of the no-objection system on people's registration behavior might therefore be more extreme than the results of this study showed (i.e. even fewer active registrations). This further demonstrates the urgency for educational initiatives around the implementation of the law and also in the future to increase these numbers.

Finally, the generalizability of the results of this study to other countries is difficult. Every country has different legal, religious and cultural contexts and beliefs about organ donation(198), which all call for a different approach in terms of legislation. The results of this study might not immediately apply to other countries, but we can still learn from each other. It is important to share experiences and adapt strategies to the context in each country. Research findings like this can help in understanding when systems are successful and could help in choosing the best fit for each country.

\section{Conclusion}

Could the no-objection system be regarded as the perfect compromise between the opt-in and opt-out system? This study suggests that it could not. For many outcomes, the no-objection system performs similar to the opt-out system (in terms of ASF, EDM and choices that are made). As family members still play an important role in this noobjection system, the impact of these registrations on the number of transplantations is very difficult to predict.

Which system is best, is difficult to conclude and depends on what is considered "best". Where the opt-out system potentially leads to the highest number of donors, the opt-in system seems better in terms of preserving people's autonomy and motivating people to make an active decision. This will continue to be a difficult balance and the context of a country will contribute to the success of a system. It is important to realize that the implementation of any registration system alone will not be enough. Flanking policies are key to support this registration system and contribute to the success. They help to create an environment that is not only effective, but also has the support from the 
society and is executable in real-life. These policies could include educational initiatives for the public, financing structures, organizational changes in the transplantation process or training for medical professionals. 


\section{APPENDIX CHAPTER 7}

Table A1. Registration choices per system

\begin{tabular}{|c|c|c|c|c|c|c|}
\hline \multirow[t]{2}{*}{ Registration system } & \multicolumn{2}{|c|}{ I do nothing } & \multicolumn{2}{|c|}{ I actively register a yes } & \multicolumn{2}{|c|}{ I actively register a no } \\
\hline & $\%$ & $95 \% \mathrm{Cl}$ & $\%$ & $95 \% \mathrm{Cl}$ & $\%$ & $95 \% \mathrm{Cl}$ \\
\hline Opt-in & 24.0 & $19.4-28.9$ & 58.7 & $54.0-63.6$ & 17.3 & $12.7-22.2$ \\
\hline Opt-out & 30.6 & $25.9-35.8$ & 49.0 & $44.2-54.2$ & 20.4 & $15.6-25.6$ \\
\hline No-objection & 29.2 & $24.2-34.3$ & 46.6 & $41.6-51.6$ & 24.2 & $19.2-29.3$ \\
\hline
\end{tabular}

Table A2. Registration choices per system and educational level

\begin{tabular}{|c|c|c|c|c|c|c|c|}
\hline \multirow[t]{2}{*}{ Educational level } & \multirow{2}{*}{$\begin{array}{l}\text { Registration } \\
\text { system }\end{array}$} & \multicolumn{2}{|c|}{ I do nothing } & \multicolumn{2}{|c|}{ I actively register a yes } & \multicolumn{2}{|c|}{ I actively register a no } \\
\hline & & $\%$ & $95 \% \mathrm{Cl}$ & $\%$ & $95 \% \mathrm{Cl}$ & $\%$ & $95 \% \mathrm{Cl}$ \\
\hline \multirow[t]{4}{*}{ Low-educated } & Opt-in & 27.8 & $18.8-37.9$ & 52.8 & $43.5-62.9$ & 19.4 & $10.2-29.5$ \\
\hline & Opt-out & 32.8 & $23.8-42.9$ & 38.5 & $29.5-48.6$ & 28.7 & $19.7-38.8$ \\
\hline & No-objection & 38.1 & $28.8-48.1$ & 36.4 & $27.1-46.5$ & 25.4 & $16.1-35.4$ \\
\hline & Total & 33.0 & 27.6-39.0 & 42.2 & $36.8-49.2$ & 24.7 & $19.3-30.7$ \\
\hline Intermediate- & Opt-in & 24.9 & $18.0-32.5$ & 56.1 & $49.2-63.7$ & 19.0 & $12.2-26.7$ \\
\hline \multirow[t]{3}{*}{ educated } & Opt-out & 30.2 & $22.9-38.1$ & 52.5 & $45.3-60.4$ & 17.3 & $10.1-25.2$ \\
\hline & No-objection & 30.3 & 23.1-38.0 & 46.2 & 39.0-53.9 & 23.6 & $16.4-31.4$ \\
\hline & Total & 28.4 & $24.2-32.9$ & 51.5 & $47.2-56.0$ & 20.1 & $15.8-24.6$ \\
\hline \multirow[t]{4}{*}{ High-educated } & Opt-in & 19.9 & $12.5-28.0$ & 66.9 & $59.6-75.1$ & 13.2 & $5.9-21.4$ \\
\hline & Opt-out & 29.3 & $21.4-38.4$ & 53.6 & $45.7-62.7$ & 17.1 & $9.3-26.3$ \\
\hline & No-objection & 19.2 & $11.2-28.8$ & 56.8 & $48.8-66.4$ & 24.0 & $16.0-33.6$ \\
\hline & Total & 22.9 & $18.2-28.1$ & 59.1 & $54.4-64.2$ & 18.0 & $13.2-23.0$ \\
\hline
\end{tabular}





\section{chapter 8 \\ general discussion}

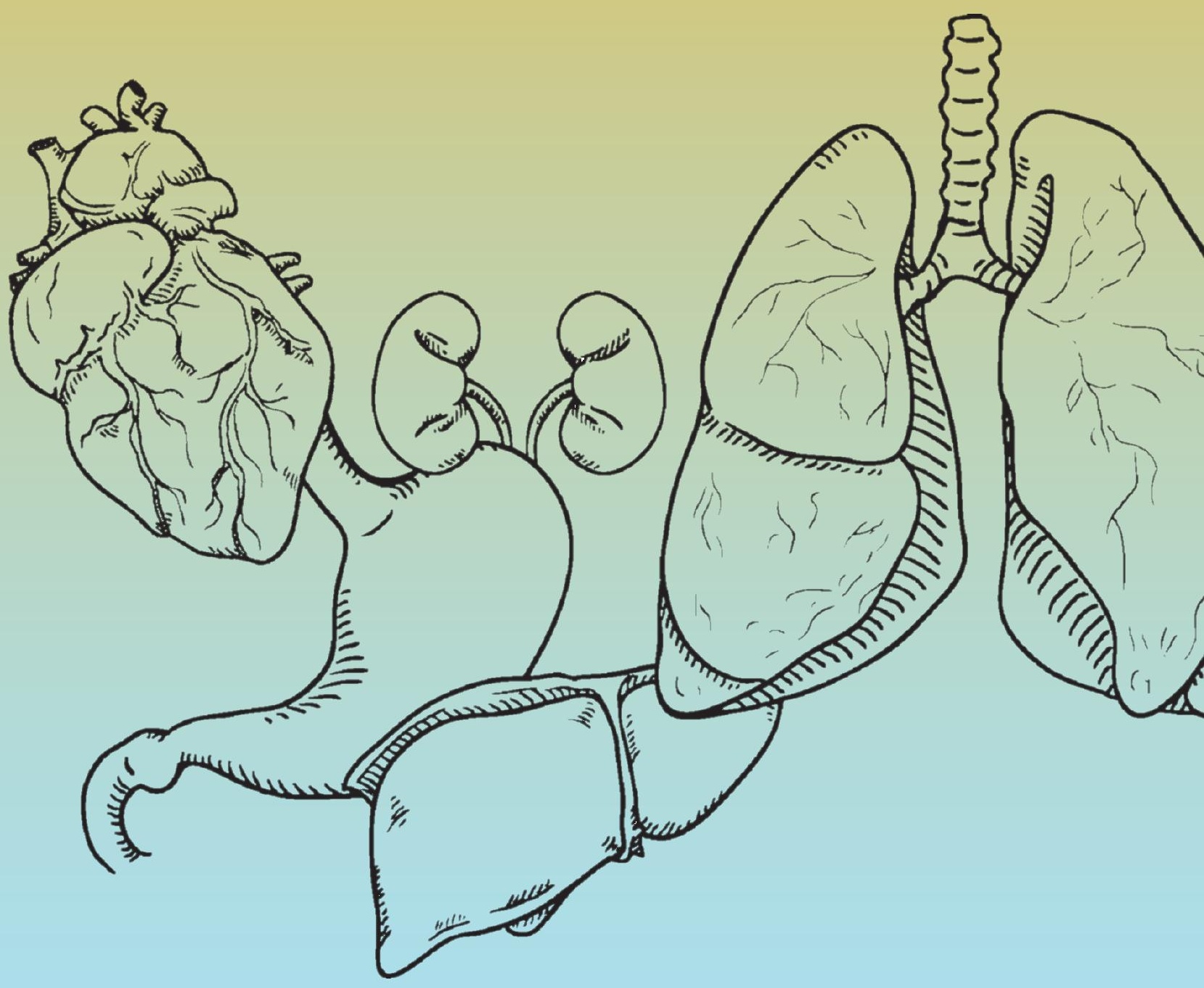


This thesis aims to contribute to a solution for the organ donation registration shortage in the Netherlands. This was done by reaching a group that has been underrepresented in organ donation education activities before: adolescents at lower educational levels. The research needed to reach this aim included the adaptation and implementation of a program in a vocational education setting, which was already proven to be effective in a high school setting. This program aims to inform participants about organ donation, to stimulate discussion among them, to support them in making a decision and to give them the tools to actually being able to register that decision, regardless of what that decision would be. The process of the adaptation, implementation and evaluation of this program is described in part one of this thesis. The main aims of this part are (1) to understand adolescents' motives to (not) register (as an organ donor), (2) to study the effectiveness of the adapted version of the organ donation education program in a lowereducated school setting and (3) to gain insight in how this program was implemented.

However, applied research is never conducted in isolation and is subject to developments in the environment in which it is taking place. In the case of this thesis; the political environment is especially relevant. From the summer of 2020 onwards, registration decisions in the Netherlands will no longer be made under the conditions of an opt-in system. The introduction of a new system was announced (a so-called no-objection system), which triggered new research questions for this thesis during the process of writing it. While the actual effects of this new registration system will only come to show after a few years, it is clear that responsibilities will shift, and decision-making will change. Part two of this thesis focuses on possible implications of this law change. The main aims of this part are to (1) express what the new law could mean for responsibilities around the organ donation decision and (2) to learn where this new law stands compared to a traditional opt-in or opt-out registration system in terms of decision-making.

In this final chapter, the main findings of the research carried out will be summarized. Moreover, it will include a reflection on the choices that were made, a theoretical reflection, a discussion on where this thesis fits in the current public and scientific debate and what its results imply for practice and future research. 


\section{COMPLEXITY OF DETERMINANT RESEARCH}

The starting point of this thesis is a determinant study. Studying determinants of a certain behaviour is needed to understand that behaviour. Knowing which determinants are associated with a behaviour should inform interventions, or even policies. It also gives us directions for the evaluation of an intervention, as a change in determinants could give an estimation of the potential impact on a change in behaviour in the future. Studying determinants of a behaviour can therefore be a very useful and important step in designing, implementing and evaluating an intervention. However, many challenges remain how to actually use data from determinant studies in a meaningful way.

The determinant study in Chapter 2 was used to understand what beliefs adolescents in vocational education have regarding organ donation (registration) and how these are associated with their registration intentions. This information is interesting in itself and also provided us with information on how to adapt the web-based organ donation intervention to the new target group. When a belief is strongly correlated with registration outcomes and has a mean which is far from the desired value, this can be an important determinant to intervene on in an intervention.

The study was conducted among 405 students attending Intermediate Vocational Education (IVE). Most beliefs were significantly associated with one or more registration outcomes and small to medium correlations were found. Also, most beliefs had a mean score around the middle of the scale. Other than that, the results were quite difficult to summarize and interpret. No beliefs really stood out and no clear patterns could be identified. It was expected to find a set of beliefs that was associated with positive registration intentions and to find a different set of beliefs associated with the intention to register as an organ donor, but this was not the case.

Registering and registering as a donor are two different behaviours. The distinction between these behaviours is very important in this project, as the aim is to support people in making and registering a decision, without pushing them towards registration 
as a donor. The results of the determinant study suggest that this differentiation might not be clear for the public. Beliefs about being an organ donor were also associated with registration behaviour in general (not necessarily as a donor); e.g. If I am an organ donor, I can find a sense of positive closure), indicating that these two behaviours intermingle in people's heads.

These results underline the complexity of organ donation registration behaviour. When comparing this behaviour to smoking or eating behaviour, organ donation registration might seem simple: it is - usually - just a one-time behaviour, requires relatively little effort and has limited options. However, when looking under the surface, it is not as easy as the behaviour would suggest. Many beliefs are associated with people's registration behaviour and none of them seems to be conclusive on its own at a group level. A complex structure of these beliefs seems to determine this behaviour. It is possible that a smaller set of beliefs could be identified that predicts their registration behaviour (intentions) at an individual level. Van Harreveld and colleagues found that a small set of salient beliefs could be very predictive of someone's behaviour(91). This might also be true when it comes to organ donation registration behaviour, but that could not be concluded from our determinant study. While this study is informative and is one of the few studies to measure this quantitatively, it also shows how little we actually know about registration behaviour.

The determinant study in this thesis emphasized the complexity of organ donation decision-making. However, the complexity is not only limited to the outcomes, but is also found in the measurements, analyses, interpretations and applications. These will all be discussed in the next paragraphs. It will include a reflection on what was done and recommendations for future research.

\section{Measurement of determinants}

While many studies assessed determinants of organ donation registration behaviour in a qualitative way, we decided to measure it in a quantitative way. In behavioural science, qualitative studies are often more focused on the individual and are more exploratory 
in nature, while quantitative research is then used to draw generalizable conclusions and is more confirmatory(198). Further, quantitative research allows you to identify differences between groups (e.g. between people who are registered and people who are not)(199). Quantitative research, in this case in the form of a survey, seemed to fit the purposes of our research better. However, several issues can be raised with this kind of research, especially in specific target groups and for specific behaviours.

\section{Target group}

First, we should ask ourselves whether the way of measuring determinants was fitting for our target group. We ended up with a selection of 25 determinants and several demographic questions for the participants to fill out. Reading all these questions, staying concentrated and answering them could be challenging for any participant. However, as our group consisted of people with lower educational levels and also relatively high prevalence of low literacy, one could wonder whether they were able to do this properly. Reading abilities of students in IVE is generally low. Most problems occur in terms of understanding written materials(200). Also, these students tend to overestimate their abilities, causing them to think they already understand a text, when that is actually not the case. Next to their low reading abilities, IVE students (especially in the lower levels of IVE) often struggle with discipline and attention problems. Therefore, there is a risk of them not being able to work themselves through all those questions, which could have affected the answers they gave and therefore the results as well. This could both have been caused by the length of the questionnaire, but also by phrasing the questions that were included.

A challenge with surveys in general, is ensuring that questions are easy to interpret and to answer. Questions that might seem perfectly clear for us as researchers, can easily be misinterpreted by the target group. There are many ways misinterpretations can occur, including difficult words derived from theory or a bad translation of a questionnaire in another language. Misinterpretations of questions could directly influence the validity of your measurement $(201,202)$. Making small changes to the questionnaire (design and format) or the questions themselves can make substantial differences in 
the answers provided by the participants(201). The process of designing a questionnaire should therefore receive the attention it deserves, as problems can be avoided later on.

In the case of the determinant study in Chapter 2, the questionnaire was designed with the target group in mind. Beliefs were carefully selected for the questionnaire, to limit the total length of the questionnaire. Also, the formulation of the questions was done with care and these were pilot tested in the target group. Further, short and clear instructions were provided both on paper and orally. Finally, the lay-out of the questionnaire was adjusted to ensure higher accessibility. However, all these precautions aside, this does not guarantee that all participants were able to read, understand and answer the questions as intended. We were still dealing with a lower literate group, which means that questionnaires in itself can already be challenging. There is no clear-cut answer on how to approach this group and how to best perform measurements on this group, but some suggestions will be given in subsection low (health) literacy.

\section{Behaviour}

A second consideration regarding the measurement of determinants relates to the behaviour that was studied. Organ donation can be regarded as a sensitive topic. A topic is considered as sensitive when the questions themselves are seen as intrusive (taboo topics), when participants are concerned about the threat of disclosure (confidentiality) or when they are concerned that their answers might be socially undesirable (social norms)(203). Organ donation registration behaviour could fall in this last category, as it is socially desirable to care about the people around you. Not being interested in being an organ donor could be perceived as being insensitive or selfish. While organ donation registration in general might not necessarily be regarded as sensitive, donation specific beliefs are often also found to be associated with organ donation registration in general (Chapter 2).

Sensitive topics can lead to large measurement errors. Asking sensitive questions could affect the outcomes of your research in three important ways(203): 1. Overall response rates, 2. Item response rates and 3. Response accuracy. As our research was conducted 
in a classroom setting, the response rate was not affected by the topic of the questionnaire. The item response rate also did not seem to be an issue in our research, as a low number of missing values was found. However, the response accuracy could be threatened by the sensitive nature of this research.

There were several ways in which we reduced the effects of asking sensitive questions. One of these relates to the mode of administration. People seem to be more willing to share sensitive information when questions are self-administered compared to administration by an interviewer $(204,205)$. Another influence on misreporting could be the presence of other people and the setting in which the data were collected(203). In our case, the questionnaires were administered in a classroom setting, in the presence of other students, their teacher and a researcher. However, the mere presence of others does not necessarily lead to measurement errors. As others were not aware of the answers that were given (which is different from, for instance, an interview), the effects on misreporting are probably limited. Further, a classroom setting is usually a better place for data collection compared to a home setting, as parents are not present. Finally, assuring students that their answers are confidential has a positive impact on their accuracy of reporting(206). In this study, this was emphasized both orally and on paper.

\section{Determinants}

A final remark about the measurement relates to the determinants that were included. A problem-driven approach was used instead of a theory-driven approach. Where a theory-driven approach is aimed at testing a theory in a certain setting, a problemdriven approach is aimed at solving a problem. A good step in that approach is to review empirical findings(207). An extensive literature review was therefore used as the basis of our questionnaire. Theoretical constructs were also represented in the topics and items (e.g. attitude), but not necessarily structured that way.

Organ donation is also a topic which is very different from any other health promotion topics (e.g. one-time behaviour, not beneficial for one's own health). Traditional sociocognitive models (e.g. Theory of Planned Behaviour, Health Belief Model) might there- 
fore not fit this behaviour properly. Limiting ourselves to the boundaries of these models, probably would have resulted in a poor overview of possible beliefs. The literature review that was done does not guarantee a complete overview either (no approach does) but did result in a very broad range of topics and items.

Further, organ donation beliefs vary greatly between countries and even between subgroups within countries. This has to do with different cultures and religions, for example, but also with different registration systems that are used. The Dutch registration system is unique in the fact that registration is possible without becoming a donor. In other countries, this distinction is not made. Research that has been performed in those countries is therefore usually focused on beliefs related to signing a donor card, while we are interested in registration behaviour in general (regardless of the decision made). Beliefs that are related to signing a donor card, are not necessarily also related to registration behaviour (or intentions) in the Dutch setting. Altruism is an example of a construct that has often been associated with organ donation registration behaviour(208, 209). Altruism refers to a willingness to act in consideration of the interests of other persons, without the need of ulterior motives(210). While this is an important construct in many other studies, the traditional usage (becoming a donor for "the greater good") does not really apply to the registration of any decision in the Netherlands. In this case, people would register to ease the burden on relatives when dying.

By measuring these determinants with a questionnaire, we chose quite a traditional approach in which explicit cognitions were measured. With this approach, we measured beliefs that people are aware of and are able to express. However, according to the implicit approach, behaviour is not solely determined by explicit cognitions, but also by implicit processes. These processes are fast, activated automatically and can occur without someone's conscious awareness(211). Human behaviour is thought to be a combination of conscious and unconscious regulations(212) and therefore, combining an explicit and implicit approach in understanding a behaviour could be very useful. Both types of cognitions could directly influence behaviour separately, but could also interact and thus reinforce or weaken each other(213). 
Where explicit cognitions are often measured by self-administered questionnaires, implicit cognitions can be measured with computerized reaction time tasks, such as the Implicit Association Test (IAT) (214) or the Single-Category Implicit Association Test (SCIAT)(215). With the IAT, associations are investigated between two pairs of binary categories (e.g. black/white and positive/negative). Participants are asked to categorize pictures and words into the categories on the side of the screen by using response keys (e.g. the $\mathrm{F}$ and $\mathrm{J}$ ). The reaction time is measured, which gives an indication of the strength of an association.

In an SC-IAT, the strength of an association is measured with a single category (e.g. Coca Cola). First, positive words (e.g. good) and attitude object words/pictures (e.g. picture of a bottle of Coca Cola) are categorized under one response key, while negative words are categorized under another key. Second, this is one the other way around. Reaction times can be compared here as well. In the field of organ donation, the SC-IAT is seen as the preferred method, as there is no obvious comparator to "organ donation". Attitude object pictures could in this case be pictures of organ donation (e.g. donor card, promotional material), combined with positive (e.g. honourable or appealing) and negative (e.g. selfish or disgusting) words(216).

While implicit attitudes seem to play a role in organ donation behaviour, these are not predictive of someone's donor status or intention on its own. It is clear that there is an association between both implicit and explicit cognitions and organ donation related behaviours, but results are quite inconclusive $(216,217)$. There seems to be a complex interplay between implicit and explicit attitudes, in which the direction and strength of these attitudes also play a role. Hübner and colleagues, for instance, suggested that when attitude strength in general is weak, increasing positive implicit associations could increase the probability of someone signing a donor card(217). In the abovementioned studies the focus is on signing a donor card, while we are interested in learning more about registration behaviour in general. This is possibly even harder to study, as the single category "organ donation registration" could be a more difficult or less clear 
concept to people. Finding pictures that clearly portray "organ donation registration" can be challenging, as people might associate this immediately with being a donor.

\section{Conclusion}

In conclusion, the measurement of determinants, especially when it comes to organ donation registration behaviours, can be challenging. There are however ways to optimize this in the future. First, one should always be aware of the target group and behaviour when choosing a measurement tool. Even when a tool is chosen, small adaptations to a questionnaire or a setting can have substantial impact on the results. And second, when the tools are available, integrating explicit and implicit cognitions, as well as their direction and strength, would help to get a fuller understanding of behaviour. When we become better at predicting behaviours, strategies to promote registration behaviour will also improve.

\section{Analysis of determinants}

In the determinant study in Chapter 2, correlations were used to find associations between the beliefs and registration behaviours. These correlations were then combined with mean scores on those beliefs for the interpretation. The correlations and means did give insights in which beliefs were more important than others but did not give the guidance for adapting the intervention that was hoped for when this project started.

Initially, it was planned to cluster the beliefs (per determinant) to end up with results that were easier to interpret and therefore easier to apply. Clustering helps to organize the beliefs into groups, in which the similarity of beliefs within groups is greater than the similarity of these beliefs with those in another cluster. These analyses are often based on the assumption that a measure consists of subscales, which in turn consist of several items each(218). Clustering the items can then determine whether the hypothesized structure of a construct can actually be confirmed(219).

This process becomes more difficult when items are not part of predefined subscales, i.e. not based on a theory. This was also the case in the determinant study that was 
performed as part of this thesis. After several attempts, these clusters could not be identified, or if they could, the clusters were not informative or easily interpretable. This is not surprising, as the questions in the questionnaire were not based on theory, but based on existing literature regarding specific beliefs - not necessarily in line with predefined theoretical constructs. There thus were no predefined subscales that could be used as a basis for the clustering.

Possibilities for analysis of determinants are not limited to the traditional ones that we often perform in the field of health promotion. Looking beyond our own field taught us new analysis methods that could provide new insights in the data. Mkhitaryan and colleagues analysed the same database by using a network approach to show how this type of analysis could also be applied to health behaviours, while it traditionally has been used to study psychological variables(220). In short, in this type of analysis, descriptive and statistical comparisons of networks are done, between groups with the presence or absence of an outcome (in this case; people with the intention to register and people without the intention to register). This could provide insight into predictors of that outcome and could therefore also inform future interventions. This is very similar to the aim of traditional analyses, but the process to get to that point is different.

With network analysis, interrelationships between items can be examined, as well as the direction and the strength of these relationships. Different centrality measures can be calculated with each node in the network; strength, closeness and betweenness centrality (explained below). This approach showed that the belief that helping other people makes you happy, has the highest centrality strength in the network. This means that this belief is strongly and directly connected to many other nodes in the network. A feeling of uneasiness about one's organs being inside someone else's body, has the highest closeness and betweenness centrality scores. This indicates that having an uneasy feeling is close to many other nodes in the network, both directly and indirectly, and that this node often lies on the shortest path between other nodes. 
Next, there are also opportunities to calculate which determinants have the shortest path to the outcome. Someone's belief that he or she still has enough time to register, has the shortest path to having the intention to register (negative correlation). This suggests that this variable has the strongest association with registration intentions, which differs from the results from the traditional correlational analyses. Further, similar to traditional analyses, network analyses have the opportunity to identify clusters of determinants. This could help in examining whether beliefs from the same theoretical domain also group together in the network. Interpreting and labelling these cluster remained a challenge as the questionnaire of the determinant study was not based on predefined clusters. In this case, the clusters did not necessarily add to the understanding of the behaviour.

Network analyses are still very new in the field of health behaviour. Applying the results of these analyses to the development of interventions is not researched properly yet. However, network analyses can provide more detailed information from the data and sometimes also yield different results. It would therefore be worthwhile to keep looking beyond the traditional analyses and be open to innovation from other fields of research.

\section{Application of determinant research}

After the measurement and analysis, the application of the results is an important step in intervention development(69). In the context of intervention development, the application of the results concerns the selection of determinants to address. The results provide insight into which determinants are most relevant for a certain behaviour and should thus be addressed in the intervention. One could choose to address all determinants that are (possibly) associated with that behaviour, but resources are always limited and therefore decisions have to be made in terms of which determinants are most important. An important example is that one cannot expose the participants to too much intervention content(221). This is especially the case when looking at a target group with lower reading abilities and sometimes a shorter attention span. Also, limiting the length of the program makes it more likely that the entire program will be implemented. 
One way of selecting determinants, includes an examination of the mean score of a certain belief (how far is this from the desired value?), combined with the association with the outcome (how strongly is this correlated with registration intentions?). When both the mean score is far from the desired value and there is a strong correlation with registration intentions, it could be valuable to select this belief for the intervention. This process is quite clear, but the application can be difficult in practice.

First, the cut-off points for selection are very arbitrary. The researcher decides what "far" or "strong" means. These are not even necessarily absolute cut-off points, but more relative to the other determinants that are included in the analysis. In the determinant study from Chapter 2, scores were in general around the middle of the scale and correlations were not that high. This makes the translation from the study to the adaptation of this intervention more difficult. Hardly any beliefs stood out in terms of mean score or correlation strength, so it is hard to make a good selection. That way, one still ends up with a large number of possibly important beliefs, but limited capacity for addressing these in the intervention.

Second, the amount of information that needs to be processed and compared is very challenging. Both the means and correlations of 25 beliefs need to be assessed simultaneously to make the best judgment for the selection of the determinants. This makes it difficult to get a clear overview. An innovative method to process all these estimates simultaneously is the Confidence Interval-Based Estimation of Relevance (CIBER) approach(93). This approach is based on the visualization of data. All estimates are combined in one figure in which different shapes and colours help the researcher to interpret the data. The cut-off points of course remain arbitrary, but making a good selection is easier and the relative importance of all determinants becomes much clearer. Unfortunately, this approach was not yet available for dichotomous outcomes at the time of analysis, as it was only based on linear correlations between variables. The possibilities are now extended and the function for dichotomous outcomes can now also be found online(222). 
The selection of determinants is thus a challenging but important step. The role of the researcher will remain important as the estimates will only provide guidance in the right direction and will not determine the final selection. However, new and innovative approaches are developing that could make this process clearer.

\section{Future recommendations}

In conclusion, many challenges remain when it comes to doing determinant research, from the measurement, to the analysis and the selection. In all these phases, choices can be made that could have potentially large impact on the results and therefore also on intervention development. Our understanding of behaviour could be enriched by an open attitude towards innovations, also from other disciplines. New approaches to the measurement, analysis and selection of determinants could provide more clarity in the complexity of determinants underlying behaviours but could also yield different or more elaborate results. Interdisciplinary cooperation, in which strengths from different approaches can be combined, is key in making progress towards a better understanding of behaviour. 


\section{SCHOOL-BASED ORGAN DONATION EDUCATION}

The next part of this thesis includes three chapters about an educational program for adolescents attending vocational education; a study protocol (Chapter 3), an effect evaluation (Chapter 4) and a process evaluation (Chapter 5). As these studies all described the same trial, they are all discussed in this same section. These chapters concern the evaluation of an organ donation education program, adapted to and mplemented in schools for vocational education in the Netherlands.

This program was developed to support young people in making and registering a decision about organ donation. After the stepwise development of the program from 2000 onwards, the program has been successfully implemented in high schools throughout the Netherlands. About 15 years after the start of this project, the program received a large update in which a video tape, a computer-tailored program and a registration exercise were replaced by one website including these components. This website contains all educational elements, as well as a manual for the teachers, and is freely available. During the project described in this thesis, the website underwent further adaptations to make it more accessible for and compatible with students attending lower educational levels as well. Tailoring an intervention to the cognitive abilities of a target group can contribute to the effectiveness of an intervention(223). These adaptations were made based on lessons learnt from the initial implementation (e.g. limited time for the registration exercise), results from the determinant study and text alterations in terms of simplified language and shortened texts. This led to a new version of the program, with the same elements as the original program, but higher accessibility for the new target group. These changes are in the first place useful for the IVE students, but higher educated students will probably benefit from this too (see: Health promotion for all).

This program was then implemented and tested in schools for IVE to study the effectiveness in this setting as well as the implementation of the program. The program was effective in increasing registration intentions as well as increasing positive beliefs and decreasing negative beliefs. While the effects on the beliefs were quite small, the 
effect on registration intentions was larger. In line with the goals of the program, no effects were found on the actual choice that students intended to register. The program was implemented well by most teachers and received positive feedback from both the teachers and the students. Teachers did adapt the program sometimes, usually in terms of the dose they delivered, in which classes with lower educational levels within IVE often were exposed to less content. Suggestions were provided for

improving the program further, but all teachers that were interviewed showed interest in using the program again in the future, often even asking about this themselves. Based on these results, it was concluded that organ donation education in a classroom setting can contribute to increasing registration rates. The following paragraphs elaborate on the effectiveness of the program and include recommendations for the future.

\section{Effectiveness of classroom organ donation education}

The effect evaluation showed that the intervention could be successful in increasing organ donation registration rates, as students in the intervention group more often showed positive registration intentions compared to students in the control group (relative increase of $32 \%$ ). This effect is very similar to the effect of the implementation of the old program in the high school setting, where a relative increase of $33 \%$ was found. It is more difficult to compare this to interventions in other countries, as the registration system in the Netherlands allows people to choose from different registration options, where in other countries registering usually means registering as a donor (or as a non-donor in case of an opt-out system). The primary outcome in this study was therefore participants' intention to register a decision, regardless of what that would be, while in other countries other outcomes fit their registration systems better. Examples of outcomes that are used in these cases are the willingness to donate $(135,137)$, to be a donor(136, 224) or to register as a donor(135). These programs often report increases in these behaviours, while the program studied in this thesis did not result in a higher proportion of students showing intentions to register as a donor, compared to other choices. Students in the experimental group did intend to register as a donor more often compared to the control group, but this difference was also found for other 
registration options (i.e. students' willingness to register in general was higher, but the registration choices did not differ significantly). Nonetheless, the effects of the study are perfectly in line with the goal of the intervention (supporting students in making a well-informed decision).

\section{Success factors}

In order to generate insights that can be used in future interventions, it is important to know what elements make this intervention successful. There are some general characteristics that are known to contribute to a successful health promotion intervention and are also likely to contribute to the success of this particular intervention. First, the program actually targets registration behaviour and not merely knowledge about the topic. Research has shown that programs that are behaviourally based, as opposed to knowledge-based, are more successful in resulting in a behaviour change $(223,225)$. This is quite a unique feature of this program, as other school-based organ donation program in the Netherlands merely focus on passing on information. As students practice with filling out a registration form, and therefore increase their self-efficacy, their intention to register also increases(25). Another strong characteristic of the program concerns the interactive nature of the program, as interactive methods are shown to be effective(223). The interaction in lesson 1 was also highly appreciated by the students and teachers. Finally, the intervention can be considered as being "complex". This means, among other things, that it contains multiple interacting components(226). The fact that the program is a combination of different sessions with different methods and goals (in line with the different determinants), could contribute to the effectiveness as well.

While it is widely acknowledged that more components lead to better results, this also leads to challenges when evaluating these interventions. With multiple components, it is difficult to draw conclusions on the specific elements that contributed to the effectiveness. In the current phase of the project, evaluating which elements account for the effects of the program becomes increasingly difficult. Since the start of the development of the original high school version of the program, there have been changes in the delivery methods, content of the program, the school setting and the 
wider context in which the program is implemented. These could all have influenced the effectiveness of the program as a whole and the elements that are in it(227). This also relates to the dose-response relationship of the program. At the moment, it is unknown whether skipping elements or adding elements accounts for higher or lower effects. In general, health promotion interventions show a dose-response relationship, in which more sessions or more time spent on a topic leads to better results $(223,228)$. Whether that would also be the case for the organ donation program cannot be concluded from the study that was conducted.

Determining the effectiveness of the different components is further complicated as the intervention can be tailored to participants on both the individual and class level. On the individual level, students receive tailored feedback on their quiz answers. Tailoring is found to be effective in engaging people and improving health behaviours in the end(229-231). Participants are all exposed to slightly different content in this part, in line with their personal misconceptions, which leads to them receiving more relevant content. This could also result in different effects. On the class level, teachers have a lot of freedom in tailoring the program to their students as well. We already allow teachers to do this and will even encourage this more in the future. Balancing program fidelity and adaptation is challenging. While standardization of an intervention can be very useful in efficacy studies (as internal validity is of high importance), flexibility and adaptability of interventions is found to be important in behavioural interventions as well, as they interact more with the context in which they are implemented(232). Adapting interventions to the local context, instead of standardizing them completely, is therefore recommended, but makes evaluation more difficult(233). The process evaluation also showed that differences between students within IVE are large, in terms of educational level and study discipline. At the end of the program, all students should have learned roughly the same, but the way to reach that can be different for different groups. Students in the lower educational levels of IVE might benefit from more guidance, shorter sessions and even less textual elements. On the other hand, students interested in health care might benefit from more challenging components, an extra assignment or more in-depth discussions. 
In general, drawing conclusions on the active ingredients in an intervention based on an intervention trial is not a good idea. Contextual factors in these trials (e.g. sample characteristics, study design choices or study quality indicators) can influence the effectiveness of certain methods(234). During the initial development of the intervention, all program elements were developed and tested separately. They were found to be effective and were then combined into one program. In theory, this process could be repeated to assess the effectiveness of the separate elements in the current program, but this also has its limitations. As mentioned before, contextual factors and implementation could have a large impact on the effectiveness of the elements(234). Further, when evaluating all elements separately, possible synergistic effects that could occur when combining the elements are not considered. For instance, making people do the registration exercise separately will probably be far less effective than making them do it after receiving information about what organ donation is and what the consequences of certain registration choices are. In other words, the total intervention effect is usually not just the sum of all the component effects(234).

If one would want to identify how effective each element is and whether a dose-response relationship exists, more creative evaluation strategies are needed. There are different examples in the literature, in which varying levels of intervention exposure can be used. Using a stepwise approach could help to identify which elements are effective. In order to do this properly, strict standardization is required. Also, controls need to be introduced to limit the variation in the implementation of the program $(235,236)$. However, this is not a desirable option, as the variation in implementation is probably an important success factor of the program. Because of the flexibility of the program, many different scenarios would have to be tested and compared.

This raises questions about the best ways to spend our resources. Apart from the practical issues related to this, the added value of doing this would be limited. The intervention was developed systematically, tested in phases and then evaluated in a large trial. The program was then carefully adapted and evaluated again, including an elaborate evaluation of the process of implementation. Reaching the target audience should 
therefore be priority now. With limited resources, it is better to invest in a proper dissemination strategy in order to have the largest public health impact. The section The future of the program: dissemination discusses possible strategies to accomplish this. Over the next years, the implementation needs to be monitored as the needs of the target group or teachers could change, the program could become outdated or new innovations could become available which could be applied to the program. As always, a careful balance should be made.

\section{The future of the program}

After implementing and testing the program in 11 schools, it can be concluded that organ donation education in a classroom setting could contribute to increasing registration rates. The process evaluation, described in Chapter 5, gives insight into how the program was implemented, but also sheds light on what the future of the program could or should look like. This evaluation both covered the content and dissemination of the program. By improving strategies on both elements, the effectiveness and final impact of the program could be optimized.

\section{Content}

Based on the process evaluation, suggestions for further improvements were formulated that could enhance the effectiveness of the program. In Chapter 5, a few suggestions are discussed, including; more interaction (and less reading), another delivery method for the registration exercise, celebrity advocacy and the addition of booster sessions. These are all aimed at changing students' behaviour through the socio-cognitive determinants. However, the environment should not be neglected. Different environmental influences play a role in organ donation decision-making. Cultural(237-240), social (family members and friends) $(65,100)$, religious $(241,242)$ and political contexts $(184,193)$ are found to be associated with people's attitude towards organ donation and their registration behaviour. These contexts can either support or inhibit people's willingness to register (as a donor). Next to the environment itself, it is also important whether people are aware of it. For instance, the official stance of someone's religion could make people decide whether they want to donate, but their awareness of 
that stance could be as important(242). Most religions do support or even encourage organ donation in the context of love for one's neighbour, but not everyone is aware of this. The same counts for the registration system in a country, in which, next to the system itself, people's awareness of that system could influence their donation decision(52, 243). The program already touches upon these contexts, but it is difficult to address all different perspectives. Integrating an environmental component in a program could be a predictor for success $(225,244)$. The next sections will elaborate specifically on the possibility to add a component to the program relating to students' families and the political context.

At first glance, organ donation seems very personal. While the program is aimed at empowering people to make their own decision and respecting every decision, their choices will impact other people as well. This includes patients and the society as a whole, but also people in their near environment (e.g., relatives) will be confronted with their choice at some point. Discussing organ donation at home can be useful in several ways. First, it could help in further increasing registration rates (as a donor). Talking about organ donation at home, especially when these conversations are positive, is correlated with more positive attitudes about organ donation(81). Having their family's support could help adolescents feel more comfortable about their decision. Also, they might be able to inspire their family members to make a decision as well. Second, it could help students to learn more about how their religion or culture perceives organ donation. This could also support them in making a decision, whether this is to become a donor or not. Third, even when these family discussions do not influence registration behaviour, family members learn more about each other's preferences. This is very important in case of a death, as they at least know more about their loved one's stance towards organ donation. This could even lead to more donations in the end. Families who discussed organ donation together are more likely to donate and knowing their loved one's wishes also increased their willingness to donate(115). Talking about organ donation at home, as an addition to classroom discussions about it, could therefore increase the effectiveness of the program in terms of registration intentions of students themselves, but could have multiple positive side effects for both the students and parents as well. 
While these conversations are expected to be effective, there are difficulties for both students and parents when it comes to actually having these conversations. Parents may avoid them as they experience discomfort talking to their children about death(245). Parents who are donors discuss it more often, have more conversations with their children about it and experience these conversations more positively(81). Educational level plays a role here as well. Parents with lower educational levels have fewer conversations with children. As parent educational levels are related to these of their children(246), the students in our target group are expected to talk about organ donation less often with their parents compared to high-educated peers.

This means that students have an important role in initiating this conversation. The organ donation program did increase students' intentions to talk to their families or friends about organ donation, but little is known about whether they actually do this. Also, students expressed that they found it more difficult to talk to others about organ donation after receiving the program, compared to students who did not receive the program yet. A previous study has shown that actually getting the conversation started was seen as the most difficult aspect(139). Adding a component to the program to help students to start this conversation at home, could be the support students need to actually talk to their families about it.

The basis could be an assignment to do at home, with guidelines to help them do it. Previous research has shown that a good preparation helps students, but still many of them feel like they need more information or assistance(139). A role play exercise in class could help them to overcome potential barriers. Practicing their conversations with their classmates could also boost the effectiveness of the program in general, as another interactive element is added. Interactive elements, especially when these are student-based, could increase the effectiveness $(247,248)$. In this target group, actively doing things instead of reading or listening is very much appreciated. The content of the role-playing exercise could again be tailored to the needs of the (sub)groups. However, whether family components work in interventions for adolescents is still up for debate. It is suggested that the influence of family members on health behaviours 
could decrease as children become older and are becoming more autonomous(249). But with the potential effects of family discussions with regard to organ donation, it is worth researching this further.

Another environmental influence to pay attention to, is the political context. As mentioned before, the donor law in the Netherlands is changing from an opt-in system to a no-objection system. From the $1^{\text {st }}$ of July 2020 onwards, this new law will come into force. In the months following this date, all Dutch citizens who are not registered yet will receive a letter asking them to make a decision about their organs and tissues. If people fail to respond to this letter and a reminder 6 weeks later, they will be recorded with a no-objection registration. In principle, organs and tissues of people with this registration could go to patients ${ }^{1}$, but family members could still object to this. This change has implications at a national level, but also for the educational program. The following section elaborates on what the law change means for the program. In the section Increasing active registration rates; no quick fix, the implications of this law on broader initiatives will be discussed.

Since the implications of the law are potentially large, the program will not need to change substantially. The core aim of the program - activating adolescents to make and register a decision - will not change. Also, the rationale for doing this - making sure your wishes are honoured and relieving pressure on medical professionals and your family will remain unchanged. If anything, actively registering becomes more important, as not making a decision will result in some sort of passive consent (no-objection registration). As explained in Chapter 6, these passive registrations are undesirable as the responsibility around the donation decision then still partly rests with the family members. In terms of the content, explaining the law and its implications needs to be included in the program. This could quite easily be done by means of a short video. Instead of creating

${ }^{1}$ When an organ or tissue is removed from the body, it is possible that it is not suitable for transplantation. The reason for this could be a low quality of the organ or when unexpected damage or a disease is found. In these cases, the organ or tissue could be used for scientific purposes. Both the donor and his/her family can object to this. This is different to donating the entire body to science. 
new content, an existing video could be used that has already been designed to inform the more vulnerable people in our society about organ donation and the new law (e.g. https://www.hoewerktorgaandonatie.nl/nl/). Further, the content of the videos, quizzes and registration exercise need to be slightly updated to the new situation.

\section{Dissemination}

Proving the effectiveness of this educational program is only the beginning of reaching higher registration rates. Sustainable implementation of the program will be needed to make a change. It is widely acknowledged that the dissemination of effective interventions remains a major challenge in the field of health promotion(250-252). The school setting has its own challenges with regard to this. Schools of course have academic priorities. From a health promoter's point of view, schools are a great setting for the implementation of health promotion programs, but schools are faced with their own curricula and competing school resources. School staff sometimes feel overwhelmed by the supply of prevention programs in the school setting and have limited opportunities to implement these programs $(253,254)$. Usually, school-based health promotion programs can be presented as integral to the school's educational program. This is because a better student health will improve the overall school performance and vice versa(255-257). However, in the case of organ donation education, this is not really a valid argument, as organ donation registration will not necessarily contribute to student health, but rather the health of the society as a whole. This challenges the dissemination process and calls for a specific strategy. The implementation itself on the other hand, is not difficult. Teachers mentioned that the length of the program and the selfexplanatory nature of the website made the implementation quite effortless. And while all teachers that participated in the trial were enthusiastic about implementing the program again, this does depend on the enthusiasm of individual teachers. The focus of the dissemination should therefore be on reach, rather than implementation strategies.

An important conclusion from the trial that was performed, was that higher level support is needed for a wider dissemination of the program. In the trial, teachers decided themselves whether they wanted to participate. While this still seems suitable in this 
IVE school setting, in which teachers have a lot of freedom over their teaching activities, support from the school level or national level could help to reach more people and to make the implementation of the program more sustainable. In the dissemination of the program, the sender of the program should therefore not only contact individual teachers, but also contact their supervisors (even if it is only with information).

The sender of the program should preferably be a well-known national organization. Nowadays, with increasingly more online sources with information, there is a lot of competition between online programs(258). These could be sources with similar goals, but on the Internet also a lot of misinformation can be found. It is therefore important to communicate from a credible source. According to the Elaboration Likelihood Model, people rely on more heuristic cues when they are not necessarily motivated or capable to process information. As teachers (or their supervisors) are usually not particularly motivated to add another program to their schedule, the credibility of the source could be an important influence on whether they accept the program or not (259).

In the case of organ donation, this could be the Dutch Transplantation Society; an organization that is responsible for organ donation education in the Netherlands and works closely together with the Dutch government. They already disseminate educational programs for schools, but do not have a separate program for students in vocational education. The educational program that has been evaluated in this thesis, has been managed by an organization called SIDVO, which is part of the Maastricht University Medical Centre. While they could be regarded as competition and both have different approaches, it would be best to overcome the differences and to join forces. Both organizations work towards the same goal and a collaboration could result in high-quality education with a large reach. Moreover, as they also contribute to the campaigns surrounding the new donor law, a collaboration could result in a uniform message and efficient use of all materials that are developed.

Another recommendation regarding the dissemination of this program concerns the integration of the program in existing materials. Integrating different programs that 
address multiple behaviours, could reduce the burden on schools and the teachers(260). Moreover, offering programs as a package could be an efficient way of disseminating health promotion programs. However, it is suggested that the change processes or effective elements for these different behaviours are similar $(261,262)$. Further research will be needed to decide which programs could be offered together. This could be offered through an organization outside of the school setting (e.g. Healthy School Approach), but for the future it might be even better to integrate this within the courses that already exist within vocational education. Most teachers mentioned a Vitality dimension within the course of Citizenship, in which different health related subjects are discussed. Designing a package in which different health topics are addressed could help teachers in Citizenship to educate their students.

The new donor law also has implications for the dissemination of the program. On the one hand, the media attention could help in creating attention for the topic of organ donation and increasing the need for educational programs about this topic. This was already seen during the recruitment for the effectiveness trial of the program, when teachers were looking for ways to discuss the upcoming law change with their students. However, it also comes with new challenges. The new donor law is quite complicated, and people have difficulties understanding what this "no-objection" actually means. The misconception exists, that a no-objection registration is the same as an active "yes". Some teachers even contacted us about the program not being necessary anymore after the law change, as "everyone automatically becomes a donor". This emphasizes the importance of proper education, not only for students but for society at large. In terms of dissemination, this means that teachers should be educated too, before they can educate their students. 
A large proportion (36\%) of the Dutch adult population has difficulties with obtaining, understanding and acting on health information, which is defined as having low levels of health literacy(263). Part of that group can also be regarded as having a low literacy level (2.5 million people in total), which means that they have difficulties with reading, writing and/or calculating in general. While this is related to educational level (i.e. low (health) literacy is found more often among lower-educated people), people with low levels of (health) literacy are found in all layers of society. While these groups all have their own characteristics, and people within these groups all cope with different issues, lower levels literacy and health literacy often go hand in hand and have similar implications for our field. A report of Nivel in which the communication about the new donor law was evaluated with special attention to people with lower health literacy, showed that there are no clear differences among people that have difficulties in obtaining, understanding or acting on health information, in terms of their levels of knowledge, need of knowledge and preferences for channels via which they would receive information(194). Therefore, this group will be discussed together as people with low (health) literacy.

Health promotion programs and campaigns that are used often fall short in terms of serving people with low (health) literacy levels. This was also seen in the evaluation of the national campaign to prepare citizens for the new donor law. The Nivel report shows that a large proportion of the participants never heard of the new donor law, and if they did, did not sufficiently understand what the law entails and what the consequences are for them(194). The materials that were used in the campaign were often too complicated, especially the written information, and it was unclear to people what the different registration options actually mean.

These observations can quite easily be translated to the organ donation registration rates, as lower-educated people less often register their decision(31). Similar results could be expected when the new organ donation law is implemented. The study reported 
in Chapter 7 showed that people with lower educational levels more often choose to do nothing (resulting in a no-objection registration) compared to people with medium or high educational levels. Further, they more often choose to register as a non-donor compared to these other groups. In general, the number of people actively registering a decision is low compared to other groups, which is undesirable.

This is just an illustration of the impact on organ donation behaviour, but lower (health) literacy is associated with many other adverse health outcomes, including less healthrelated knowledge, poorer health status, increased hospitalization and less health promoting behaviours(264-266). Reaching them with health promotion initiatives is therefore very important. Differences in health outcomes are already large between groups of different education or literacy levels but will only increase if programs and campaigns are not able to reach the lower-educated and literate groups with information they can process and apply. If we succeed in designing materials that better match their needs in this regard, inequalities between these groups could be limited.

\section{Health promotion initiatives for low (health) literate people}

It is evident that health promotion initiatives should be adjusted to people with lower (health) literacy levels. With regard to the organ donation program, we were aware of the educational level of the target group and the relatively high proportion of people with low literacy levels in that group. We adjusted the high school program to their literacy levels in several ways; language was simplified, informational texts were shortened, and the quizzes were shortened. When evaluating the program, it turned out that students did not read the texts properly and quizzes were quickly skipped through. This illustrates that even when we adapt interventions to our best abilities, they could still fall short. Elsewhere in this chapter, options are discussed to further improve the program. This following section will include more general strategies health promoters can use when developing interventions for people with lower (health) literacy levels.

First, it is important to think about the type of materials that you want to use. The fact that people with lower (health) literacy levels have difficulties with reading and/or 
understanding and/or applying this information, does not mean that written materials have to be discarded all together. Simple written information can sometimes even be preferred over information from digital sources, as many people with lower health literacy levels, also have difficulties with using a computer(194). However, mostly there is a disparity between the reading level of educational materials and the reading level of the people that have to read this information(267). When using written information, one should thus make sure that the level matches the reading level of the target group. There are more general guidelines to improve the readability of written materials for this target group, including using a large font (14-point), short sentences (maximum of 8 words) and active voice(268). Other recommendations include using uppercase (capital) and lowercase (small) letters, avoiding handwritten and cursive texts, using subheadings, only elaborating on one idea per sentence or paragraph and chunking words or ideas together in a meaningful context(267). Combining written materials with verbal information and/or visual aids is also found to be effective(267-271). This could improve the understanding of the written information.

Developing these materials can be challenging, as it is difficult to put yourself as a health promotor in the position of someone with lower (health) literacy levels. Pharos is a Dutch national expertise centre which aims to contribute to reducing health inequalities. They have designed a checklist to support professionals in developing accessible educational materials(272). This checklist can be used for materials such as brochures or videos, but also for eHealth applications, such as websites or apps. The checklist consists of 78 items in different categories, such as needs assessment, development or lay-out(273). Additional criteria are added when an eHealth application is developed, such as ease of use or the possibility to ask for help. When an intervention is already developed, they also offer an instrument (voorlichtingsmateriaal beoordelingsinstrument) to assess existing material. It is based on the American PEMAT (Patient Education Materials Assessment Tool) (274), and can be used to evaluate and compare the understandability and actionability of educational materials. The instrument helps health promotors (and others) to walk through the material and look at it from the perspective of the target group and to assess it on different criteria. One score is provided 
for understandability and one for actionability, in which a higher score indicates better materials. This enables health promotors to compare different materials. This tool was not used when adapting the educational program to the new target group. In hindsight, it would have been of added value to use the instrument for existing materials in order to further improve the program in terms of accessibility.

While it is very useful to use such a tool for existing materials, it still comes down to professionals trying to take the perspective of the target group. It is known that there are incongruities in assumptions between public health practitioners and their target groups $(275,276)$. Professionals therefore run the risk of using materials that do not fit the target group. An example of this is that simplifying materials could end up being childish and could therefore be insulting to the user(267). Students made comments on this in the organ donation program as well. In the videos in lesson 1a, words or short sentences appeared sometimes to emphasize something that was said. Students perceived this as "childish" or "annoying". Issues like these could have been avoided if students would have been involved in the intervention development. This could prevent making choices based on wrong assumptions and could also help to tailor the information better to their language abilities(277). The Pharos checklist gives suggestions for this as well.

\section{Research in low (health) literate groups}

Designing better interventions for low (health) literate groups, also means that these groups should be involved in research more often. This could be challenging as most people are not open about their (health) literacy problems, which could lead to them filling out forms incorrectly(278). There is no clear-cut answer to the question how to do research in these groups, but there are some suggestions on how to at least improve our methods. There are many qualitative research methods (e.g. focus groups, interviews), which could be useful as participants do not have to read (much). However, this does not mean that questions are properly understood, as they are often still based on the same theories as used in questionnaires. Adapting the language level to the participants is therefore still necessary. There are also possibilities to do quantitative research among these groups as well, as written materials are not necessarily bad. 
When collecting data through questionnaires, the same basic guidelines should be followed as when developing interventions, in terms of use of language, lay-out, etc. For questionnaires, Pharos has some further advices, such as providing an option between "yes" and "no", asking the user how long the questionnaire can be or not using statements, as they might believe these to be true(273). Further, it could help to have a professional or someone else present when they fill out questionnaires to assist when needed. There are also more innovative initiatives to help people with filling out questionnaires, such as interactive touch screen questionnaires(279, 280). Different tools are embedded in these types of questionnaires to support people, such as a recorded version of the question, graphics or interactive self-explaining scales. These show promising results in people with lower (health) literacy levels, but their application in large-scale research might be challenging.

A possibly more feasible tool to improve questionnaires concerns cognitive interviewing(202). This method is designed to find out whether a questionnaire fulfils its intended purpose, by interviewing individuals. It can be based on two procedures; think-aloud interviewing and verbal probing. Think-aloud interviewing is about asking the interviewee to verbalize their thoughts while answering the questions. Verbal probing is a procedure in which the interviewer actively uses probe questions to collect information on different levels, such as comprehension (e.g. What does ... mean to you?) or recall (e.g. How sure are you that you ...?). This method has also been found to be useful in people with lower literacy levels(281).

\section{Health promotion for all}

It is thus of high importance to put extra effort in reaching the lower (health) literate people in the society with health promotion initiatives and research. In the case of the organ donation program, we knew beforehand that we were dealing with a lowereducated population in which low literacy is relatively more prevalent than in higher educated groups. However, as mentioned before, people with lower (health) literacy levels can be found in all layers of society and are often not visible. In every research project, these people will be present among the study subjects, often without the 
researcher being aware of it. So abovementioned recommendations are not limited to studies in vulnerable groups but are also applicable to studies in the general population. Accessible information, that is easy to understand, is something that all people will benefit from. Higher educated individuals and professionals often also prefer reading easier texts(282). Paying more attention to the accessibility, readability and actionability of materials could help in gathering valuable data, developing better interventions and eventually also help to tackle the inequalities in the society. 


\section{INCREASING ACTIVE REGISTRATION RATES:}

NO OUICK FIX

To date, organ donation campaigns have mainly been based on a whole population approach. This is also the case in the on-going campaign in which the public is informed about the new donor law; "Nederland legt het uit" ("The Netherlands explain"). The main idea of this campaign is that different Dutch citizens, famous or not, explain to each other how the new donor law works. It includes, among other things, television and radio commercials, online banners and outdoor advertising(283). A brochure was sent to all households, and can also be found in hospitals, libraries and pharmacies. The campaign is divided in different phases, in which first awareness is raised, then the focus is on attitude, knowledge and behaviour and finally a repetition campaign.

While the campaign has multiple well-thought-out elements, there are some disadvantages of such an approach. Campaigns like these often only reach small and shortterm effects(284). Further, whole population approaches could have an unintended effect of augmenting social inequalities(285, 286). More vulnerable individuals are found to be the least able to positively respond to whole population approaches. This is also known as the inverse care law, which originally states that the availability of good medical care tends to vary inversely with the need of the population served (287). In this context, this means that those who already have the possibilities to adapt to new situations, will also be the ones who benefit most from whole population approaches.

The evaluation of the organ donation campaign in people with lower (health) literacy showed that this is happening in this campaign as well(194). People are exposed to the content of the campaign (e.g. the TV commercials or the brochure) but have difficulties with understanding what is actually meant for them and how they should act on it. The study described in Chapter 7 also suggests that people from lower educational levels are less inclined to make an active decision when presented with a no-objection regis- 
tration system, compared to medium and higher educated people. This suggests that the current campaign might show positive effects on a population level, but vulnerable groups are left behind. An alternative approach to educating people about organ donation could be a vulnerable group approach.

A vulnerable group can be defined as a group that shares social characteristics that generate exposure to other risks(285). In the context of organ donation registration, this might not necessarily be a risk, but the likelihood of a passive registration, in which cases their relatives have to make the decision on their behalf when they die. With a vulnerable group approach specific attention is given to vulnerable groups, which in this case could be groups in which lower registration rates are found. These could be groups with lower (health) literacy, lower educational levels, elderly or people with a non-western migration background(31). The organ donation program described in this thesis could also be seen as a vulnerable group approach, as students from lower educational levels were targeted. The program has the potential to increase registration rates, but this can of course not be seen as the holy grail to solve the registration problem. Vulnerable group approaches work best when combined with whole population approaches(285). Increasing active registration rates under the new law can therefore only be achieved when whole population approaches and vulnerable group approaches are combined to increase active registrations in the entire population, without widening the gap between groups.

\section{Integral approach}

In 2008, the Masterplan Organ Donation called for an integral approach to solve the donor shortage(7). In this plan, different strategies were suggested on several levels, including the organization in hospitals, education to the public and a new law. All recommendations from this Masterplan were implemented, except for the law change. The plan did not lead to the desired results. One important let-down was the fact that registration rates did not change as much as was hoped. Now that finally the legal framework is also provided, in the form of a no-objection system, there is hope that this is the missing piece in this integral approach. 
In 2009, Taels and van Raaij performed a study in which different potential organ donation systems were tested(48). All these systems did not perform better in terms of registration rates than the current opt-in system. Also, there is no robust evidence that countries with an opt-out system have higher donation rates(288, 289). While the law change could be another piece of the puzzle, it is not likely that it will be the ultimate solution for the registration and donation shortage. As family members will still have an important say in this new system, the impact of the no-objection system on the donation rates is difficult to predict.

An important goal of the program is that all Dutch citizens will have 'a' registration behind their name within one year after the introduction of the new law, so it is clear that the number of registrations dramatically increases to a $100 \%$. However, a new challenge is then to increase the number of active registrations. The study in Chapter 7 shows that there is a risk that the proportion of active registrations will decrease, and more people will register a no, especially in the low-educated group. As described in Chapter 6, the system that was chosen in the end, the no-objection system, is more complicated than most opt-out systems in other countries. It is not only about ticking a box but weighing different options that have consequences which might not be clear to everyone. This could influence the effectiveness of the system, but also means that there is a responsibility to ensure that citizens understand what their choice means and have the capabilities to opt-out.

Next to the initiatives that are already there, more could be done to support vulnerable groups. The evaluation from Nivel shows that the current campaign does not meet the needs of the vulnerable groups(194). While there have been recent initiatives for these groups, such as the earlier mentioned video with a simple explanation about the new law, it is known that people with lower (health) literacy levels are less likely to go and look for health information themselves(290-292). Their information tends to come from more passive sources, such as the television (293). They are less likely to look for information on the internet themselves(293) and often trust on information from their social network(292). 
Therefore, a more proactive approach is needed for these groups, in which they are offered the support they need. This could be a medical professional, such as their GP. People with lower health literacy levels, tend to trust their health professional more than the government or the media(294). Another option is a person with higher health literacy levels in their own social network. People with higher health literacy levels often provide health information to others in their social network(295), so could also be important in offering support when it comes to organ donation decision-making. This could be a family member, a friend, or someone from a local organization, such as a library or a community centre. This support should go way beyond the provision of information, as this is not sufficient to help people make informed choices(296). As a first step, they could provide help with reading the information materials. Next, they could help with making the decision. As mentioned before, people with lower (health) literacy levels like to trust on others or hear about their experiences when making a decision(292).

Finally, there is an intention-behaviour gap in organ donation registration behaviour(196). Even when people have made a decision, moving from the intention to register to actually taking action can be a problem. The study in Chapter 7 shows the possible width of this gap, as participants showed high intentions to register under the conditions of the current opt-in system (76\%), while actual registration rates are much lower (42\%). When looking closer at the different educational levels, it is clear that this gap is even larger among low-educated people (72\% versus $20 \%$ ) compared to intermediate (75\% versus 56\%) or high-educated people (80\% versus 58\%)(31). This suggests that the difference in registration rates between educational levels might not be caused by a large difference in willingness to register, but the ability to take action.

An explanation for the intention-behaviour gap could be the final hurdle in organ donation decision-making; filling out the registration form. Filling out forms is difficult for many people, particularly for people with low literacy levels(128). Education initiatives tend to focus on the provision of information and often lack practical guidance. In the new law, it is assumed that people who do not respond to the request to make a 
decision, are okay with the no-objection registration, while they might not respond because they have difficulties interpreting the information, do not understand the urgency or have difficulties with filling out the form. Further, the registration form that is currently used does not meet the guidelines to improve readability and understandability of written materials, such as a large font, double spacing, easier language, etc. The online version of the form is easier, but requires some digital skills, that many lowliterate people lack. Vulnerable groups would benefit from an easier paper-based form. As the possibilities for making this a reality seem limited from a legal point of view, receiving help from others when filling out the form is key(297).

The Masterplan Organ donation suggested an integral approach to organ donation. This integral approach should also be applied to reaching these vulnerable groups. Different sectors and people should work together to make an informed registration under the new law possible for all citizens. This means a collaboration between health care professionals and social networks, including as community centres, libraries or schools. Not every strategy will work for all individuals with lower (health) literacy levels, as they all face different challenges and have different needs. So multiple strategies are needed to reach this group. As emphasized in Chapter 6, the government should take its responsibility to make and execute a sustainable plan in which continuous support can be provided to these groups, also after the new law has commenced. We are not there yet. Registration rates are not where they should be. But with out-of-the-box initiatives, a personal approach, a collaboration between different sectors and a lot of support, this could change. 


\section{GENERAL CONCLUSION}

Low organ donation registration rates remain a complex problem in the Netherlands. Providing education in a school setting could contribute to increasing these rates, especially among people who have not been reached by other initiatives properly. It is proven to be effective on different educational levels, was received well by students and staff and therefore a wider dissemination is recommended. It has the potential to reach a large and important group with education and support.

However, school-based education on its own is not enough. An integral approach is needed in which whole population approaches have to be combined with vulnerable group approaches. The new donor law could be an important part of this comprehensive strategy, but the complexity of the law could impact peoples' decision-making and registration behaviour, especially in those vulnerable groups. More efforts are needed to proactively reach these groups and to contribute to more informed decisions and more active registrations under the new donor law. 



\section{Valorisation addendum}

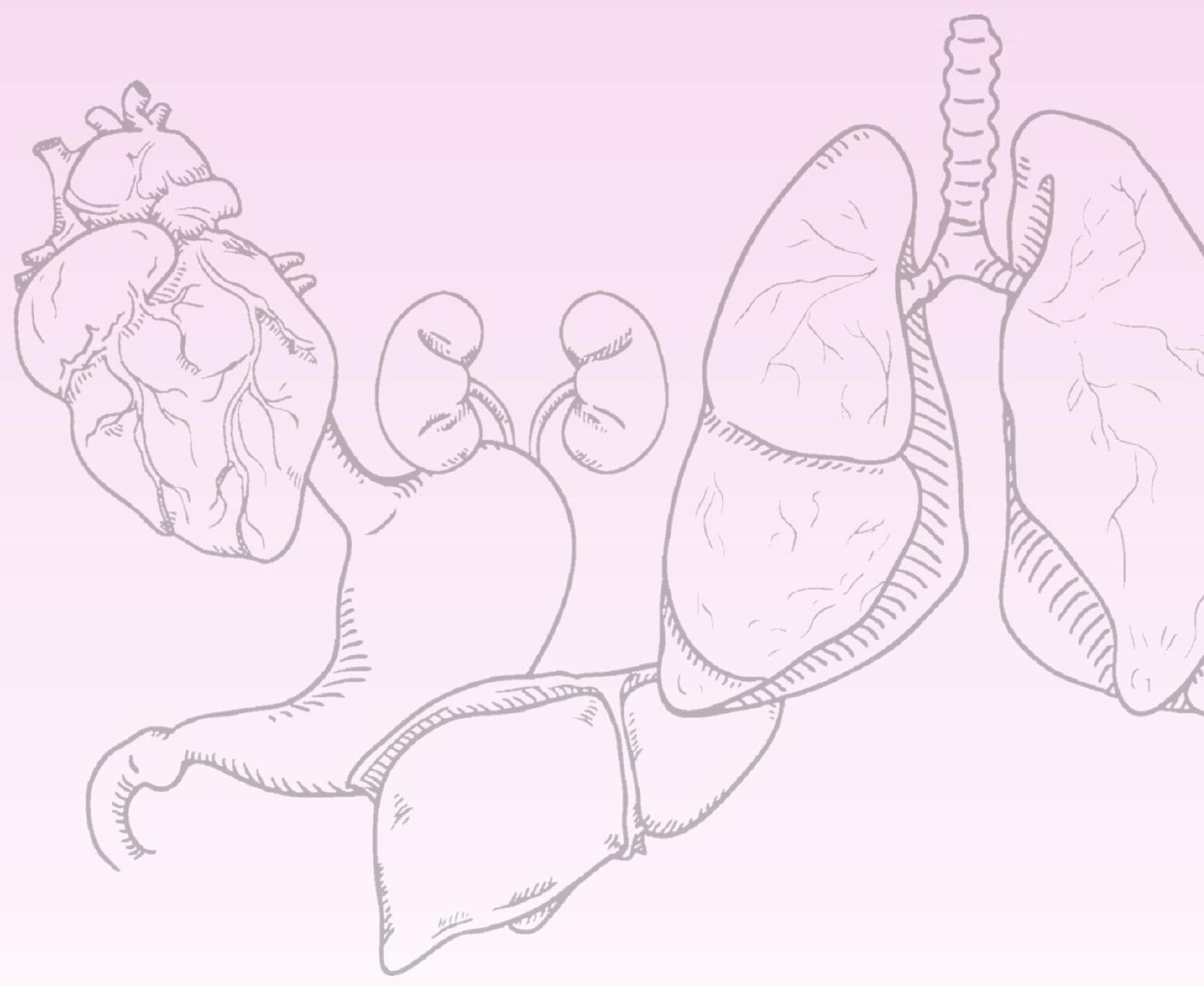


Obtaining a PhD was never a goal in itself for me. I had the ambition to improve society through my day-to-day activities at work. This project gave me the opportunity to do so. While research might have a scientific value first, in the long run, the societal value of doing research in the field of health promotion is large. Research can be put to use in several ways. This chapter will elaborate on the relevance of the research presented in this thesis.

The societal value of this thesis is to contribute to increasing organ donation registration rates among lower-educated adolescents in the Netherlands. This was done through the adaptation and implementation of a web-based educational program in schools for vocational education. Adolescents were encouraged to actively make a decision about organ donation and to register this decision.

Encouraging adolescents to register a decision does not necessarily benefit their own health. Increasing registration rates is however essential to lower the burden on many others in society, including their own family members, patients on the waiting list and medical professionals. If people register an active decision, it takes away the insecurities about organ donation when someone dies. Further, if more people register as a donor, it has the potential to help more patients. At this moment, many families reject the idea of organ donation when they are confronted with a proposal when a loved one dies, while actually, the majority of the Dutch population is willing to donate their organs.

The societal value of this topic is undeniable. This chapter will explain how this value was further increased during the project and what could be done in the future for the program to reach its full potential.

\section{Sharing of findings, data and products}

The results of and materials used in the studies in this thesis could/should be of interest to several target groups. Throughout the project, we therefore actively invested in sharing the findings of our research and the data and products that we used with others. This further increases the relevance of the research in this thesis. 
First of all, other researchers could benefit from the studies that were done. Our research was conducted in a very specific setting: a Dutch lower-educated school setting. As a very large group of people attends this type of education, insights could be useful for other (health promotion) programs in this school setting. Further, even if the topic or target group of this research is outside of researchers' own expertise or interest, general lessons can be learned about e.g. implementation in a school setting, working with a heterogeneous target group or adapting interventions. The results of our studies could then be applied to new contexts, also in other countries.

The findings of all studies were published in international peer-reviewed scientific journals, preferably open-access, or are available at a pre-print server. Further, the results were presented at several (inter)national conferences. All publications include a link to Open Science Framework, where other researchers could find the questionnaires, interview guides, syntaxes, datasets (without personal data) and other materials of that particular study. Doing this maximizes scrutiny of the research that was done, allows for a replication of the research and facilitates the use of the data in meta-analyses(132).

With a project that has a high direct relevance for society, it is important to not only share with the scientific community, but also with others that can benefit from the results. The results of the studies were therefore shared with different target groups in different ways. First, the results and the program were shared with other parties in the field, including policy makers, that are working on organ donation education. This can help us to learn from each other and improve the quality of organ donation education. Also, policies could eventually assist in embedding organ donation education in the curricula at schools.

Efforts were also made to reach other (health) professionals in the field. This was done by publishing a Dutch opinion piece in a journal directed at health professionals. Further, the results of the studies were used in education at Maastricht University and University College Venlo. By doing this, the results do not only reach current health 
professionals in the field, but also health promotors in training - these are the health professionals of the future.

Finally, actions were taken to inform the general public about the results of the studies. This was done by informing participants in the studies of the results. After the determinant study (Chapter 2) and evaluation study (Chapter 3 to 5) participating schools were informed about the results of the study in layman's terms. The results of the study in Chapter 7 were shared with the Flycatcher community and in the form of a press release. This helps to involve the general public more in the research that we do, which is especially important with a topic like this.

\section{Dissemination of the program}

The program has been developed with care and has been proven to be effective in both a high school and vocational school setting. The program goes beyond the provision of information and is unique in its focus on behaviour (i.e., registration). It further has a specific focus on a vulnerable group in our society when it comes to organ donation decision-making. This makes the program a valuable addition to existing organ donation registration initiatives in the Netherlands.

Based on the effect evaluation, suggestions were given to further improve the program, which could increase the effectiveness. These suggestions were taken into consideration and possibilities are explored to add these to the program. However, having an effective, high-quality program is not enough to have an impact on the society. With limited resources, the question is whether these are spent best on optimizing the program even more. Spending resources on reaching a large number of schools and students therefore seems more valuable.

The positive results of the evaluation study encourage a national dissemination of the program. Currently, half a million people attend Intermediate Vocational Education in the Netherlands(298). Sustained implementation of the program in this type of education could be an efficient way to reach a large group of people with accessible informa- 
tion. As it prepares people for actually filling out the registration form, participants in the program are more likely to register a decision afterwards. The potential impact of a national dissemination of this program on organ donation registration rates in the Netherlands is therefore large.

For the evaluation study, teachers (or their department heads) were contacted individually and seemed to have a lot of freedom to decide whether or not to implement the program. As the curriculum of Citizenship is not strictly decided, this leaves room for teachers to give their own interpretation to the course. This could be an advantage for a dissemination of the program. Teachers play an important role in the implementation of the program. They are not just study objects, but actively contribute to the success of the program. All participating teachers were interested in using the program again and many are still contacting me today to ask whether they could use the program again in their class. The teachers' enthusiasm shows promise for the dissemination.

However, targeting all teachers individually is very time consuming and keeping up with the staff turnover is difficult. The challenge for the dissemination of this program might therefore not lie in finding teachers that are willing to participate, but to mobilize entire schools or departments to disseminate it within their schools or departments. This is not an easy task considering the liberal nature of the curriculum of Citizenship. However, if the program can be integrated within the curriculum of a school or department, chances are higher that the implementation of the program can be sustained.

There are many facilitating factors for the dissemination of the program. The program is not too long and can therefore easily fit in an existing schedule. Further, the program is very easy to use, and teachers can start with the implementation without further requirements or materials. The website is self-explanatory, and teachers can download a manual for further information. The relevance of organ donation registration for this age group further facilitates the dissemination as well as the fact that the program is free of charge for everyone. However, all these facilitating factors do not guarantee 
that the program is automatically picked up by the target group. An active strategy is needed to reach school boards, departments or individual teachers.

The program is currently owned by a small, local foundation called SIDVO. It is unlikely that this organization has the resources to disseminate the program nationally and to sustain implementation over time. It is therefore recommended to find a larger, national organization to become responsible for the dissemination of the program and keeping it up to date. Ideally, the program would become part of the national organ donation campaign from the Ministry of Health, Welfare and Sports and the Dutch Transplantation Society. The program could then be part of a uniform message and all campaign components could reinforce each other. Communication with both organizations has been initiated during the project and opportunities were explored for a collaboration or takeover. 

References

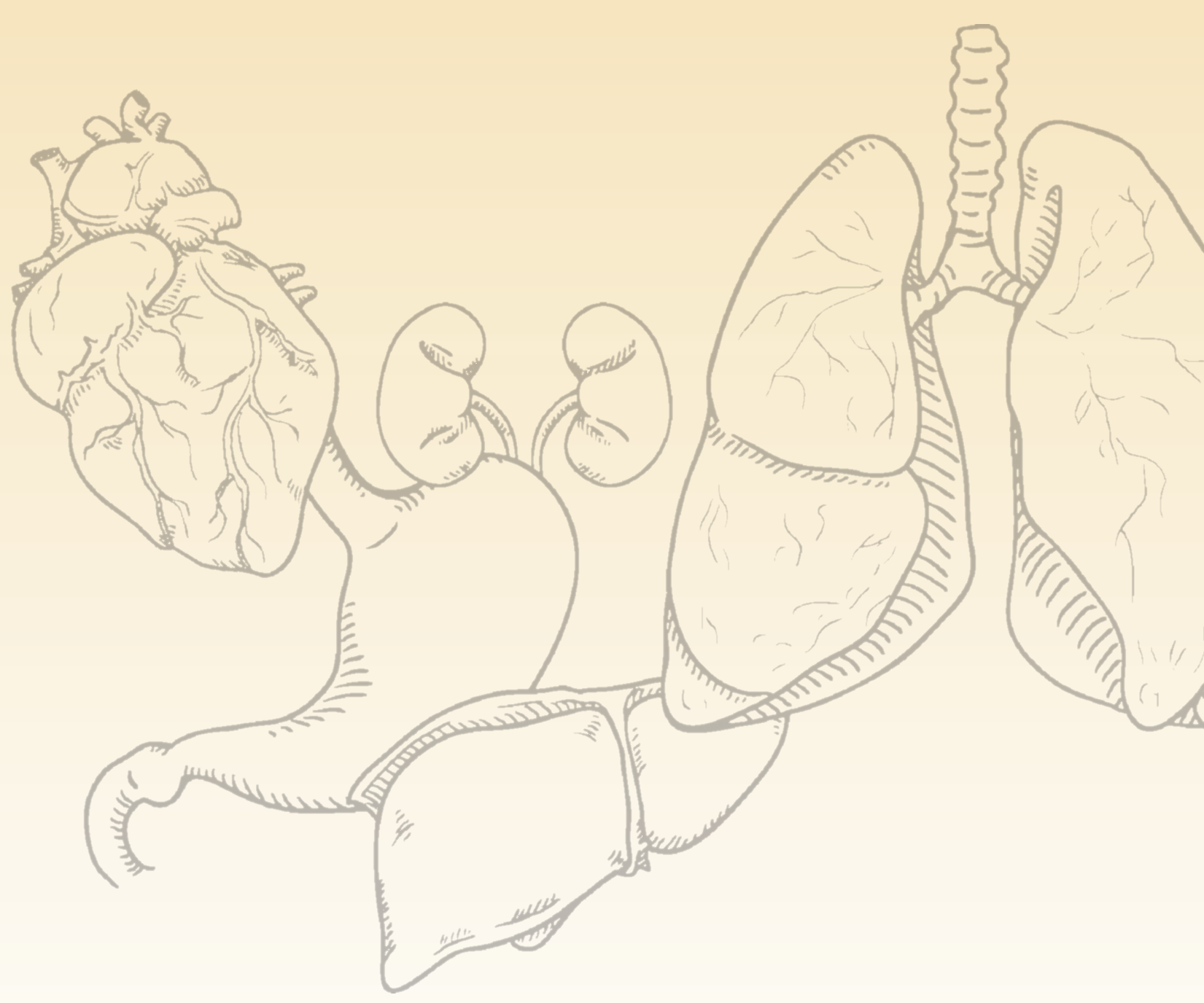


1. Linden PK. History of solid organ transplantation and organ donation. Critical Care Clinics. 2009;25(1): 165-84, ix.

2. Coppen R, Paul K, Avezaat C, Hagenaars J, Friele R, Bal R. Praktijken van orgaandonatie in Nederlandse ziekenhuizen. Utrecht/Rotterdam: Nivel, Erasmus University; 2011.

3. Rudge C, Matesanz R, Delmonico FL, Chapman J. International practices of organ donation. BJA: British Journal of Anaesthesia. 2012;108(Suppl. 1):i48-i55.

4. Rithalia A, McDaid C, Suekarran S, Myers L, Sowden A. Impact of presumed consent for organ donation on donation rates: a systematic review. BMJ. 2009;338:a3162.

5. Blokker B. NRC checkt: 'Kans dat geregistreerde na overlijden donor wordt is 1 op 10.000' [Internet]. 2018 [cited 1 August 2019]. Available from: https://www.nrc.nl/nieuws/2018/01/30/kans-dat-geregistreerdena-overlijden-donor-wordt-is-1-op-10000nrc-checkt-a1590256.

6. Chatterjee P, Venkataramani AS, Vijayan A, Wellen JR, Martin EG. The effect of state policies on organ donation and transplantation in the United States. JAMA Internal Medicine. 2015;175(8):1323-9.

7. Coordinatie Groep Orgaandonatie. Masterplan Orgaandonatie: De vrijblijvendheid voorbij. Den Haag: Coordinatie Groep Orgaandonatie; 2008.

8. Meloen JD. Orgaandonatie in Nederland voor en na de Wet op de Orgaandonatie: trends, achtergronden en organisatie. Utrecht: Nivel; 2000.

9. Centraal Bureau voor de Statistiek. 6,3 miljoen personen in donorregister [Internet]. Den Haag/Heerlen: CBS; 2018 [cited 6 February 2019]. Available from: https://www.cbs.nl/nl-nl/nieuws/2018/32/6-3miljoen-personen-in-donorregister.

10. Jansen NE, van Leiden HA, Haase-Kromwijk BJ, Hoitsma AJ. Organ donation performance in the Netherlands 2005-08; medical record review in 64 hospitals. Nephrology Dialysis Transplantation. 2010;25(6):1992-7.

11. de Groot J, van Hoek M, Hoedemaekers C, Hoitsma A, Schilderman H, Smeets W, et al. Request for organ donation without donor registration: a qualitative study of the perspectives of bereaved relatives. BMC Medical Ethics. 2016;17(1):38.

12. Siminoff LA, Lawrence RH. Knowing patients' preferences about organ donation: does it make a difference? Journal of Trauma and Acute Care Surgery. 2002;53(4):754-60.

13. Nederlandse Transplantatiestichting. Aantal orgaantransplantaties: Aantal orgaantransplantaties met organen van overleden donoren [Internet]. Leiden: NTS; 2019 [cited 3 July 2019]. Available from: https://www.transplantatiestichting.nl/cijfers/organen-jaarcijfers/aantal-orgaantransplantaties.

14. Nederlandse Transplantatiestichting. Wachtlijsten voor organen: Hoeveel patiënten staan op een wachtlijst voor 1 of meer organen? [Internet]. Leiden: NTS; 2019 [cited 3 July 2019]. Available from: https://www.transplantatiestichting.nl/cijfers/organen-jaarcijfers/wachtlijsten-voor-organen.

15. Ploeg R, Berger S, Abdo F, Reinders M. Het orgaandonorregistratiesysteem in Europese landen: Waarom een Actief Donor Registratiestyeem voor Nederland een onmistbaar sluitstuk is bij het terugdringen van wachtlijsten voor patienten die wachten op een donororgaan 2017. Available from: https://nierstichting.nl/ media/filer_public/72/cd/72cd8d9a-7c7f-46b5-b98d-10c6e7d5faOf/201705-nierstichting_rapportorgaandonatie_int.pdf.

16. Kloosterman R, Houwen Kvd. Houdingen ten aanzien van orgaandonatie en orgaanontvangst [Internet]. Den Haag/Heerlen: Centraal Bureau voor de Statistiek; 2012 [cited 16 July 2019]. Available from: https:// www.cbs.nl/nl-nl/achtergrond/2012/15/houdingen-ten-aanzien-van-orgaandonatie-en-orgaanontvangst.

17. Abrahams R. Reconstructie: De Grote Donorshow [Internet]. Hilversum: deLagarde by Varagids; 2017 [cited 17 July 2019]. Available from: https://delagarde.nl/reconstructie-de-grote-donorshow.

18. 2 Miljoen Handtekeningen. Campagnes orgaandonatie kosten minimaal 20 miljoen $€$, maar lever(d)en niets méér op [Internet]. 2015 [cited 1 August 2019]. Available from: http://2mhclub.nl/orgaandonatie/ persbericht-campagnes-orgaandonatie-kostten-20-miljoen-maar-leverden-niets-meer-op/ \#.XUKiQ̨ugzZaQ.

19. Schnabel P. Een jaar Wet op de Orgaandonatie. Nederlands Tijdschrift voor Geneeskunde. 1999;143:600-1.

20. Wakefield C, Watts K, Homewood J, Meiser B, Siminoff L. Attitudes toward organ donation and donor behaviour: a review of the international literature. Progress in Transplantation. 2010;20(4):380-91.

21. O'Carroll RE, Foster C, McGeechan G, Sandford K, Ferguson E. The “ick" factor, anticipated regret, and willingness to become an organ donor. Health Psychology. 2011;30(2):236.

22. van Mossevelde E. Onderzoek: Orgaandonatie [Internet]. Hilversum: 1V Jongerenpanel; 2013 [cited 17 July 2019]. Available from: https://eenvandaag.avrotros.nl/fileadmin/editorial/docs/rapportorgaandonatie.pdf. 
23. Li AHT, Rosenblum AM, Nevis IF, Garg AX. Adolescent classroom education on knowledge and attitudes about deceased organ donation: a systematic review. Pediatric Transplantation. 2013;17(2):119-28.

24. Reubsaet A, Brug J, Nijkamp MD, Candel M, Van Hooff J, Van den Borne H. The impact of an organ donation registration information program for high school students in the Netherlands. Social Science \& Medicine. 2005;60(7):1479-86.

25. Reubsaet A, Brug J, De Vet E, Van Den Borne B. The effects of practicing registration of organ donation preference on self-efficacy and registration intention: An enactive mastery experience. Psychology and Health. 2003;18(5):585-94.

26. Reubsaet A, Brug J, Kitslaar J, Van Hooff J, Van Den Borne H. The impact and evaluation of two schoolbased interventions on intention to register an organ donation preference. Health Education Research. 2004;19(4):447-56.

27. Onderwijs in Cijfers. Ontwikkeling van het aantal deelnemers [Internet]. Den Haag: Ministerie van Onderwijs, Cultuur en Media; 2019 [cited 1 August 2019]. Available from: https://www.onderwijsincijfers. $\mathrm{nl} /$ kengetallen/onderwijs-algemeen/leerlingen-en-studenten/aantallen-ontwikkeling-van-het-aantaldeelnemers.

28. IJzermans J, Haase B. Het donorsysteem werkt alleen goed als iedereen meedoet [Internet]. 2015 [cited 17 July 2019]. Available from: https://www.volkskrant.nl/columns-opinie/het-donorsysteem-werktalleen-goed-als-iedereen-meedoet b89c3515/.

29. Cox D. Naar een goed gevoel: communicatie en niet-registratie bij donorvoorlichting. Den Haag: Wijzer Adviesbureau; 2005.

30. Nijkamp M, Hollestelle M, Zeegers M, Van den Borne B, Reubsaet A. To be(come) or not to be(come) an organ donor, that's the question: a meta analysis of determinant and intervention studies. Health Psychology Review. 2008;2(1):20-40.

31. Peters F, Schmeets H. Bevolkingstrends. Het donorregister: wie doet mee en wie niet? Den Haag/Heerlen: Centraal Bureau voor de Statistiek; 2015.

32. MBO Raad. Feiten en cijfers: Studenten [Internet]. Woerden: MBO Raad; 2019 [cited 1 October 2019]. Available from: https://www.mboraad.nl/het-mbo/feiten-en-cijfers/studenten.

33. MBO Raad. Infographic mbo in Nederland [Internet]. Woerden: MBO Raad; 2019 [cited 1 October 2019]. Available from: https://www.mboraad.nl/infographic-mbo-nederland.

34. Groeneveld M, Steensel Kv. Kenmerkend mbo: Een vergelijkend onderzoek naar de kenmerken van mbo-leerlingen, vmbo-leerlingen en de generatie Einstein. Hilversum: Hiteq; 2009.

35. Wang S, Moss JR, Hiller JE. Applicability and transferability of interventions in evidence-based public health. Health Promotion International. 2005;21(1):76-83.

36. Payne AA, Gottfredson DC, Gottfredson GD. School predictors of the intensity of implementation of school-based prevention programs: results from a national study. Prevention Science. 2006;7(2):225-37.

37. Victora CG, Habicht J-P, Bryce J. Evidence-based public health: moving beyond randomized trials. American Journal of Public Health. 2004;94(3):400-5.

38. Cambon L, Minary L, Ridde V, Alla F. A tool to analyze the transferability of health promotion interventions. BMC Public Health. 2013;13(1):1184.

39. Lesterhuis M. De docent competent. De opvattingen van docenten die lesgeven aan mbo - niveau 1 en 2 [master's thesis]. Utrecht: Utrecht University; 2010.

40. Christoffels I, Groot A, Clement C, Lam J-F. Preventie door interventie. Literatuurstudie naar lees- en schrijfachterstanden bij kinderen en jongeren: prevalentie, relevante factoren en mogelijke interventies. 's-Hertogenbosch: Expertisecentrum Beroepsonderwijs; 2017.

41. Sallis JF, Owen N, Fisher EB. Ecological models of health behavior. In: Glanz K, Rimer BK, Viswanath K, editors. Health behavior and health education: theory, research, and practice, 4th ed. San Francisco, CA, US: Jossey-Bass; 2008. p. 465-85.

42. Noyes J, McLaughlin L, Morgan K, Walton P, Curtis R, Madden S, et al. Short-term impact of introducing a soft opt-out organ donation system in Wales: before and after study. BMJ open. 2019;9(4):e025159-e.

43. Ministerie van Volksgezondheid WeS. Invoering nieuwe donorwet (actieve donorregistratie) [Internet]. Den Haag: Rijksoverheid; 2019 [cited 27 July 2019]. Available from: https://www.rijksoverheid.nl/onderwerpen/orgaandonatie-en-weefseldonatie/actieve-donorregistratie.

44. Johnson EJ, Goldstein D. Do defaults save lives? Science. 2003;302:1338-9.

45. Organ Donation Taskforce. The potential impact of an opt out system for organ donation in the UK. London: Department of Health and Social Care; 2008. 
46. Bramhall S. Presumed consent for organ donation: a case against. Annals of The Royal College of Surgeons of England. 2011;93(4):270-2.

47. Shepherd L, O'Carroll RE, Ferguson E. An international comparison of deceased and living organ donation/ transplant rates in opt-in and opt-out systems: a panel study. BMC Med. 2014;12:131.

48. Taels M, Raaij Fv. Eindrapport: Orgaandonatie, een vervolgonderzoek naar beslissystemen, de donorkaart en het donorformulier. Tilburg: Universiteit van Tilburg; 2009.

49. Dijkstra PA. Voorstel van wet van het lid Pia Dijkstra tot wijziging van de Wet op de orgaandonatie in verband met het opnemen van een actief donorregistratiesysteem [Internet]. Den Haag: Tweede Kamer der Staten Generaal; 2019 [cited 19 July 2019]. Available from: https://www.tweedekamer.nl/kamerstukken/wetsvoorstellen/detail?cfg=wetsvoorsteldetails\&qry=wetsvoorstel\%3A33506.

50. Eerste Kamer der Staten Generaal. Initatiefvoorstel - Pia Dijkstra over het opnemen van een actief donorregistratiesysteem: hoofdelijke stemming [Internet]. Den Haag: Eerste Kamer der Staten Generaal; 2018 [cited 19 July 2019]. Available from: https://www.eerstekamer.nl/id/vkmOe3pn05hu/document_ extern/33506_hoofdelijke_stemming_wetsvoor/f=/vkmOe4c1e7ka.pdf.

51. NOS. Na aannemen donorwet ruim 30.000 nieuwe nee-registratie [Internet]. 2018 [cited 19 July 2019]. Available from: https://nos.nl/artikel/2217153-na-aannemen-donorwet-ruim-30-000-nieuwe-nee-r egistraties.html.

52. Mossialos E, Costa-Font J, Rudisill C. Does organ donation legislation affect individuals' willingness to donate their own or their relative's organs? Evidence from European Union survey data. BMC Health Services Research. 2008;8:48.

53. Symvoulakis EK, Markaki A, Galanakis C, Klinis S, Morgan M, Jones R. Shifting towards an opt-out system in Greece: a general practice based pilot study. International Journal of Medical Sciences. 2013;10(11):1547-51.

54. Ministerie van Volksgezondheid, Welzijn en Sport. Je keuze vastleggen. Dat doe je voor elkaar. Den Haag: Rijksoverheid; 2018.

55. Matesanz R. Newsletter transplant: international figures on donation and transplantation 2014. Strasbourg: EDQM; 2015.

56. Ministerie van Volksgezondheid, Welzijn en Sport. Overzicht registraties [Internet]. 2016 [cited 15 November 2016]. Available from: https://www.donorregister.nl/over-het-donorregister/cijfers.

57. Frutos M, Blanca M, Mansilla J, Rando B, Ruiz P, Guerrero F, et al. Organ donation: a comparison of donating and nondonating families. Transplantation Proceedings. 2005;37(3):1557-9.

58. Centraal Bureau voor de Statistiek. Statline: Donorregistratie; persoonskenmerken [Internet]. Den Haag/Heerlen: CBS; 2016 [updated 12-10-2016; cited 25 November 2016]. Available from: http://statline.cbs.nl/Statweb/publication/?DM=SLNL\&PA=82814NED\&D1=a\&D2=a\&D3=I\&VW=T.

59. Coppen R, Friele RD, Gevers SK, Van Der Zee J. Donor education campaigns since the introduction of the Dutch organ donation act: increased cohesion between campaigns has paid off. Transplant International. 2010;23(12):1239-46.

60. Coppen R, Friele RD, Marquet RL, Gevers SK. Opting-out systems: no guarantee for higher donation rates. Transplant International. 2005;18(11):1275-9.

61. Ministerie van Volksgezondheid, Welzijn en Sport. Respons aanschrijvingen - jongeren [Internet]. Den Haag: Rijksoverheid; 2016 [cited 4 March 2019]. Available from: https://web.archive.org/ web/20170314103917/https://www.donorregister.nl/cijfers/responsaanschrijvingen/jongeren.

62. Albright CL, Glanz K, Wong L, Dela Cruz MR, Abe L, Sagayadoro TL. Knowledge and attitudes about deceased donor organ donation in Filipinos: a qualitative assessment. Transplantation Proceedings. 2005;37(10):4153-8.

63. Molzahn AE, Starzomski R, McDonald M, O'Loughlin C. Aboriginal beliefs about organ donation: some Coast Salish viewpoints. Canadian Journal of Nursing Research. 2004;36(4):110-28.

64. Sanner MA. Exchanging spare parts or becoming a new person? People's attitudes towards receiving and donating organs. Social Science and Medicine. 2001;52(10):1491-9.

65. Irving MJ, Jan S, Tong A, Wong G, Craig JC, Chadban S, et al. What factors influence people's decisions to register for organ donation? The results of a nominal group study. Transplant International. 2014;27(6):617-24.

66. Centraal Bureau voor de Statistiek. Niet-westerse allochtoon [Internet]. Den Haag/Heerlen: CBS; 2017 [cited 13 June 2017]. Available from: https://www.cbs.nl/nl-nl/dossier/_links\%20oude\%20site/nietwesters-allochtoon. 
67. Gorsuch RL. Psychology of religion. Annual Review of Psychology. 1988;39(1):201-21.

68. Gorsuch RL, McPherson SE. Intrinsic/extrinsic measurement: I/E-revised and single-item scales. Journal for the Scientific Study of Religion. 1989:348-54.

69. Eldredge LKB, Markham CM, Ruiter RA, Fernández ME, Kok G, Parcel GS. Planning health promotion programs: an intervention mapping approach. San Fransisco, CA: John Wiley \& Sons; 2016.

70. Newton JD. How does the general public view posthumous organ donation? A meta-synthesis of the qualitative literature. BMC Public Health. 2011;11(1):791.

71. Braun KL, Nichols R. Death and dying in four Asian American cultures: a descriptive study. Death Studies. 1997;21(4):327-59.

72. Randhawa G. An exploratory study examining the influence of religion on attitudes towards organ donation among the Asian population in Luton, UK. Nephrology Dialysis Transplantation. 1998;13(8):1949-54.

73. Davis C, Randhawa G. The influence of religion on organ donation and transplantation among the Black Caribbean and Black African population - a pilot study in the United Kingdom. Ethnicity and Disease. 2006;16(1):281-5

74. Exley C, Sim J, Reid N, Jackson S, West N. Attitudes and beliefs within the Sikh community regarding organ donation: a pilot study. Social Science and Medicine. 1996;43(1):23-8.

75. Thompson VLS. Educating the African-American community on organ donation. Journal of the National Medical Association. 1993;85(1):17-9.

76. Arriola KRJ, Perryman JP, Doldren M. Moving beyond attitudinal barriers: understanding African Americans' support for organ and tissue donation. Journal of the National Medical Association. 2005;97(3):339-50.

77. Morgan SE, Harrison TR, Afifi WA, Long SD, Stephenson MT. In their own words: the reasons why people will (not) sign an organ donor card. Health Communication. 2008;23(1):23-33.

78. Davis C, Randhawa G. "Don't know enough about it!": awareness and attitudes toward organ donation and transplantation among the Black Caribbean and Black African population in Lambeth, Southwark, and Lewisham, United Kingdom. Transplantation. 2004;78(3):420-5.

79. Nizza IE, Britton HP, Smith JA. 'You have to die first': exploring the thoughts and feelings on organ donation of British women who have not signed up to be donors. Journal of Health Psychology. 2016;21(5):650-60.

80. Reubsaet A, van den Borne B, Brug J, Pruyn J, van Hooff H. Determinants of the intention of Dutch adolescents to register as organ donors. Social Science \& Medicine. 2001;53(3):383-92.

81. Sirois BC, Sears Jr SF, Marhefka S. Do new drivers equal new donors? An examination of factors influencing organ donation attitudes and behaviors in adolescents. Journal of Behavioral Medicine. 2005;28(2):201-12.

82. Bokhorst CL, Sumter SR, Westenberg PM. Social support from parents, friends, classmates, and teachers in children and adolescents aged 9 to 18 years: who is perceived as most supportive? Social Development. 2010;19(2):417-26.

83. Morgan M, Mayblin M, Jones R. Ethnicity and registration as a kidney donor: the significance of identity and belonging. Social Science and Medicine. 2008;66.

84. Moloney G, Walker I. Talking about transplants: social representations and the dialectical, dilemmatic nature of organ donation and transplantation. British Journal of Social Psychology. 2002;41(2):299-320.

85. Sanner MA. Attitudes toward organ donation and transplantation: a model for understanding reactions to medical procedures after death. Social Science and Medicine. 1994;38(8):1141-52.

86. Arriola KRJ, Perryman JP, Doldren MA, Warren CM, Robinson DHZ. Understanding the role of clergy in African American organ and tissue donation decision-making. Ethnicity and Health. 2007;12(5):465-82.

87. Kennedy K. Organ donation and transplantation in India: an inquiry in Kerala. Journal of Social Distress and the Homeless. 2002;11(1):41-67.

88. Fahrenwald NL, Stabnow W. Sociocultural perspective on organ and tissue donation among reservationdwelling American Indian adults. Ethnicity and Health. 2005;10(4):341-54.

89. Bhengu BR, Uys HHM. Organ donation and transplantation within the Zulu culture. Curationis. 2004;27(3):24-33.

90. Peters TG, Kittur DS, McGaw LJ, First MR, Nelson EW. Organ donors and nondonors: an American dilemma. Archives of Internal Medicine. 1996;156(21):2419-24.

91. van Harreveld F, van der Pligt J, de Vries NK. The structure of attitudes: attribute importance, accessibility and judgement. The British Journal of Social Psychology. 2000;39:363. 
92. Fishbein M, Ajzen I. Predicting and changing behavior: the reasoned action approach. New York/Hove: Psychology Press, Taylor \& Francis Group; 2010.

93. Crutzen R, Peters G-JY, Noijen J. Using confidence interval-based estimation of relevance to select social-cognitive determinants for behavior change interventions. Frontiers in Public Health. 2017;5(165).

94. Rosenthal JA. Qualitative descriptors of strength of association and effect size. Journal of Social Service Research. 1996;21(4):37-59.

95. Hughes CC, Jones AL, Feemster KA, Fiks AG. HPV vaccine decision making in pediatric primary care: a semi-structured interview study. BMC Pediatrics. 2011;11(1):74.

96. Stevens $C$. Applying a single category implicit association test methodology to organ donation attitudes-assessing the gap between implicit and explicit beliefs [bachelor's thesis]. Oxford: Oxford Brookes University; 2013.

97. Strack F, Deutsch R. Reflective and impulsive determinants of social behavior. Personality and Social Psychology Review. 2004;8(3):220-47.

98. Moinester M, Gottfried R. Sample size estimation for correlations with pre-specified confidence interval. The Quantitative Methods for Psychology. 2014;10(2):124-30.

99. AlKhawari FS, Stimson GV, Warrens AN. Attitudes towards transplantation in U.K. Muslim Indo-Asians in West London. American Journal of Transplantation. 2005;5(6):1326-31.

100. Brug J, van Vugt M, van Den Borne B, Brouwers A, van Hooff H. Predictors of willingness to register as an organ donor among Dutch adolescents. Psychology and Health. 2000;15(3):357-68.

101. Frates J, Garcia Bohrer G. Hispanic perceptions of organ donation. Progress in Transplantation. 2002;12(3):169-75.

102. Hayward C, Madill A. The meanings of organ donation: Muslims of Pakistani origin and white English nationals living in North England. Social Science and Medicine. 2003;57(3):389-401.

103. Lai AL, Dermody J, Hanmer-Lloyd S. Shedding the cocoon: a 'mortal embodiment' perspective of organ donation in supporting and enhancing life. Advances in Consumer Research. 2007;34:167-74.

104. Molzahn AE, Starzomski R, McDonald M, O'Loughlin C. Chinese Canadian beliefs toward organ donation. Qualitative Health Research. 2005;15(1):82-98.

105. Molzahn AE, Starzomski R, McDonald M, O'Loughlin C. Indo-Canadian beliefs regarding organ donation. Progress in Transplantation. 2005;15(3):233-9.

106. Morgan SE, Harrison TR, Long SD, Afifi WA, Stephenson MS, Reichert T. Family discussions about organ donation: how the media influences opinions about donation decisions. Clinical Transplantation. 2005;19(5):674-82.

107. Reubsaet A, Brug J, van den Borne B, van Hooff H. Predictors of organ donation registration among Dutch adolescents. Transplantation. 2001;72(1):51-6.

108. Trompeta JA, Cooper BA, Ascher NL, Kools SM, Kennedy CM, Chen J-L. Asian American adolescents' willingness to donate organs and engage in family discussion about organ donation and transplantation. Progress in Transplantation. 2012;22(1):33-70.

109. Wittig DR. Organ donation beliefs of African American women residing in a small southern community. Journal of Transcultural Nursing. 2001;12(3):203-10.

110. Nederlandse Transplantatiestichting. Jaarverslag 2015: samen sterker. Leiden: Nederlandse Transplantatiestichting; 2015.

111. Bandura A. Self-efficacy: The exercise of control. New York, NY: W H Freeman/Times Books/ Henry Holt \& Co; 1997.

112. Kohl FML, Crutzen R, de Vries KN. Online prevention aimed at lifestyle behaviors: a systematic review of reviews. Journal of Medical Internet Research. 2013;15(7):e146.

113. Cobiac LJ, Vos T, Barendregt JJ. Cost-effectiveness of interventions to promote physical activity: a modelling study. PLoS Med. 2009;6(7):e1000110.

114. Tieben N, de Graaf PM, de Graaf ND. Changing effects of family background on transitions to secondary education in the Netherlands: consequences of educational expansion and reform. Research in Social Stratification and Mobility. 2010;28(1):77-90.

115. Siminoff LA, Gordon N, Hewlett J, Arnold RM. Factors influencing families' consent for donation of solid organs for transplantation. Journal of the American Medical Association. 2001;286(1):71-7.

116. Heij K, Haitjema T, Lam JF. Taalniveau in het MBO. Lienden: Bureau ICE; 2008.

117. Steenaart E, Crutzen R, de Vries NK. Complexity of organ donation registration: determinants of registration behavior among lower-educated adolescents. Transplantation Proceedings.

2018;50(10):2911-23. 
118. Steckler AB, Linnan L, Israel B. Process evaluation for public health interventions and research. San Francisco, CA: Jossey-Bass; 2002.

119. Wilding S, Conner M, Sandberg T, Prestwich A, Lawton R, Wood C, et al. The question-behaviour effect: a theoretical and methodological review and meta-analysis. European Review of Social Psychology. 2016;27(1):196-230.

120. Gruijters SL. Baseline comparisons and covariate fishing: bad statistical habits we should have broken yesterday. European Health Psychologist. 2016;18(5):205-9.

121. Browne WJ, Lahi MG, Parker RM. A guide to sample size calculations for random effect models via -simulation and the MLPowSim software package. Bristol, United Kingdom: University of Bristol; 2009.

122. Ivers NM, Halperin IJ, Barnsley J, Grimshaw JM, Shah BR, Tu K, et al. Allocation techniques for balance at baseline in cluster randomized trials: a methodological review. Trials. 2012;13(1):120.

123. Candel MJ, Van Breukelen GJ. Sample size adjustments for varying cluster sizes in cluster randomized trials with binary outcomes analyzed with second-order PQL mixed logistic regression. Statistics in Medicine. 2010;29(14):1488-501.

124. Rogers EM. Diffusion of innovations. 4th ed. New York City, NY: Simon and Schuster; 2010.

125. Crutzen R, Roosjen JL, Poelman J. Using Google Analytics as a process evaluation method for Internetdelivered interventions: an example on sexual health. Health Promotion International. 2013;28(1):36-42.

126. Adami M, Kiger A. The use of triangulation for completeness purposes. Nurse Researcher. 2004;12(4):19-29.

127. Hussein A. The use of triangulation in social sciences research: can qualitative and quantitative methods be combined? Journal of Comparative Social Work. 2015;4(1):1-12.

128. Stichting Lezen en Schrijven. Laaggeletterdheid in Nederland [Internet]. Den Haag: Stichting Lezen en Schrijven; 2017 [cited 6 February 2018]. Available from: https://www.lezenenschrijven.nl/overlaaggeletterdheid/.

129. Steenaart E, Crutzen R, Candel MJ, de Vries NK. A web-based education program to encourage organ donation registration among lower-educated adolescents in the Netherlands: study protocol for a cluster randomized controlled trial. Trials. 2018;19(1):532.

130. Stroup WW. Generalized linear mixed models: modern concepts, methods and applications. Boca Raton, FL: CRC press; 2012.

131. Benjamini Y, Hochberg Y. Controlling the false discovery rate: a practical and powerful approach to multiple testing. Journal of the Royal statistical society: series B (Methodological). 1995;57(1):289-300

132. Peters G-JY, Abraham C, Crutzen R. Full disclosure: doing behavioural science necessitates sharing. The European Health Psychologist. 2012;14(4):77-84.

133. MBO Raad. Feiten en cijfers: Studenten [Internet]. Woerden: MBO Raad; 2017 [cited 19 January 2019]. Available from: https://www.mboraad.nl/het-mbo/feiten-en-cijfers/studenten.

134. Sommet N, Morselli D. Keep calm and learn multilevel logistic modeling: a simplified three-step procedure using Stata, R, Mplus, and SPSS. International Review of Social Psychology. 2017;30(1):203-18.

135. Merion RM, Vinokur AD, Couper MP, Jones EG, Dong Y, Wimsatt M, et al. Internet-based intervention to promote organ donor registry participation and family notification. Transplantation. 2003;75(8):1175-9.

136. Anantachoti P, Gross CR, Gunderson S. Promoting organ donation among high school students: an educational intervention. Progress in Transplantation. 2001;11(3):201-7.

137. Cárdenas V, Thornton JD, Wong KA, Spigner C, Allen MD. Effects of classroom education on knowledge and attitudes regarding organ donation in ethnically diverse urban high schools. Clinical Transplantation. 2010;24(6):784-93.

138. Smits M, Van Den Borne B, Dijker AJ, Ryckman RM. Increasing Dutch adolescents' willingness to register their organ donation preference: the effectiveness of an education programme delivered by kidney transplantation patients. The European Journal of Public Health. 2005;16(1):106-10.

139. Tamburlin JA, Thompson SJ, Simon M. Life and death decisions: using school-based health education to facilitate family discussion about organ and tissue donation. Death Studies. 2004;28(7):643-57.

140. Steenaart E, Crutzen R, de Vries NK. Implementation of an interactive organ donation education program for Dutch lower-educated students: a process evaluation. BMC Public Health. 2020;20(1):739.

141. Steenaart E, Crutzen R, de Vries NK. Geen bezwaar tegen de nieuwe donorwet, maar wel nog meer verantwoordelijkheid. Tijdschrift voor Gezondheidswetenschappen. 2018;96(3):134-5.

142. Ralph A, Chapman JR, Gillis J, Craig JC, Butow P, Howard K, et al. Family perspectives on deceased organ donation: thematic synthesis of qualitative studies. American Journal of Transplantation. 2014;14(4):923-35. 
143. Nederlandse Transplantatiestichting. Jaarverslag 2017: Verbinden voor leven. Leiden: Nederlandse Transplantatiestichting; 2017.

144. Vinokur AD, Merion RM, Couper MP, Jones EG, Dong Y. Educational web-based intervention for high school students to increase knowledge and promote positive attitudes toward organ donation. Health Education \& Behavior. 2006;33(6):773-86.

145. Steenaart E, Crutzen R, Candel M, de Vries NK. The effectiveness of an interactive organ donation education intervention for Dutch lower-educated students: a cluster randomized controlled trial. Trials. 2019;20(1):643.

146. Bandura A. Social foundations of thought and action: a social cognitive theory. Englewood Cliffs, NJ: Prentice-Hall; 1986.

147. Guest G, MacQueen KM, Namey EE. Applied thematic analysis. Thousand Oaks, CA: Sage Publications; 2011.

148. Larson RJ, Woloshin S, Schwartz LM, Welch HG. Celebrity endorsements of cancer screening. Journal of the National Cancer Institute. 2005;97(9):693-5.

149. Sabel MS, Dal Cin S. Trends in media reports of celebrities' breast cancer treatment decisions. Annals of Surgical Oncology. 2016;23(9):2795-801.

150. Hoffman SJ, Tan C. Biological, psychological and social processes that explain celebrities' influence on patients' health-related behaviors. Archives of Public Health. 2015;73(1):3.

151. Panis K, Van Den Bulck H. Celebrities' quest for a better world: Understanding Flemish public perceptions of celebrities' societal engagement. Javnost-The Public. 2012;19(3):75-92.

152. Brown WJ, Basil MD, Bocarnea MC. The influence of famous athletes on health beliefs and practices: Mark McGwire, child abuse prevention, and androstenedione. Journal of Health Communication. 2003;8(1):41-57.

153. Brown WJ, De Matviuk MAC. Sports celebrities and public health: Diego Maradona's influence on drug use prevention. Journal of Health Communication. 2010;15(4):358-73.

154. Yoo W. The influence of celebrity exemplars on college students' smoking. Journal of American College Health. 2016;64(1):48-60.

155. Durlak JA, DuPre EP. Implementation matters: A review of research on the influence of implementation on program outcomes and the factors affecting implementation. American Journal of Community Psychology. 2008;41(3-4):327-50.

156. Ringwalt CL, Ennett S, Johnson R, Rohrbach LA, Simons-Rudolph A, Vincus A, et al. Factors associated with fidelity to substance use prevention curriculum guides in the nation's middle schools. Health Education \& Behavior. 2003;30(3):375-91.

157. Chambers DA, Glasgow RE, Stange KC. The dynamic sustainability framework: addressing the paradox of sustainment amid ongoing change. Implementation Science. 2013;8(1):117.

158. Hansen WB, Pankratz MM, Dusenbury L, Giles SM, Bishop DC, Albritton J, et al. Styles of adaptation: the impact of frequency and valence of adaptation on preventing substance use. Health Education. 2013;113(4):345-63.

159. Lendrum A, Humphrey N, Greenberg M. Implementing for success in school-based mental health promotion: the role of quality in resolving the tension between fidelity and adaptation. Shute R, Slee $P$, editors. London: Routledge; 2016. 53-63 p.

160. US Department of Health and Human Services. Finding the balance: program fidelity and adaptation in substance abuse prevention. Washington: USDHHS; 2002.

161. Botvin GJ. Advancing prevention science and practice: challenges, critical issues, and future directions. Prevention Science. 2004;5(1):69-72.

162. Dusenbury L, Brannigan R, Falco M, Hansen WB. A review of research on fidelity of implementation: implications for drug abuse prevention in school settings. Health Education Research. 2003;18(2):237-56.

163. Hall G, Hord SM. Implementing change: patterns, principles, and potholes. 4th ed. Upper Saddle River, NJ: Pearson; 2014.

164. White D, Pitts M. Health promotion with young people for the prevention of substance misuse. London: Health Education Authority; 1997.

165. McBride N. A systematic review of school drug education. Health Education Research. 2003;18(6):729-42.

166. Alharbi M, Gallagher R, Kirkness A, Sibbritt D, Tofler G. Long-term outcomes from Healthy Eating and Exercise Lifestyle Program for overweight people with heart disease and diabetes. European Journal of Cardiovascular Nursing. 2016;15(1):91-9.

167. Goldberg L, Lockwood C, Garg B, Kuehl KS. Healthy team healthy U: a prospective validation of an evidence-based worksite health promotion and wellness platform. Frontiers in Public Health. 2015;3:188. 
168. Figueroa C, Mesfum E, Acton N, Kunst A. Medical students' knowledge and attitudes toward organ donation: results of a Dutch survey. Transplantation Proceedings. 2013;45(6):2093-7.

169. Feeley TH. College students' knowledge, attitudes, and behaviors regarding organ donation: an integrated review of the literature. Journal of Applied Social Psychology. 2007;37(2):243-71.

170. Kressel LM, Chapman GB, Leventhal E. The influence of default options on the expression of end-of-life treatment preferences in advance directives. Journal of General Internal Medicine. 2007;22(7):1007-10.

171. Schweitzer M, Hershey JC, Asch DA. Individual choice in spending accounts can we rely on employees to choose well? Medical Care. 1996;34(6):583-93.

172. Blumenthal-Barby JS, Burroughs H. Seeking better health care outcomes: the ethics of using the "nudge". The American Journal of Bioethics. 2012;12(2):1-10.

173. Hanssens C. Legal and ethical implications of opt-out HIV testing. Clinical Infectious Diseases. 2007;45(Suppl. 4):S232-9.

174. Sheeran P. Intention-behavior relations: a conceptual and empirical review. European Review of Social Psychology. 2002;12(1):1-36.

175. Voyer B. 'Nudging'behaviours in healthcare: Insights from behavioural economics. British Journal of Healthcare Management. 2015;21(3):130-5.

176. O'Connor AM. Validation of a Decisional Conflict Scale. Medical Decision Making. 1995;15(1):25-30.

177. Bovens L. The ethics of nudge. In: Grüne-Yanoff T, Hansson, S.O., editor. Preference change: approaches from philosophy, economics and psychology. Berlin/New York: Springer, Theory and Decision Library A; 2009. p. 207-20.

178. Jacob M-A. Another look at the presumed-versus-informed consent dichotomy in postmortem organ procurement. Bioethics. 2006;20(6):293-300.

179. Arvanitis A, Kalliris K, Kaminiotis K. Are defaults supportive of autonomy? An examination of nudges under the lens of Self-Determination Theory. The Social Science Journal. 2019.

180. Van Petegem S, Soenens B, Vansteenkiste M, Beyers W. Rebels with a cause? Adolescent defiance from the perspective of reactance theory and self-determination theory. Child Development. 2015;86(3): 903-18.

181. O'Connor AM, Drake ER, Wells GA, Tugwell P, Laupacis A, Elmslie T. A survey of the decision-making needs of Canadians faced with complex health decisions. Health Expectations. 2003;6(2):97-109.

182. Sunstein CR. Do people like nudges. Administrative Law Review. 2016(2):177-232.

183. Deci EL, Ryan RM. The "what" and "why" of goal pursuits: human needs and the self-determination of behavior. Psychological Inquiry. 2000;11(4):227-68.

184. Moseley A, Stoker G. Putting public policy defaults to the test: the case of organ donor registration. International Public Management Journal. 2015;18(2):246-64.

185. Faul F, Erdfelder E, Buchner A, Lang A-G. Statistical power analyses using G^ Power 3.1: tests for correlation and regression analyses. Behavior Research Methods. 2009;41(4):1149-60.

186. Van Petegem S, Zimmer-Gembeck MJ, Soenens B, Vansteenkiste M, Brenning K, Mabbe E, et al. Does general parenting context modify adolescents' appraisals and coping with a situation of parental regulation? The case of autonomy-supportive parenting. Journal of Child and Family Studies. 2017;26(9):2623-39.

187. Centraal Bureau voor de Statistiek. 42 procent geregistreerd in Donorregister [Internet]. Den Haag/ Heerlen: CBS; 2019 [cited 19 May 2020]. Available from: https://www.cbs.nl/nl-nl/nieuws/2019/21/42procent-geregistreerd-in-donorregister.

188. Mackay D, Robinson A. The ethics of organ donor registration policies: nudges and respect for autonomy. The American Journal of Bioethics. 2016;16(11):3-12.

189. Bester JC, Gross JA. Organ donor registration reconsidered: how current practices strain autonomy. The American Journal of Bioethics. 2016;16(11):33-5.

190. Taylor JS. Personal autonomy, posthumous harm, and presumed consent policies for organ procurement. Public Affairs Quarterly. 2006;20(4):381-404.

191. Gill MB. Presumed consent, autonomy, and organ donation. Journal of Medicine and Philosophy. 2004;29(1):37-59

192. Ritchie KC, Chorney J, Hong P. Parents' decisional conflict, self-determination and emotional experiences in pediatric otolaryngology: A prospective descriptive-comparative study. International Journal of Pediatric Otorhinolaryngology. 2016;86:114-7.

193. Van Dalen HP, Henkens K. Comparing the effects of defaults in organ donation systems. Social Science \& Medicine. 2014;106:137-42. 
194. Rolink M, Heijmans M, Rademakers J. Communicatie over de nieuwe donorwet: Aandachtspunten bij mensen met beperkte gezondheidsvaardigheden. Utrecht: Nivel; 2019.

195. Webb TL, Sheeran P. Does changing behavioral intentions engender behavior change? A meta-analysis of the experimental evidence. Psychological Bulletin. 2006;132(2):249.

196. Schütt GR. 25 years of organ donation: European initiatives to increase organ donation. Transplantation Proceedings. 2002;34(6):2005-6.

197. Guy BS, Aldridge A. Marketing organ donation around the globe. Marketing Health Services. 2001;21(4):30.

198. Gelo O, Braakmann D, Benetka G. Quantitative and qualitative research: beyond the debate. Integrative Psychological and Behavioral Science. 2008;42(3):266-90.

199. de Vries H, Weijts W, Dijkstra M, Kok G. The utilization of qualitative and quantitative data for health education program planning, implementation, and evaluation: a spiral approach. Health Education Quarterly. 1992;19(1):101-15.

200. Neuvel J, Bersee T, Exter dH, Tijssen M. Nederlands in het middelbaar beroepsonderwijs. 's Hertogenbosch: CINOP; 2004.

201. Willis G. Cognitive evaluation of survey instruments: state of science and future directions. In: Krosnick JA, Presser S, Fealing KH, Ruggles S, Vannette DL, editors. The future of survey research: challenges and opportunities. Alexandria, VA: The National Science Foundation Advisory Committee for the Social, Behavioral and Economic Sciences Subcommittee on Advancing SBE Survey Research; 2015. p. 74-7.

202. Willis GB, Artino Jr AR. What do our respondents think we're asking? Using cognitive interviewing to improve medical education surveys. Journal of Graduate Medical Education. 2013;5(3):353-6.

203. Tourangeau R, Yan T. Sensitive questions in surveys. Psychological Bulletin. 2007;133(5):859.

204. Hochstim JR. A critical comparison of three strategies of collecting data from households. Journal of the American Statistical Association. 1967;62(319):976-89.

205. Johnson TP. Sources of error in substance use prevalence surveys. International Scholarly Research Notices. 2014:923290.

206. Singer E, Von Thurn DR, Miller ER. Confidentiality assurances and response: a quantitative review of the experimental literature. Public Opinion Quarterly. 1995;59(1):66-77.

207. Ruiter RA, Crutzen R. Core processes: how to use evidence, theories and research in planning behavior change interventions. Frontiers in Public Health, section Public Health Education and Promotion. 2020: In Press. doi:10.31234/osf.io/j4ftz.

208. Morgan S, Miller J. Communicating about gifts of life: the effect of knowledge, attitudes, and altruism on behavior and behavioral intentions regarding organ donation. Journal of Applied Communication Research. 2002;30(2):163-78.

209. Wu AMS, Tang CS, Yogo M. Death anxiety, altruism, self-efficacy, and organ donation intention among Japanese college students: a moderated mediation analysis. Australian Journal of Psychology. 2013;65(2):115-23.

210. Nagel T. The possibility of altruism. Princeton, NJ: Princeton University Press; 1978.

211. Fazio RH, Olson MA. Implicit measures in social cognition research: their meaning and use. Annual Review of Psychology. 2003;54(1):297-327.

212. Vrabel J, Zeigler-Hill V. Standard Social Science Model (SSSM) of Personality. In: Zeigler-Hill V, Shackelford TK, editors. Encyclopedia of personality and individual differences. New York, NY: Springer; 2017.

213. Muschalik C, Crutzen R, Candel MJJM, Elfeddali I, de Vries H. Implicit attitudes and explicit cognitions jointly predict a reduced red meat intake: a three-wave longitudinal study. Health Psychology and Behavioral Medicine. 2020;8(1):73-95.

214. Greenwald AG, McGhee DE, Schwartz JL. Measuring individual differences in implicit cognition: the implicit association test. Journal of Personality and Social Psychology. 1998;74(6):1464-80.

215. Karpinski A, Steinman RB. The single category implicit association test as a measure of implicit social cognition. Journal of Personality and Social Psychology. 2006;91(1):16.

216. Joshi MS, Stevens C. Implicit attitudes to organ donor registration: altruism and distaste. Health Psychology and Behavioral Medicine. 2017;5(1):14-28.

217. Hübner G, Mohs A, Petersen LE. The role of attitude strength in predicting organ donation behaviour by implicit and explicit attitude measures. Open Journal of Medical Psychology. 2014;3:355-63.

218. Farrelly CM, Schwartz SJ, Amodeo AL, Feaster DJ, Steinley DL, Meca A, et al. The analysis of bridging constructs with hierarchical clustering methods: an application to identity. Journal of Research in Personality. 2017;70:93-106. 
219. Dimitrov DM, Atanasov DV. Conjunctive and disjunctive extensions of the least squares distance model of cognitive diagnosis. Educational and Psychological Measurement. 2012;72(1):120-38.

220. Mkhitaryan S, Crutzen R, Steenaart E, de Vries NK. Network approach in health behavior research: how can we explore new questions? Health Psychology and Behavioral Medicine. 2019;7(1):362-84.

221. Crutzen R, Peters G-JY. The book of behavior change (1st Ed.). doi:10.5281/zenodo.35709672019.

222. Peters G-J. RDocumentation: CIBER [Internet]. 2019 [cited 8 May 2020]. Available from: https://www.rdocumentation.org/packages/behaviorchange/versions/0.2.0/topics/CIBER.

223. Peters LWH, Kok G, Ten Dam GTM, Buijs GJ, Paulussen TGWM. Effective elements of school health promotion across behavioral domains: a systematic review of reviews. BMC Public Health. 2009;9(1):182.

224. Weaver M, Spigner C, Pineda M, Rabun KG, Allen MD. Knowledge and opinions about organ donation among urban high school students: pilot test of a health education program. Clinical Transplantation. 2000;14(4):292-303.

225. Hoelscher DM, Evans A, Parcel G, Kelder S. Designing effective nutrition interventions for adolescents. Journal of the American Dietetic Association. 2002;102(3, Supplement):S52-63.

226. Craig P, Dieppe P, Macintyre S, Michie S, Nazareth I, Petticrew M. Developing and evaluating complex interventions: the new Medical Research Council guidance. BMJ. 2008;337:a1655.

227. Cambon L, Minary L, Ridde V, Alla F. Transferability of interventions in health education: a review. BMC Public Health. 2012;12(1):497.

228. Martín Cantera C, Puigdomènech E, Ballvé JL, Arias OL, Clemente L, Casas R, et al. Effectiveness of multicomponent interventions in primary healthcare settings to promote continuous smoking cessation in adults: a systematic review. BMJ Open. 2015;5(10):e008807.

229. Kreuter MW, Caburnay CA, Chen JJ, Donlin MJ. Effectiveness of individually tailored calendars in promoting childhood immunization in urban public health centers. American Journal of Public Health. 2004;94(1):122-7.

230. Kreuter MW, Oswald DL, Bull FC, Clark EM. Are tailored health education materials always more effective than non-tailored materials? Health Education Research. 2000;15(3):305-15.

231. Krebs P, Prochaska JO, Rossi JS. A meta-analysis of computer-tailored interventions for health behavior change. Preventive Medicine. 2010;51(3):214-21.

232. Bopp M, Saunders RP, Lattimore D. The tug-of-war: fidelity versus adaptation throughout the health promotion program life cycle. The Journal of Primary Prevention. 2013;34(3):193-207.

233. Campbell MJ, Donner A, Klar N. Developments in cluster randomized trials and statistics in medicine. Statistics in Medicine. 2007;26(1):2-19.

234. Peters G-JY, De Bruin M, Crutzen R. Everything should be as simple as possible, but no simpler: towards a protocol for accumulating evidence regarding the active content of health behaviour change interventions. Health Psychology Review. 2015;9(1):1-14.

235. Farmer A, Wade A, Goyder E, Yudkin P, French D, Craven A, et al. Impact of self monitoring of blood glucose in the management of patients with non-insulin treated diabetes: open parallel group randomised trial. BMJ (Clinical research ed). 2007;335(7611):132.

236. Bellg AJ, Borrelli B, Resnick B, Hecht J, Minicucci DS, Ory M, et al. Enhancing treatment fidelity in health behavior change studies: best practices and recommendations from the NIH Behavior Change Consortium. Health Psychology. 2004;23(5):443.

237. Alden $\mathrm{DL}$, Cheung $\mathrm{AH}$. Organ donation and culture: a comparison of Asian American and European American beliefs, attitudes, and behaviors. Journal of Applied Social Psychology. 2000;30(2):293-314.

238. Lock M, Crowley-Makota M. Situating the practice of organ donation in familial, cultural, and political context. Transplantation Reviews. 2008;22(3):154-7.

239. Evers KA, Lewis DD, Schaeffer MJ. Sociological and cultural factors affecting consent for organ donation. Critical Care Nurse. 1999;19(4):57.

240. Schulz PJ, Nakamoto K, Brinberg D, Haes J. More than nation and knowledge: cultural micro-diversity and organ donation in Switzerland. Patient Education and Counseling. 2006;64(1-3):294-302.

241. Cotrau P, Hodosan V, Vladu A, Daina C, Daina LG, Pantis C. Ethical, socio-cultural and religious issues in organ donation. Maedica. 2019;14(1):12-4.

242. Horton RL, Horton PJ. Knowledge regarding organ donation: identifying and overcoming barriers to organ donation. Social Science \& Medicine. 1990;31(7):791-800.

243. Shepherd L, O'Carroll RE. Awareness of legislation moderates the effect of opt-out consent on organ donation intentions. Transplantation. 2013;95(8):1058-63. 
244. Parcel GS, Kelder SH, Basen-Engquist K. The school as a setting for health promotion. In: Poland BD, Green LW, Rootman I, editors. Settings for health promotion: linking theory and practice. Thousand Oaks, CA: Sage Publications; 2000. p. 86-119.

245. Barry MM, Margaret M. Death education: knowledge, attitudes, and perspectives of Irish parents and teachers. Death Studies. 2000;24(4):325-33.

246. van Gaalen R, Bakker B, van der Laan J, Westerman S, Scholtus S. Bevolkingstrends 2014. Hoeveel ouderlijk gezang klinkt door in het gepiep van de jongen? Over de samenhang tussen milieu van herkomst en schoolprestaties van kinderen. Den Haag/Heerlen: Centraal Bureau voor de Statistiek; 2014.

247. Tobler NS, Roona MR, Ochshorn P, Marshall DG, Streke AV, Stackpole KM. School-based adolescent drug prevention programs: 1998 meta-analysis. Journal of Primary Prevention. 2000;20(4):275-336.

248. Tobler NS, Stratton HH. Effectiveness of school-based drug prevention programs: a meta-analysis of the research. Journal of Primary Prevention. 1997;18(1):71-128.

249. Kriemler S, Meyer U, Martin E, van Sluijs EMF, Andersen LB, Martin BW. Effect of school-based interventions on physical activity and fitness in children and adolescents: a review of reviews and systematic update. British Journal of Sports Medicine. 2011;45(11):923-30.

250. Kerner J, Rimer B, Emmons K. Introduction to the special section on dissemination: dissemination research and research dissemination: how can we close the gap? Health Psychology. 2005;24(5):443.

251. Owen N, Glanz K, Sallis JF, Kelder SH. Evidence-based approaches to dissemination and diffusion of physical activity interventions. American Journal of Preventive Medicine. 2006;31(4, Suppl.):35-44.

252. Bumbarger B, Perkins DF. After randomised trials: issues related to dissemination of evidence-based interventions. Journal of Children's Services. 2008;3(2):55-64.

253. Lee A, Keung M, Tsang C. Difficulties faced by health educators in Hong Kong: from barriers to strategies. Journal of Primary Care and Health Promotion. 2004;1:17-22.

254. Clift S, Jensen BB. The health promoting school: international advances in theory, evaluation and practice. Copenhagen: Danish University of Education Press; 2005.

255. Dix KL, Slee PT, Lawson MJ, Keeves JP. Implementation quality of whole-school mental health promotion and students' academic performance. Child and Adolescent Mental Health. 2012;17(1):45-51.

256. Murray NG, Low BJ, Hollis C, Cross AW, Davis SM. Coordinated school health programs and academic achievement: a systematic review of the literature. Journal of School Health. 2007;77(9):589-600.

257. Wald A, Muennig PA, O'Connell KA, Garber CE. Associations between healthy lifestyle behaviors and academic performance in U.S. undergraduates: a secondary analysis of the American College Health Association's National College Health Assessment II. American Journal of Health Promotion. 2014;28(5):298-305.

258. Cugelman B, Thelwall M, Dawes PL. Dimensions of web site credibility and their relation to active trust and behavioural impact. Communications of the Association for Information Systems. 2009;24:26.

259. O'Keefe DJ. Persuasion: Theory and Research. 3rd ed. Thousand Oaks, CA: SAGE Publications, Inc.; 2016.

260. Young I. Conference report: Education \& health in partnership: a european conference linking education with the promotion of health in schools. Woerden: NIGZ; 2002.

261. Prochaska JJ, Spring B, Nigg CR. Multiple health behavior change research: an introduction and overview. Preventive Medicine. 2008;46(3):181-8.

262. Paulussen T, Panis R, Peters L, Buijs G, Wijnsma P. Stand van zaken schoolgezondheidsbeleid in Nederland: Een inventariserend onderzoek. Woerden: NIGZ; 1998.

263. Pharos. Laaggeletterdheid en beperkte gezondheidsvaardigheden [Internet]. Utrecht: Pharos; 2018 [cited 19 March 2020]. Available from: https://www.pharos.nl/factsheets/laaggeletterdheid-enbeperkte-gezondheidsvaardigheden/.

264. Berkman ND, Sheridan SL, Donahue KE, Halpern DJ, Crotty K. Low health literacy and health outcomes: an updated systematic review. Annals of Internal Medicine. 2011;155(2):97-107.

265. DeWalt DA, Berkman ND, Sheridan S, Lohr KN, Pignone MP. Literacy and health outcomes. Journal of General Internal Medicine. 2004;19(12):1228-39.

266. Fleary SA, Joseph P, Pappagianopoulos JE. Adolescent health literacy and health behaviors: a systematic review. Journal of Adolescence. 2018;62:116-27.

267. Cowan CF. Teaching patients with low literacy skills. In: Lowenstein AJ, Bradshaw MJ, editors. Fuszard's innovative teaching strategies in nursing. 3rd ed. Gaithersburg, MD: Aspen Publishers, Inc.; 2004. p. 278-89.

268. Doak CC, Doak LG, Root JH. Teaching patients with low literacy skills. 2nd ed. Philadelphia, PA: Lippincott; 1996. 
269. Houts PS, Doak CC, Doak LG, Loscalzo MJ. The role of pictures in improving health communication: a review of research on attention, comprehension, recall, and adherence. Patient Education and Counseling. 2006;61(2):173-90.

270. Johnson A, Sandford J, Tyndall J. Written and verbal information versus verbal information only for patients being discharged from acute hospital settings to home. Cochrane Database of Systematic Reviews. 2003;2003(4):CD003716.

271. Houts PS, Witmer JT, Egeth HE, Loscalzo MJ, Zabora JR. Using pictographs to enhance recall of spoken medical instructions II. Patient Education and Counseling. 2001;43(3):231-42.

272. Pharos. Online checklist toegankelijke informatie [Internet]. Utrecht: Pharos; [cited 23 March 2020]. Available from: https://www.pharos.nl/kennisbank/checklist-toegankelijke-informatie/.

273. Pharos. Checklist toegankelijke informatie [Internet]. Utrecht: Pharos; [cited 23 March 2020]. Available from: https://checklisttoegankelijkeinfo.pharos.nl/checklist.

274. Shoemaker SJ, Wolf MS, Brach C. Development of the Patient Education Materials Assessment Tool (PEMAT): a new measure of understandability and actionability for print and audiovisual patient information. Patient Education and Counseling. 2014;96(3):395-403.

275. Garcia A. Is health promotion relevant across cultures and the socioeconomic spectrum? Family \& Community Health. 2006;29(1):20S-7S.

276. Laurier E, McKie L, Goodwin N. Daily and lifecourse contexts of smoking. Sociology of Health \& IIIness. 2000;22(3):289-309.

277. Heide Ivd, Rademakers J. Laaggeletterdheid en Gezondheid. Stand van zaken. Utrecht: Nivel; 2015

278. Ghiassi R, Cummin A, Slingsby L, Wolfenden H, Bailey L, De Los Santos SM, et al. Can patients selfadminister the epworth sleepness scale? Thorax. 2007;62:A110.

279. Cremers AHM, Welbie M, Kranenborg K, Wittink $H$. Deriving guidelines for designing interactive questionnaires for low-literate persons: development of a health assessment questionnaire. Universal Access in the Information Society. 2017;16(1):161-72.

280. Hahn EA, Cella D, Dobrez D, Shiomoto G, Marcus E, Taylor SG, et al. The talking touchscreen: a new approach to outcomes assessment in low literacy. Psycho-Oncology: Journal of the Psychological, Social and Behavioral Dimensions of Cancer. 2004;13(2):86-95.

281. Rosal MC, Carbone ET, Goins KV. Use of cognitive interviewing to adapt measurement instruments for low-literate Hispanics. The Diabetes Educator. 2003;29(6):1006-17.

282. Rijksoverheid. Aanbevolen richtlijnen: Taalniveau B1 [Internet]. Den Haag: Rijksoverheid; [cited 23 March 2020]. Available from: https://www.communicatierijk.nl/vakkennis/rijkswebsites/aanbevolen-richtlijnen/ taalniveau-b1.

283. Bruins B. Kamerbrief Voortgangsverslag implementatie nieuwe Donorwet [Internet]. Den Haag: Tweede Kamer der Staten-Generaal; 2019 [cited 24 March 2020]. Available from: https://www.tweedekamer.nl/ kamerstukken/moties/detail?id=2019Z08820\&did=2019D17966.

284. Snyder LB. Meta-Analyses of Mediated Health Campaigns. Mass media effects research: advances through meta-analysis. Mahwah, NJ, US: Lawrence Erlbaum Associates Publishers; 2007. p. 327-44.

285. Frohlich KL, Potvin L. Transcending the known in public health practice. American Journal of Public Health. 2008;98(2):216-21.

286. Viswanath K, Finnegan JR. Reflections on community health campaigns: secular trends and the capacity to effect change. In: Hornik R, editor. Public health communication: evidence for behavior change. London. Mahwah, NJ: Lawrence Erlbaum Associates; 2002. p. 289-312.

287. Hart J. The inverse care law. The Lancet. 1971;297(7696):405-12.

288. Molina Pérez A, Rodríguez-Arias D, Delgado-Rodríguez J, Morgan M, Frunza M, Randhawa G, et al. Public knowledge and attitudes towards consent policies for organ donation in Europe. A systematic review. Transplantation Reviews. 2019;33(1):1-8.

289. Arshad A, Anderson B, Sharif A. Comparison of organ donation and transplantation rates between opt-out and opt-in systems. Kidney International. 2019;95(6):1453-60.

290. Nijman J, Hendriks M, Brabers A, de Jong J, Rademakers J. Patient activation and health literacy as predictors of health information use in a general sample of Dutch health care consumers. Journal of Health Communication. 2014;19(8):955-69.

291. Kim SH, Utz S. Association of health literacy with health information-seeking preference in older people: a correlational, descriptive study. Nursing \& Health Sciences. 2018;20(3):355-60. 
292. Ellis J, Mullan J, Worsley A, Pai N. The role of health literacy and social networks in arthritis patients' health information-seeking behavior: a qualitative study. International Journal of Family Medicine. 2012;2012:397039.

293. Bodie GD, Dutta MJ. Understanding health literacy for strategic health marketing: eHealth literacy, health disparities, and the digital divide. Health Marketing Quarterly. 2008;25(1-2):175-203.

294. Mackert M, Mabry-Flynn A, Champlin S, Donovan EE, Pounders K. Health literacy and health information technology adoption: the potential for a new digital divide. Journal of Medical Internet Research. 2016;18(10):e264.

295. Smith SK, Dixon A, Trevena L, Nutbeam D, McCaffery KJ. Exploring patient involvement in healthcare decision making across different education and functional health literacy groups. Social Science \& Medicine. 2009;69(12):1805-12.

296. Hibbard JH, Peters E, Dixon A, Tusler M. Consumer competencies and the use of comparative quality information: it isn't just about literacy. Medical Care Research and Review. 2007;64(4):379-94.

297. Youmans SL, Schillinger D. Functional health literacy and medication use: the pharmacist's role. Annals of Pharmacotherapy. 2003;37(11):1726-9.

298. Onderwijs in Cijfers. Aantal studenten in het mbo [Internet]. Den Haag: Ministerie van Onderwijs, Cultuur en Media; 2020 [cited 15 June 2020]. Available from: https://www.onderwijsincijfers.nl/kengetallen/mbo/ studenten-mbo/aantallen-studenten-mbo. 

Summary

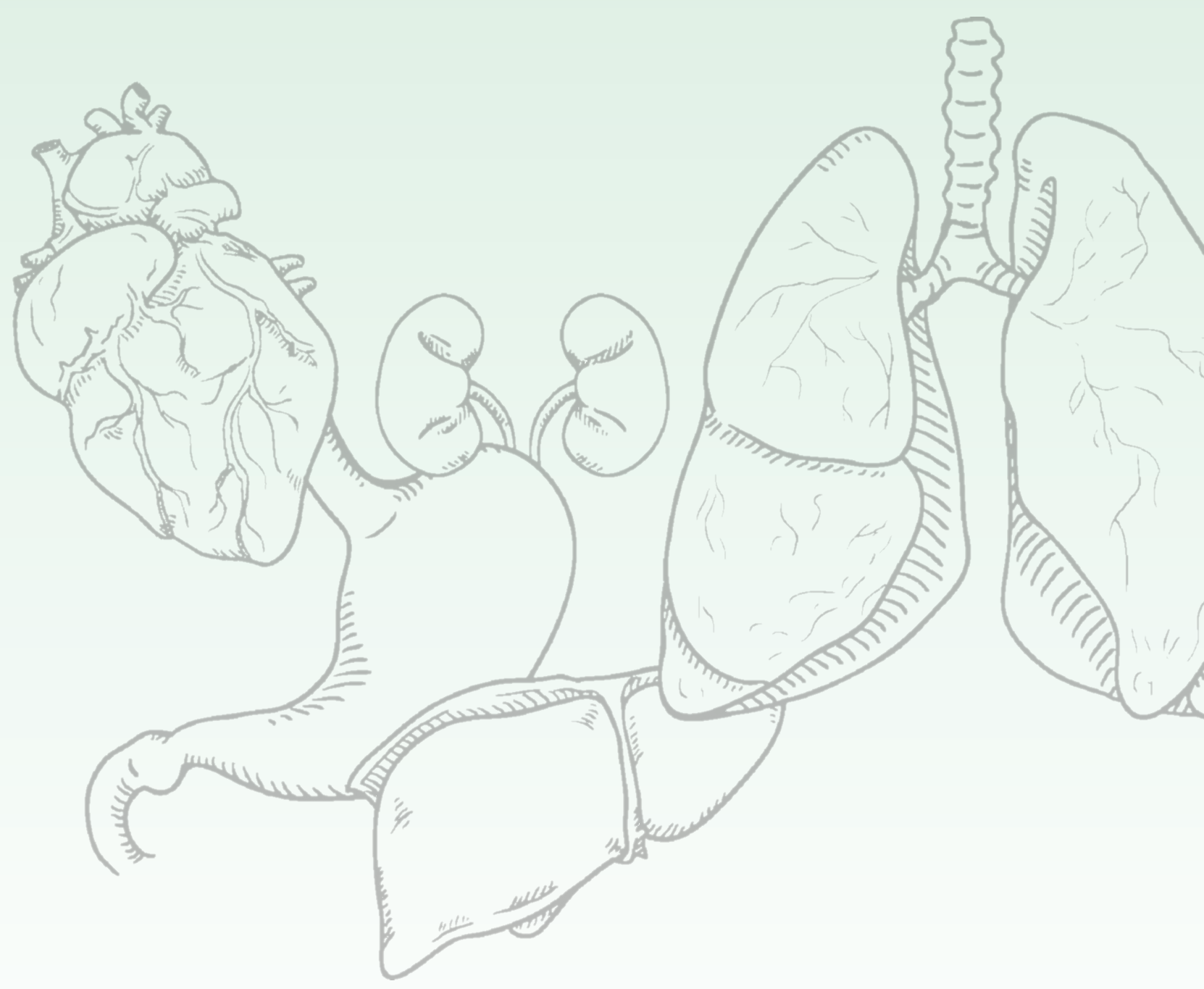


Low organ donation registration rates remain a public health challenge in many countries, including the Netherlands. The low registration rates, combined with the relatively small proportion of those who actively register as a donor, place a high burden on patients, medical professionals and family members - as explained in Chapter 1. Many campaigns have been launched over the years to increase these rates, but do often not provide people with the support that is needed to be able to make and register a decision. School-based education does have the potential to provide this support.

\section{Part 1: Organ donation education}

This first part of the thesis describes the adaptation, implementation and evaluation of a school-based interactive educational program about organ donation. The program was translated from a high school setting to a lower education school setting (i.e. vocational education). The registration rates among lower-educated people are especially low and they are not properly reached by other organ donation initiatives. This program aims to inform these adolescents about organ donation, to stimulate discussion among them, to support them in making a decision and to give them the tools to actually being able to register that decision, regardless of what that decision would be.

The main aim of the first part of this thesis was to evaluate the interactive organ donation program in a vocational education school setting. Adaptions needed to be made to make it more suitable and accessible for students at lower educational levels. The adapted version of the program was then implemented in schools for vocational education and an evaluation study was done regarding both the effects and implementation of the program.

\section{Determinants of registration behaviour}

The determinant study described in Chapter $\mathbf{2}$ was used to learn more about specific beliefs that lower-educated adolescents have regarding organ donation and registration. The results of this study were used to adapt the content of the educational program to this group. A cross-sectional quantitative study was conducted among students in vocational education, focusing on 25 beliefs about organ donation and the 
association between these beliefs and registration (intention) outcomes. Most beliefs had mean scores that showed room for improvement. These could be important targets for interventions aimed at increasing registration rates, including the program central in this thesis. Associations between these beliefs and registration (intention) outcomes were often small to medium in terms of association strength. Most beliefs that had any association with a certain outcome measurement (e.g. intention to register), were associated with other outcome measurements as well (e.g. intention to register as a donor).

Organ donation behaviour is thus complex and associated with many underlying beliefs. Interventions aimed at changing registration behaviour, should not only be aimed at increasing knowledge, but also addressing the underlying beliefs.

\section{Evaluation of the organ donation education program}

The studies in Chapter 3, 4 and $\mathbf{5}$ describe the cluster randomized controlled trial (CRCT) used to assess the effectiveness and quality of implementation of the adapted organ donation program, with the final aim to encourage lower-educated adolescents to register a well-informed decision about organ donation.

Chapter 3 elaborates on the different components of the program (i.e. video fragments and discussion, quizzes with tailored feedback and an exercise filling out a registration form) and provides a detailed protocol for the evaluation study. It described how different data sources are combined (i.e. questionnaires, Google Analytics, interviews and logbooks) to get a complete overview of the effectiveness and implementation of the organ donation education program.

Chapter 4 shows that after receiving the program, more students were intending to register a decision, but the proportion of them who wanted to become a donor did not. The aim of the program - to support decision-making, without guiding them toward a specific decision - was thus achieved. Also, students' intentions to talk to family members or friends about organ donation increased. Furthermore, the program has a positive impact on their knowledge, misconceptions and other beliefs. So, providing 
students with clear information, opening the discussion and supporting them in decision-making and the registration of that choice, could be an important step towards higher registration rates.

Chapter 5 presents the findings of the process evaluation of the educational program. This study was done to understand both the (quality of) implementation as well as to contextualize the possible effects of the program. The program was implemented in 11 schools for vocational education by teachers in Citizenship. Teachers agreed that the program was very compatible with their other teaching activities, but some found it difficult to prioritize the topic of organ donation. Overall, the program was well received by both students and teachers. Most teachers implemented all components but did make on-the-spot adaptations to fit their students' capabilities and needs better. The process evaluation revealed ways in which the program could be further improved (e.g., alternative delivery methods for lesson 2 and guidelines for teachers to adapt the program to their students at different levels within vocational education).

The results of the evaluation study show possibilities to disseminate the program on a larger scale, in order to reach a large group of adolescents and increase registration rates in this group. To have an impact on a national level, support on a higher level is needed (both within schools and at policy level).

\section{Part 2: Organ donation registration systems}

As long as organ donation exists, there have been discussions about the best way to coordinate the registration of people who are willing to donate (or not). In many countries, an opt-in system (i.e. explicit consent) or an opt-out system (i.e. presumed consent) is used. In 2018, a law change was announced in the Netherlands (to be implemented in 2020), to move from an opt-in system to a soft version of an opt-out system: the no-objection system. Within this new law, people are asked to register their preferences regarding organ donation after death by a letter from the government. If people fail to respond within 6 weeks after a reminder letter, they will be recorded with a no-objection registration. This means that, when they die, their organs could go to a 
patient. However, family members still have the opportunity to oppose the transplantation if they can make a reasonable case that their loved one actually did not want this.

\section{Shifting responsibilities}

Chapter 6 describes what this new law could mean for responsibilities around the donation decision and questions whether citizens are ready for this law change. In the new donor law, the responsibility of the donation decision will shift from the relatives more towards the "owner" of the organs, who will be expected to make a decision while still alive. In this way, the new law is supposed to relieve pressure on relatives. The question is whether a no-objection registration will actually lead to more clarity than no registration at all, as it is still not an active decision by the deceased person. It is therefore of great importance that the number of no-objection registrations will be limited, and people register an actual yes or no.

The new donor law is complex, especially the exact meaning and consequences of the no-objection registration. It is therefore important for the government to realize that their responsibilities are also extended. We cannot expect all citizens to be able to make and register a decision based on a letter, so educational initiatives need to be employed. These should not be limited to only giving information but require active involvement of and support for citizens when making their organ donation decision. Further, repetitive exposure to explanations of rules and consequences is needed for the entire population. This should include accessible, understandable information for everyone who would like to register their decision at a later date or wants to change their registration.

\section{Organ donation registration systems}

Chapter 7 describes where the new donor law stands compared to a traditional opt-in or opt-out system in terms of decision-making. A representative sample of the Dutch population was asked to fill out a questionnaire after being presented with a description of one of those registration systems. Policy makers presented the no-objection system as the perfect compromise between an opt-in and an opt-out system, but this study 
suggests that it is not. The no-objection system performs similar to the opt-out system in terms of experienced autonomy, effective decision-making and the choices people make, while the currently used opt-in system shows higher levels of autonomy, more active registrations and more active yes registrations. Finally, the registration choices of especially lower educated participants under the conditions of the no-objection system suggest that they might not fully understand what this system (i.e. the new donor law) entails. This further strengthens the recommendations from Chapter 6.

Which system is best, is difficult to conclude and depends on what is considered "best". Where the opt-out system potentially leads to the highest number of donors, the opt-in system seems better in terms of preserving people's autonomy and motivating people to make an active decision. Next to the system itself, flanking policies, including support for the public (e.g. education and other campaigns) are key.

\section{Discussion}

Chapter 8 discusses the main findings of the reported studies, reflects on choices that were made, reflects on theory, places this thesis in the current public and scientific debate and provides the implications and recommendations for research and practice. It elaborates further on the complexity of determinant research in terms of the outcomes, measurements, analyses, interpretations and applications of this research. The effectiveness of the educational program is discussed in more detail, after which recommendations are given for the future of the program, both in terms of the content of the program and the dissemination. Further, low (health) literacy is discussed. Suggestions are given on how to involve low (health) literate people better in health promotion initiatives and research. Finally, organ donation campaigns are discussed, especially in light of the new donor law. It is argued that an integral approach is needed to increase active registration rates.

Low organ donation registration rates remain a complex problem in the Netherlands. Providing education in a school setting could contribute to increasing these rates, especially among people who have not been properly reached by other initiatives. It 
has the potential to reach a large and important group with education and support. However, school-based education on its own is not enough. The complexity of the new donor law comes with new challenges. More efforts are needed to proactively reach vulnerable groups and to contribute to more informed decisions and more active registrations under the new donor law. 



\section{Samenvatting}

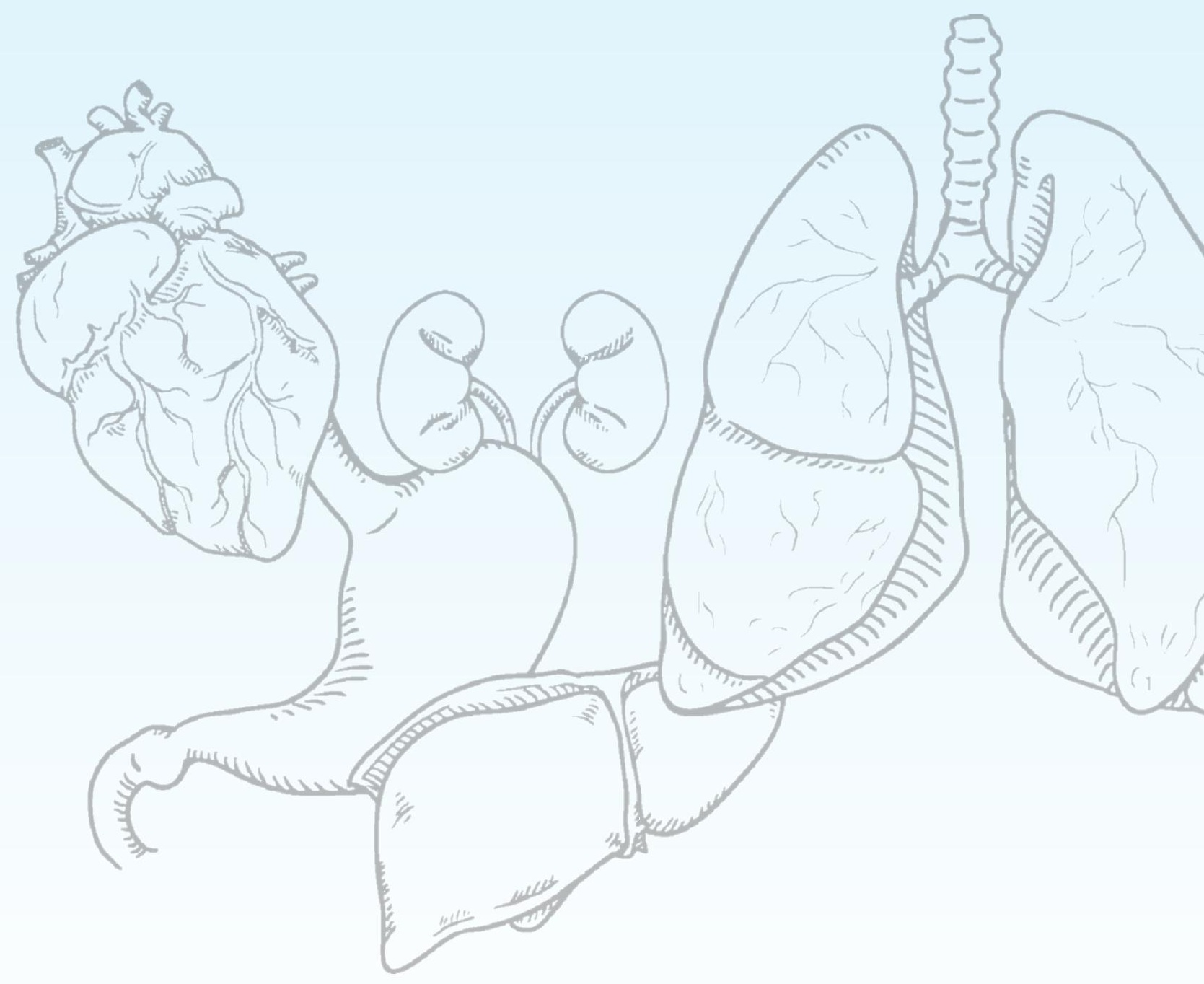


Het lage aantal orgaandonatieregistraties blijft een uitdaging voor de volksgezondheid in veel landen, waaronder Nederland. De lage registratiecijfers, in combinatie met de relatief kleine proportie van mensen die actief geregistreerd staan als donor, zorgen voor een hoge last voor patiënten, artsen en familieleden - zoals uitgelegd in Hoofdstuk 1. Over de jaren heen zijn er veel campagnes gelanceerd om deze cijfers te verhogen, maar vaak geven ze niet de ondersteuning die mensen nodig hebben om een keuze te kunnen maken en registreren. Educatie op scholen heeft de mogelijkheid om deze ondersteuning te bieden.

\section{Deel 1: Orgaandonatie educatie}

Het eerste deel van dit proefschrift beschrijft de aanpassing, implementatie en evaluatie van een interactief lesprogramma over orgaandonatie voor gebruik op scholen. Het programma is vertaald van een middelbare schoolsetting (havo/vwo) naar een schoolsetting met een lager opleidingsniveau (mbo). De registratiecijfers zijn met name laag bij lager opgeleide mensen en deze groep wordt ook niet goed bereikt door andere initiatieven aangaande orgaandonatie. Het lesprogramma heeft als doel om adolescenten te informeren over orgaandonatie, een discussie op gang te brengen, hen ondersteuning te bieden bij het maken van een keuze en hen de middelen te geven om die keuze ook daadwerkelijk te kunnen registreren, ongeacht wat die keuze is.

Het voornaamste doel van het eerste deel van dit proefschrift was om het interactieve orgaandonatieprogramma te evalueren in een mbo-schoolsetting. Aanpassingen waren nodig om het programma geschikter en toegankelijker te maken voor adolescenten op een lager opleidingsniveau. De aangepaste versie van het programma werd vervolgens geïmplementeerd op mbo-scholen. Er werd een evaluatie gedaan van zowel de effecten van het programma als de implementatie.

\section{Determinanten van registratiegedrag}

De determinantenstudie in Hoofdstuk 2 werd gedaan om meer te weten te komen over de specifieke opvattingen (beliefs) die lager opgeleide adolescenten hebben over orgaandonatie en -registratie. De resultaten van deze studie zijn gebruikt om de 
inhoud van het lesprogramma aan te passen aan deze groep. Een cross-sectionele kwantitatieve studie werd uitgevoerd onder mbo-studenten, waarbij 25 opvattingen over orgaandonatie centraal stonden en gekeken werd hoe deze opvattingen gerelateerd waren aan registratie(-intentie) uitkomsten. Bij veel opvattingen lag de gemiddelde score rond het midden van de schaal, wat ruimte voor verbetering laat zien. Deze opvattingen zouden een belangrijke focus kunnen zijn voor interventies met als doel om registratiecijfers te verhogen, net als het programma dat beschreven wordt in dit proefschrift. De associaties tussen deze opvattingen en registratie(-intentie) uitkomsten waren vaak klein tot middelmatig van grootte. De meeste opvattingen die een associatie met één uitkomstmaat hadden (bv. intentie om te registreren), hadden ook een associatie met andere uitkomstmaten (bv. intentie om te registreren als donor).

Orgaandonatiegedrag is dus complex en geassocieerd met veel onderliggende opvattingen. Interventies met als doel om registratiegedrag te veranderen, zouden niet alleen moeten focussen op het vergroten van kennis, maar ook op deze onderliggende opvattingen.

\section{Evaluatie van het orgaandonatie lesprogramma}

De studies in Hoofdstuk 3, 4 en $\mathbf{5}$ beschrijven een cluster randomized controlled trial (CRCT) om de effectiviteit en kwaliteit van implementatie te bepalen van het aangepaste orgaandonatie lesprogramma. Het uiteindelijke doel van dit programma was om lager opgeleide adolescenten aan te moedigen een geïnformeerde keuze te registreren over orgaandonatie.

Hoofdstuk 3 gaat dieper in op de verschillende onderdelen van het programma (namelijk: videofragmenten met discussies, quizzen met feedback op maat en een oefening om het registratieformulier in te vullen) en beschrijft daarnaast een gedetailleerd protocol voor de evaluatiestudie. Het beschrijft hoe verschillende databronnen gecombineerd worden (vragenlijsten, Google Analytics, interviews en logboeken) om een compleet overzicht te krijgen van de effectiviteit en implementatie van het orgaandonatie lesprogramma. 
Hoofdstuk 4 laat zien dat adolescenten na afloop van het lesprogramma vaker van plan waren zich te registreren, maar dat de proportie van hen die donor wilde worden niet vergrootte. Het doel van het programma - om ondersteuning te bieden bij het maken van een keuze, zonder deelnemers richting een specifieke keuze te sturen - werd dus gehaald. Daarnaast waren adolescenten vaker van plan om met hun familieleden en vrienden te praten over orgaandonatie. Ook had het programma een positieve impact op hun kennis, misconcepties en andere opvattingen. Adolescenten duidelijke informatie geven, de discussie starten en hen ondersteunen bij het maken en registreren van een keuze kan dus een belangrijke stap zijn richting hogere registratiecijfers.

Hoofdstuk 5 presenteert de resultaten van de procesevaluatie van het lesprogramma. Deze studie heeft inzicht gegeven in de (kwaliteit van) implementatie en gaf de mogelijkheid om de effecten van het programma in een context te plaatsen. Het programma is geïmplementeerd op 11 mbo-scholen door Burgerschap-docenten. Docenten waren het erover eens dat het programma zeer compatibel was met hun andere lesactiviteiten, maar sommigen vonden het wel lastig om het onderwerp orgaandonatie prioriteit te geven. Over het algemeen werd het programma goed ontvangen door zowel de studenten als de docenten. De meeste docenten hadden alle onderdelen geïmplementeerd, maar maakten soms wel ter plekke aanpassingen om het beter aan te laten sluiten bij de capaciteiten en behoeftes van hun studenten. De procesevaluatie onthulde verschillende manieren waarop het programma verder verbeterd kan worden (bv. alternatieve lesmethodes voor les 2 en instructies voor docenten om het programma aan te passen aan hun studenten op verschillende niveaus binnen het mbo).

De resultaten van de evaluatiestudie laten mogelijkheden zien om het programma te dissemineren op grotere schaal, zodat een grote groep adolescenten bereikt kan worden en de registratiecijfers in deze groep kunnen toenemen. Ondersteuning van hogere echelons (zowel binnen scholen als op beleidsniveau) zal nodig zijn om een nationale impact te hebben. 


\section{Deel 2: Orgaandonatie registratiesystemen}

Zo lang als orgaandonatie mogelijk is, zijn er discussies geweest over hoe het registreren van mensen die hun organen willen afstaan (of niet) het best geregeld kan worden. In veel landen wordt een opt-in systeem (expliciete consent) of een opt-out systeem (veronderstelde toestemming) gebruikt. In 2018 werd in Nederland een wetswijziging aangekondigd (die in 2020 geïmplementeerd is), waarbij van een opt-in systeem overgestapt wordt op een softe versie van een opt-out systeem: het geen-bezwaar systeem. Binnen deze nieuwe wet wordt mensen via een brief van de overheid gevraagd om hun voorkeuren wat betreft orgaandonatie na overlijden door te geven. Wanneer mensen niet reageren binnen 6 weken na een herinneringsbrief, zullen ze geregistreerd worden met een geen-bezwaar registratie. Dit betekent dat in geval van overlijden hun organen naar een patiënt zouden kunnen gaan. Familieleden hebben echter nog altijd de mogelijkheid om de transplantatie tegen te gaan als zij het aannemelijk kunnen maken dat hun geliefde dit niet had gewild.

\section{Verschuivende verantwoordelijkheden}

Hoofdstuk 6 legt uit wat de nieuwe wet kan betekenen voor de verantwoordelijkheid rondom de donatiekeuze en stelt de vraag of Nederlanders wel klaar zijn voor deze wetswijziging. In de nieuwe wet verschuift de verantwoordelijkheid voor de donatiekeuze van nabestaanden meer richting de "eigenaar" van de organen, die verwacht wordt een keuze te maken bij leven. Op deze manier zou de nieuwe wet de druk op nabestaanden moeten verlichten. De vraag is of een geen-bezwaar registratie daadwerkelijk meer duidelijkheid geeft dan wanneer iemand helemaal geen registratie heeft, aangezien dit nog steeds geen actieve keuze is door de overleden persoon. Het is daarom belangrijk om het aantal geen-bezwaar registraties zo laag mogelijk te houden en om mensen een echte 'ja' of 'nee' te laten registreren.

De nieuwe donorwet vergroot de complexiteit van de keuze omtrent registratie, en dan vooral met betrekking tot de exacte betekenis en consequenties van een geenbezwaar registratie. Het is daarom belangrijk dat de overheid zich realiseert dat haar verantwoordelijkheden ook worden uitgebreid. We kunnen niet verwachten dat alle 
inwoners in staat zijn een keuze te maken op basis van een brief, dus zullen voorlichtingsinitiatieven nodig zijn. Deze moeten niet beperkt blijven tot informatievoorziening, maar zullen moeten bestaan uit actieve betrokkenheid van en ondersteuning voor inwoners bij het maken van een orgaandonatie keuze. Verder zal herhaaldelijke blootstelling aan uitleg van de regels en consequenties nodig zijn voor de hele populatie. Dit moet bestaan uit toegankelijke, begrijpelijke informatie voor iedereen die een keuze op een later tijdstip wil maken of zijn keuze wil wijzigen.

\section{Orgaandonatie registratiesystemen}

Hoofdstuk 7 beschrijft waar de nieuwe donorwet staat in vergelijking met een traditioneel opt-in of opt-out system als het gaat om besluitvorming. Een representatieve steekproef van Nederlandse volwassenen werd gevraagd een vragenlijst in te vullen na blootstelling aan een uitleg over één van deze registratiesystemen. Beleidsmakers hebben het geen-bezwaar systeem gepresenteerd als een perfect compromis tussen een opt-in- en opt-out systeem, maar deze studie laat zien dat dit niet het geval is. Het geen-bezwaar systeem presteert vergelijkbaar met het opt-out systeem als het gaat om ervaren autonomie, effectieve besluitvorming en de keuzes die mensen maken, terwijl het huidige opt-in systeem leidt tot hogere niveaus van autonomie, meer actieve registraties en meer actieve ja-registraties. Ten slotte suggereren de registratiekeuzes van lager-opgeleide deelnemers bij een geen-bezwaar systeem dat ze niet helemaal begrijpen wat dit systeem (de nieuwe donorwet) inhoudt. Dit benadrukt de relevantie van de aanbevelingen van Hoofdstuk 6 des te meer.

Welk systeem het beste is, is moeilijk te zeggen en hangt ook af van wat "beste" betekent. Terwijl een opt-out systeem mogelijk tot het hoogste aantal donoren leidt, lijkt het opt-in systeem beter als het gaat om het bewaken van de autonomie van mensen en het motiveren van mensen om een actieve keuze te maken. Naast het systeem zelf, is flankerend beleid, inclusief ondersteuning voor de bevolking (bv. educatie en andere campagnes), essentieel. 


\section{Discussie}

Hoofdstuk 8 bediscussieert de belangrijkste resultaten van de beschreven studies, reflecteert op de keuzes die zijn gemaakt, bevat een reflectie op de theorie, plaatst dit proefschrift in het huidige publieke en wetenschappelijke debat en geeft implicaties en aanbevelingen voor onderzoek en de praktijk. Het gaat dieper in op de complexiteit van determinantenonderzoek met betrekking tot de uitkomsten, metingen, analyses, interpretaties en toepassingen hiervan. De effectiviteit van het lesprogramma wordt in meer detail bediscussieerd, waarna aanbevelingen worden gegeven voor de toekomst van het programma, zowel voor de inhoud als de disseminatie. Verder worden laaggeletterdheid en lage gezondheidsvaardigheden besproken. Er worden suggesties gegeven hoe deze groepen beter te betrekken bij gezondheidsbevorderingsinitiatieven en onderzoek. Ten slotte worden orgaandonatiecampagnes besproken, vooral in de context van de nieuwe donorwet. Er wordt aangevoerd dat een integrale aanpak nodig is om actieve registratiecijfers te verhogen.

De lage orgaandonatieregistratiecijfers blijven een complex probleem in Nederland. Het geven van educatie in een schoolsetting kan bijdragen aan het verhogen van deze cijfers, vooral bij mensen die niet goed genoeg bereikt worden door andere initiatieven. Het geeft de mogelijkheid om een grote en belangrijke groep te bereiken met educatie en ondersteuning. Educatie op scholen is echter niet genoeg. De complexiteit van de nieuwe donorwet leidt tot nieuwe uitdagingen. Er zijn meer inspanningen nodig om kwetsbare groepen op een proactieve manier te bereiken en daarmee bij te dragen aan meer geïnformeerde keuzes en meer actieve registraties onder de nieuwe donorwet. 



\section{Curriculum Vitae}

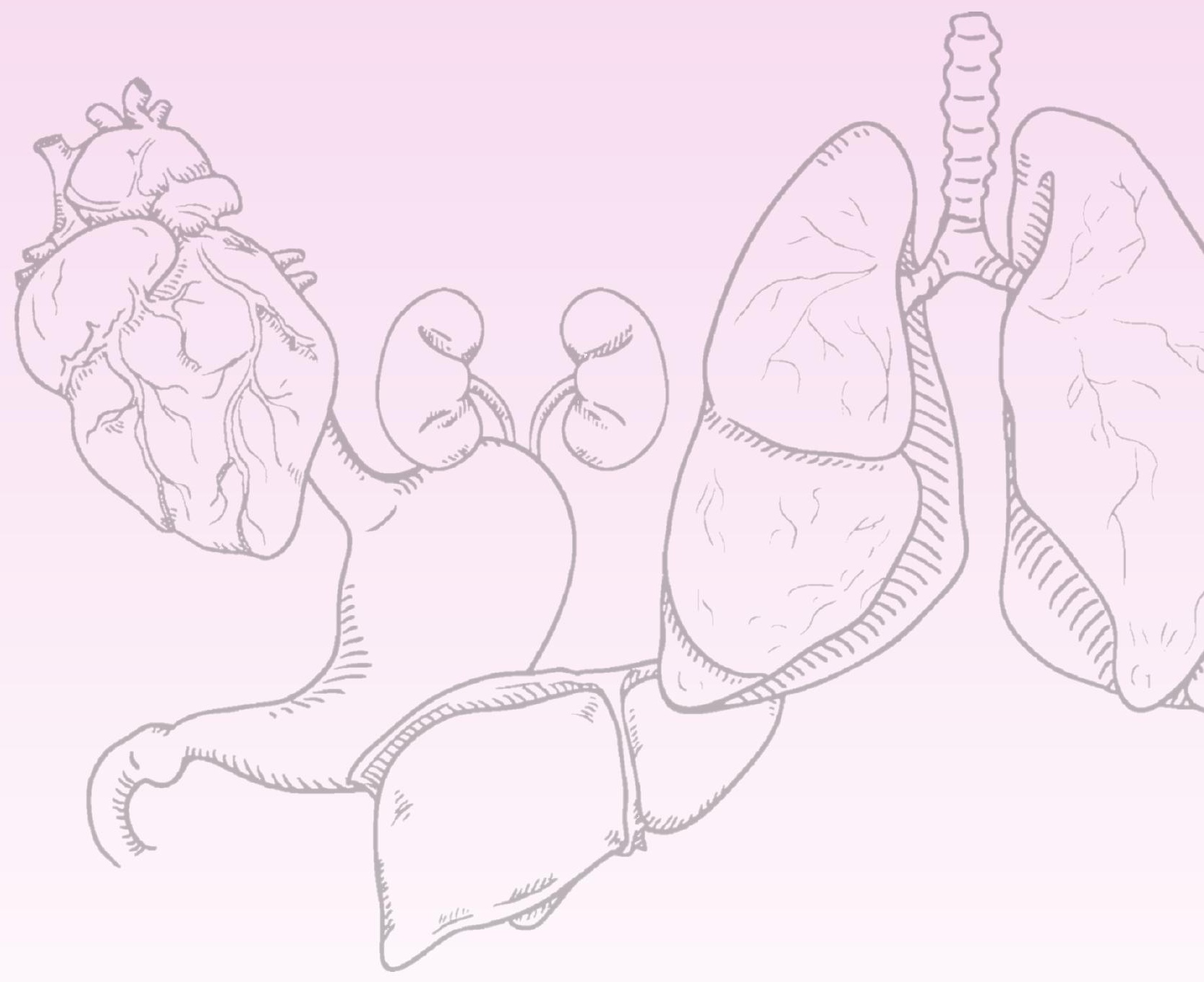




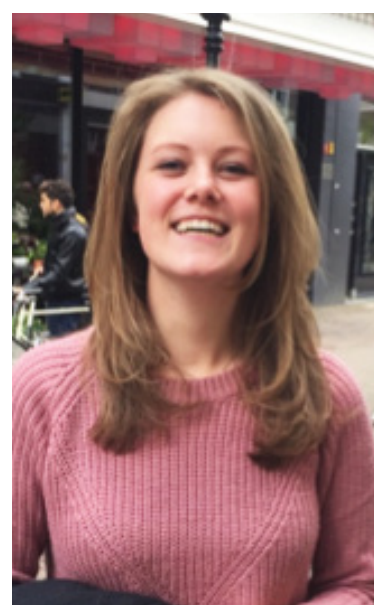

Esther Steenaart was born in Alkmaar on May 13th, 1994.

She graduated from the Bachelor Health Sciences in 2015, with a minor in Biomedical and Health Interventions (VU, Amsterdam).

Her bachelor thesis focused on parental feeding styles and vegetable intake of their children. She moved to Maastricht to start the Master Health Education and Promotion (Maastricht University, Maastricht) and graduated a year later.

She wrote her master thesis on organ donation registration systems, which opened the door to a PhD position. She prolonged her stay in Maastricht and started as a PhD candidate at the Department of Health Promotion in October 2016.

During her PhD, Esther was active as a PhD representative at CAPHRI. She was also involved in many educational tasks and obtained her Basic Teaching Qualification in 2019.

Esther currently works as a trainee at the Ministry of Health, Welfare and Sports in The Hague. 



\section{Publication list}

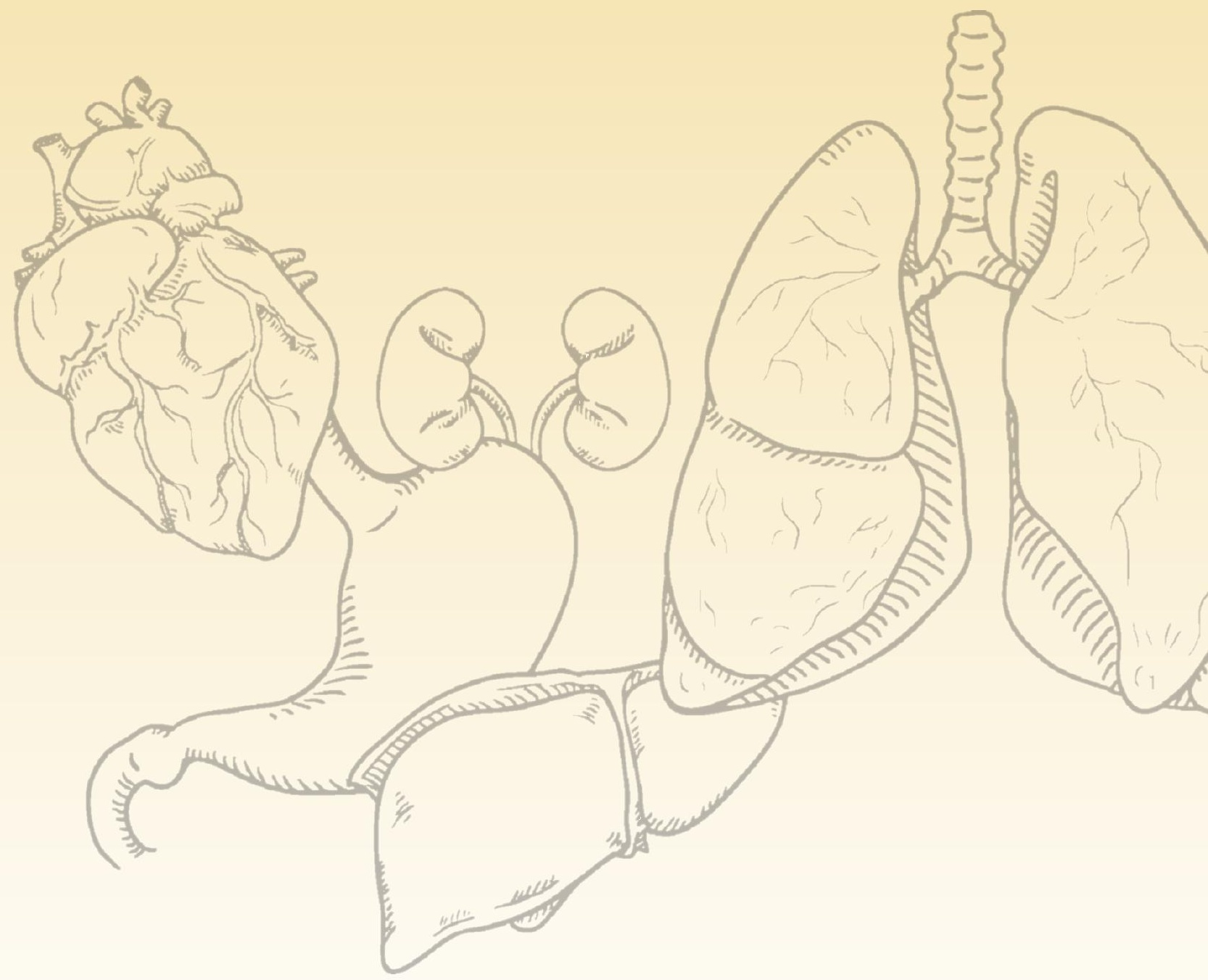




\section{PUBLICATIONS PRESENTED IN THIS DISSERTATION}

Steenaart, E., Crutzen, R., \& de Vries, N. K. Complexity of organ donation registration: determinants of registration behavior among lower-educated adolescents. Transplantation Proceedings. 2018;50(10):2911-2923.

Steenaart, E., Crutzen, R., Candel, M. J., \& de Vries, N. K. A web-based education program to encourage organ donation registration among lower-educated adolescents in the Netherlands: study protocol for a cluster randomized controlled trial. Trials. 2018;19(1):532

Steenaart, E., Crutzen, R., Candel, M. J., \& de Vries, N. K. The effectiveness of an interactive organ donation education intervention for Dutch lower-educated students: a cluster randomized controlled trial. Trials. 2019;20(1):643

Steenaart, E., Crutzen, R., \& de Vries, N. K. Implementation of an interactive organ donation education program for Dutch lower-educated students: a process evaluation. BMC Public Health. 2020;20(1):739.

Steenaart, E., Crutzen, R., \& de Vries, N. K. Geen bezwaar tegen de nieuwe donorwet, maar wel nog meer verantwoordelijkheid. Tijdschrift voor Gezondheidswetenschappen. 2018;96(3-4):134-135.

Steenaart, E., Crutzen, R., \& de Vries, N. K. Beyond the ticked box: organ donation decision-making under different registration systems. Psychology and Health. Forthcoming 2020. doi:10.1080/08870446.2020.1811867.

\section{OTHER PUBLICATIONS}

Mkhitaryan, S., Crutzen, R., Steenaart, E., \& de Vries, N. K. Network approach in health behavior research: how can we explore new questions? Health Psychology and Behavioral Medicine. 2019;7(1):362-384. 
International Society for Organ Donation and Procurement Conference, 2017, Geneva, Switzerland

Oral presentation: A web-based education program to stimulate organ donation registration among lower-educated adolescents in the Netherlands: A study protocol for a cluster randomized controlled trial

\section{CAPHRI Research Day, 2018, Maastricht, the Netherlands}

Poster (won public poster award): How to save a life: Teaching lower-educated students about organ donation

Association for Researchers in Psychology and Health Conference, 2019, Egmond aan Zee, the Netherlands

Oral presentation: How to save a life: Teaching lower-educated adolescents about organ donation

Division of Health Psychology Annual Conference, 2019, Manchester, United Kingdom Oral presentation (as part of a symposium): Implementing an interactive organ donation education program in a lower-educated Dutch school setting.

Schools for Health in Europe, 2019, Moscow, Russia

Oral presentation: Organ donation decision-making: Teaching about organ donation in a lower-educated Dutch school setting. 

Dankwoord

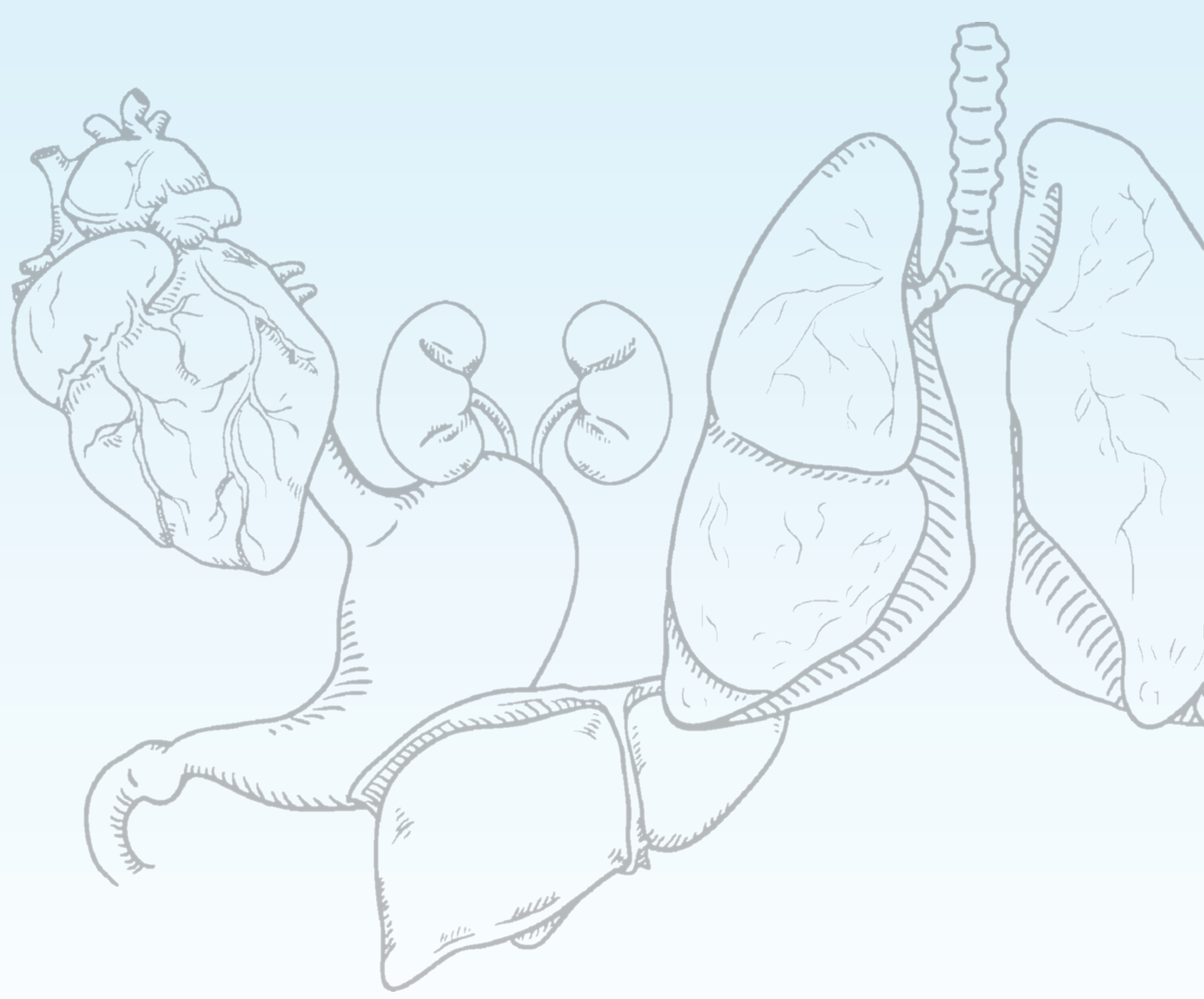


Na een totale periode van bijna 5 jaar in Maastricht, waarvan bijna 4 jaar als promovenda, neem ik nu echt afscheid. Als nuchtere Noord-Hollandse heb ik mij uiteindelijk meer thuis gevoeld in Zuid-Limburg dan ik van tevoren had gedacht. Het zijn jaren geweest die ik niet zal vergeten. Door alles wat ik geleerd heb, de uitdagingen, de successen, maar vooral door een groep bijzondere mensen om mij heen. In dit laatste hoofdstuk wil ik deze mensen graag bedanken voor hun bijdrage aan deze tijd.

Ik ben heel trots op het team waarmee ik heb mogen werken. Een klein, toegankelijk team, met drie heel verschillende persoonlijkheden. Een team waarin tijdens de overleggen ook altijd ruimte was voor een grapje, geklaag of een persoonlijk gesprek. Niet alleen oog voor het onderzoek, maar ook voor elkaar.

Rik; even binnenlopen voor een vraag, een appje over de stemming van de nieuwe donorwet, een uitgebreide brainstormsessie, súpersnelle feedback op alles wat ik schreef. Je stond 24/7 aan en daar mocht ik altijd gebruik van maken. Je enthousiasme werkte aanstekelijk en hierdoor kreeg ook ik steeds meer zin om nieuwe dingen uit te zoeken. Als ik dan met een idee of voorstel bij je in de deuropening stond, zei je 'ja, cool!' en mocht ik het gaan uitwerken. Hierdoor kreeg ik de mogelijkheid om m'n PhD echt eigen te maken. Dat gold niet alleen voor het onderzoek, want je stimuleerde mij ook om kansen te pakken op het gebied van onderwijs, congressen en cursussen. Door jou vertrek ik met veel meer dan een proefschrift uit Maastricht. Bedankt voor je optimisme, open blik en vertrouwen. Ik gun iedereen een Rik als begeleider.

Nanne; ik weet nog goed dat ik na onze eerste ontmoeting, bij het sollicitatiegesprek, een beetje overrompeld naar huis ging. De vragen die je stelde, de manier waarop je mij uit de tent probeerde te lokken; ik wist niet goed wat ik ermee aan moest. Misschien zijn het onze gedeelde Friese roots, waardoor we toch een goede match bleken. Gedurende mijn PhD ben je mij blijven uitdagen om net dat stapje verder te gaan, om van iets goeds iets nog beters te maken. Ondanks je drukke agenda en je kantoor helemaal boven in dat torentje, heb ik altijd het gevoel gehad dat ik welkom was voor advies of inspiratie. Jouw oprechte interesse in mijn project en in mij als persoon heb ik heel 
bijzonder gevonden. Je hebt mij in de afgelopen jaren de kans gegeven om te investeren in mijn onderzoek, mijzelf en in mijn toekomst en daar ben ik je heel dankbaar voor. En ja; ik ben nog steeds gelukkig!

Math; bedankt voor de statistische hulp, vooral bij de evaluatiestudie. Je nam altijd rustig de tijd om dingen uit te leggen op een manier die ik ook begreep.

Stichting SIDVO; bedankt voor de mogelijkheden die ik heb gekregen via jullie interventie. Jullie hebben grootse idealen en ik hoop dat die, deels via deze interventie, waargemaakt kunnen worden. Hopelijk is er een mooie toekomst weggelegd voor dit programma en kunnen veel docenten en studenten er gebruik van maken.

Alle docenten en studenten van de deelnemende scholen; zonder jullie was mijn PhD echt niet mogelijk geweest. Ik wil jullie allemaal heel graag bedanken voor jullie enthousiasme!

De beoordelingscommissie heeft past aan het eind van mijn proefschrift een rol gespeeld, maar wel een heel belangrijke. Bedankt Stef, Bart, Luuk, Helen en Ronan voor de tijd en de energie die jullie gestoken hebben in het lezen van mijn proefschrift.

Alle (ex)-GVO-collega's; bedankt voor de gezellige jaren op de vakgroep! Ik viel wel op als Hollander met die harde $\mathrm{G}$ en rollende $\mathrm{R}$, maar heb me heel welkom gevoeld en veel van jullie geleerd. Jullie hebben allemaal op jullie eigen manier een belangrijke bijdrage geleverd aan mijn tijd hier. De TMO/vakgroepuitjes, carnaval en borrels zal ik niet vergeten (en gelukkig hebben we de foto's nog). De dames van het secretariaat, Kim, Patricia, Daisy en Denise; bedankt voor jullie ondersteuning met alles afgelopen jaren! Voor vragen over declaraties, agenda's, nietmachines en regelementen kon ik altijd bij jullie terecht, maar ook voor een gezellig praatje. Leon; ik wil jou natuurlijk bedanken voor de ICT-ondersteuning en het verjagen van de muizen/vliegen, maar vooral voor de praatjes en gezelligheid op kantoor. Wat hebben we gelachen! Verder wil ik vooral Stef, Francine en Kathelijne bedanken voor de ondersteuning en motiverende woorden 
wat betreft het geven van onderwijs. Ik heb dit altijd een ontzettend leuk onderdeel van m'n werk gevonden en heb dat ook aan jullie te danken!

In het bijzonder wil ik Thomas, Marjolein, Marion en Stan bedanken voor de gezelligheid en steun zowel op kantoor als daarbuiten.

Thomas; team borrel! Jeetje, wat heb jij mijn tijd in Maastricht leuk gemaakt! Ik vond het heerlijk om met je te kunnen praten over alles wat ons bezighield op werk, maar vooral ook over alles daarbuiten (bitterballen, otters, het kofschip). Ik hoop dat we dit nog vaak over mogen doen!

Marjolein; allebei vanuit Noord-Holland naar het verre zuiden getrokken voor onze PhD. Ik vond het heel fijn om tijdens onze etentjes lekker te kletsen, soms over ons leuke leven hier in Maastricht en soms over het gemis van onze vrienden en familie. Ik hoop dat we elkaar weer tegenkomen in het westen!

Marion; wat ontzettend leuk om jou ontmoet te hebben! Samen naar Parijs, de Efteling, Moskou. Ik kan het eigenlijk kort houden: het was een feestje ;)

Stan; wat was het leuk met jou op GVO! We liepen de deur bij elkaar plat, konden kletsen over niks, maar elkaar ook verder helpen in ons werk. Ik hoop ooit nog samen een gastoptreden te mogen doen op een CAPHRI-borrel en luidkeels Pianoman, Ik leef niet meer voor jou en Angels mee te kunnen zingen!

Karin en Thomas; het was ontzettend leuk om samen met jullie PhD rep te zijn! Hoe tof het ook was om samen evenementen te organiseren, ideeën uit te wisselen, mee te denken over CAPHRI, en nieuwsbrieven te schrijven; de borrels zullen mij toch het meeste bijblijven! Hannerieke; bedankt voor de ondersteuning en het vertrouwen in ons. Jij hebt ons het gevoel gegeven dat onze mening ertoe deed en hielp ons met het uitvoeren van ideeën. Maurice en Martijn, M\&M; wat was het fijn om zulke open en toegankelijke mensen in het management te hebben! Mooi dat jullie PhD's echt 
een actieve rol geven in de besluitvorming bij CAPHRI. Het is een waardevolle ervaring geweest!

John en Pit (en Bes); bedankt dat jullie mij zo'n welkom gevoel hebben gegeven en meteen hebben opgenomen in de familie. Wat heb ik genoten van de dagen in Ouddorp en alle gezellige etentjes. En wat kan ik met jullie lachen!

Lieve vrienden en vriendinnen in Alkmaar, Amsterdam, Utrecht, Rotterdam; Bedankt voor het afleggen van al die lange reizen naar 'het buitenland'. Ondanks de afstand, heb ik me heel erg gesteund gevoeld door jullie.

Sofieke; ik wil je bedanken voor je trouwe vriendschap in de afgelopen jaren. Je lieve berichtjes en enorme interesse in wat ik aan het doen was, hebben me zo goed gedaan! Het was heerlijk als je weer een weekendje (met of zonder de mannen) naar Maastricht kwam. Na al die jaren wonen we nu eindelijk weer (bijna) bij elkaar om hoek en kunnen we weer gaan lunchen, tennissen, skeeleren en wijntjes drinken. Ik heb er zin in!

Lisette; mijn persoonlijke cheerleader! Je was vaak een van de eersten die mijn nieuwe publicaties las en vertelde dan hoe trots je op me was. Bedankt voor al die keren dat je er was wanneer ik iemand nodig had om mee te praten, de bezoekjes aan Maastricht en de gezellige good-old-times in de Stapper. En mocht ik ooit ook maar lichtelijk een Limburgs accent hebben aangenomen, dan was ik die weer kwijt na 5 minuten met jou aan de telefoon (Allukmaar)!

Barbara en Rosanne; wie had dat gedacht, toen wij in 2012 tijdens de intro-week in 1 groepje werden gezet... Hoe tof, dat we alle drie een PhD zijn gaan doen! We zaten in hetzelfde schuitje, maar toch was alles bij jullie anders. Ontzettend leuk om jullie verhalen te horen en om oude herinneringen van Amsterdam op te halen. Wie weet dat we ooit nog eens teruggaan naar de Gieter, maar vooral hoop ik dat we nog heel veel nieuwe herinneringen mogen maken samen! 
Corné, Ronald, Harold en Vincent; op de camping, in de grot, boven de Hema. Ik kon er altijd op rekenen dat jullie van de partij waren (als er maar nacho's waren)! De flauwe grapjes, dorpsfeestjes, brakke ontbijtjes: ik zou ze voor geen goud willen missen! En jullie ook niet.

Roxelane; ooit begon ons Maastricht-avontuur samen toen we allebei besloten hier een master te gaan doen. Wat was het een leuk jaar, samen vanuit ons appartementje Maastricht ontdekken! Daarna moest ik het alleen doen en zat er $250 \mathrm{~km}$ tussen ons. Maar op afstand ben je er altijd een beetje bij geweest.

Verder verdienen mijn beide paranimfen een speciaal plekje hier. Want wat zijn jullie belangrijk voor mij geweest tijdens mijn PhD! Ik vind het heel bijzonder dat jullie tijdens mijn verdediging achter mij staan.

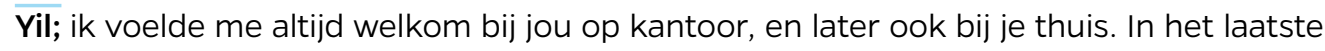
jaar zijn we steeds dichter naar elkaar toegegroeid. Ons spontane tripje naar Lissabon, vlak voor de Coronacrisis uitbrak, was een vakantie om niet te vergeten. Ik hoop echt dat we dat nog vaak over gaan doen. Sindsdien ben ik je steeds meer gaan waarderen. Als collega, maar vooral als betrokken, behulpzame, lieve en stoere vriendin! Sinds we thuis moesten werken, hebben we al snel besloten elkaar als 'huisgenoten' te behandelen en zagen we elkaar bijna dagelijks. Je hebt mij meegenomen naar de mooiste (en lekkerste!) plekjes in Maastricht. Ik kijk met heel veel plezier terug op onze lange wandelingen, middagen op het balkon, TLC-sessies (Eddy en de zusjes), Prix etentjes en avondjes met Wizzy op te bank. Het afscheid viel ons allebei zwaar, maar dankzij jou heb ik een fantastisch excuus om regelmatig Maastricht weer te komen bezoeken!

Karlijn; het lijkt nog maar zo kortgeleden, 3 oktober 2016, dat wij samen begonnen op ons kantoortje (later liefkozend 'ons hol'). Allebei niet van hier, allebei in het diepe gesprongen. Ons hol werd al snel ons 2e huis met een koelkast, dozen aan decoratie 
(gesorteerd per seizoen), een kast vol met smaakjes thee en ons chocoladeschaaltje (oké, dat laatste was een slechte zet). Elke ochtend een verse pot koffie, altijd iemand om even bij te kunnen ventileren (oftewel 'even ons ei luchten'), altijd tijd voor een oppeppend woordje en vooral ook altijd tijd om even te lachen (sorry, collega's). Jij bent een tijd lang de persoon geweest die ik verreweg het meeste zag. We wisten op een gegeven moment wat de ander dacht door alleen maar naar elkaar te kijken. Dus werd het ook wel tijd om afscheid te nemen. The end of an era, ja. Maar ook de start van een nieuwe. Want ik heb niet alleen een ontzettend leuke collega gehad, maar een vriendin voor het leven ontmoet!

Lieve familie, en dan in het bijzonder Anouk, Mam, Pap; Ik heb jullie best laten schrikken, toen ik na mijn master besloot om nóg 4 jaar in Maastricht te blijven. Maar jullie stonden meteen achter mijn keuze. Bedankt dat jullie zo hebben meegeleefd, al was het soms op afstand.

Anouk; ze zeggen wel eens dat zussen verschillende bloemen uit dezelfde tuin zijn. Ondanks onze verschillen, ben ik heel blij jou als zus te hebben. Ik hoop op nog veel gezellige etentjes en uitstapjes samen!

Mam; wat ben ik jou dankbaar, gewoon, omdat je mijn moeder bent. Omdat je ervoor zorgde dat ik altijd wist dat je trots op me was. Zo hing je mijn nieuwe publicaties thuis op de wc op, zodat iedereen die op bezoek kwam het kon zien. Je stuurde lieve kaartjes en boekte maanden van tevoren weekendjes Maastricht. Ik bleef ondertussen ook altijd welkom in Alkmaar, dan haalde je me op bij het station en hadden we alweer de slappe lach nog voor ik in de auto stapte. En als ik boven kwam, dan stond er een opgemaakt bed met een lief briefje op het kussen op me te wachten.

Pap; daar reden we weer. Met een volle auto en aanhangwagen naar Limburg, nee, Zuid-Limburg. We gingen elkaar weer missen, maar je motiveerde mij ook om deze kans met beide handen aan te pakken. Je hebt mij altijd het vertrouwen gegeven dat ik het kon. Als iets soms even tegenzat, of ik thuis miste, kon ik je op ieder moment van 
de dag bellen voor advies of gewoon een praatje. Wat ben ik blij dat ik je nu ook gewoon weer kan bellen voor een kopje koffie of hulp bij het in elkaar zetten van een kast. En natuurlijk voor een knuffel, want die heb ik denk ik wel het meest gemist.

Bas; ik wil jou bedanken voor je bemoedigende woorden, je goede adviezen, je kritische blik en gewoon; het feit dat je er was. Want vanzelfsprekend was dat niet. Jij in Rotterdam, ik in Maastricht. Ik wil niet weten hoeveel kilometers we hebben afgelegd in de auto en de trein. Ondanks de afstand, was je heel betrokken bij mijn PhD. Als ik zelf soms niet meer goed wist wat ik deed, vertelde jij me altijd hoe trots je op me was. We praatten veel over mijn onderzoek, je hielp me met het bedenken wat mijn titel en liet mij ruim twee jaar mijn uiterste best doen om jou ervan te overtuigen donor te worden. Wat hebben we genoten van het zonnige zuiden en het rumoerige Rotterdam. Maar ondertussen hadden we het langeafstands-spelletje wel uitgespeeld. Ik heb ontzettend veel zin om nu samen met jou op avontuuuur te gaan in onze nieuwe stad! 
